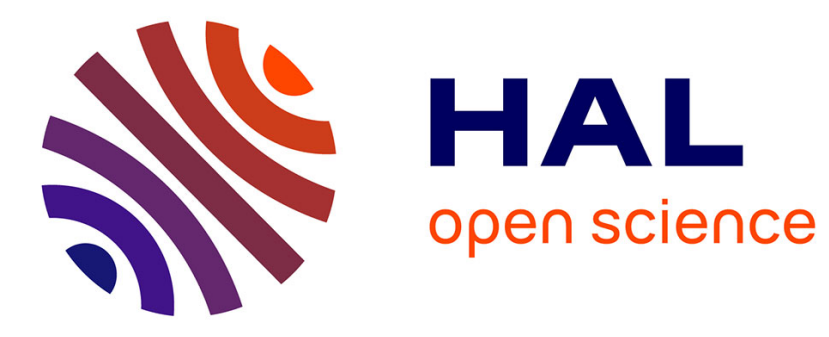

\title{
System controls of coastal and open ocean oxygen depletion
}

Grant C Pitcher, Arturo Aguirre-Velarde, Denise Breitburg, Jorge Cardich, Jacob Carstensen, Daniel J Conley, Boris Dewitte, Anja Engel, Dante Espinoza-Morriberón, Georgina Flores, et al.

\section{To cite this version:}

Grant C Pitcher, Arturo Aguirre-Velarde, Denise Breitburg, Jorge Cardich, Jacob Carstensen, et al.. System controls of coastal and open ocean oxygen depletion. Progress in Oceanography, 2021, 197, 10.1016/j.pocean.2021.102613 . hal-03399031v3

\section{HAL Id: hal-03399031 \\ https://hal.science/hal-03399031v3}

Submitted on 23 Oct 2021

HAL is a multi-disciplinary open access archive for the deposit and dissemination of scientific research documents, whether they are published or not. The documents may come from teaching and research institutions in France or abroad, or from public or private research centers.
L'archive ouverte pluridisciplinaire HAL, est destinée au dépôt et à la diffusion de documents scientifiques de niveau recherche, publiés ou non, émanant des établissements d'enseignement et de recherche français ou étrangers, des laboratoires publics ou privés. 


\section{System controls of coastal and open ocean oxygen depletion}

Grant C. Pitcher ${ }^{\mathrm{a}, \mathrm{b},{ }^{*}, \text { Arturo Aguirre-Velarde }}{ }^{\mathrm{c}}$, Denise Breitburg ${ }^{\mathrm{d}}$, Jorge Cardich ${ }^{\mathrm{e}}$, Jacob Carstensen ${ }^{\mathrm{f}}$, Daniel J. Conley ${ }^{\mathrm{g}}$, Boris Dewitte ${ }^{\mathrm{h}, \mathrm{i}, \mathrm{j}, \mathrm{k}}$, Anja Engel ${ }^{\mathrm{l}}$, Dante Espinoza-Morriberón ${ }^{\mathrm{m}, \mathrm{n}}$, Georgina Flores ${ }^{\mathrm{m}}$, Véronique Garçon ${ }^{\mathrm{o}}$, Michelle Graco ${ }^{\mathrm{m}}$, Marilaure Grégoire $^{\mathrm{p}}$, Dimitri Gutiérrez ${ }^{\mathrm{e}, \mathrm{m}}$, José Martin Hernandez-Ayon ${ }^{\mathrm{q}}$, Huai-Hsuan May Huang ${ }^{\mathrm{r}, \mathrm{s}}$, Kirsten Isensee ${ }^{\mathrm{t}}$, María Elena Jacinto ${ }^{\mathrm{c}}$, Lisa Levin ${ }^{\mathrm{u}}$, Alberto Lorenzo $^{\mathrm{v}}$, Eric Machu ${ }^{\mathrm{w}, \mathrm{x}}$, Lander Merma ${ }^{\mathrm{e}}$, Ivonne Montes ${ }^{\mathrm{y}}$, Naqvi SWA ${ }^{\mathrm{z}}$, Aurelien Paulmier ${ }^{\mathrm{aa}}$, Michael Roman ${ }^{\mathrm{ab}}$, Kenneth Rose ${ }^{\mathrm{ab}}$, Raleigh Hood ${ }^{\mathrm{ab}}$, Nancy N. Rabalais ${ }^{\mathrm{ac}}$, Anne Gro V. Salvanes ${ }^{\text {ad }}$, Renato Salvatteci ${ }^{\text {ae }}$, Sonia Sánchez ${ }^{\mathrm{m}}$, Abdelfettah Sifeddine ${ }^{\text {af }}$, Abdoul Wahab Tall ${ }^{\text {ag }}$, Anja K. van der Plas ${ }^{\text {ah }}$, Moriaki Yasuhara ${ }^{\text {ai, aj }}$, Jing Zhang ${ }^{\text {ak, al }}$, ZY Zhu ak, al

${ }^{a}$ Fisheries Research and Development, Department of Forestry, Fisheries and the Environment, Cape Town, South Africa

${ }^{\mathrm{b}}$ Department of Biological Sciences, University of Cape Town, South Africa

${ }^{c}$ Dirección General de Investigaciones en Acuicultura, Instituto del Mar del Perú (IMARPE), Esquina Gamarra y General Valle s/n, Callao, Peru

${ }^{\mathrm{d}}$ Smithsonian Environmental Research Center, Edgewater, MD 21037, USA

e Programa de Maestría de Ciencias del Mar y proyecto Magnet (Fondecyt-UPCH), Avda. Honorio Delgado 430, Urb. Ingeniería, San Martin de Porres, Lima 31, Peru

${ }^{\mathrm{f}}$ Department of Bioscience, Aarhus University, 4000 Roskilde, Denmark

${ }^{\mathrm{g}}$ Department of Geology, Lund University, 22362 Lund, Sweden

${ }^{\mathrm{h}}$ Laboratoire d'Etudes en Géophysique et Océanographie Spatiales- LEGOS, UMR5566 -CNRS/IRD/UT/CNES, Toulouse, France

${ }^{\mathrm{i}}$ Centro de Estudios Avanzados en Zonas Áridas, La Serena, Chile

${ }^{j}$ Departamento de Biología Marina, Facultad de Ciencias del Mar, Universidad Católica del Norte, Coquimbo, Chile

${ }^{\mathrm{k}}$ Millennium Nucleus for Ecology and Sustainable Management of Oceanic Islands (ESMOI), Coquimbo, Chile

${ }^{1}$ GEOMAR Helmholtz Centre for Ocean Research Kiel, 24105 Kiel, Germany

${ }^{\mathrm{m}}$ Dirección General de Investigaciones Oceanográficas y Cambio Climático, Instituto del Mar del Perú (IMARPE), Esquina Gamarra y General Valle s/n, Callao, Peru

${ }^{\mathrm{n}}$ LOCEAN-IPSL, IRD/CNRS/Sorbonnes Universités (UPMC)/MNHN, UMR7159, 4 Place Jussieu, Case 100, 75252 Paris Cedex05, France

${ }^{\circ}$ CNRS/LEGOS, 31401 Toulouse Cedex 9, France

${ }^{\mathrm{p}}$ Department of Astrophysics, Geophysics and Oceanography, MAST-FOCUS Research Group, Université de Liège, 4000 Liège, Belgium

${ }^{\mathrm{q}}$ Instituto de Investigaciones Oceanológicas, Universidad Autónoma de Baja California, Baja California, Mexico

${ }^{\mathrm{r}}$ School of Biological Sciences and Swire Institute of Marine Science, The University of Hong Kong, Kadoorie Biological Sciences Building, Pokfulam Road, Hong Kong Special Administrative Region

${ }^{\mathrm{s}}$ GeoZentrum Nordbayern, Universität Erlangen-Nüanberg, Loewenichstraße 28, D-91054 Erlangen, Germany

${ }^{\mathrm{t}}$ Intergovernmental Oceanographic Commission of UNESCO, 75732 Paris, CEDEX 7, France

${ }^{\mathrm{u}}$ Center for Marine Biodiversity and Conservation and Integrative Oceanography Division, Scripps Institution of Oceanography, University of California, San Diego, CA 92093, USA

${ }^{v}$ Laboratorio Costero de Pisco, Instituto del Mar del Perú (IMARPE), Los Libertadores A-12, Paracas, Pisco, Peru

${ }^{\mathrm{w}}$ Laboratoire d'Océanographie Physique et Spatiale (LOPS), IUEM, Univ. Brest, CNRS, IRD, Ifremer, Brest, France

${ }^{\mathrm{x}}$ Laboratoire de Physique de l'Atmosphère et de l'Océan Siméon Fongang (LPAOSF), Ecole Supérieure Polytechnique, Université Cheikh Anta DIOP, Dakar, Senegal

${ }^{\mathrm{y}}$ Instituto Geofísico del Perú, Lima, Peru

${ }^{\mathrm{z}}$ Environment and Life Sciences Research Center, Kuwait Institute for Scientific Research, Salmiya 22017, Kuwait

${ }^{a}$ Laboratoire d'Etudes en Géophysique et Océanographie Spatiales- LEGOS, UMR5566 -CNRS/IRD/UT/CNES, Toulouse, France

${ }^{\mathrm{ab}}$ University of Maryland Center for Environmental Science, Horn Point Laboratory, Cambridge, MD 21613, USA

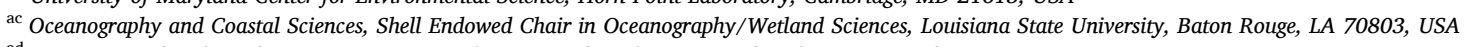

${ }^{\text {ad }}$ Department of Biological Sciences, University of Bergen and Bjerknes Centre for Climate Research, Bergen, Norway

${ }^{\text {ae }}$ Institute of Geosciences, Kiel University, Ludewig-Meyn-Str. 10, 24118 Kiel, Germany

${ }^{a f}$ LOCEAN-IPSL, IRD/CNRS/Sorbonnes Universités (UPMC)/MNHN, UMR7159, 4 Place Jussieu, Case 100, 75252 Paris Cedex05, France

${ }^{\text {ag }}$ Laboratoire de Physique de l'Atmosphère et de l'Océan Siméon Fongang (LPAOSF), Ecole Supérieure Polytechnique, Université Cheikh Anta DIOP, Dakar, Senegal

${ }^{\text {ah }}$ Ministry of Fisheries and Marine Resources, PO Box 912, Swakopmund, Namibia

ai School of Biological Sciences and Swire Institute of Marine Science, University of Hong Kong, Hong Kong Special Administrative Region

\footnotetext{
* Corresponding author at: Fisheries Research and Development, Private Bag X2, Rogge Bay, 8012 Cape Town, South Africa.

E-mail address: GrantP@daff.gov.za (G.C. Pitcher).
} 
aj State Key Laboratory of Marine Pollution, City University of Hong Kong, Hong Kong Special Administrative Region

${ }^{\text {ak }}$ State Key Laboratory of Estuarine and Coastal Research, East China Normal University, 500 Dongchuan Road, Shanghai 200241, China

${ }^{\text {al }}$ School of Oceanography, Shanghai Jiao Tong University, 1954 Huashan Road, Shanghai 200030, China

\section{A R T I C L E I N F O}

\section{Keywords:}

Ventilation

Stratification

Global warming

Eutrophication

Respiration

Deoxygenation

\begin{abstract}
A B S T R A C T
The epoch of the Anthropocene, a period during which human activity has been the dominant influence on climate and the environment, has witnessed a decline in oxygen concentrations and an expansion of oxygendepleted environments in both coastal and open ocean systems since the middle of the 20th century. This paper provides a review of system-specific drivers of low oxygen in a range of case studies representing marine systems in the open ocean, on continental shelves, in enclosed seas and in the coastal environment. Identification of similar and contrasting responses within and across system types and corresponding oxygen regimes is shown to be informative both in understanding and isolating key controlling processes and provides a sound basis for predicting change under anticipated future conditions. Case studies were selected to achieve a balance in system diversity and global coverage. Each case study describes system attributes, including the present-day oxygen environment and known trends in oxygen concentrations over time. Central to each case study is the identification of the physical and biogeochemical processes that determine oxygen concentrations through the tradeoff between ventilation and respiration. Spatial distributions of oxygen and time series of oxygen data provide the opportunity to identify trends in oxygen availability and have allowed various drivers of low oxygen to be distinguished through correlative and causative relationships. Deoxygenation results from a complex interplay of hydrographic and biogeochemical processes and the superposition of these processes, some additive and others subtractive, makes attribution to any particular driver challenging. System-specific models are therefore required to achieve a quantitative understanding of these processes and of the feedbacks between processes at varying scales.
\end{abstract}

\section{Introduction}

The global ocean is increasingly modified by human activities and one of the important responses to these changes is the deoxygenation of coastal and open ocean waters (Breitburg et al., 2018). Low oxygen environments in the ocean have existed through geological time in coastal and ocean systems where oxygen sinks exceed sources of oxygen at varying time scales (Fennel and Testa, 2019). More specifically, the proposed epoch of the Anthropocene, a period during which human activity has been the dominant influence on climate and the environment, has witnessed a decline in oxygen concentrations and an expansion of oxygen-depleted environments since the middle of the 20th century (Breitburg et al., 2018). This loss of oxygen from the ocean serves as a major stressor, affecting biogeochemical cycles and marine ecosystems, and may also interact with other stressors leading to synergistic impacts (Gruber et al., 2011; Bopp et al., 2013).

The recent collation of global open ocean oxygen data shows an average decrease in oceanic oxygen content of more than $2 \%$ since 1960 , with estimates varying broadly between ocean basins, regions and water depths (Schmidtko et al., 2017; Levin, 2018; IPCC, 2019). Ocean models predict a continued decline in oxygen inventory of $1-7 \%$ by the year 2100 (Keeling et al., 2010; Long et al., 2016). Calculations further indicate that rates of deoxygenation are greater in coastal environments than in the open ocean (Gilbert et al., 2010) and in the coastal environment, the number of sites of hypoxia reported in 2008 was considered to have increased by an order of magnitude since the 1960s (Dias and Rosenberg, 2008). These trends of deoxygenation caused the Intergovernmental Oceanographic Commission (IOC) to establish the expert group, the Global Ocean Oxygen Network $\left(\mathrm{GO}_{2} \mathrm{NE}\right)$ in 2016, tasked with improving our understanding of deoxygenation and its impacts and providing a global and multidisciplinary appraisal of the problem. The undertaking of this review paper was prioritized by the $\mathrm{GO}_{2} \mathrm{NE}$ in an effort to synthesize our knowledge and to provide an inclusive perspective of the drivers of deoxygenation in both coastal and open ocean systems. Understanding how and why oxygen varies in space and time is of fundamental importance as this variability shapes the biogeochemical and ecological structure of marine systems.

System sources and sinks of oxygen are dictated by a number of physical and biogeochemical processes, and their imbalance may drive deoxygenation (Peña et al., 2010; Testa and Kemp, 2011; Friedrich et al.,
2014; Fennel and Testa, 2019; Oschlies et al., 2018). In surface waters, oxygen concentrations are strongly dependent on air-sea exchange, whereas in bottom waters, particularly in shallow waters, exchange across the sediment-water interface is often significant. Advection by currents is responsible for the flux, both lateral and vertical, of oxygen across system boundaries, and mixing and diffusion are also important physical processes particularly in determining the vertical distribution of oxygen. Therefore, long water residence time and intense stratification tend to isolate water masses from oxygen supply. Biogeochemical processes that affect oxygen concentrations include the production of oxygen and organic matter through photosynthesis and their consumption through respiration and remineralization. Consequently, surface waters usually contain high concentrations of oxygen as a result of photosynthesis and atmospheric exchange. However, in subsurface waters, photosynthesis is diminished and oxygen sinks may begin to dominate supply. Oxygen consumption typically occurs through the oxidation of organic matter in both the water column and sediments, largely by means of aerobic respiration, but as oxygen concentrations are depleted, a sequence of microbially-mediated anaerobic respiratory processes may dominate using electron acceptors other than oxygen. Nevertheless, regardless of aerobic or anaerobic pathways, respiration and the ultimate consumption of oxygen is determined by the supply of organic matter.

Although the independent drivers of oxygen production and consumption in the coastal and open ocean environments are generally known, deoxygenation results from a complex interplay of these hydrographic and biogeochemical processes and there is a clear need for a better mechanistic understanding of oxygen depletion on a variety of scales and across systems. The superposition of these processes, some additive and other subtractive in the net outcome of hypoxia or anoxia, makes attribution to any particular driver challenging. Model development is therefore a likely requirement for providing a quantitative assessment of the contribution of these different processes to observed changes in oxygen, which will in turn also facilitate improved prediction. This paper seeks to provide a review of system-specific drivers of low oxygen in a range of case studies representing marine systems in the open ocean, on continental shelves, in enclosed seas and in the coastal environment (Fig. 1.1). Identification of similar and contrasting responses within and across system types and corresponding oxygen regimes is shown to be informative both in understanding and isolating 
key controlling processes and, ultimately, in predicting changes in oxygen under past and anticipated future conditions.

Case studies were selected to achieve a balance in system diversity and geographic coverage (Fig. 1.1). Each case study sets out to describe system attributes, including the present-day oxygen environment and known trends in oxygen concentrations over time. Central to each case study is the identification of the physical and biogeochemical processes that serve to transition each system from net autotrophy to net heterotrophy, thereby leading ultimately to either hypoxia or anoxia. Finally, comment is provided with each case study on the susceptibility of each system to further deoxygenation particularly where predictions are available through model simulations and output. The value of within and across system comparison in guiding future observation and modelling needs is also demonstrated.

While the need to use a single unit for oxygen concentration remains a priority, the case studies below express oxygen concentrations in a variety of units as determined by their use in the original publication. For ease of conversion: $1.0 \mathrm{ml}^{-1}=1.4 \mathrm{mg} \mathrm{l}^{-1}=44.66 \mu \mathrm{mol}^{-1} \mathrm{O}_{2}$; and $1 \mu \mathrm{mol} 1^{-1}=0.9737 \mu \mathrm{mol} \mathrm{kg}{ }^{-1}$ at seawater density of $1.027 \mathrm{~g} \mathrm{~cm}^{-3}$. In some cases, the partial pressure of oxygen $\left(\mathrm{pO}_{2}\right)$ is presented and expressed in kilopascals: at $100 \%$ saturation, $\mathrm{pO}_{2}=21 \mathrm{kPa}=21 \mu \mathrm{M}$ at $10^{\circ} \mathrm{C}$.

\section{Open oceans}

The eastern tropical oceans are generally characterised by large volumes of oxygen depleted waters at an intermediate-depth referred to Oxygen Minimum Zones (OMZs; Paulmier and Ruiz-Pino, 2009). The hypoxic waters of these regions are typically found between 100 and $1000 \mathrm{~m}$ depth where ventilation is weak and the consumption of oxygen high driven by the sinking of particulate matter. Case studies are presented for the Eastern Tropical Pacific (ETP) with a focus on the Eastern Tropical South Pacific (ETSP), and the Eastern Tropical North Atlantic (ETNA). These OMZs differ in that the OMZ of the ETSP covers a much greater area and oxygen concentrations in its core region are considerably lower than those in the OMZ of the ETNA. In the Indian Ocean, oxygen deficient subsurface waters do not develop on its eastern boundary as in the Atlantic and Pacific Oceans, but are found in the north in the ocean basins of the Arabian Sea and the Bay of Bengal. A case study of the OMZs of the North Indian Ocean serves to contrast the drivers of oxygen depletion in these two ocean basins (Arabian Sea and Bay of Bengal) with those in the ETSP and the ETNA.

\subsection{Eastern tropical Pacific $O M Z$}

\subsubsection{A system of two OMZs}

The meridional extension of the Eastern Tropical Pacific (ETP) OMZ is from $40^{\circ} \mathrm{S}$ to $30^{\circ} \mathrm{N}$ at thermocline depths ranging from 100 to $1000 \mathrm{~m}$. The OMZ reaches its shallowest depths and lowest oxygen concentrations in the coastal regions where thermocline waters have been isolated from the atmosphere for the longest time. In the near equatorial region of the open ocean, oxygen concentrations tend to increase, separating the ETP into the Eastern Tropical North Pacific (ETNP) OMZ (off Mexico and Central America) and the Eastern Tropical South Pacific (ETSP) OMZ (off Peru and Chile). These two well-defined OMZs are connected through intricate pathways and their equatorward edges are characterised by oxygen peaks termed secondary oxygen maxima (Margolskee et al., 2019). Both systems comprise three layers: an upper layer demarcated by an oxycline at around $100 \mathrm{~m}$ depth (shallower close to the coast and deeper offshore), a core layer of $\mathrm{O}_{2}<20 \mu \mathrm{moll}^{-1}$ between 400 and $1000 \mathrm{~m}$, and a lower layer demarcated by a less intense oxygen gradient extending to about $3500 \mathrm{~m}$ below the core (Paulmier and RuizPino, 2009). In the core layer $\left(\mathrm{O}_{2}<20 \mu \mathrm{mol}^{-1}\right)$, both OMZs exhibit a tongue-like shape extending offshore that differs in terms of thickness, intensity and oxygen concentration (Fig. 2.1.1).

While the same physical attribute of low ventilation contributes to their existence, the two OMZ systems exhibit significant differences, which are yet to be fully understood. For instance, while the ETNP OMZ is more extensive and intense, the ETSP OMZ is shallower (e.g., Fuenzalida et al., 2009; Paulmier and Ruiz-Pino, 2009). In recent years, much progress in our understanding of the dynamics of these OMZs has been achieved from experimentation with regional biogeochemical coupled models with a focus on the ETSP OMZ (Montes et al., 2014; Vergara et al., 2016). However, gaps remain in our knowledge of the mechanisms controlling variability within the ETNP OMZ due to biases and limitations in state-of-the art global coupled models (Cabré et al., 2015), to the different climatic and geographical settings of the ETNP OMZ, and to the relative paucity of in situ data.

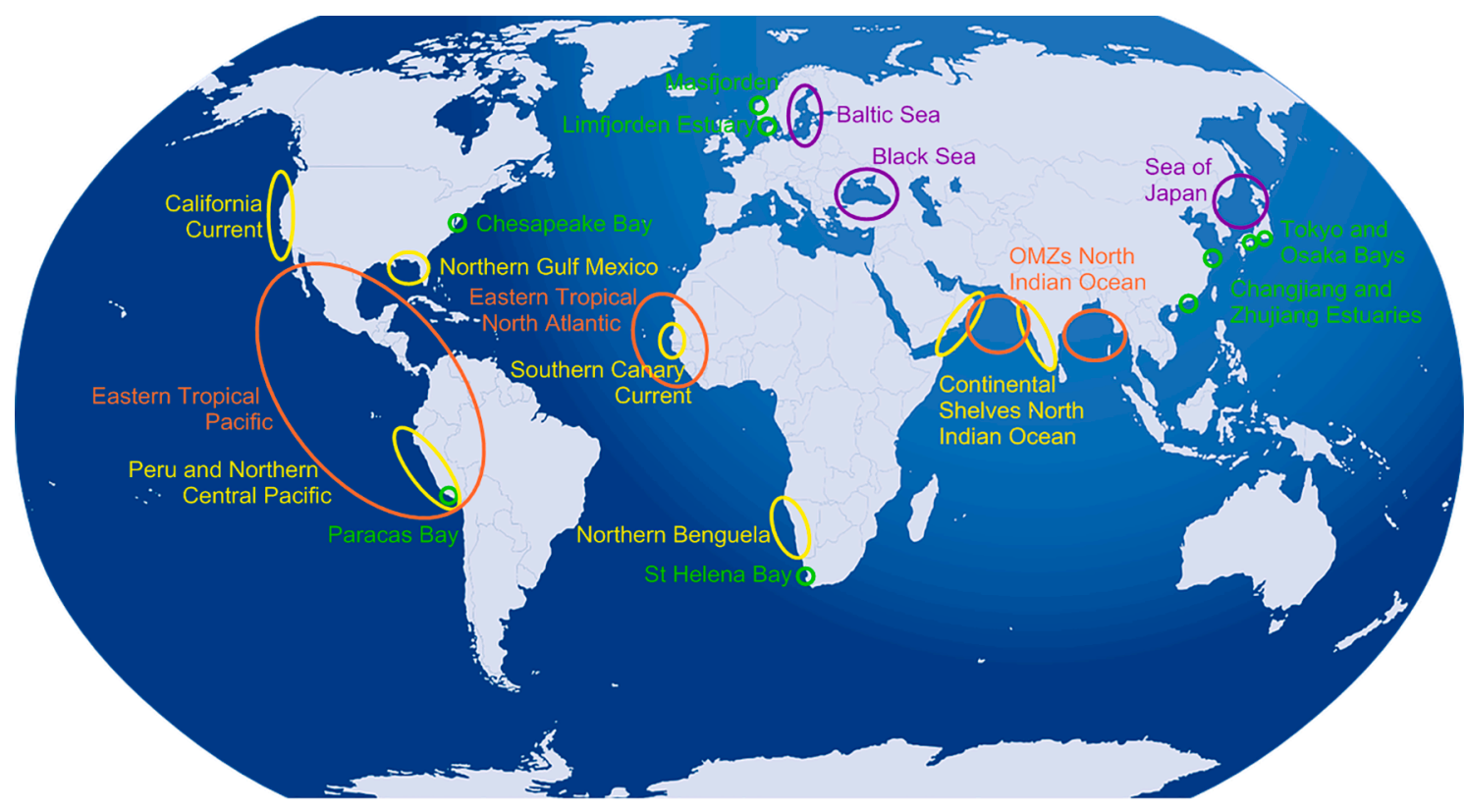

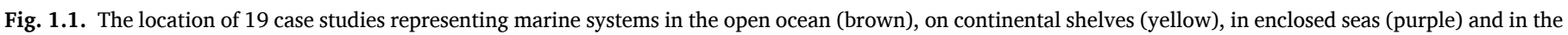
coastal environment (green). (For interpretation of the references to color in this figure legend, the reader is referred to the web version of this article.) 

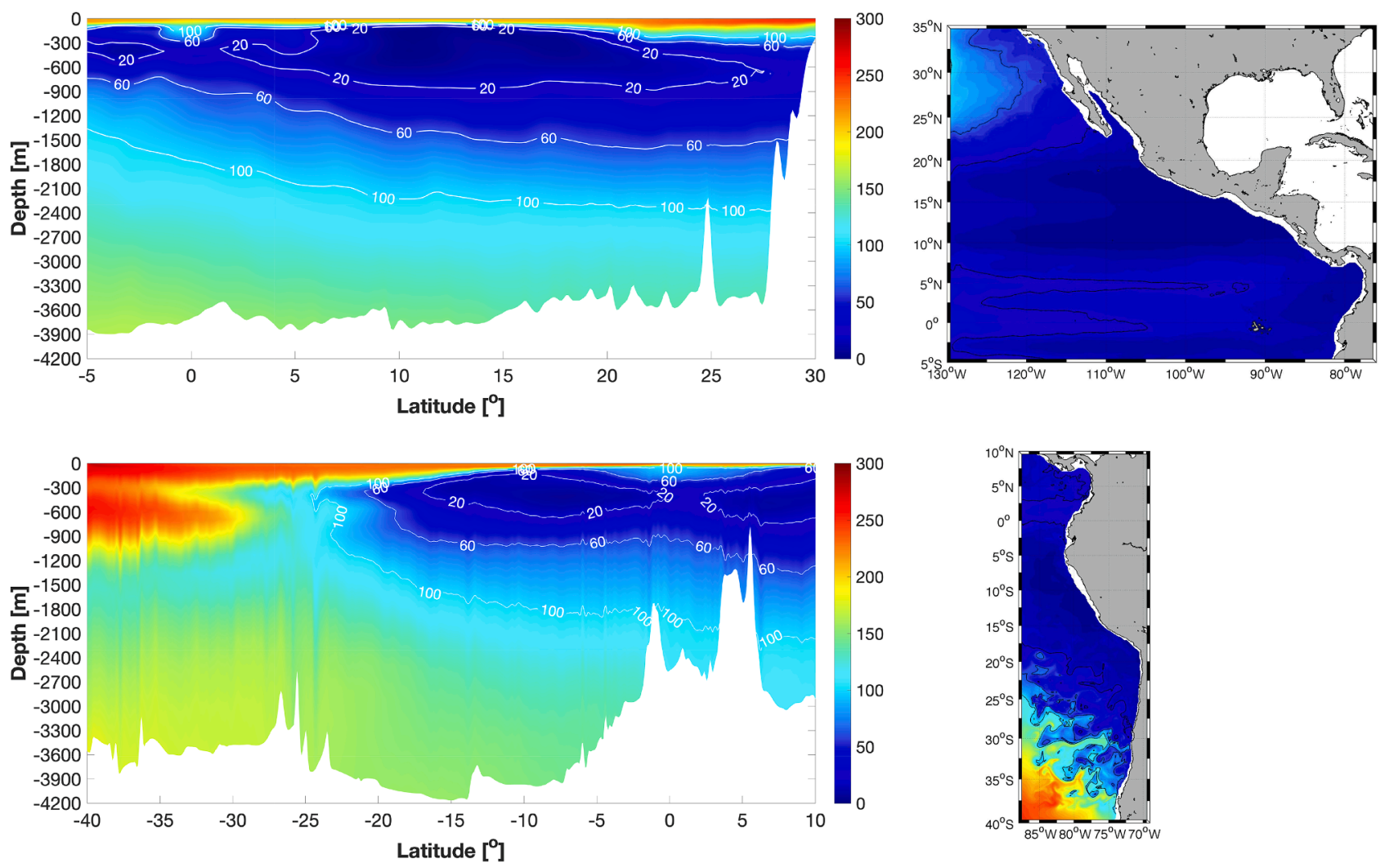

Fig. 2.1.1. Vertical sections (left) and horizontal distributions ( $400 \mathrm{~m}$ depth; right) of annual mean oxygen concentration extracted from high-resolution coupled physical-biogeochemical model outputs (ROMS-BioEBUS, Dewitte et al., 2012; Gutknecht et al., 2013a,b; Montes et al., 2014) configured for the Eastern Tropical North Pacific (ETNP, top) and Eastern Tropical South Pacific (ETSP, bottom) at $116^{\circ} \mathrm{W}$ and $87^{\circ} \mathrm{W}$, respectively. Oxygen concentrations of 20,60 and $100 \mu \mathrm{mol} \mathrm{l}^{-1}$ are depicted as white contours.

\subsubsection{Drivers of oxygen variability in the ETSP}

The ETSP OMZ is primarily maintained by the combination of sluggish oceanic circulation and high or moderate rates of organic matter decomposition consuming dissolved oxygen (Paulmier and Ruiz-Pino, 2009; Breitburg et al., 2018), and the balance of these physical and biogeochemical processes may vary at different timescales. Due to the favourable coastline geometry for planetary wave energy transmission, the OMZ of the ETSP is strongly influenced by remote variability generated in the equatorial central Pacific (i.e., El Niño) that modulates coastal upwelling driven by the divergence in Ekman transport and mesoscale activity (see Fig. 2.1.2). In terms of mean circulation, waters transported by the Equatorial Current System (Equatorial Undercurrent: EUC, primary and secondary Southern Subsurface countercurrents: pSSCC and sSSCC - also known as Tsuchiya Jets) are important in OMZ dynamics in that they supply waters of different oxygen content to the ETSP OMZ. Estimates from model simulations indicate that the main contributor to changes in oxygen fluxes to the coastal system comes from the EUC $\left(\sim 300 \times 10^{3} \mathrm{~mol} \mathrm{~s}^{-1}\right)$, while the pSSCC $\left(\sim 70 \times 10^{3} \mathrm{~mol} \mathrm{~s}^{-1}\right)$ and the $\operatorname{sSCCC}\left(>\sim 20 \times 10^{3} \mathrm{~mol} \mathrm{~s}^{-1}\right)$ have only marginal contributions (Montes et al., 2014). These estimates are consistent with available observations (e.g., Stramma et al., 2010a,b) that indicate that the ETSP OMZ is ventilated by zonal jets (i.e., pSSCC and SSSCC) rich in nutrients but low in oxygen (e.g., Llanillo et al., 2013); these zonal jets contribute to the reduction of mean OMZ oxygen levels coincident with reductions attributed to the respiration of organic matter (Monteiro et al., 2006; 2011; Brandt et al., 2010; Llanillo et al., 2013). In terms of variability in the OMZ, variability in advection is an order of magnitude larger than the variability in biogeochemical processes. Advection is particularly strong across the OMZ boundaries where the strongest gradients in oxygen are found (particularly in the vicinity of the oxycline and near the coast). Non-linear advection also contributes to transient (i.e., non steady) local gradients in oxygen associated with either local biogeochemical aerobic processes (like oxic decomposition and nitrification in the region of the oxycline) and/or high frequency mesoscale activity generating oxygen gradients within a larger scale mean flow (Montes et al., 2014).

In particular, the boundaries of the ETSP OMZ are characterized by strong gradients in oxygen content and the presence of highly turbulent zones (Montes et al., 2014; Vergara et al., 2016), where mesoscale structures play a dual role in determining high frequency variability (Bettencourt et al., 2015). At depths between $\sim 400$ and $\sim 600 \mathrm{~m}$, model simulations indicate that mesoscale eddies and fronts act as barriers to the entry of oxygen into the OMZ core. Here eddies serve to modulate oxygen diffusion across the OMZ borders and thereby maintain the separation of oxygen-rich and oxygen-poor waters. However, sporadically, eddies may introduce waters with high oxygen content across the borders of OMZs. These events result in fluxes of oxygen an order of magnitude higher than mean fluxes, thereby contributing significantly to the ventilation of the OMZ. At shallower depths, eddies formed near the coast due to the instability of coastal currents (Capet et al., 2008) to induce subduction and offshore transport, thereby carrying their water properties westward. This lateral transport exports nutrients off-shore (Rossi et al., 2008; Gruber et al., 2011; Stramma et al., 2013) leading to a reduction in biological production and vertical export from coastal areas. These processes are likely to be influential in ventilating the OMZ. For instance, a reduction in oxygen concentration in the OMZ could be achieved by a reduction in the meridional and vertical eddy activity, as in the Northern Tropical Atlantic OMZ (e.g., Brandt et al., 2010). Model simulations also indicate that the oxygen eddy flux is modulated at seasonal timescales, which could explain seasonal variation in the ETSP OMZ (Vergara et al., 2016). Finally, open ocean conditions may impact coastal conditions because reduced ventilation events (e.g., associated 


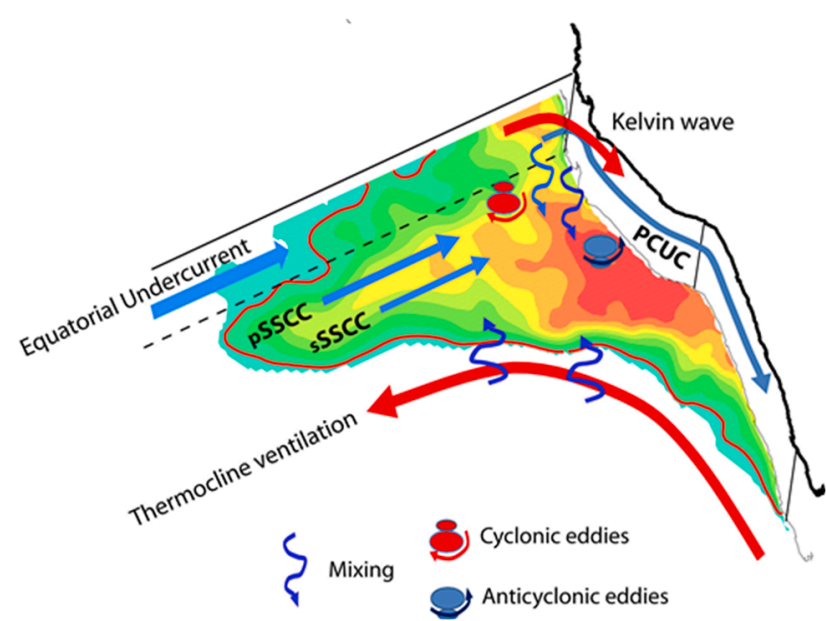

Fig. 2.1.2. Schematic of the main physical processes involved in the maintenance and variability of the Eastern Tropical South Pacific OMZ. Colored contouring represents oxygen concentration (logarithmic scale), where the darkest red contour corresponds to waters with oxygen concentrations $<1 \mathrm{ml}^{-1}$ at $300 \mathrm{~m}$ (CARS data, www.cmar.csiro.au/cars). Light blue arrows correspond to subsurface currents (PCUC: Peru-Chile Undercurrent, pSSCC, sSSCC: primary and secondary Southern Subsurface countercurrents, respectively). Anticyclonic eddies are in red and cyclonic eddies in blue. The thick red long arrow curving from south to west represents ventilation of the thermocline, that is, in its conceptual view, the subsurface equatorward transport of water masses through potential vorticity conservation from the surface in the mid to high-latitudes. Along this water mass pathway, the OMZ limit can be eroded through diapycnal mixing (blue squiggly arrows). (For interpretation of the references to color in this figure legend, the reader is referred to the web version of this article.)

with SSCC) can enhance the OMZ near the continent, promoting local anaerobic biogeochemistry (Monteiro et al., 2011).

At lower frequencies, the El Niño-Southern Oscillation (ENSO) is the main driver of variability in the ETSP OMZ. The strong Eastern Pacific El Niño events have the most obvious impact on the ETSP OMZ through the advection of warm waters along and off the coast of Peru and Chile. However, weaker Central Pacific El Niño events are more influential through the propagation of coastal-trapped Kelvin waves along the coast that modulate coastal upwelling and produce vertical displacements of the upper limit of the coastal OMZ (Morales et al., 1999; Hormazabal et al., 2006; Graco et al., 2017). A modeling study focusing on the extreme El Niño event of 1997-98 and the La Niña event of 1999-2000 showed contrasting changes in the ETSP OMZ and the oxycline associated with the horizontal and vertical advection of nitrate (Mogollón and Cali, 2018). Simulation results indicate a reduced OMZ during El Niño years as a consequence of the horizontal advection of warm, nutrientpoor waters into the region, whereas during La Niña years there is a tendency for the OMZ to expand due to the vertical advection of cold, nutrient-rich waters that promote biological activity. An asymmetric response of the ETSP OMZ to different types of El Niño has been reported by Garçon et al. (2019), where the Eastern Pacific El Niño events yield a larger OMZ reduction while the Central Pacific El Niño events are associated with an intensified OMZ that may favour more deoxygenated water conditions. The scarcity of subsurface oxygen data has limited investigation of OMZ variability at low frequencies, although historical data suggest an expanding trend including a significant decadal component (Stramma et al., 2008). Potentially important processes in the forcing of the OMZ have been documented based on regional and global models and they revealed a significant dependence on model parameterizations and resolution. The few high-resolution data sets available suggest that organic matter degradation within the OMZ plays a significant role in the high frequency variability of oxygen (e.g., Bretagnon et al., 2018), a process not suitably accounted for in current models.

At decadal scales, our understanding of the variability of the ETP OMZ is even more limited due to the superimposition of a long-term climate trend and higher frequency climate oscillations. Decadal variance in particular can arise from the reddening of the variability spectrum of the physical and biological drivers; whereby variance is manifest at low frequencies and high frequency perturbations are dampened (Ito and Deutsch, 2010). Sensitivity experiments with a global coupled biogeochemical-circulation model suggest that when the ETP OMZ experiences environmental physical forcing typical of the positive phase of the Pacific Decadal Oscillation (PDO), the volume of suboxic regions may expand by $7 \%$ over 50 years due to a slow-down in large scale circulation related to a decrease in the intensity of the trade winds (Duteil et al., 2018). The prevailing positive PDO conditions since 1975 may therefore have contributed significantly to the current long-term trend of deoxygenation in the ETP. It is noteworthy that the ETP OMZ is influenced by a variety of physical mechanisms from equatorial regions at different time scales, and their relationship with the dynamics of the OMZ remains largely unknown. This holds true especially in the ETNP OMZ where few studies have been undertaken to establish a clear understanding of the drivers of low oxygen. The ETNP OMZ, specifically the oceanic region off Mexico, is characterized by strong vertical stratification with low primary productivity (Maske et al., 2010; Franco et al., 2014). This OMZ is also influenced by various climatic modes at both interannual to decadal timescales (i.e., ENSO [Frischknecht et al., 2015], the North Pacific Meridional Mode and the North Pacific Gyre Oscillation [Di Lorenzo et al., 2008]), the role of which on OMZ variability has not been extensively documented. Nevertheless, it is likely that the OMZ off Mexico is modulated by ENSO (Durazo, 2009; Kurczyn et al., 2012) as demonstrated during the El Niño of 2015-16 when an incursion of oxygenated water modified the local structure of an intense and shallow OMZ, partially eroding and intensifying the oxycline (Trucco et al., 2019).

\subsubsection{The susceptibility of the ETP OMZ to further deoxygenation}

At climatic timescales, there is a concern about the possible expansion of the ETP OMZ in a warmer climate. Oxygenation proxies in paleoceanographic records show expansion of the ETP OMZ in association with events of global-warming during the recent deglaciation (e.g., Moffitt et al., 2015), similar to present observations of change due to anthropogenic perturbations (e.g., Stramma et al., 2008; Ito et al., 2016). Oxygen decreases recorded in the equatorial region and in the upper-ocean of the ETSP OMZ during the last five decades are associated with the expansion of the OMZ (Czeschel et al., 2012; Schmidtko et al., 2017). For the ETP OMZ, projections of models under the scenario of global warming indicate a considerable decrease in oxygen content (more pronounced in the ETNP than ETSP OMZ) in response to warming and a reduction in oxygen solubility, and to increased stratification and reduced ventilation (Bopp et al., 2013; Oschlies et al., 2018).

\subsection{Eastern tropical North Atlantic $O M Z$}

\subsubsection{Oxygen distribution in the open ETNA}

In the eastern tropical North Atlantic (ETNA) two permanent OMZs are observed: a deep OMZ with a core depth located at about $400 \mathrm{~m}$ and, closer to the shelf, a shallower OMZ at about $100 \mathrm{~m}$ depth (Karstensen et al., 2008; Brandt et al., 2015). Oxygen concentrations in these two OMZs rarely fall below $40 \mu \mathrm{mol} \mathrm{kg}{ }^{-1}$ (e.g., Bange et al., 2010). Lowest oxygen concentrations at the core of the deep OMZ are found off the continental margin at about $20^{\circ} \mathrm{W}$ and $10^{\circ} \mathrm{N}$ (Brandt et al., 2015). The spatial propagation of the deep OMZ into the ETNA is bounded in the north by the North Equatorial Current (NEC) and in the south by zonal flows near the Equator (North Equatorial Counter Current and the North Equatorial Undercurrent). Towards the east, the OMZ extends into the coastal waters of Northwest Africa (Mauritania and Senegal) and weakens in the west towards the high-oxygen boundary regime of the 
North Brazil Current (Fig. 2.2.1). Water masses above the OMZ core $(200-400 \mathrm{~m})$ are poorly ventilated and show long residence times leading to an estimated age of these waters of more than 90 years (Duteil et al., 2014a,b).

In addition to the two permanent OMZs, localized low-oxygen cyclonic eddies and anticyclonic mode water eddies have been recently reported for the ETNA. These eddies are referred to as "dead zone" eddies because the oxygen concentration within the eddy core may fall below $2 \mu \mathrm{mol} \mathrm{kg}{ }^{-1}$ (Fig. 2.2.2; Karstensen et al., 2017). Dead zone eddies are thought to originate from the highly productive coastal upwelling region off West Africa and subsequently propagate westwards into the open Atlantic. Oxygen concentrations in these eddies are lowest at $40-60 \mathrm{~m}$ depth, and are therefore notably shallower than the permanent OMZs (Fiedler et al., 2016; Schütte et al., 2016a,b).

The ETNA OMZ has been expanding over the past decades as evidenced by both a decline in core oxygen concentration and an increase in the vertical extent of the OMZ as observed during the period 1960-2008 (Fig. 2.2.3; Stramma et al., 2008). The rate of deoxygenation in the ETNA was estimated to be equivalent to an integrated net loss of $136 \mu \mathrm{mol} \mathrm{m}^{-2} \mathrm{yr}^{-1}$ and this loss is associated with an increase in the vertical extent of OMZ waters of $<90 \mu \mathrm{mol} \mathrm{kg}^{-1}$ by $85 \%$; from a thickness of $370 \mathrm{~m}$ in 1960 to $690 \mathrm{~m}$ in 2006. An analysis of more recent oxygen concentrations (2006-2015) showed different decadal trends within the OMZ core for upper $(200-400 \mathrm{~m})$ versus deeper (400-1000 m) water masses (Hahn et al., 2017). While oxygen concentration continued to decline $\left(-5.9 \pm 3.5 \mu \mathrm{mol} \mathrm{O} \mathrm{kg}^{-1}\right.$ decade $\left.^{-1}\right)$ in the upper oxycline, oxygen concentration below the OMZ core increased $\left(4.0 \pm 1.6 \mu \mathrm{mol} \mathrm{O}_{2} \mathrm{~kg}^{-1}\right.$ decade $\left.^{-1}\right)$. If this trend continues the OMZ is expected to shoal with severe consequences for surface ocean biota. Causes for the shoaling of the OMZ are not fully understood but may be related to weakened ventilation and/or enhanced biological oxygen consumption.

\subsubsection{Controls of oxygen in the ETNA}

Oxygen concentrations in the deep OMZ of the ETNA, like in other parts of the ocean, are controlled by the physical supply and biological consumption of oxygen. Analyses showed that meridional eddy fluxes contribute the most to the ventilation of the OMZ (about 60\%), followed by the contribution from diapycnal mixing (about 20-30\%) (Brandt et al., 2015). Expansion of the ETNA OMZ over recent decades (Stramma et al., 2008; Hahn et al., 2017) indicates that oxygen supply is unable to meet oxygen demand created by the remineralization of sinking particulate organic matter (Matear and Hirst, 2003). Biological processes of oxygen consumption, which are less constrained than the physical processes of supply and loss in the oxygen budget of the ETNA, show relatively higher temporal and spatial variability. Organic matter sustaining heterotrophic respiration in the ETNA OMZ is supplied mainly by the vertical settling of particles produced within the euphotic zone or transported from the more productive upwelling regions along the West African coast via the Canary Current System.

The capture of sinking particles by drifting sediment traps has shown that particulate organic carbon (POC) fluxes in the ETNA region off Mauritania $\left(\sim 10^{\circ} \mathrm{N}, 21^{\circ} \mathrm{W}\right)$ decrease from 69 to $76 \mathrm{mg} \mathrm{C} \mathrm{m}^{-2} \mathrm{~d}^{-1}$ at $100 \mathrm{~m}$ to $24-28 \mathrm{mg} \mathrm{C} \mathrm{m}^{-2} \mathrm{~d}^{-1}$ in the OMZ core at $400 \mathrm{~m}$ (Engel et al., 2017). This POC loss of $41-52 \mathrm{mg} \mathrm{C} \mathrm{m}^{-2} \mathrm{~d}^{-1}$ indicates an average heterotrophic respiration rate of $4.7-5.9 \mu \mathrm{mol} \mathrm{O} \mathrm{O}_{2} \mathrm{~kg}^{-1} \mathrm{yr}^{-1}$ within the upper $300 \mathrm{~m}$ of the mesopelagic water column, assuming a respiratory quotient (RQ) of $\left[\mathrm{CO}_{2}\right]$ : $\left[\mathrm{O}_{2}\right]$ of 0.89 after Williams and Giorgio (2005). This approximation, however, only includes the fast sinking particles that are typically captured with sediment traps and assumes that their loss from sinking fluxes is due to complete oxidation to $\mathrm{CO}_{2}$ without significant production of recalcitrant suspended or dissolved organic matter. Thus, these respiration estimates are at the lower end of the range of biological oxygen consumption rates $\left(10 \mu \mathrm{mol} \mathrm{kg}^{-1} \mathrm{yr}^{-1}\right.$ at $100 \mathrm{~m}$ depth to about $6 \mu \mathrm{mol} \mathrm{kg}^{-1}$ year $^{-1}$ in the OMZ core) estimated for the ETNA from apparent oxygen utilization (AOU) (Karstensen et al., 2008). The carbon flux attenuation observed in the ETNA by Engel et al. (2017) is less than would be expected based on the ambient temperature and the assumption that organic carbon flux attenuation can be predicted for oxygen replete areas from in situ temperature for the upper $500 \mathrm{~m}$ (Marsay et al., 2015). The ETNA POC export flux data thus suggests that organic carbon remineralization, and hence oxygen consumption in the OMZ, may be reduced compared to fully oxygenated waters.

Enhanced biological productivity and the accumulation of particulate and dissolved organic matter from anticyclonic mode water eddies has been reported for the ETNA (Löscher et al., 2015). This may be explained by a combination of high nutrient concentrations in the coastal upwelling waters in which eddies originally form, and continued vertical advection of nutrient-rich waters from below the euphotic zone. The enhanced productivity, in turn, leads to considerably higher oxygen consumption rates within the eddy $\left(0.26 \mu \mathrm{mol} \mathrm{kg} \mathrm{kg}^{-1} \mathrm{~d}^{-1}\right.$; Fiedler et al., 2016) compared to the surrounding waters $\left(0.03 \mu \mathrm{mol} \mathrm{kg}^{-1} \mathrm{day}^{-1}\right.$; Karstensen et al., 2015). These high oxygen consumption rates lead to dead zone eddies with particularly low oxygen concentrations (Löscher et al., 2015; Fiedler et al., 2016). Oxygen depletion within the eddy core

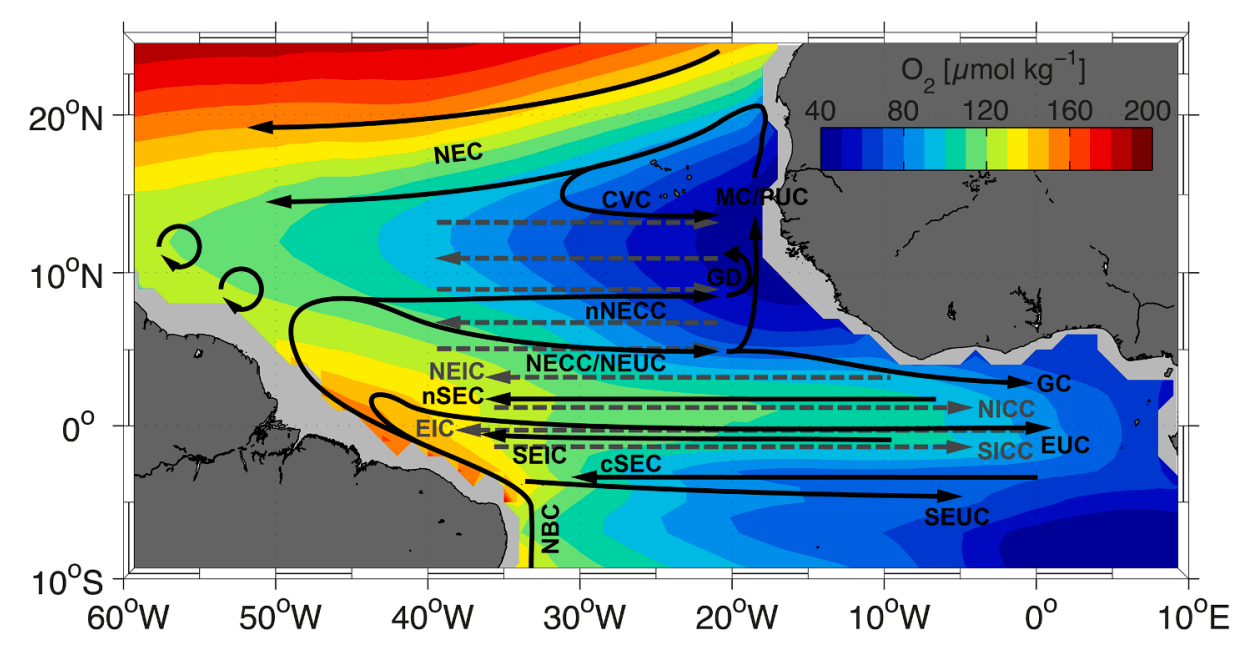

and Southern Intermediate Countercurrent (SICC). From Hahn et al. (2017).
Fig. 2.2.1. Oxygen concentration $\left(\mu \mathrm{mol} \mathrm{kg}{ }^{-1}\right)$ at the potential density surface $27.1 \mathrm{~kg} \mathrm{~m}^{-3}$ as obtained from MIMOC (monthly, isopycnal and mixedlayer ocean climatology; Schmidtko et al., 2017). The deep oxygen minimum zone in the ETNA extends from the African coast in the east to the highoxygen boundary regime of the North Brazil Current in the West. Superimposed solid arrows denote the surface currents: North Equatorial Current (NEC), Cape Verde Current (CVC), Mauritania Current/ poleward undercurrent (MC/PUC), Guinea Dome (GD), North Equatorial Countercurrent/North Equatorial Undercurrent (NECC/NEUC), northern branch of the NECC (nNECC), northern and central branches of the South Equatorial Current (nSEC, cSEC), Equatorial Undercurrent (EUC), South Equatorial Intermediate Current (SEIC), South Equatorial Undercurrent (SEUC) and North Brazil Current (NBC). Dashed arrows denote currents at intermediate depth: North Equatorial Intermediate Current (NEIC), Equatorial Intermediate Current (EIC), Northern Intermediate Countercurrent (NICC) 

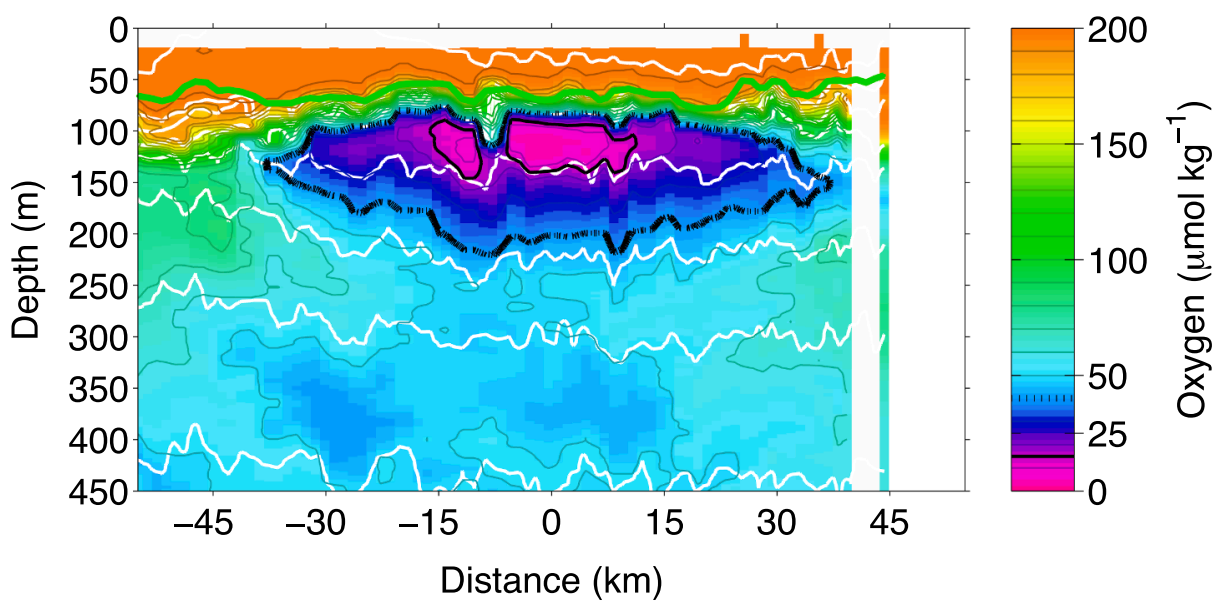

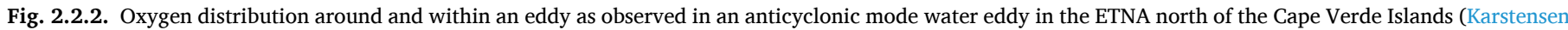

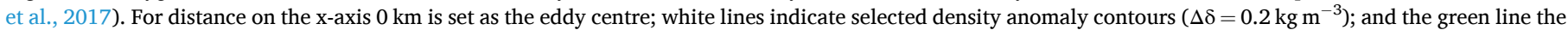
base of the mixed layer. (For interpretation of the references to color in this figure legend, the reader is referred to the web version of this article.)

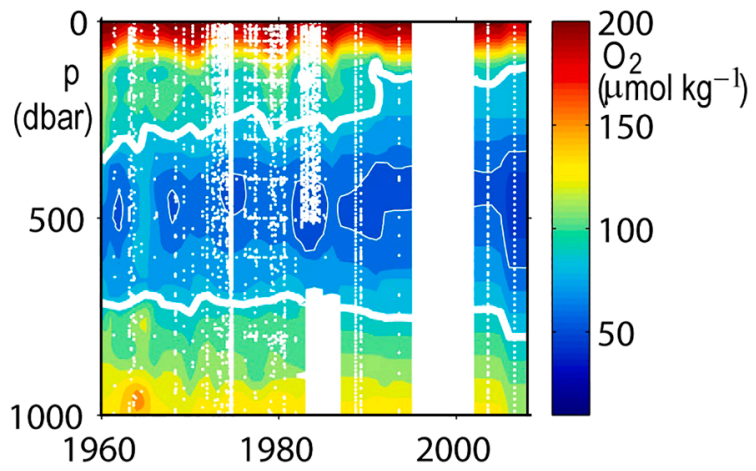

Fig. 2.2.3. Changes in dissolved oxygen concentration indicate an expansion of the OMZ in the eastern tropical North Atlantic $\left(10^{\circ}\right.$ to $14^{\circ} \mathrm{N}, 20^{\circ}$ to $\left.30^{\circ} \mathrm{W}\right)$ over the years 1960-2008 as shown by Stramma et al. (2008).

is assumed to progress while the eddy travels along its pathway from the coast to the open Atlantic because the high rotational speed impedes oxygen exchange between the eddy core and the surrounding water mass.

Meso- and sub-mesoscale physical processes, such as the formation of eddies and filaments, can play an important role in the organic carbon (and thus oxygen) budget in the open ETNA as eddies and filaments affect lateral transport from the eastern boundary upwelling regions (Álvarez-Salgado et al., 2007). For the Canary Current System, the offshore flux of organic carbon in the upper $100 \mathrm{~m}$ has been estimated as $8-34 \%$ of net community production of the coastal system and can extend up to $1500 \mathrm{~km}$ into the open North Atlantic (Lovecchio et al., 2018). The lateral supply of organic matter may thereby contribute to sustaining net heterotrophy and hence the biological drawdown of oxygen in the open North Atlantic (Hoppe et al., 2002). Organic matter in the dissolved and colloidal phases may play a particular role in this offshore transport, as concentrations in upwelling regions are typically high and sinking losses negligible. For the upwelling regions off Northwest Africa and north-west Iberia, reported accumulation rates of DOC and POC are similarly high (Álvarez-Salgado et al., 2001). A recent study off Mauritania suggested that, in addition to new DOC production, the off-shore transport of DOC may also be fueled by the upwelling of DOC previously released during particle decomposition on the shelf (Thomsen et al., 2019). However, for assessing the role of lateral advection of organic matter as part of the coupling between the productive shelf system and the open ocean, more information is needed on meso- and sub-mesoscale transport processes and the rates of biological turn-over and respiration during the course of transport.

\subsubsection{Future changes in ETNA OMZ}

Predicting the future development of the OMZ in the open ETNA region is largely limited by the inability of models to accurately reproduce the present vertical oxygen distribution, in particular the separation between the shallow and deep OMZ (Matear and Hirst, 2003; Duteil et al., 2014a,b). In addition, the contribution of biological and biogeochemical processes to the observed and increasing imbalance of the oxygen budget in the ETNA is largely unknown. Changes in biological oxygen consumption could in principle be related to: (1) enhanced export of organic matter, (2) a change in sinking particle composition (i. e., increasing C: $\mathrm{N}$ ratios) or increased lability, (3) reduced sinking speed or (4) changes in temperature. Better understanding of how warming will decrease oxygen solubility in surface waters and increase upper ocean stratification with consequences for vertical mixing, subduction and ocean circulation is needed. Warming may also affect upwelling at eastern continental margins and therefore the production of organic matter and its transport to the open ETNA by lateral transport. Furthermore, the frequency and strength of mesoscale eddies may change in the future with potential consequences for both the supply of organic matter and oxygen to the open Atlantic. Oxygen budgets of the ETNA are sensitive to the highly oxic equatorial currents (Brandt et al., 2010; Duteil et al., 2014a,b). Assessing variations in biogeochemical and physical forcing, including current intensity and zonal meandering, will therefore also be crucial in estimating future changes in the ETNA OMZ.

\subsection{OMZs of North Indian Ocean}

The lowest oxygen concentrations in the Indian Ocean are observed in its two northern basins, namely the Arabian Sea and the Bay of Bengal (Wyrtki, 1971). The OMZs of the Indian Ocean differ from the OMZs in the Pacific and the Atlantic Oceans in that the most pronounced oxygen deficiency in subsurface waters of the Indian Ocean does not develop along its eastern boundary. This results in the conspicuous absence of low oxygen conditions in waters off the west coast of Australia, and is in contrast to acute oxygen depletion that occurs at comparable latitudes off the west coasts of South America and Africa.

\subsubsection{OMZs of the Arabian Sea and Bay of Bengal}

The mesopelagic oxygen minimum zones (OMZs) of the Arabian Sea and Bay of Bengal are among the largest found in the oceans (Paulmier and Ruiz-Pino, 2009). The anomalous location of the Indian Ocean's OMZs in these two northern basins is the consequence of two unique geographical features: (1) the connection of the Indian Ocean to the 
Pacific Ocean through the Indonesian seas; and (2) the limited northward extension of the Indian Ocean to $\sim 25^{\circ} \mathrm{N}$ due to the Eurasian landmass. The porous low-latitude eastern boundary allows the inflow of warm, less-saline water (known as the Indonesian Throughflow) from the Pacific Ocean to the Indian Ocean (Gordon, 2005), which contributes to the anomalous (poleward) surface flow (the Leeuwin Current) off western Australia. The low latitude northern boundary has an even more pronounced effect on the oceanography of the Indian Ocean at latitudes greater than $10^{\circ} \mathrm{N}$ (the Hydrochemical Front; Wyrtki, 1973) in that it results in a unique monsoon circulation characterized by complete reversals of the atmospheric and surface oceanic circulations once every six months. The monsoon winds fertilize the surface waters of the Northwestern Indian Ocean (Arabian Sea) through the upwelling of nutrient-rich subsurface waters in summer and convective overturning in winter, making the Arabian Sea highly productive on an annual basis (Naqvi et al., 2006a). This, in turn, elevates oxygen demand at depth through the sinking of particulate organic matter from the surface layer. The low latitude northern boundary also severely restricts subsurface water mass formation north of the equator, except to a very limited extent in the two Mediterranean-type marginal seas - the Red Sea and Persian Gulf. Thus, most ( 90\%) of the mesopelagic ventilation is by waters of the southern hemisphere, principally the Indian Ocean Central Water (IOCW) or the Subantarctic Mode Water, that are relatively more oxygenated and cross the equator in the western Arabian Sea mostly during the Southwest Monsoon (SWM) (Swallow, 1984; Naqvi et al., 2010a). Thus, the occurrence of OMZs in the northern basins of the Indian Ocean is due to both moderately high oxygen consumption rates arising from the elevated productivity of the region and a severely restricted oxygen supply via lateral advection (Swallow, 1984; Naqvi, 1987; Warren, 1994; Howell et al., 1997).

The varying balance between the oxygen demand for respiration and its supply via ventilation creates geographical changes in oxygen deficiencies in the North Indian Ocean, both within and between the two major basins. The Arabian Sea is far more productive than the Bay of Bengal (Naqvi et al., 2006a). The Arabian Sea is also relatively better ventilated at mid-depths because, in addition to the above-mentioned flow of intermediate waters of southern origin that cross the equator only in the western Indian Ocean, it also receives high salinity, oxygenated waters from the Red Sea and the Persian Gulf. Remarkably, while the overall range of minimum dissolved oxygen concentrations in the OMZs of the two basins is quite small $\left(<0.2 \mathrm{mll}^{-1}\right)$, the two basins are characterized by vastly different biogeochemical regimes that have been apparently stable on at least decadal time scales. How the delicate balance between oxygen consumption and supply is sustained and how the balance will respond to human activities (Stramma et al., 2008; Schmidtko et al., 2017), are issues of enormous biogeochemical and ecological significance that are not well understood (Bristow et al., 2017).

\subsubsection{Reducing versus non-reducing OMZs}

Once oxygen becomes limiting, anaerobic respiratory pathways are initiated whereby microbes utilize other electron acceptors for the degradation of organic matter. These oxidants are believed to be utilized sequentially in the order of decreasing energy yield $\left(\mathrm{NO}_{\mathrm{x}}>\mathrm{Mn}(\mathrm{IV})>\mathrm{Fe}\right.$ (III) $>\mathrm{SO}_{4}^{2-}>\mathrm{CO}_{2}$ ) (Froelich et al., 1979). The free energy change $\left(\Delta \mathrm{G}^{\mathrm{O}}\right)$ associated with the oxidation of $1 \mathrm{~mol}$ of glucose using $\mathrm{O}_{2}, \mathrm{NO}_{3}^{-}$and $\mathrm{Mn}$ (IV) are similar $(-3190,-3130$ and $-3005 \mathrm{KJ}$, respectively; Froelich et al., 1979). Thus, some overlapping of respiration involving these electron acceptors (together referred to as "suboxic" processes) may occur. In fact, coincidence of maxima in nitrite $\left(\mathrm{NO}_{2}^{-}\right)$, an intermediate of denitrification $\left(\mathrm{NO}_{3}^{-} \rightarrow \mathrm{NO}_{2}^{-} \rightarrow \mathrm{NO} \rightarrow \mathrm{N}_{2} \mathrm{O} \rightarrow \mathrm{N}_{2}\right.$ ), and $\mathrm{Mn}$ (II) within the core of the Arabian Sea OMZ strongly points to contemporaneous reduction of $\mathrm{NO}_{\mathrm{x}}$ and $\mathrm{Mn}(\mathrm{IV})$ (Saager et al., 1989; Farrenkopf and Luther, 2002). A maximum in Fe(II) is also found within the same layer (Moffett et al., 2007, 2015), despite the much lower energy yield for Fe (III) reduction $\left(\Delta \mathrm{G}^{\mathrm{o}}=-1410 \mathrm{KJ}\right.$ mole $\mathrm{e}^{-1}$ glucose). It is not clear whether this maximum is produced in situ or transported from the continental margin. In either case, concentrations of Mn and Fe are too low (a few $\mathrm{nM}$ ) for these electron acceptors to be significant contributors to organic matter degradation. Sulphate is by far the most abundant $(>28 \mathrm{mM}$ ) electron acceptor in seawater, but the associated energy yield $\left(\Delta \mathrm{G}^{\mathrm{o}}=-380 \mathrm{KJ}\right.$ mole ${ }^{-1}$ glucose) is an order of magnitude smaller than that provided by $\mathrm{O}_{2}, \mathrm{NO}_{\mathrm{x}}$ or $\mathrm{Mn}$. Therefore, sulphate reduction in the water column has been thought to occur only after all $\mathrm{NO}_{\mathrm{x}}$ has been fully utilized. However, Canfield et al. (2010) provided evidence for significant sulphate reducing activity within the OMZ off Chile based on labelling experiments and metagenomic sequencing of the microbial community. They proposed that the sulphide produced was oxidized by $\mathrm{NO}_{\mathrm{x}}$. Even though this process has not been closely examined in other OMZs, its reported coupling with the nitrogen cycle and the low concentrations of the other electron acceptors are used to support the longheld view that the biogeochemistry of OMZs is dominated by the nitrogen cycle (Canfield et al., 2010). What is most intriguing, however, is that the reductive nitrogen transformations are extremely sensitive to the ambient oxygen concentrations even close to levels of detection.

The extreme sensitivity of nitrogen redox processes to oxygen concentrations in the low range is clearly seen in the distribution of oxygen and $\mathrm{NO}_{2}^{-}$along a transect extending from the Omani coast to the Indian coast (Fig. 2.3.1). The accumulation of $\mathrm{NO}_{2}^{-}$(called the secondary nitrite maximum (SNM)) only occurs within the upper one-third or so of the $\mathrm{OMZ}$ and within a fairly well-defined zone that extends from the Indian shelf in the northeastern Arabian Sea to the central Arabian Sea (Fig. 2.3.1a). The apparent separation of the zone of active pelagic denitrification from the productive upwelling centers is unique to the Arabian Sea, as in the Pacific and Atlantic oceans these zones are associated with the productive eastern boundary upwelling systems. This anomaly in the Arabian Sea mainly arises from a more vigorous ventilation of the OMZ from the south in the western Arabian Sea, and also through the advection of the Persian Gulf Water (PGW) in the northern Arabian Sea (Codispoti et al., 2001). In addition, stronger vertical eddy mixing in the western Arabian Sea and the offshore transport of detritus have also been proposed to contribute to the location of the most intense OMZ in the central and northeastern parts of the basin (Kim et al., 2001; McCreary et al., 2013).

The seasonality and probably the interannual variability of advection of relatively oxygenated intermediate waters result in seasonal and interannual shifts in the western boundary of the SNM zone in the western Arabian Sea (Rixen et al., 2014). The monsoon-forced seasonal reversals of both surface and subsurface circulations also bring about substantial temporal changes in the OMZ off the Indian coast (Naqvi et al., 2009). The prevalence of relatively low $\mathrm{NO}_{2-}$ concentrations off the Indian coast attributed to the northward transport of slightly more oxygenated waters by the West India Undercurrent (WIUC) during the SWM when the surface flow is toward the equator is evident in Fig. 2.3.1 (Naqvi et al., 2006b). Such poleward undercurrents are ubiquitous in eastern boundary upwelling systems (McCreary, 1981). At its peak, waters of the WIUC may be identified by lower salinity and higher oxygen content extending down to approximately $400 \mathrm{~m}$ depth and up to $200 \mathrm{~km}$ offshore from the continental slope off Goa $\left(\sim 15^{\circ} \mathrm{N}\right.$ latitude) (Naqvi et al., 2006b). The associated injection of oxygen into the OMZ prevents the water from becoming reducing just off the continental margin at least up to $17^{\circ} \mathrm{N}$ during the SWM, thereby accounting for the observed offshore intensification of denitrification (Fig. 2.3.1). This pattern is different from that seen in other OMZs, especially off Peru, where the most intense denitrification occurs within the poleward undercurrent (Codispoti et al., 1989). Naqvi et al. (2006b) attributed this anomaly to lower oxygen demand within the WIUC arising from the lower productivity of overlying waters, implying the dominant role of physical processes in the development of the OMZ of the Arabian Sea.

Within the reducing/denitrifying portion (SNM) of the OMZ, oxygen concentrations (Fig. 2.3.1b) are close to or below the detection limit of the sensitive colorimetric procedure suitable for measurements in the 

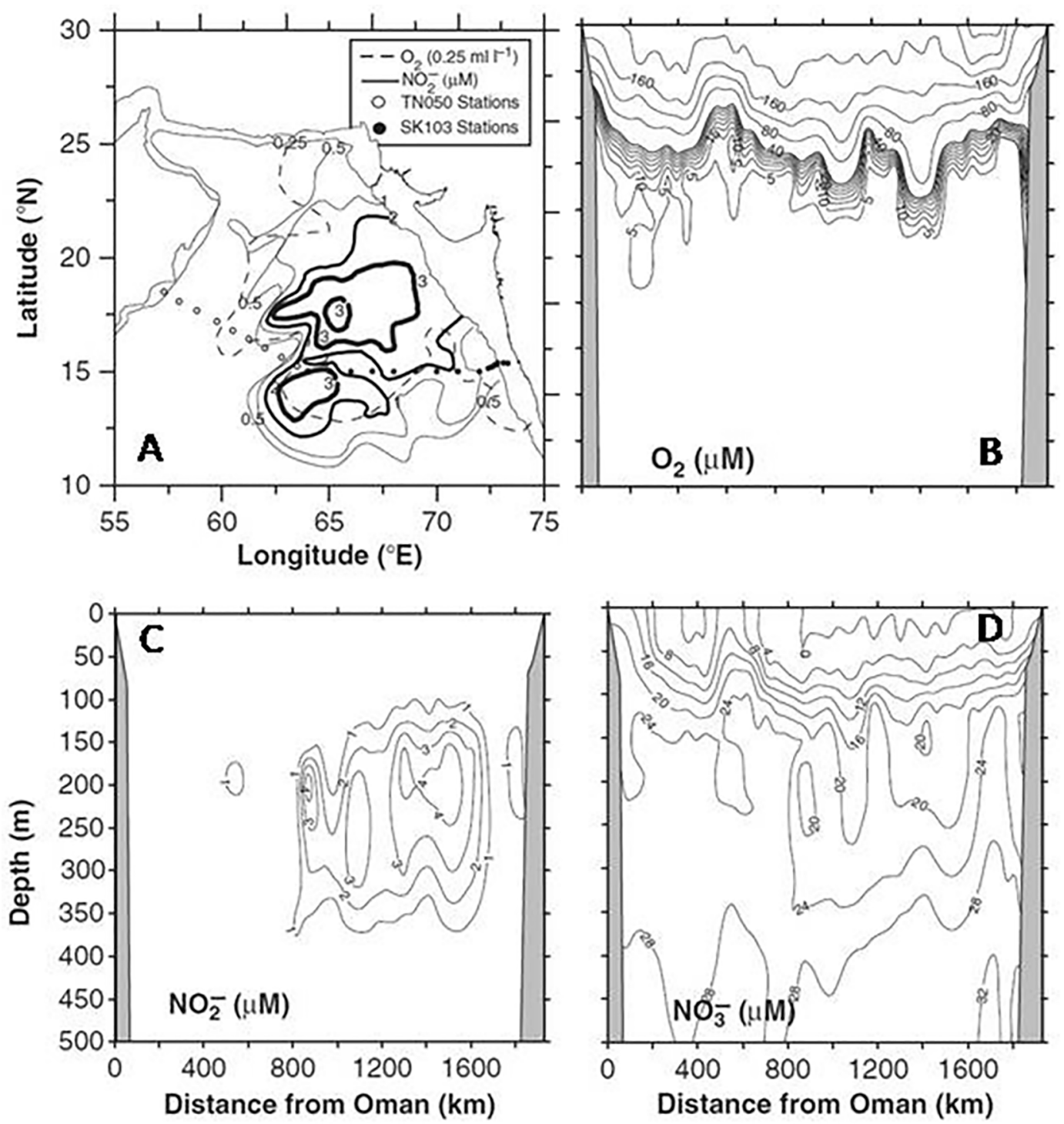

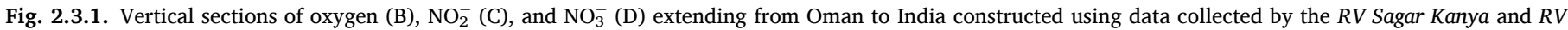

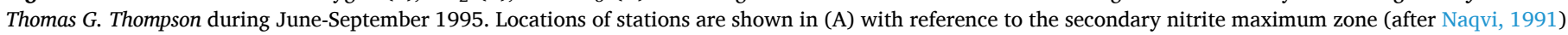
and the zone of minimum Winkler $\mathrm{O}_{2}$ at $300 \mathrm{~m}$ as demarcated by the $0.25 \mathrm{ml}^{-1}$ contour (dotted curve) (after Wyrtki, 1971). From Naqvi et al. (2006a).

low range (Broenkow and Cline, 1969), rendering these waters functionally anoxic (Lam et al., 2011; Thamdrup et al., 2012). In addition to the $\mathrm{NO}_{2}^{-}$maximum, this zone exhibits all the characteristics of a "suboxic" system, including a $\mathrm{NO}_{3}^{-}$minimum, a $\mathrm{N}_{2} \mathrm{O}$ minimum sandwiched between two maxima, prominent deficiencies in $\mathrm{NO}_{3}^{-}$and excess $\mathrm{N}_{2}$ (Fig. 2.3.2). Maxima in beam attenuation constant (turbidity), total bacterial counts and activity of the electron transport system (ETS), a measure of respiration rates, are also associated with the SNM (Naqvi et al., 1993) as are maxima in reduced $\mathrm{Mn}$ and Fe (II), Mn (II) and iodide (Farrenkopf and Luther, 2002; Moffett et al., 2007, 2015). Loss of $\mathrm{NO}_{3}^{-}$ to $\mathrm{N}_{2}$ is also indicated by natural isotope abundance measurements that show large enrichment of the heavier isotopes $\left({ }^{15} \mathrm{~N}\right.$ and $\left.{ }^{18} \mathrm{O}\right)$ in $\mathrm{NO}_{3}^{-}$and its depletion in $\mathrm{N}_{2}$ (Brandes et al., 1998; Gaye et al., 2013). Moreover, while $\mathrm{N}_{2} \mathrm{O}$ within the SNM is highly enriched with the heavier isotopes (Naqvi et al., 1998a,b), the $\delta^{15} \mathrm{~N}$ and $\delta^{18} \mathrm{O}$ values of $\mathrm{NO}_{2}^{-}$are quite low (mostly negative), indicating substantial reoxidation of $\mathrm{NO}_{2}^{-}$to $\mathrm{NO}_{3}^{-}$ (Gaye et al., 2013; Martin and Casciotti, 2017). Like the other microbial and chemical characteristics, the trends of natural isotope abundance in the Arabian Sea are typical of the reducing marine OMZs (Casciotti, 2016). Thus, despite different physical processes causing the development of OMZs within the Indian Ocean, the microbial response to anoxia and associated biogeochemical transformations appear quite similar.

In addition to denitrification, nitrogen loss within OMZs also occurs through anaerobic ammonium oxidation (anammox, $\mathrm{NO}_{2-}+\mathrm{NH}_{4}^{+} \rightarrow$ $\mathrm{N}_{2}+2 \mathrm{H}_{2} \mathrm{O}$ ), a relatively recently discovered autotrophic process (Strous et al., 1999). Direct measurements of $\mathrm{N}_{2}$ production rates in OMZs using labelled substrates have often shown anammox to be more important than denitrification (Kuypers et al., 2015; Thamdrup et al., 2006; Hamersley et al., 2007), with a couple of notable exceptions. Ward et al. (2009) found denitrification to be the major nitrogen loss process in the Arabian Sea. However, observations by Lam et al. (2011) made at about the same time yielded low rates of both denitrification and anammox, but high $\mathrm{NO}_{2}^{-}$oxidation rates, within the SNM zone. Outside this zone, off Oman, Jensen et al. (2011) found significant nitrogen loss to occur through a coupling between anammox and dissimilatory nitrate reduction to ammonium (DNRA). Ward et al. (2009) reported higher anammox rates in the OMZ in the eastern tropical South Pacific (ETSP) off Peru. However, Dalsgaard et al. (2012) showed that although denitrification occurred less frequently than anammox in the ETSP, when evident in functionally anoxic waters, it was quantitatively far more important than anammox and accounted for the majority of the overall nitrogen loss. Interestingly, regardless of which process was found to be 

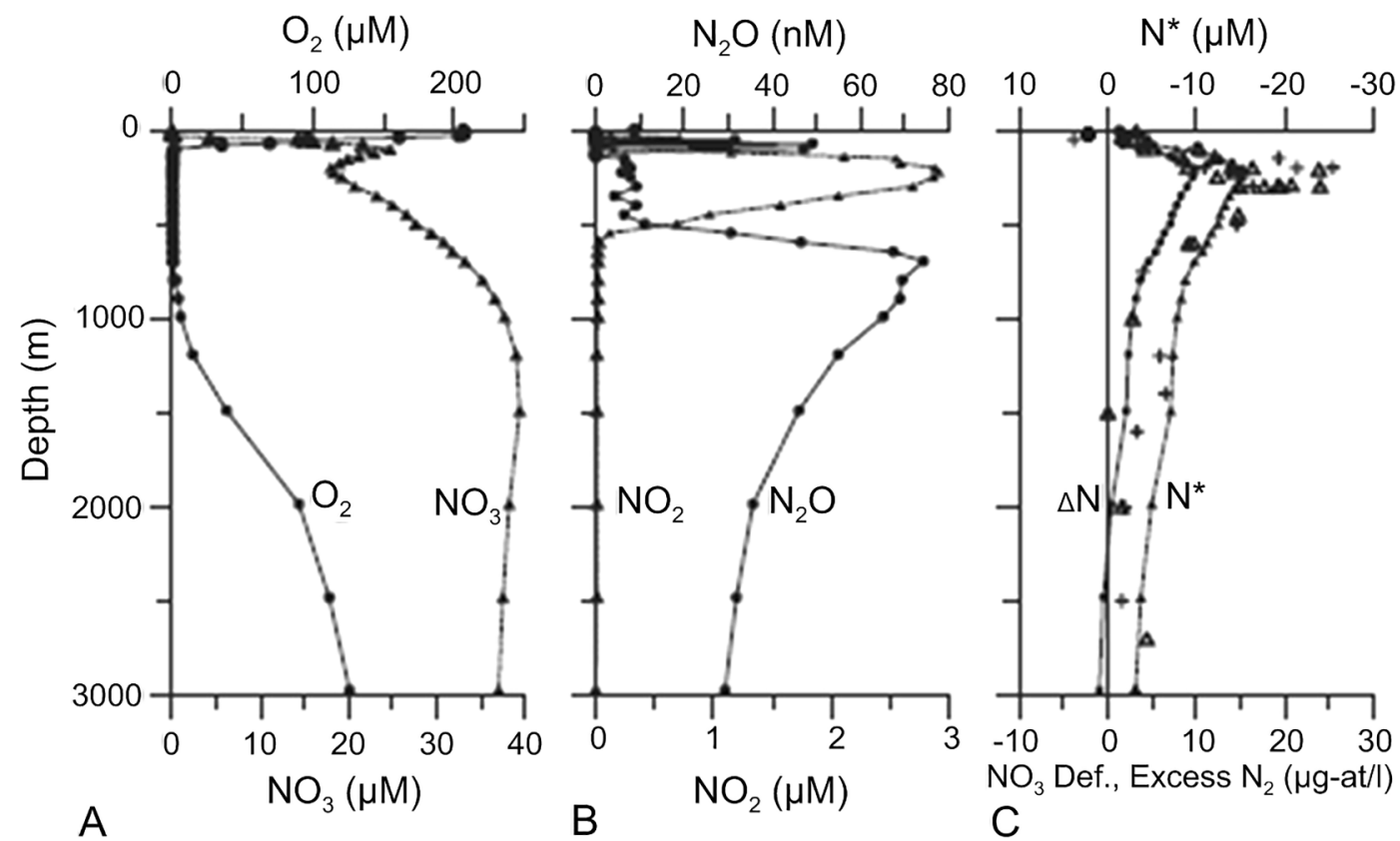

Fig. 2.3.2. Vertical profiles at $19^{\circ} \mathrm{N}, 67^{\circ} \mathrm{E}$ of (a) oxygen (circles) and $\mathrm{NO}_{3}^{-}$(triangles); (b) $\mathrm{N}_{2} \mathrm{O}$ (circles) and $\mathrm{NO}_{2}^{-}$(triangles); (c) $\mathrm{NO}_{3}^{-}$deficit according to Codispoti et al. (2001) (dots connected by the solid line), $\mathrm{N}^{*}$ according to Gruber and Sarmiento (1997) (small filled triangles connected by the dashed line), and "excess $\mathrm{N}_{2}$ " calculated from the $\mathrm{N}_{2} / \mathrm{Ar}$ ratio (larger unconnected symbols - crosses for data collected on two different cruises from this station and triangles for those from other stations also located within the denitrification zone). After Naqvi et al. (2006b).

more important (denitrification or anammox), molecular studies have demonstrated the presence of organisms with the genetic capability to perform both processes even though these genes might not be expressed (e.g., Ward et al., 2009; Lam et al., 2011). These observations suggest low but more common anammox activity seemingly controlled by the supply of $\mathrm{NH}_{4}^{+}$, and more vigorous, albeit episodic, denitrification activity, depending on the availability of organic matter and a complete loss of dissolved oxygen.
The OMZ of the Bay of Bengal is possibly the most unique of all oceanic OMZs. Based on circulation alone, the lowest oxygen concentrations in the Indian Ocean are expected to occur in this basin. Indeed, the minimum values within the Bay of Bengal OMZ are distinguishable from those in the Arabian Sea when determined with the titrimetric Winkler procedure. However, the SNM is seldom found in the Bay of Bengal, and $\mathrm{NO}_{3}^{-}$concentrations within the $\mathrm{OMZ}$ are much higher than those in the Arabian Sea at comparable latitudes (Fig. 2.3.3). Recent
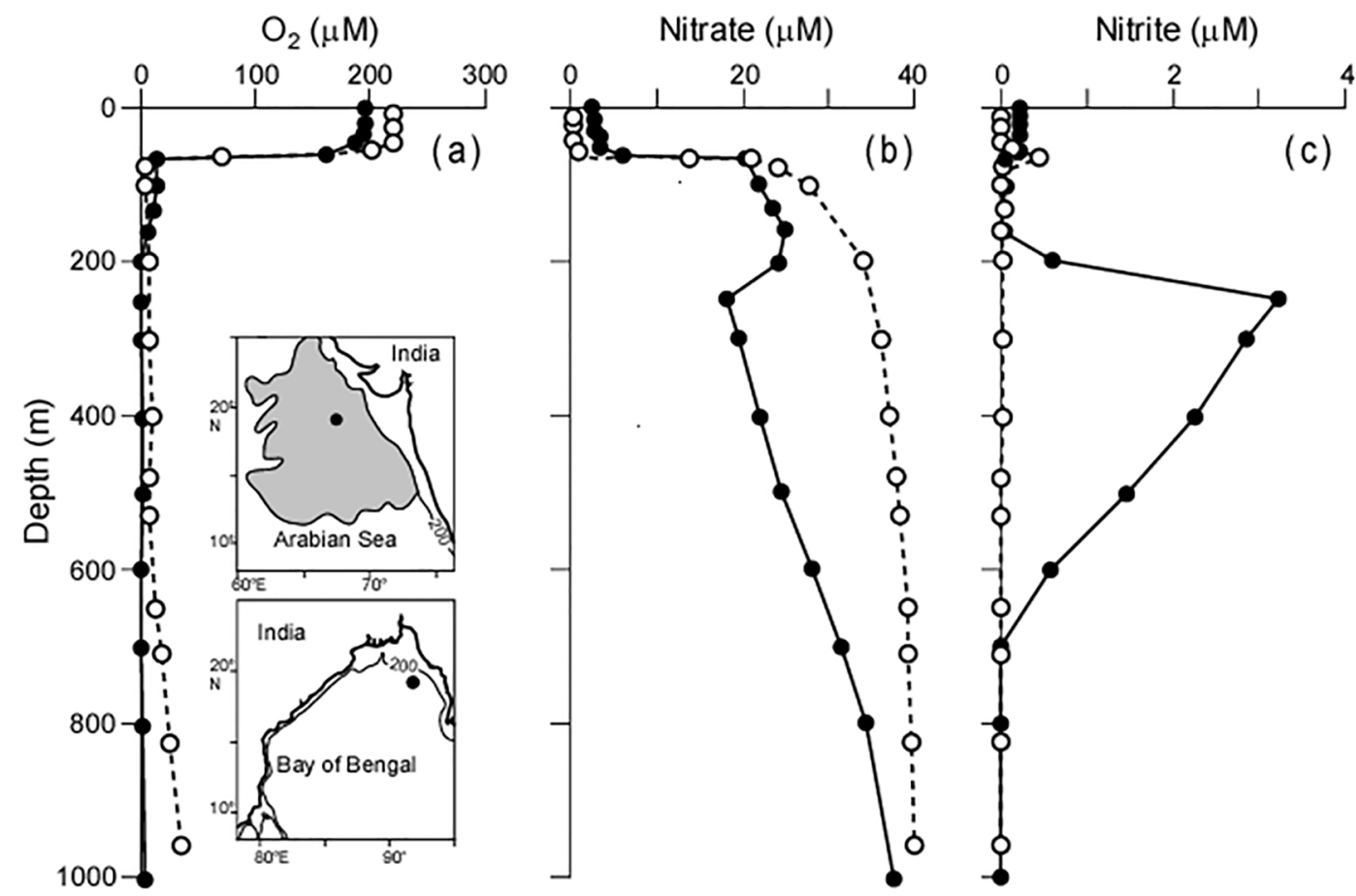

Fig. 2.3.3. Comparison of typical vertical profiles of Winkler oxygen (a), $\mathrm{NO}_{3}^{-}$(b), and $\mathrm{NO}_{2}^{-}$(c) in the Arabian Sea (solid circles) and Bay of Bengal (open circles). Station locations are shown in the insets and the shaded area marks the zone of denitrification in the Arabian Sea. 
measurements using the STOX sensor have shown that the Bay of Bengal OMZ contains traces of oxygen (10-200 nM) that can, in rare cases, fall below the detection limit $(7-12 \mathrm{nM})$ of the STOX electrode (Bristow et al., 2017). Out of the seven stations sampled in the study, traces of $\mathrm{NO}_{2}^{-}$(maximum $180 \mathrm{nM}$ ) were detected within a narrow layer close to the top of the OMZ only at one station. Measurements of the $\mathrm{N}_{2} / \mathrm{Ar}$ ratio indicated the presence of excess $\mathrm{N}_{2}(2-3 \mu \mathrm{M})$, and isotopic analysis revealed elevated $\delta^{15} \mathrm{~N}_{-} \mathrm{NO}_{3}^{-}$(by $1.5 \%$ ) (Bristow et al., 2017). This, in conjunction with a significant $\mathrm{NO}_{3}^{-}$deficit $(<4 \mu \mathrm{M})$, suggests biological production of $\mathrm{N}_{2}$ from $\mathrm{NO}_{3}^{-}$. Analysis of microbial genes indicated the presence of a microbial community equipped for both denitrification and anammox, quite similar to that found in other OMZs, and labelling experiments demonstrated the potential for anammox in the presence of $\mathrm{NO}_{2}^{-}$. Bristow et al. (2017) proposed that traces of oxygen within the Bay of Bengal OMZ supported $\mathrm{NO}_{2}^{-}$oxidation, thereby restricting its conversion to $\mathrm{N}_{2}$ through anammox or denitrification.

The key question that arises from these observations related to denitrification and anammox in the Bay of Bengal is what prevents the removal of traces of oxygen? One possible explanation is the large quantities of lithogenic material carried to the Bay of Bengal by numerous rivers. This material may be incorporated into particle aggregates providing ballast and thereby facilitating their rapid sedimentation to the seafloor with less degradation in the water column (Ittekkot et al., 1992; Rao et al., 1994). Support for this hypothesis is provided by much lower respiration rates in the water column in the Bay of Bengal than in the Arabian Sea (Naqvi et al., 1996). Using a series of model simulations, Al Azhar et al. (2017) demonstrated that the deeper remineralization depth (RD) in the Bay of Bengal, potentially arising from the above-mention ballast effect, could explain the contrasting distributions of oxygen and $\mathrm{NO}_{3}^{-}$in the Arabian Sea versus the Bay of Bengal and the confinement of denitrification to the Arabian region. In fact, a similar mechanism (progressive offshore shoaling of RD from the Omani coast) has been invoked to contribute to the offshore strengthening of the OMZ in the Arabian Sea as well, although the causative process of iron limitation controlling phytoplankton composition and thereby export of organic matter to the deep sea is different (Naqvi et al., 2010b). Finally, McCreary et al. (2013) have shown that the absence of upwelling, and consequently reduced availability of detritus along the western boundary, might also be a factor responsible for the weaker OMZ in the Bay of Bengal.

\subsubsection{Trends of deoxygenation}

Using global data sets, Stramma et al. (2008) showed that the rate of oxygen loss was the highest $\left(0.34 \mu \mathrm{mol} \mathrm{kg}{ }^{-1} \mathrm{yr}^{-1}\right)$ in the North Pacific and the lowest $\left(0.09 \mu \mathrm{mol} \mathrm{kg}{ }^{-1} \mathrm{yr}^{-1}\right)$ in the equatorial Indian Ocean. Schmidtko et al. (2017) also found that of the estimated 4.8 petamol of oxygen lost from the oceans, the combined contribution by the equatorial Indian Ocean and the southern Indian Ocean was only 8.5\%. Based on these analyses, the ongoing decrease in dissolved oxygen inventory in the Arabian Sea and Bay of Bengal combined appears to be $\ll 0.055$ petamol decade ${ }^{-1}$. The observed decreases in oxygen along the west coast of India, in the Gulfs of Aden and Oman, and in the northern Bay of Bengal were not accompanied by increases in apparent oxygen utilization (AOU) implying that the change is mainly due to a decrease in oxygen solubility in warming waters. Significantly, maximal deoxygenation in the equatorial Indian Ocean appears to be occurring along the western boundary where the more oxygenated intermediate waters originating in the south cross the equator into the Arabian Sea, which has important implications for future developments of the OMZs of the North Indian Ocean.

Three recent studies have dealt with deoxygenation of the upper water column in the Northwestern Indian Ocean. Two of these (Piontkovski and Queste, 2016; Queste et al., 2018) focused on the western Arabian Sea and the Gulf of Oman. Analysing data collected during the period 1960-2010, Piontkovski and Queste (2016), updating Piontkovski and Al-Oufi (2015), reported warming of water at $300 \mathrm{~m}$ by
$1.15 \pm 0.48^{\circ} \mathrm{C}$ over five decades and shoaling of the oxycline at a rate of $\sim 19 \mathrm{~m}^{\text {decade }}{ }^{-1}$. The observed oxygen decrease within the OMZ was especially pronounced during the SWM, with the most recent data (2000-2010) indicating nearly anoxic conditions. Queste et al. (2018) combined the historical data with glider time series to show that within the core of the OMZ in the Gulf of Oman oxygen levels have fallen from 6 to $12 \mu \mathrm{mol} \mathrm{kg}{ }^{-1}$ at the time of the International Indian Ocean Expedition (IIOE) in the 1960 s to $<2 \mu \mathrm{mol} \mathrm{kg}{ }^{-1}$ in recent times. Although this shift is subtle and could, to some extent, be accounted for by the improved quality of recent data, it is potentially significant given the abovementioned sensitivity of nitrogen redox processes to vanishingly low oxygen levels.

The third study relating to deoxygenation in the Northwestern Indian Ocean was by Banse et al. (2014), who focused on the more intense OMZ in the central Arabian Sea. They utilized oxygen data (measured by the titrimetric Winkler procedure with visual end point detection) collected from 1959 to 2004 at stations located within zonally-paired boxes of $1^{\circ}$ latitude $\times 2^{\circ}$ longitude; the boxes were centered at the latitudes of 8,10 , $12,15,18,20$, and $21^{\circ} \mathrm{N}$ and the longitudes of $65^{\circ}$ and $67^{\circ} \mathrm{E}$. Linear regression of oxygen concentration on year separately for the northeast monsoon and SWM showed a complex pattern. Within the boxes located at $8-12^{\circ} \mathrm{N}$ outside the SNM zone, oxygen appeared to have increased with time in the majority of cases. In contrast, within the OMZ, an opposite trend was observed in most cases, except for the boxes located at $20-21^{\circ} \mathrm{N}$. The observed rate of oxygen decrease (median $0.12 \mu \mathrm{M} \mathrm{yr}^{-1}$ ), is close to the lower range of rates of oxygen decline reported by Stramma et al. (2008). Similarly, where the slopes were positive, although not statistically significant at $20-21^{\circ} \mathrm{N}$ latitudes, the maximal slope value was only $\sim 0.10 \mu \mathrm{M} \mathrm{yr}^{-1}$.

$\mathrm{NO}_{2}^{-}$is a useful parameter to examine in the assessment of deoxygenation within OMZs because it acts as a surrogate of functional anoxia (Thamdrup et al., 2012). The SNM in the Arabian Sea has been known since the John Murray Expedition in 1933-1934 (Gilson, 1937), which means that parts of the Arabian Sea OMZ have been functionally anoxic for at least 80 years. The $\mathrm{NO}_{2}^{-}$concentration provides a measure of the extent of denitrification (Naqvi, 1991; Bulow et al., 2010), but it is not clear whether denitrification in the Arabian Sea has intensified in recent years. Repeated measurements at two locations (at $19.75^{\circ} \mathrm{N}, 64.62^{\circ} \mathrm{E}$, going back to 1977 , and at $\sim 15^{\circ} \mathrm{N}, 68^{\circ} \mathrm{E}$, going back to 1979 ) showed large interannual changes in $\mathrm{NO}_{2}^{-}$concentration but no long-term trends. Using the data collected during the US JGOFS cruises in 1994-1995, Rixen et al. (2014) demonstrated that the area with $\mathrm{NO}_{2}^{-}$ $>2 \mu \mathrm{M}$ was $63 \%$ larger in 1995 than that estimated earlier (Naqvi, 1991). However, these authors also note that these observations may indicate considerable seasonal and interannual variations in denitrification rather than a simple increasing temporal trend.

In order to investigate deoxygenation trends within the OMZ of the Bay of Bengal, Naqvi (2021) compared the earliest available oxygen data from this region collected during the IIOE with recent values. Five oxygen profiles obtained during 20-22 April 1963 on R.V. Anton Bruun are compared with observations on a cruise of R.V. Roger Revelle on 27 April 2007 at the same location (Lat. $18^{\circ} \mathrm{N}$, Long. $89^{\circ} \mathrm{E}$; Fig. 2.3.4). In 1963 , the Winkler oxygen concentrations within the depth range $\sim 200-400 \mathrm{~m}$, measured with manual titration with visual end point detection, averaged $8.33 \pm 2.11 \mu \mathrm{M}$, with a minimum value of of $5.36 \mu \mathrm{M}$. The corresponding average and minimum values in 2007, based on automated titrations, were $2.63 \pm 0.26 \mu \mathrm{M}$ and $2.26 \mu \mathrm{M}$, respectively. Taking into consideration the slight overestimation of oxygen (by $\sim 0.04 \mathrm{ml}^{-1}$ or $1.8 \mu \mathrm{M})$ by the manual method, the inferred decrease in oxygen, although subtle, is still significant. Measurements using a STOX sensor, having a detection limit of 7-12 nM, at this site in January-February 2014 on board R.V. Sagar Kanya yielded a minimum oxygen concentration of $36 \mathrm{nM}$ (Bristow et al., 2017). Oxygen could not be detected in six samples taken elsewhere. These observations suggest that oxygen levels within the OMZ of the Bay of Bengal might have decreased slightly, but significantly, over the past five decades and that this OMZ is 


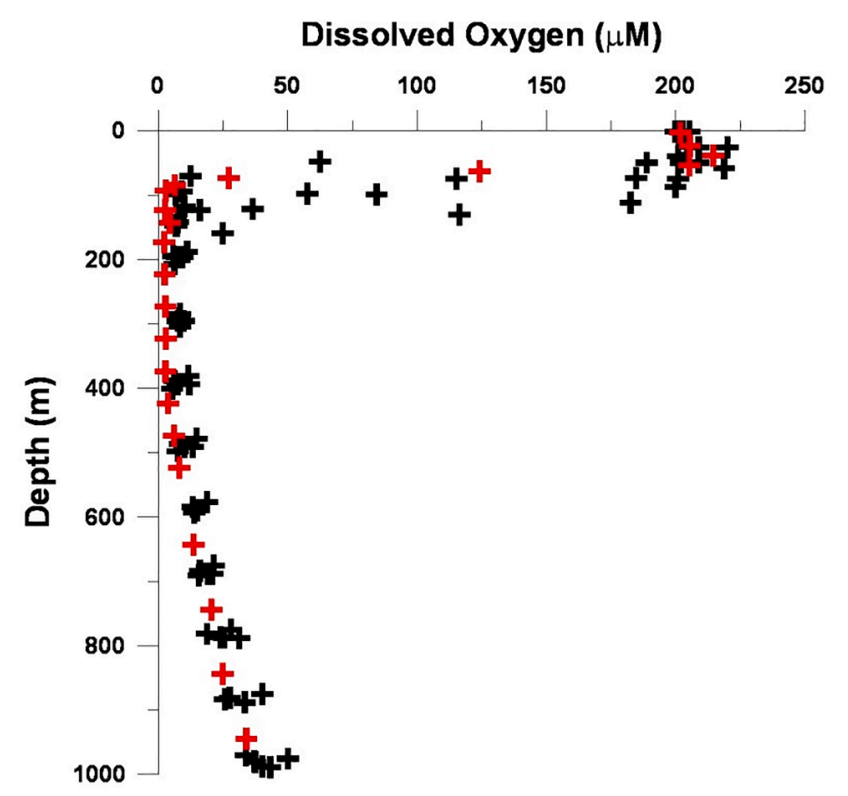

Fig. 2.3.4. Comparison of oxygen distribution in the northern Bay of Bengal in the vicinity of Lat. $18^{\circ} \mathrm{N}$, Long. $89^{\circ} \mathrm{E}$ based on sampling in April 1963 (black symbols) and April 2007 (red symbols). (For interpretation of the references to color in this figure legend, the reader is referred to the web version of this article.)

on the verge of turning functionally anoxic (Bristow et al., 2017). However, the lower OMZ appears to have remained remarkably stable for over 5 decades.

\subsubsection{Future scenarios}

The above review suggests that the rate of deoxygenation in the water column of the North Indian Ocean is substantially lower than in most other oceanic areas (Schmidtko et al., 2017; Stramma et al., 2008). However, given the large volume of water in the region that contain only traces of oxygen and is thus on the verge of turning anoxic, even small declines in oxygen levels in these waters may potentially have a disproportionally large impact on the ecosystem and biogeochemistry. Such a decrease may occur due to a decline in the oxygen concentrations in intermediate waters crossing the equator in the western Arabian Sea, as well as a change in the volume of these waters arising from altered circulation. Moreover, oxygen demand at mid-depth may also increase locally due to the intensification of upwelling (Goes et al., 2005). The monsoons are known to play an important role in regulating the intensity of the OMZ, and the associated biogeochemical transformations, as indicated by the sedimentary record (Altabet et al., 2002). Because global warming is projected to significantly impact the SWM (Turner and Annamalai, 2012), monsoons represent an important region-specific anthropogenic forcing that is likely to modify oxygen distribution in the North Indian Ocean in the future (Lachkar et al., 2018). The ongoing increase in nutrient loading from land is another way by which human activities could increase subsurface oxygen demand. In the case of the North Indian Ocean, especially the Bay of Bengal that is surrounded by densely-populated land masses, this effect may not be restricted to the formation of coastal low-oxygen (dead) zones and the expansion/ intensification of the existing ones, but it may also have basin-wide impacts. The extreme sensitivity of the Bay of Bengal OMZ to human activities can, therefore, not be overstated.

Another region-specific feature is that the OMZ of the Arabian Sea is the only OMZ in the world that is ventilated by freshly-formed water masses in the two Mediterranean-type marginal seas, namely the Red Sea and Persian Gulf. Of these, the Persian Gulf Water (PGW) flows directly into the layer where denitrification is the most intense. Thus, oxygen supply by this water mass controls denitrification in the northwestern Arabian Sea and Gulf of Oman (Codispoti et al., 2001; Banse et al., 2014). The PGW also has higher concentrations of total organic carbon (TOC) (Al-Said et al., 2018) than the water with which it mixes (Hansell and Peltzer, 1998). Changes in the preformed concentrations of both TOC and oxygen in the PGW may potentially impact redox cycling within the Arabian Sea OMZ. The emergence of hypoxia in the central Gulf (Al-Ansari et al., 2015) and high concentrations of TOC in the northern Gulf, one of the principal sites of formation of Gulf Deep Water, suggest that such a change may already be underway as a consequence of unprecedented eutrophication in the Gulf (Al-Yamani and Naqvi, 2019).

\section{Continental shelves}

Continental shelves represent the interface between the populated coastline and the open oceans, and the oxygen regime of the shelf environment may be strongly influenced by these adjoining environments. In this regard, the interaction between ocean-shelf exchange in controlling shelf ventilation and the role of shelf geometry in regulating productivity and retaining organic carbon are central to the development of shelf hypoxia and anoxia. Case studies presented here include the eastern boundary upwelling systems off California, Peru and Northern and Central Chile, Namibia and Senegal; the northern Gulf of Mexico; and the continental shelves of the North Indian Ocean.

\subsection{California Current}

The California Current Ecosystem (CCE) extends along the west coast of the USA from Washington State to Baja California $\left(50^{\circ} \mathrm{N}-25^{\circ} \mathrm{N}\right)$. This major upwelling region is forced by winds of the North Pacific High, the Aleutian Low and a thermal low-pressure system off California and northern Mexico (Checkley and Barth, 2009). Their relative importance varies seasonally, with latitude and inshore versus offshore. The CCE is a productive ecosystem consisting of a southward flowing, relatively shallow California Current and beneath this a northward flowing California Undercurrent. The California Current is fed by cold, fresh, nutrient-poor, oxygen-rich, high $\mathrm{pH}$ waters from the North Pacific Current, whereas the California Undercurrent, situated around 100-300 m ( $\left.\sigma_{\theta} \sim 26.6\right)$, contains low-oxygen waters derived from North Equatorial Pacific Intermediate waters that are warm, salty and relatively acidic (Meinvielle and Johnson, 2013; Evans et al., 2020). Wind driven upwelling is largely coastal, occurring at depths of $100-200 \mathrm{~m}$ and at rates of $10-20 \mathrm{~m} \mathrm{~d}^{-1}$, but also can be a product of wind stress curl, which results from spatially variable surface Ekman layer transport driven by horizontal differences in the surface wind stress. Wind stress curl yields a much lower rate of upwelling $\left(0.1-0.2 \mathrm{~m} \mathrm{~d}^{-1}\right)$ than Ekman transport but can represent a significant fraction of the total (Checkley and Barth, 2009). There is considerable spatial variability in upwelling dynamics along the California Current with different patterns in the northern and southern regions (Checkley and Barth, 2009). Throughout the CCE, high biological productivity generates a permanent oxygen minimum zone (OMZ; $\mathrm{O}_{2}<0.20 \mu \mathrm{mol} \mathrm{kg}^{-1}$ ) at approximately 450-1000 m depth (Fig. 3.1.1). Above this zone, oxygen limited waters occur $\left(\mathrm{O}_{2} 20-60 \mu \mathrm{mol} \mathrm{kg}{ }^{-1}\right)$, with the hypoxic zone $\left(60 \mu \mathrm{mol} \mathrm{kg}{ }^{-1}\right)$ sometimes extending to or onto the shelf (Checkley and Barth, 2009; Gilly et al., 2013).

\subsubsection{Time scales of oxygen variability and its drivers}

California Current System (CCS) waters, and those below, experience oxygen variability over time scales spanning nearly 8 orders of magnitude (Levin et al., 2015). At very long time scales, bathyal OMZs expand and contract over glacial-interglacial periods throughout the Quaternary (Moffitt et al., 2014, 2015). Analyses of foraminiferal communities, sediment varves, redox metals and $\delta^{15} \mathrm{~N}$ data have documented large changes in bottom-water oxygenation off California during the last 


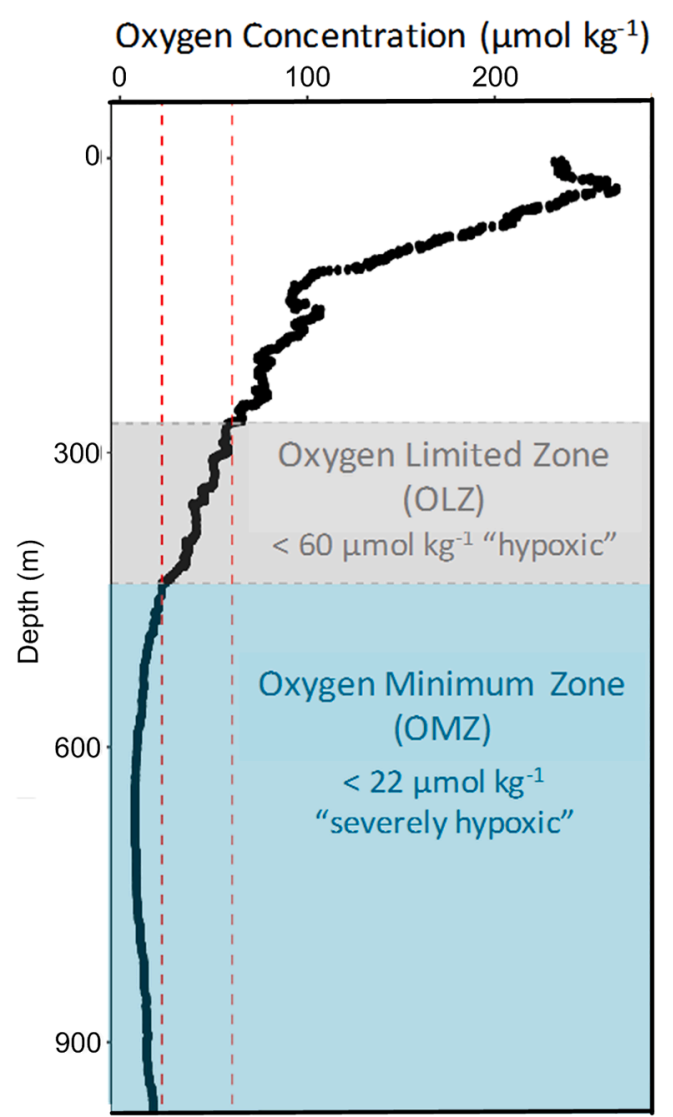

Fig. 3.1.1. Typical southern California oxygen profile illustrating zones described in Gilly et al. (2013); modified from Levin and Gallo (2019).

deglaciation (Ohkushi et al., 2013; Myhre et al., 2017). These changes are driven by warming and cooling events that can be abrupt, and may have caused much larger oxygen perturbations than observed in the modern records.

Hydrographic data collected by the California Cooperative Fisheries Investigation (CalCOFI), initiated in 1951, and additional moorings that record oxygen continuously at specific stations, have provided considerable insight into oxygen variability and its drivers in the CCS during the past half century. Off southern California, very low oxygenation was observed in the $1950 \mathrm{~s}$ and $2000 \mathrm{~s}$ but higher concentrations occurred within this period during the 1970s and 1980s (Fig. 3.1.2a) (McClatchie et al., 2010). Multi-decadal oxygen variation in the CCS has been linked to the changing influence of the North Pacific Gyre driven by the Pacific Decadal Oscillation (Pozo Buil and Di Lorenzo, 2017), and the influence of the California Undercurrent inshore and to the south (Meinvielle and Johnson, 2013). Oxygen also varies inter annually with ENSO cycles that influence the relative contribution of different source waters, the strength of upwelling, mixed layer depth and productivity (Bograd et al., 2019). At depths of $100-200 \mathrm{~m}$ there is significant ENSO-related variability in the contributions of Pacific Subarctic Upper Water to the southern CCS. These contributions vary with distance from shore and are greatest during La Niña years, while Pacific Equatorial water contributes more to inshore, deeper waters during El Niño (Bograd et al. 2019). Cooler La Niña conditions generally enhance productivity and lead to lower oxygen levels through increased biogeochemical drawdown whereas the opposite occurs during El Niño (Fig. 3.1.2b) (Nam et al., 2011). The strength of coupling of ENSO to CCS dynamics varies with water depth and La Niña generally has a stronger influence than El Niño (Fiedler and Mantua, 2017).

The CCE exhibits a clear seasonal wind cycle with peak upwelling occurring in spring every year; leading to lowest oxygen in late spring and early summer in southern California (Fig. 3.1.2c; Send and Nam, 2012; Nam et al., 2015). While upwelling brings lower oxygen waters to the surface, upwelling also brings nutrients. Seasonal hypoxia associated with summer upwelling is well documented off Washington and Oregon from 1950 to 1986; but in 2006 this was more extensive on the WA shelf (covering $5000 \mathrm{~km}^{2}$ ) with concentrations of $0.5 \mathrm{mll}^{-1}$ being lower than any previous observations (Connolly et al., 2010). Siedlecki et al. (2015) found that respiration of primary production is responsible for $50-60 \%$ of the seasonal decline of oxygen on the Washington and Oregon shelves, with local retentive circulation processes determining the spatial patterns of respiration-induced hypoxia. Seasonal hypoxia was initially observed on the Oregon inner shelf $(20-50 \mathrm{~m})$ in 2002 (Grantham et al., 2004) and has continued off Oregon in most years (Chan et al., 2008). Proposed explanations involve reductions in winds that normally mix and oxygenate shelf waters, lowered oxygen levels in source waters and intensification of upwelling, which has increasingly brought low oxygen, high $\mathrm{CO}_{2}$ waters onto the shelf and fueled intensified respiration (Chan et al., 2008; Feely et al., 2008; 2018). Similar severe shelf hypoxic events are rarely reported in the southern CCS. However, inshore anoxia occurred off San Diego, CA in May 2020 following a massive bloom of Lingulodinium polyedra potentially enabled by warming and excess precipitation the previous month (Anderson and Hepner-Medina, 2020).

Oxygenation in the CCE is also highly sensitive to short-term winds and associated nutrient inputs that yield event-scale changes in oxygenation. Week-long upwelling and relaxation episodes occur in waters off southern California (Fig. 3.1.2 d). On wide shelves, these episodes lead to declines in oxygen associated with increased biogeochemical oxygen consumption on the inner shelf; in contrast on narrow shelves, the oxygen increases (Send and Nam, 2012). Alongshore advection transports the oxygen signal that persists for days to weeks. Continuous monitoring on the shelf also revealed semidiurnal fluctuations associated with internal tides and in kelp forests, with diel cycling of oxygen linked to kelp photosynthesis (Fig. 3.1.2e; Frieder et al., 2012).

\subsubsection{Long-term oxygen trends}

Superimposed on decadal, inter annual, seasonal and higherfrequency variability are longer term trends of declining oxygen on the outer shelf and upper slope over the past 30-35 y (Bograd et al., 2008; 2015; Ren et al., 2018; Evans et al., 2020), often with greater oxygen loss inshore than offshore (Bograd et al., 2015; 2019). Oxygen loss has been documented across the full latitudinal range of the California Current, including a decline of: (1) $-0.83 \mu \mathrm{mol} \mathrm{kg}^{-} 1 \mathrm{y}^{-1}$ from 1979 to 2011 in Canadian waters southwest of Vancouver Island (Fig. 3.1.3a; Crawford and Pena, 2013); (2) $-0.9 \mu \mathrm{mol} \mathrm{kg}^{-1} \mathrm{y}^{-1}$ along the Newport Hydrographic Line off Oregon (Fig. 3.1.3b; Pierce et al., 2012); (3) $-1.92 \mu \mathrm{mol} \mathrm{kg}^{-1} \mathrm{y}^{-1}$ observed at $250-400 \mathrm{~m}$ off Monterey from 1998 to 2013 (Fig. 3.1.3c; Ren et al., 2018); and (4) off southern California $-2.1 \mu \mathrm{mol} \mathrm{kg}^{-1} \mathrm{y}^{-1}$ from 1984 to 2012 (Fig. 3.1.3d; Bograd et al., 2008, 2015) and $-0.97 \mu \mathrm{mol} \mathrm{kg} \mathrm{kg}^{-1}$ at $100-400 \mathrm{~m}$ from 1993 to 2018 (Evans et al., 2020). Some of the steepest declines are evident at $\sigma_{\theta}=26.5$, in the core of the California Undercurrent, consistent with a strengthened advection of the northward flowing California Undercurrent and increased input of and remineralization within Pacific Equatorial Water (PEW) (Meinvielle and Johnson, 2013; Bograd et al., 2015; Evans et al., 2020). The influence of PEW in the California Undercurrent at $\sigma_{\theta}=26.5$ falls from $90 \%$ to $50 \%$ between $25^{\circ} \mathrm{N}$ and $31^{\circ} \mathrm{N}$, remains relatively constant to $36^{\circ} \mathrm{N}$, and then decays to about $20 \%$ by $50^{\circ} \mathrm{N}$ (Meinvielle and Johnson, 2013).

There has been a significant shoaling of the OMZ upper boundary ( $20 \mu \mathrm{mol} \mathrm{kg}{ }^{-1}$ isocline) by $69 \mathrm{~m}$ off Oregon (Pierce et al., 2012) and of the hypoxic boundary ( $60 \mu \mathrm{mol} \mathrm{kg}{ }^{-1}$ isocline) by up to $90 \mathrm{~m}$ within portions of the southern CCS (Bograd et al., 2008). Since 1980, the CCS has effectively experienced a northward shift of subsurface water mass characteristics, with the tropical source waters of the PEWs also possibly 

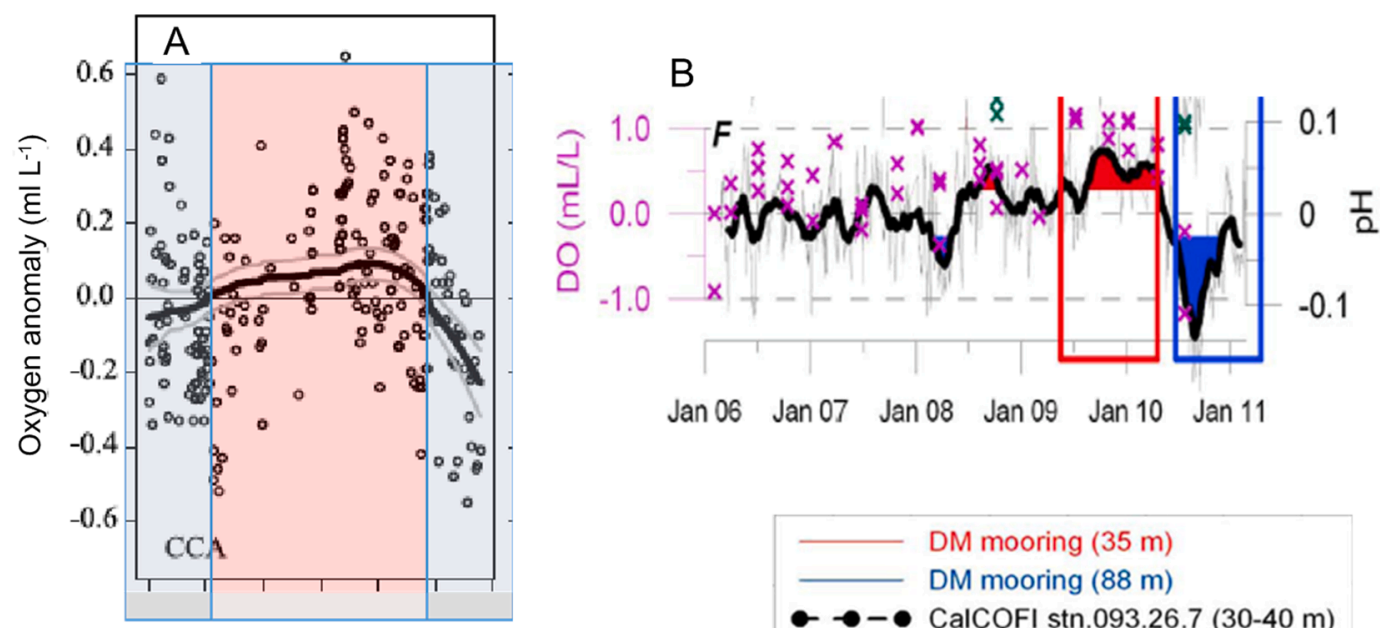

$\operatorname{Jan} 06 \quad \operatorname{Jan} 07 \quad \operatorname{Jan} 08 \quad \operatorname{Jan} 09 \quad \operatorname{Jan} 10 \quad \operatorname{Jan} 11$

\section{C}

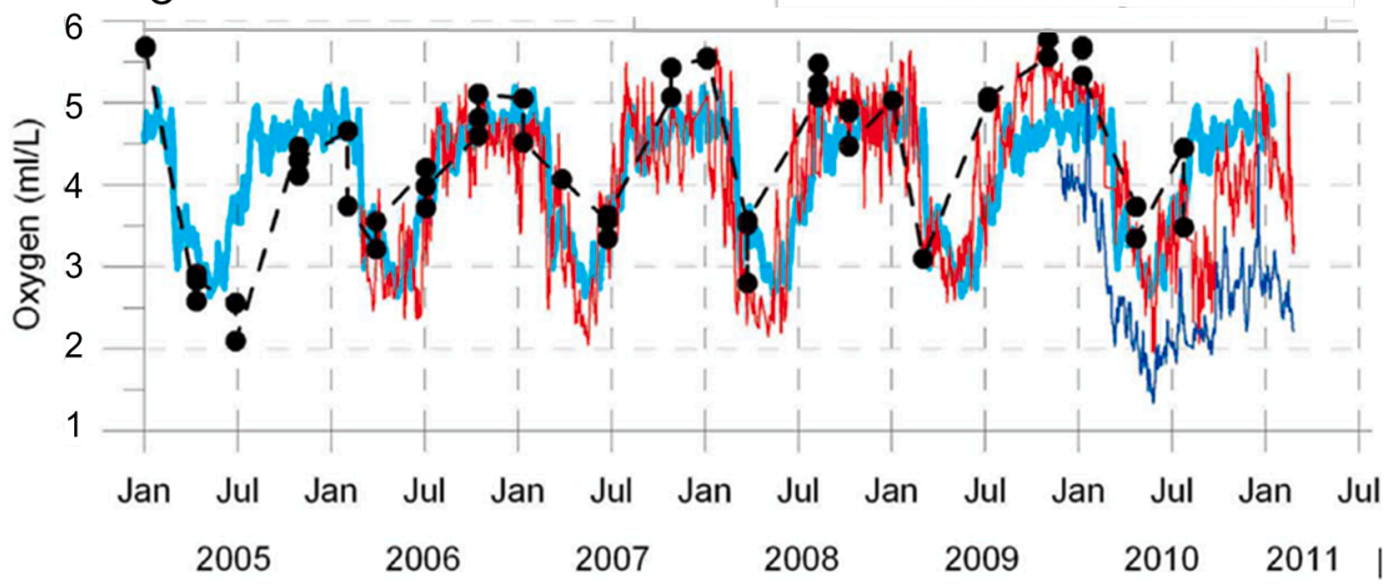

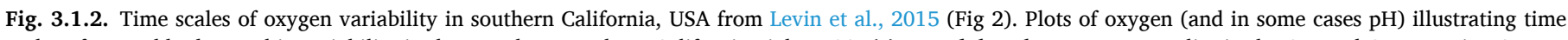

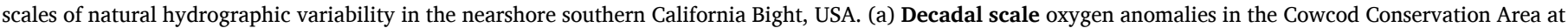

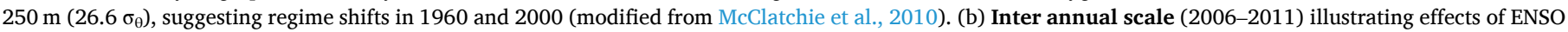

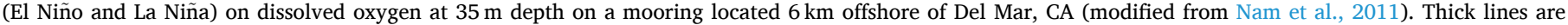

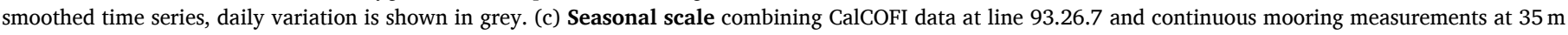

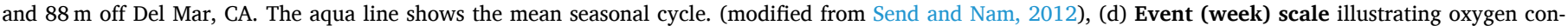

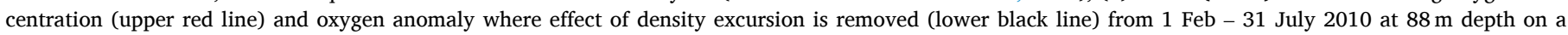

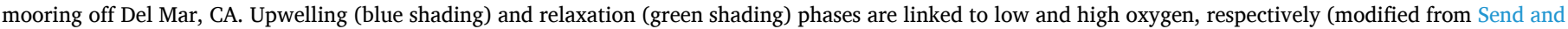

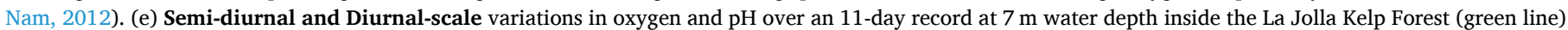

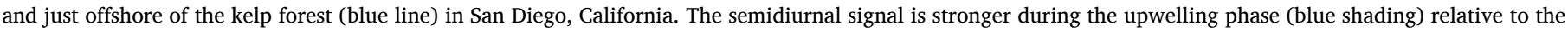

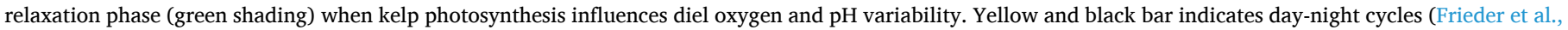
2012, and unpublished). (For interpretation of the references to color in this figure legend, the reader is referred to the web version of this article.)

declining in oxygen during this period. Interestingly, there is no longterm oxygen loss in the upper California Current at $\sigma_{\theta}=25.8$ (Bograd et al., 2015; Ren et al., 2018).

Ren et al. (2018) noted different oxygen dynamics along different isopycnals off Monterey CA between 1980 and 2013. At shallower depths $\left(50-100 \mathrm{~m} ; 25.5 \sigma_{\theta}\right)$, variation in oxygen was strongly interannual with low-frequency oscillations at periods of $<10 y$. At 50-100 $\mathrm{m}\left(26.1 \sigma_{\theta}\right)$, a significant oxygen decline is superimposed on inter annual variability, while at 300-350 $\mathrm{m}\left(26.7 \sigma_{\theta}\right)$, the linear decline in oxygen, both inshore and offshore, is much stronger and inter annual variability is weak. Beyond $300-350 \mathrm{~m}$, oxygen increases at 27.3-27.4 $\sigma_{\theta}$ at about $0.4 \mu \mathrm{Mol} \mathrm{kg} \mathrm{kg}^{-1}$. Oxygen variability above $300 \mathrm{~m}$ is significantly correlated with the North Pacific Gyre Oscillation (NPGO) (R-0.72) and the Upwelling Index $(\mathrm{R}=0.63)$, but not with the Oceanic Nino Index (Ren et al., 2018).

A box model investigating the causes of dramatic oxygen declines at $26.7 \sigma_{\theta}$ off Monterey (almost $40 \%$ decline at $300 \mathrm{~m}$ since 1980) suggests that $62-73 \%$ of observed declines can be attributed to remote forcing (i. e., oxygen declines in source waters feeding both the California Current and the California Undercurrent). The North Pacific Waters (e.g., at Station Papa) have experienced declining oxygen over this period (Whitney et al., 2007). A shallower region of major oxygen decline off Monterey at $100 \mathrm{~m}$ is possibly indicative of increased remineralization from local primary production (Ren et al., 2018), which has increased (Chavez et al., 2011).

Oxygen changes in southern California are accompanied by increases in nitrate and phosphate, which largely mirror the oxygen trends and are interpreted at the basin scale as being remotely forced in a manner similar to oxygen (Bograd et al., 2015). These changes may influence both phytoplankton biomass and the composition of the plankton, including the incidence of the neurotoxin-producing Pseudo-nitzschia (Sekula-Wood et al., 2011; Kahru et al., 2012).

Upwelling contributes to oxygen loss through direct contribution of low-oxygen waters and by the introduction of nitrogen that stimulates 


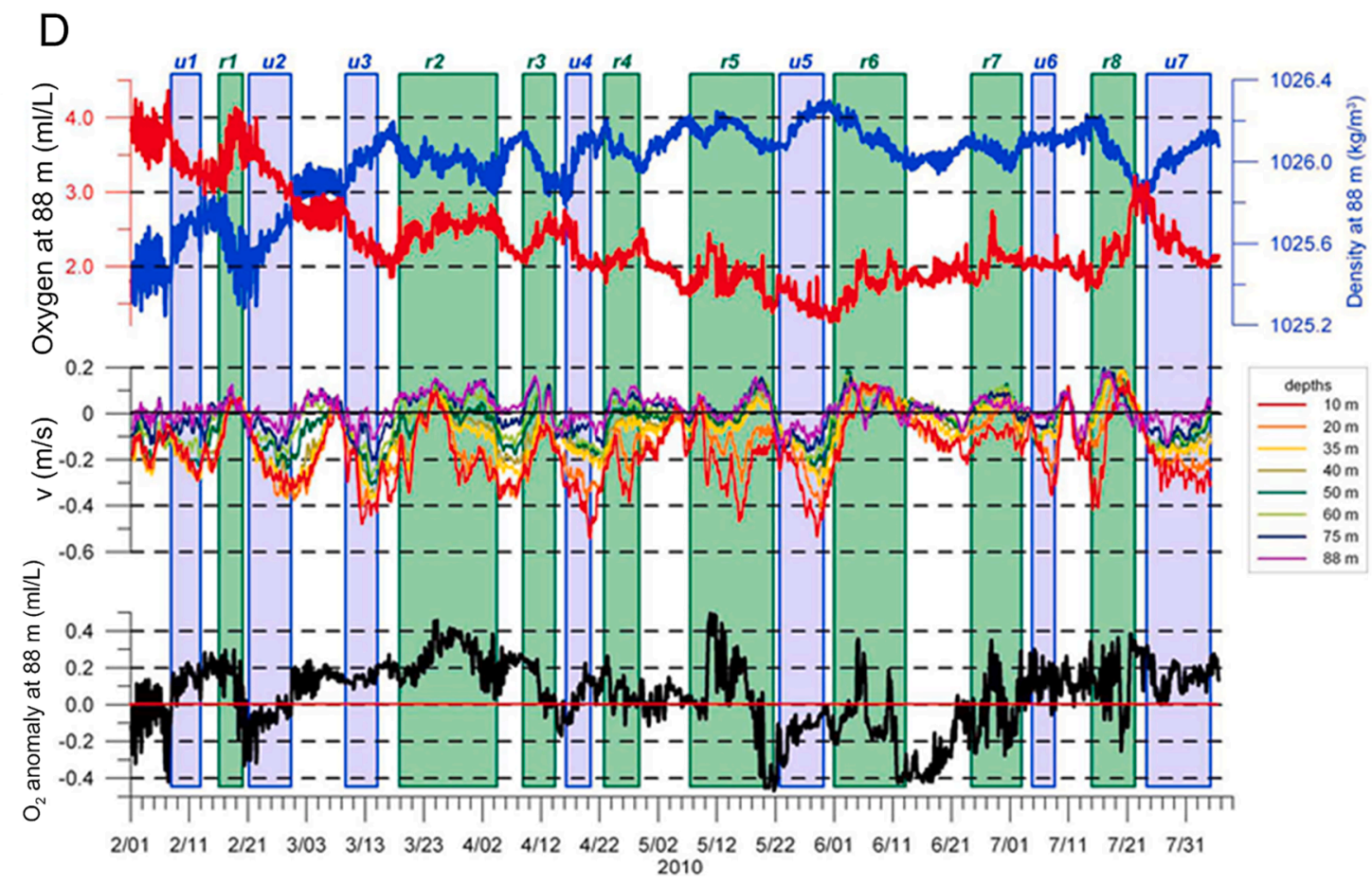

E
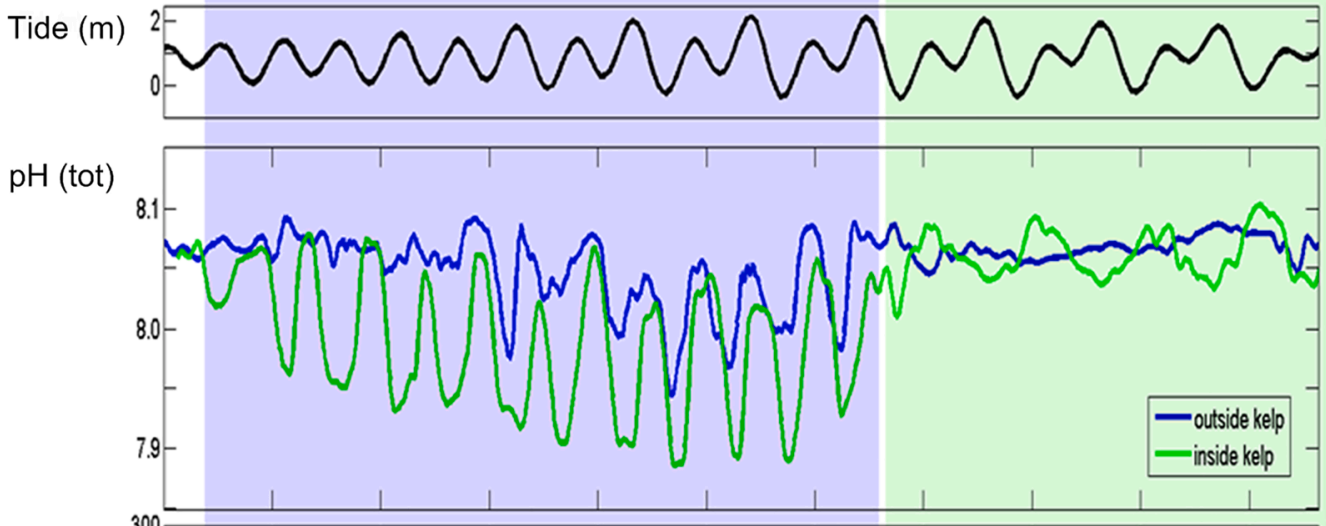

DO

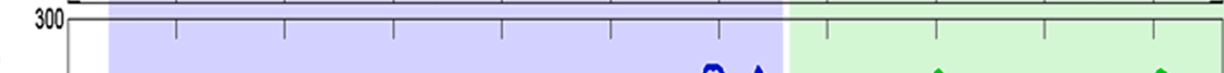

$\left(\mu \mathrm{mol} \mathrm{kg}{ }^{-1}\right)$

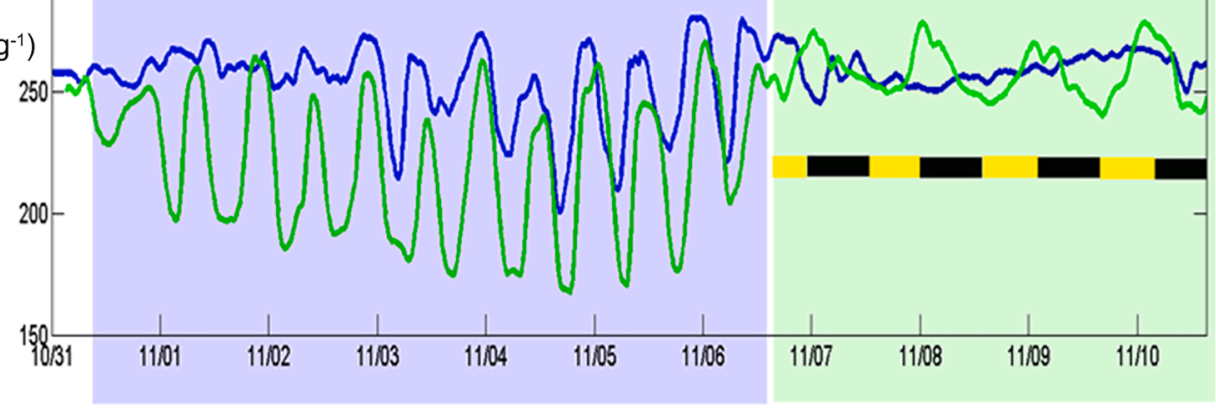

Fig. 3.1.2. (continued).

productivity and subsequent respiration. Over the past 60 years, upwelling winds have intensified in the CC, with warm season analyses more likely to show this pattern than annually summarized data (Sydeman et al., 2014), and with greater intensification at higher latitudes (Wang et al., 2015). The Bakun hypothesis of increased landtemperature differential offers one explanation for intensified upwelling; other studies suggest that the poleward migration and intensification of major atmospheric high-pressure cells are driving intensified coastal upwelling (Rykaczewski et al., 2015).

Most of the nitrogen input into the California Current at the regional bight-wide spatial scale is attributed to upwelling-driven processes, which is the largest source of nitrogen by an order of magnitude relative to effluent and by two orders of magnitude relative to riverine runoff (Howard et al., 2014). However, at smaller spatial scales commensurate with algal bloom development, wastewater effluent and upwelling contributed the same quantity of nitrogen in several sub regions of the 

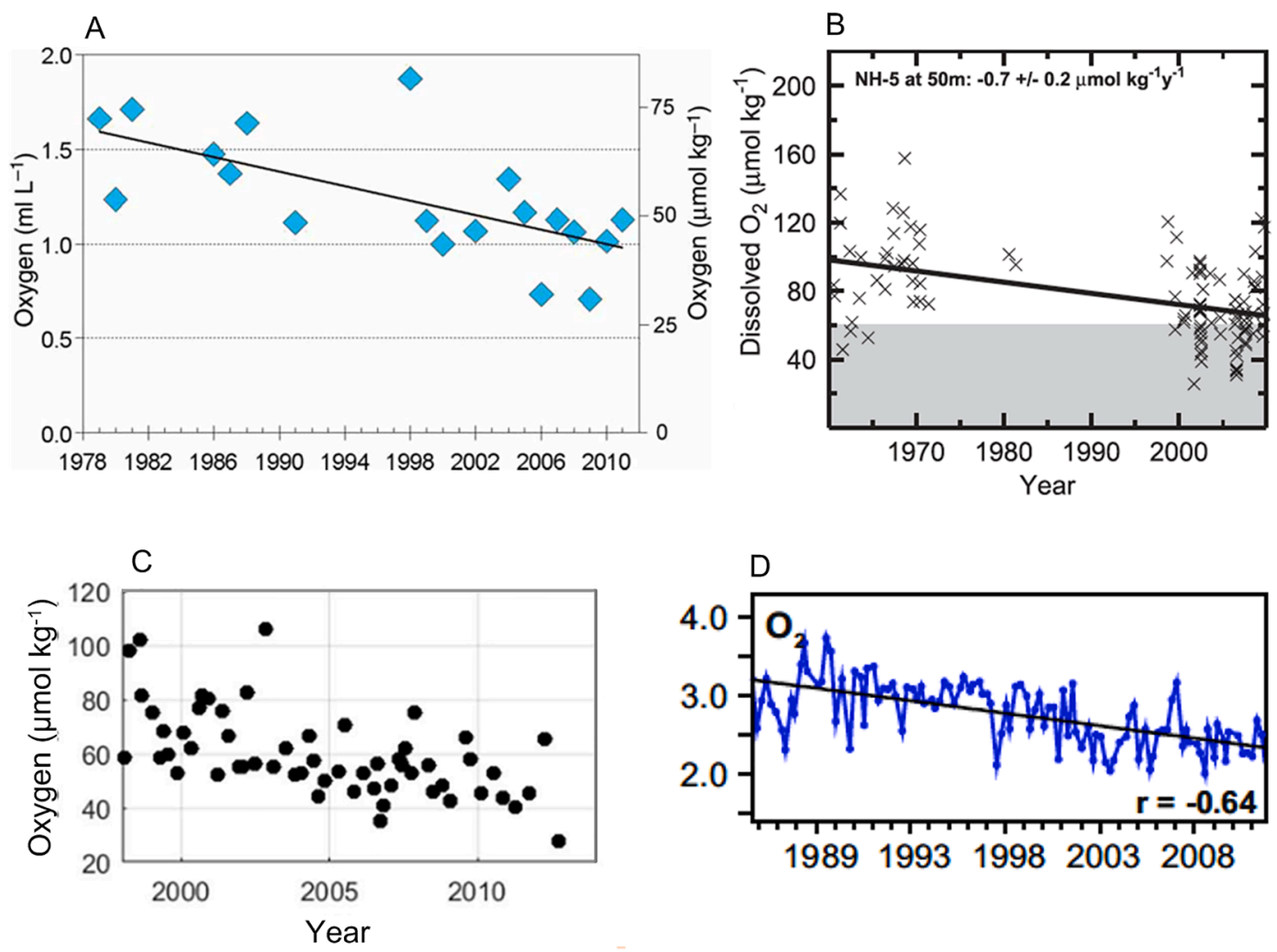

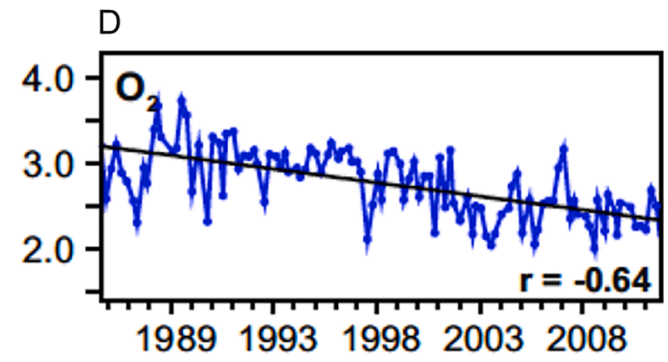

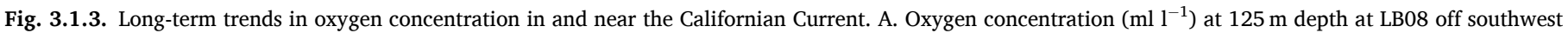

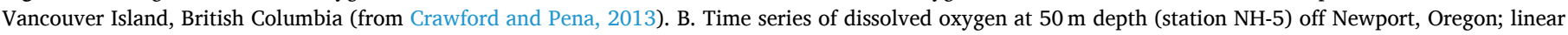

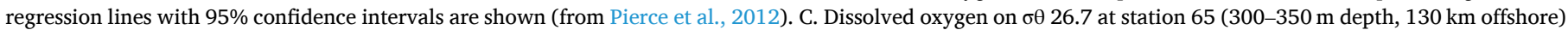

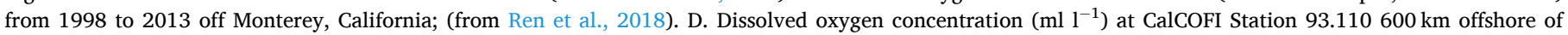
southern California on the $\sigma_{\theta} 26.5 \mathrm{~kg} \mathrm{~m}^{3}$ isopycnal surface from 1984 to 2012 (from Bograd et al., 2015).

Southern California Bight. Thus, it is unlikely that land-derived nitrogen is contributing significantly to ocean deoxygenation. Increases in nutrient concentrations and nutrient ratios have been observed in the upwelling source waters of the CCS (Rykaczewski and Dunne, 2010; Bograd et al., 2015), which are likely to affect both phytoplankton biomass and composition. Notably, modeling indicates that mesoscale eddies in the CCS reduce the input of nutrients and phytoplankton growth by transporting nutrients offshore (Gruber et al., 2011). Processes such as stratification or offshore transport that diminish nutrient concentrations may reduce biogeochemical demand for oxygen by lowering primary production. A major challenge lies in understanding how secular climate change (warming) affects oxygenation through the combined, and sometimes counteracting, effects on physical and biogeochemical processes of altered stratification, upwelling, solubility, nutrient input, mixed depth and advection. While solubility and stratification effects of warming have likely lowered oxygen levels of CC source waters in the subarctic and tropical Pacific, none of the observed declines in oxygen have been unequivocally and mechanistically attributed to climate change.

A long-standing question is whether the observed long-term, secular declines in oxygen in the CCS are attributable to climate change (i.e. global warming). Given that the long-term trends are superimposed on considerable oxygen variability manifested on multiple time scales (Fig. 3.1.2), they are difficult to disentangle from tracer distributions without modeling. The contributions of different drivers (water mass advection, remineralization and upwelling) and depth-specific trends in the northern vs southern CCS make the anthropogenic climate change contributions nuanced at best. Natural variations from ENSO can affect Pacific Equatorial Water contributions in southern California by about $10 \%$ (Bograd et al. 2019). Oxygen increase in the subsurface southern CCS from 1985 to $1993\left(+20 \pm 5 \mu \mathrm{Mol} \mathrm{kg}^{-1}\right)$ followed by an oxygen decline from 1993 to $2018\left(-24 \pm 2 \mu \mathrm{Mol} \mathrm{kg}^{-1}\right.$ ) (Evans et al., 2020) reflects a decadal shift, the link of which to global warming is unclear. Warming effects on solubility in the Northern Equatorial Pacific Intermediate Water would not explain oxygen loss in the southern California region, whereas internal remineralization off Mexico and an increased contribution of Northern Equatorial Pacific Intermediate Water can. Further water mass analyses conducted using time series data from other parts of the CCS may help resolve these questions (Evans et al., 2020).

\subsubsection{Future predictions and susceptibility to deoxygenation}

Wang et al. (2015) projected increased upwelling intensity in other Eastern Boundary Upwelling Systems but not in the CC where greater uncertainty reflected regional controls associated with the atmospheric response to climate change. In contrast, Xiu et al. (2018), using projections to 2049, showed increased upwelling intensity associated with stronger alongshore winds in the coastal region, and enhanced upperocean stratification in both the CC and open ocean. This prediction was generated by a high-resolution ( $7 \mathrm{~km}$ in the horizontal) coupled physical-biological model based on the Regional Ocean Modeling System (ROMS) and the Carbon, Silicate, and Nitrogen Ecosystem model (CoSiNE-31) that included 31 chemical and biological variables, multiple plankton functional groups and multiple nutrient forms. Projections of the coupled model used dynamic downscaling from the climate simulated by an earth system model over the CC region from 1970 to 2049 under the representative concentration pathway 8.5. Warming enhanced nutrient fluxes to the deep source waters of the CC and increased winds and eddies transported these to the euphotic zone. The phytoplankton response to this input, however, was non-linear, making the projection of effects on oxygen into the future difficult. If equatorial wind stress continues to increase and deoxygenation occurs linearly in southern California at the rates documented from 1993 to 2018, then 
waters at $150-325 \mathrm{~m}$ depth are projected to become hypoxic $(60 \mu \mathrm{Mol}$ $\mathrm{kg}^{-1}$ ) by 2034 (Evans et al., 2020). Coupled Model Intercomparison Project Phase 5 RCP 8.5 projections, dynamically downscaled within ROMS projected to 2100 predict considerably greater loss of oxygen in the northern than southern CCS, but with loss of aerobic habitat for anchovy in the southern CCS (Howard et al., 2020). Notably, the high oxygen variability in the CCS and uncertainty contribute to very long time of emergence of an anthropogenic climate-driven oxygen signal in the CCS (Long et al., 2016).

Most of the low-oxygen waters $\left(<60 \mu \mathrm{mol} \mathrm{kg}^{-1}\right)$ that are widespread on the Washington and Oregon shelf are also acidified, with low aragonite saturation ( $<7.6$ and $<0.6$, respectively) (Feely et al., 2018). Acidification occurs because respiration drives much of the temporal variation in oxygen and organic matter respiration releases $\mathrm{CO}_{2}$. Understanding both the drivers and ecosystem responses to hypoxia in the CCS will almost certainly require integrated study with ocean acidification.

In summary, oxygen is highly dynamic in the CCS but ocean deoxygenation is a notable long-term ( $\sim 30$ year) trend that is superimposed on this finer-scale variability. This is manifested as shoaling oxyclines and declining oxygen concentrations at specific water densities. Both remote forcing by North Pacific and Pacific Equatorial source waters, which are experiencing oxygen loss from remineralization, stratification and changes in gas solubility, and intensified upwelling and biogeochemical drawdown contribute to the downward trends in oxygen. Presently, there is no consensus as to whether these declines in oxygen are a result of anthropogenic climate change or natural variability.

\subsection{Northern Gulf of Mexico}

The oxygen deficient bottom-water area of the northern Gulf of Mexico, often called the "dead zone," is the second largest humancaused area of hypoxia (dissolved oxygen concentration $<2 \mathrm{mgl}^{-1}$ ) in the global coastal ocean. Here the term 'dead zone' refers to an area in which bottom-dragging trawls fail to capture fish, shrimp or crabs when the oxygen concentration falls below a critical level near the seabed (Renaud, 1986). Hypoxia is but one of the symptoms of eutrophication that tracks increases in human population, a focusing of that populace in coastal regions, agricultural expansion in river basins, and increasing food and energy consumption (Bennett et al., 2001; Galloway and Cowling, 2002; Rabalais, 2004; Rabalais et al. 2007a,2007b; Galloway et al., 2008).

\subsubsection{System description and known oxygen trends}

The northern Gulf of Mexico represents a coastal margin (continental shelf) that receives excess nutrient loads from the Mississippi River watershed and a subsequent worsening of oxygen depletion since the 1950s when agriculture expanded along with increased fertilizer application. The area, because of high freshwater inputs and their primarily westward transport along the Louisiana coast, results in a salinity-stratified system for most of the year with a strengthening of the pycnocline in summer from thermal warming. Tropical storms and cold fronts disrupt the stratification to varying levels so that the oxygen depletion is temporarily alleviated, but otherwise hypoxia can be present from February to November, with bottom-water hypoxic conditions being most persistent and severe from May through to September.

The Mississippi River drainage is by far the dominant source of nutrients fueling the northern Gulf of Mexico hypoxic zone. The combined flows of the Mississippi and Atchafalaya Rivers accounted for $91 \%$ of the estimated total nitrogen load (Dunn, 1996). If only streams between Galveston Bay (Texas) and the Mississippi River delta are considered (i. e., those most likely to influence the zone of hypoxia), then the combined flows of the Mississippi and Atchafalaya Rivers account for $96 \%$ of the annual freshwater discharge and $98.5 \%$ of the total annual nitrogen load. Similar calculations for the annual total phosphorus load are $88 \%$ of the total 37 streams and $98 \%$ of the streams between Galveston Bay and the Mississippi River delta. The nitrogen sources come from a watershed that is primarily an agricultural landscape with $90 \%$ of the nonpoint sourced nitrogen loading from corn and soybean crops $(52 \%)$, other crops (14\%), atmospheric deposition (16\%) and urban and population-related sources (9\%) (Alexander et al., 2008). Inputs of phosphorus are primarily from crops (43\%), pasture and range (37\%), and urban and population-related sources (12\%) (Alexander et al., 2008). As one moves away from the discharges of the Mississippi and Atchafalaya Rivers, there is a consistent westward and downstream transition from lower to higher salinities, higher to lower nutrients, and higher to lower surface chlorophyll concentrations (Walker and Rabalais, 2006).

The shelf-wide distribution of hypoxia is determined annually from an 8 to 9-day mapping cruise in mid-summer, usually in late July (Rabalais et al., 1996). The average area of the hypoxic zone is 14 $000 \mathrm{~km}^{2}$ over the period 1985-2020 (no values for 1989 and 2016) with the largest measured zone approaching $23000 \mathrm{~km}^{2}$ in 2017 (Fig. 3.2.1). The yearly estimates of the hypoxic zone and factors important in its distribution are recorded in http://www.gulfhypoxia.net. The hypoxic water mass extends west from the Mississippi River birdfoot delta across the Louisiana shelf and onto the upper Texas coast, and from within
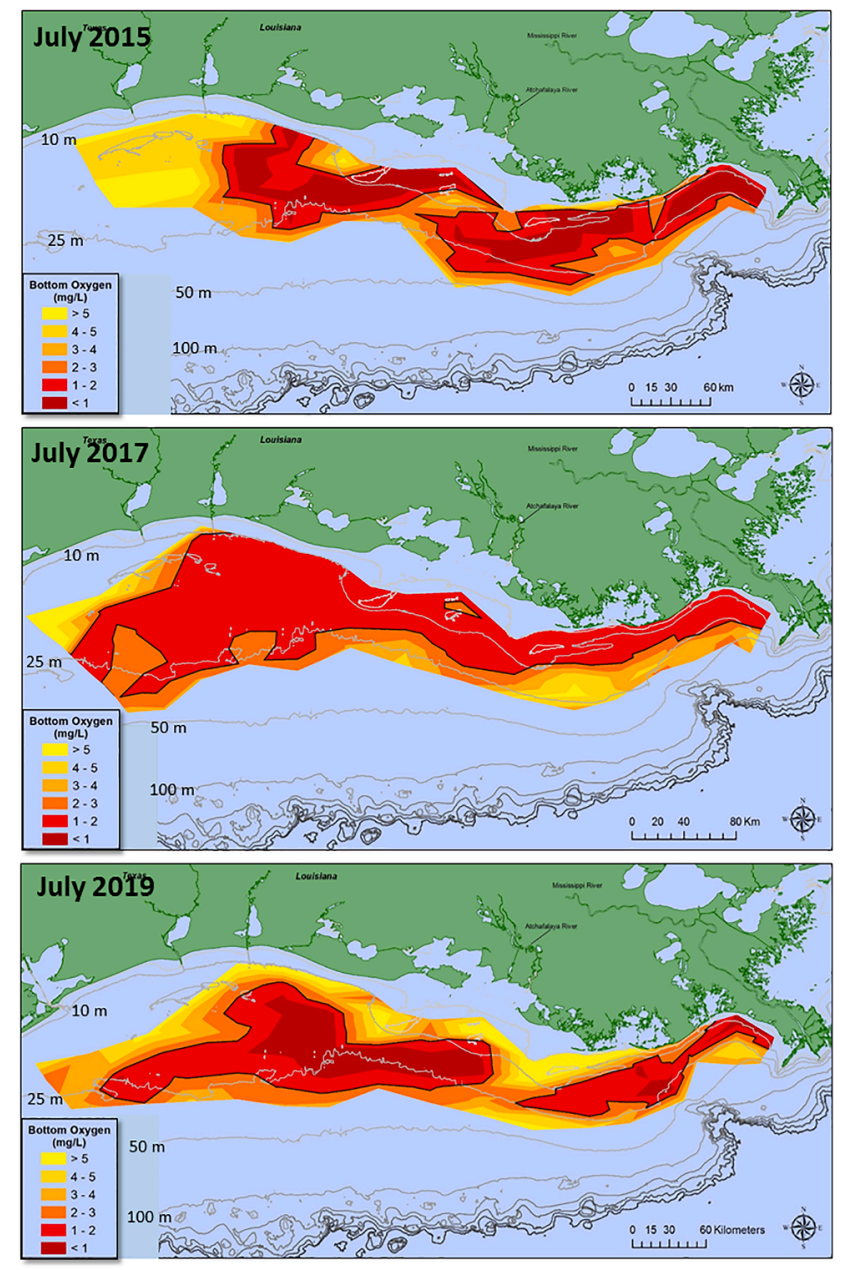

Fig. 3.2.1. Distribution of bottom-water dissolved oxygen $<2 \mathrm{mg} \mathrm{l}^{-1}$ along the Louisiana shelf for mid-summer cruises in 2015, 2017, and 2019. Data source: Nancy N. Rabalais, Louisiana Universities Marine Consortium/Louisiana State University, and R. Eugene Turner, Louisiana State University. On-line at https://gulfhypoxia.net/research/shelfwide-cruises and long-term data resides at NODC, NCEI. Differences in the westward extent and the total bottom area hypoxia depend on winds and currents at the time of the monitoring cruise and the nitrate load in May, respectively. 
$1 \mathrm{~km}$ of the barrier shoreface to as much as $125 \mathrm{~km}$ offshore. Hypoxia is found in water depths up to $60 \mathrm{~m}$, but more typically between 5 and $30 \mathrm{~m}$. Hypoxia is not found just in a thin lens overlying bottom sediments, but intrudes well up into the water column depending on the location of the pycnocline. When dissolved oxygen falls below $2 \mathrm{mg} \mathrm{l}^{-1}$, it often falls below $1 \mathrm{mg} \mathrm{l}^{-1}$ and is sometimes anoxic. Mid-summer hypoxic zones primarily form a continuous band of low oxygen bottom waters across the Louisiana shelf, but the distribution of hypoxia is sometimes located in disjunct sections down-plume of the Mississippi and Atchalafaya river outflows. Wind-driven currents from the west to the east across the Louisiana shelf often force the hypoxic water mass onto the southeastern shelf in mid to late summer (Rabalais et al., 2010, 2018).

Once hypoxia becomes well-established in mid-summer, much of the onshore to offshore variation in distribution can be attributed to windinduced cross-shelf advection (Rabalais et al., 1991) (Fig. 3.2.2). The low oxygen water mass is displaced into deeper water following winds that produce downwelling-favorable conditions. Upwelling-favorable conditions push the hypoxic water mass closer to the barrier island shore. It is the impingement of these hypoxic water masses close to shore that results in "jubilees" along Louisiana barrier islands. Jubilees are events that usually follow a north wind and movement of the hypoxic water mass onshore where stunned or stressed fish, shrimp and crabs are concentrated in the shallow waters along the beach and can be easily harvested. A jubilee "gone bad" occurs when the water mass is extremely low in oxygen or contains hydrogen sulfide, and the trapped fish cannot escape, resulting in massive fish kills.

Continuously recording oxygen meters deployed near the bottom (20-m water depth) off Terrebonne Bay (100 km west of the Mississippi River) and off Caminada Pass (50 km west of the Mississippi River) where the shelf slope gradient is much greater depict dominant scales of variability (Rabalais et al., 1994; Fig. 3.2.3). The pattern generally depicted off Terrebonne Bay is persistent hypoxia and often anoxia for extended periods of the record during May to September. By comparison, the oxygen meter deployed closer to the Mississippi River (Caminada Pass), but influenced by tidally-advected deeper well-oxygenated water, was hypoxic $44 \%$ of the record from mid-June through midOctober (compared to $75 \%$ at the station off Terrebonne Bay).

Paleo indicators in dated sediment cores show that hypoxic conditions likely began to appear around the 1950s and became more severe since the 1970s with the tripling of the nitrate flux from the Mississippi River to the Gulf of Mexico (Rabalais et al. 2007a). Whereas Gulf of Mexico coastal hypoxia has been systematically mapped only since 1985, there are data that document the presence of hypoxia since the early 1970s (Rabalais et al., 2002). One might expect a propensity for the northern Gulf of Mexico ecosystem to develop hypoxia naturally
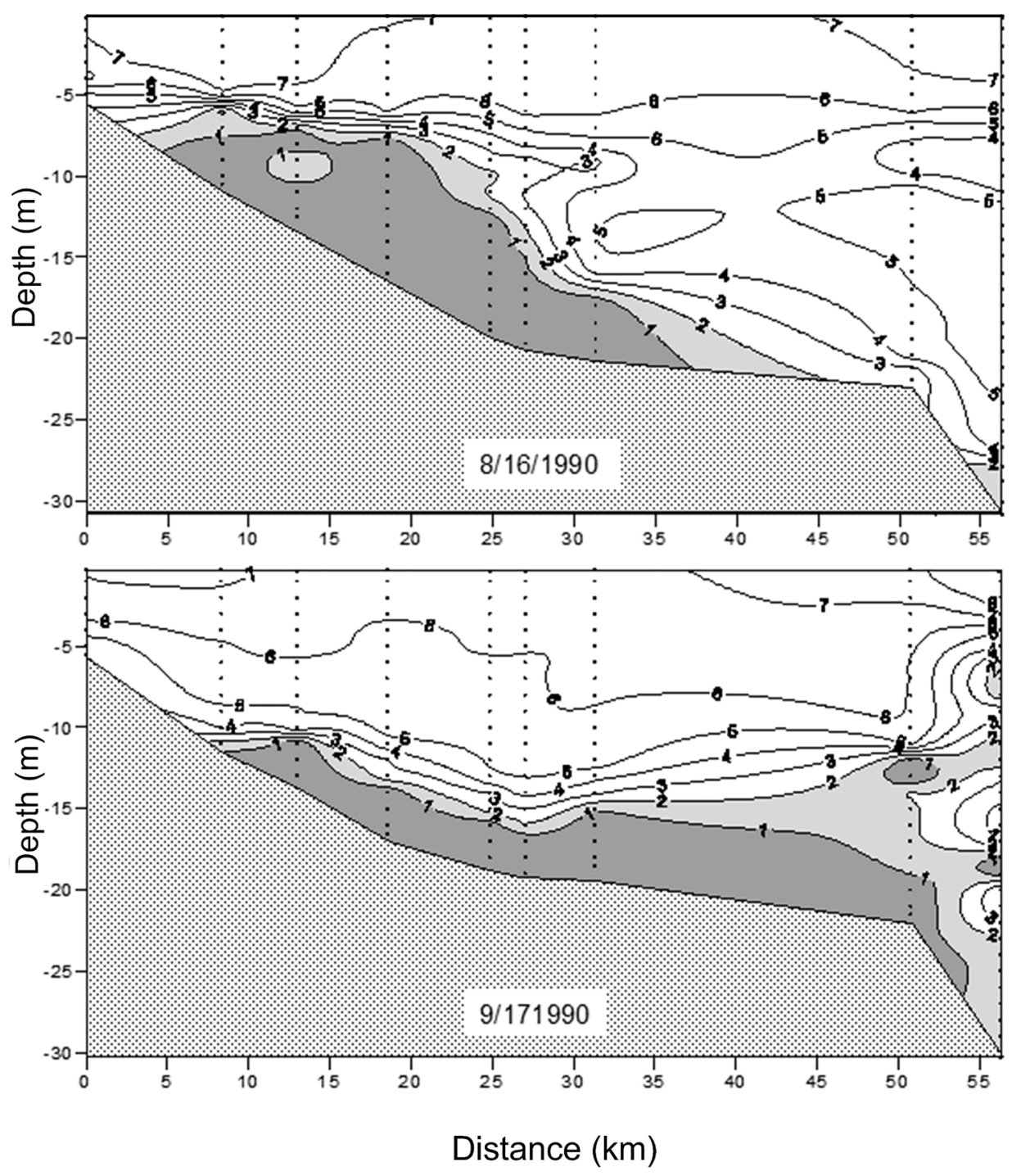

Fig. 3.2.2. Cross-shelf contours for dissolved oxygen concentration $\left(\mathrm{mg}^{-1}\right)$ during an upwelling-favorable wind condition (16 August 1990) and a downwellingfavorable wind condition (17 September 1990) (from Rabalais et al., 1999 with permission from the author). 

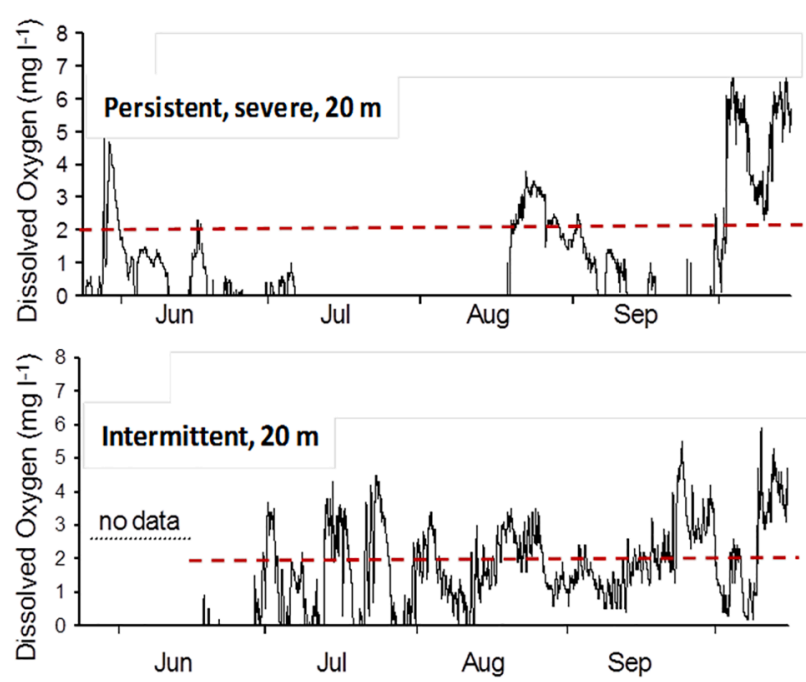

Fig. 3.2.3. Time-series plots of bottom dissolved oxygen concentration ( $\mathrm{mg}^{-1}$ at hourly intervals) at a persistently hypoxic station off Terrebonne Bay and an intermittently hypoxic station off Caminada Pass (from Rabalais et al., 1994 with permission from the author).

because of the high volume of fresh water and nutrients delivered by the Mississippi River and the nature of the stratified coastal system. However, sediment core indicators clearly document recent eutrophication and increased organic sedimentation in bottom waters, with the changes more apparent in areas of chronic hypoxia and coincident with the increasing nitrogen loads from the Mississippi River system in the 1950s (Eadie et al., 1994; Turner and Rabalais, 1994; Rabalais et al., 2007a, 2014). This evidence comes as an increased accumulation of diatom remains (biologically bound silica) and marine-origin carbon (stable carbon isotope analysis) accumulation in the sediments. While presentday foraminiferal diversity is generally low in the Louisiana bight, comparisons among assemblages from areas of different oxygen depletion indicate that the dominance of Ammonia parkinsoniana over Elphidium spp. (A-E index) was much more pronounced in oxygen-depleted compared to well-oxygenated waters (Rabalais et al., 1996; Sen Gupta et al., 1996). Buliminella morgani, a hypoxia-tolerant species, known only from the Gulf of Mexico, dominates the present-day population ( $>50 \%$ ) within areas of chronic seasonal hypoxia, and has increased markedly in recent decades. The hypoxia-intolerant foraminiferan Quinqueloculina sp. was a conspicuous member of the fauna from 1700 to 1900 , indicating that oxygen stress was not a problem prior to 1900 .

\subsubsection{Causes and controls of low oxygen}

Stratification and nutrient-enhanced primary production are both required for the development of hypoxia in the northern Gulf of Mexico, but the increases in nutrient loads are considered the driving force in the initial development of hypoxia off the Mississippi River and its worsening over time. The combination of high freshwater discharge, long residence time, seasonal reduction in wind mixing, regional circulation, and summer warming controls the strength of stratification that goes through a well-defined seasonal cycle. The physical structure of the water column and high nutrient loads that enhance primary production lead to a perennial and annual formation of the bottom-water hypoxic water mass that is dominant from spring through late summer.

The effluent from the Mississippi River basin enters the Gulf of Mexico and brings with it runoff, primarily non-point runoff from about $41 \%$ of the lower 48 United States. The three-fold increase in nitrate-N since the 1950s has worsened hypoxia in terms of its severity and its areal extent, with changes apparent since about 1985. A good predictor for the size of the bottom area of hypoxia in mid-summer is the load of nitrate- $\mathrm{N}$ from the Mississippi River in May (Turner et al., 2008). The timing of maximum loads allows phytoplankton biomass to increase offshore, excess organic matter to reach the inner and middle continental shelf sediments, and respiration to draw down the oxygen in a stratified water column. Increasing nitrogen loads are the primary factor in the formation and worsening of hypoxia, but phosphorus loads are also important in stimulating excess phytoplankton production.

The forms of nitrogen and phosphorus, their loads, and their ratios in nutrient-laden waters reaching the Gulf of Mexico affect the eventual productivity of Gulf phytoplankton. If a nutrient is considered to be limiting to the growth of phytoplankton in a coastal system, then the increased loads of that nutrient will stimulate phytoplankton growth leading to eutrophication. Most marine waters are considered nitrogenlimited for growth of phytoplankton, whereas fresh waters are considered to be phosphorus-limited. There are multiple examples, however, of deviation from this dichotomy. For example, Turner and Rabalais (2013) performed a series of nutrient limitation bioassays over a range of geography, salinity and water depth for a 30 -y period in the area of low oxygen on the Louisiana shelf. They found that the number of Nlimited bioassays was five times greater than the P-limited bioassays. $\mathrm{N}+\mathrm{P}$ synergism occurred where salinity was $>20$, and represented $59 \%$ of all samples that were not light-limited. Because of these more recent studies, dual control of nitrogen and phosphorus is recommended for eutrophied coastal waters experiencing oxygen deficiency (Paerl et al., 2016).

For oxygen deficiency to develop, the water column must be stratified so that the bottom layer is isolated from the higher oxygen concentrations of surface waters. The diffusion of oxygen from surface to bottom is prevented by the presence of the pycnocline that forms a density barrier below which decomposition of organic matter leads to reduced oxygen levels in the bottom waters. The source of the organic matter settling to the seabed in the northern Gulf of Mexico is mostly from phytoplankton growth stimulated by riverine-delivered nutrients, although some river-borne organic matter is also delivered by the Mississippi River (Eadie et al., 1994; Turner and Rabalais, 1994). The concentrations and total loads of nitrogen, phosphorus, and silica to the coastal ocean influence the productivity of the phytoplankton community, the types of phytoplankton that are most likely to grow, and ultimately the downward flux of phytoplankton-derived organic matter (Lohrenz et al., 1997; Turner et al., 1998; Dortch et al., 2001). Phytoplankton not incorporated into the food web and fecal material generated by the food web sink into bottom waters where they are decomposed by aerobic bacteria, causing oxygen depletion. The relative influence of the physical features of the system and the progression of biological processes varies spatially and over an annual cycle. Both are inter-related in the northern Gulf of Mexico and directly linked with the dynamics of the Mississippi and Atchafalaya river discharges.

\subsubsection{Predictions of the future oxygen environment}

For many environmental problems, including excess nutrients, agreement among scientists, political institutions, and society on policy and intervention measures is required despite the scientific uncertainty. Fortunately, around the globe, measures to decrease excess nutrient loads proceeded without complete scientific consensus on which nutrients to reduce, how much, and by what methods. For example, in the case of the area of bottom-water hypoxia west of the Mississippi River discharge, initial estimates of hypoxia extent turned out to be lower than the areas predicted in subsequent modeling analyses (Justić et al., 2007). In addition, climate change scenarios for the Mississippi River watershed and conditions in coastal waters will likely aggravate the conditions of low oxygen in the northern Gulf of Mexico (Rabalais et al., 2014). Knowledge gaps will remain and new ones will arise, but most action plans for reducing and mitigating the effects of nutrients are conceived within a long-term adaptive management strategy that links management actions with monitoring, research, modeling, and a commitment to long-term assessment and management. 


\subsection{Peru and Northern-Central Chile}

The shelf and slope off Peru and Northern-Central Chile are strongly influenced by the Eastern Tropical South Pacific (ETSP) oxygen minimum zone (OMZ), where cumulative oxygen depletion is attributed to the low oxygen content of source waters, poor ventilation, a long residence time, and the decay of the high biological production sinking from surface waters (Pennington et al., 2006). The OMZ of the ETSP accounts for $11 \%$ of the global volume of OMZ waters, and it is the fourth largest OMZ in terms of area. The upper boundary is shallower than that of other OMZs, attaining its shallowest depth off Central Peru (Helly and Levin, 2004) and entering into the euphotic layer. Near the equator, the OMZ upper boundary is deeper $(>200 \mathrm{~m})$ and under the influence of equatorial circulation (Stramma et al., 2010a,b). From the equatorial line to the Central Peruvian coast, the upper boundary shoals, and the OMZ thickens and gains in intensity (Fig. 3.3.1), as oxygen is further depleted by the decomposition of sinking organic matter through the water column. Farther south, the OMZ volume shrinks gradually, due to ventilation of the upper water column caused by coastal upwelling and stronger wind mixing and by mixing of the lower water column with oxygenated Antarctic Intermediate Waters (Fuenzalida et al., 2009). The OMZ waters are also characterized by low pH (León et al., 2010) and high dissolved inorganic carbon, accumulated from the respiration of decaying organic matter in the water column (Paulmier and Ruiz-Pino, 2009). Further, oxygen deficiency also favours denitrification and anammox (anaerobic ammonium oxidation) as the main respiratory pathways, resulting in significant nitrogen loss and nitrate deficiency in upwelling waters (Lam et al., 2009).

\subsubsection{Ecological effects in the water column and margin sediments}

Oxygen deficiency shapes the distribution and life cycles of living communities in the water column and at the seafloor. The vertical distribution and diel migrations of several groups of zooplankton and meroplankton are limited by oxygen-deficient waters (Criales-Hernández et al., 2008; Antezana, 2009; Escribano et al., 2009). The restricted vertical distributions affect the patterns of retention and export production in the upwelling areas. Habitat compression appears to favour efficient trophic transfer to the upper levels of the food web, contributing to the exceptional fish productivity of the system. Moreover, the dominance of the Peruvian anchovy nearshore, where the oxycline is shallower, is likely to be explained by the greater tolerance of anchovy to hypoxia than the Peruvian sardine and other pelagic nekton (Bertrand et al., 2011; Alegre et al., 2015). Conversely, under less intense oxygen deficiency, a higher abundance of these pelagic species in the coastal waters occur at multiple time-scales (Salvatteci et al., 2019a).

Demersal and benthic biodiversity are higher on the Northern Peruvian shelf, where the upper limit of the OMZ is deeper (Gutiérrez et al., 2006). Farther south, the benthic communities are highly variable in the shallow subtidal zone, which is characterised by episodic oxygen deficiency (Tarazona et al., 1988; Arntz et al., 2006; Aguirre-Velarde et al., 2019). With increasing water depth and oxygen deficiency, benthic macrofauna tend to disappear, while the biomasses of sulphuroxidizing bacterial mats (Thioploca spp), benthic foraminifera and nematodes rapidly increase (Levin et al., 2002; Gutiérrez et al., 2008; Cardich et al., 2015). Inner shelf sediments are typically sulfidic and rich in freshly sedimented phytodetritus (Gutiérrez et al. 2008; Cardich et al. 2015). In some areas, free sulfide is found in bottom waters and is eventually advected to the surface (Schunk et al., 2013). Sedimentary organic matter (SOM) preservation is low, as frequent shallow oxygenation events promote carbon recycling. From the outer shelf to the OMZ core (at 300-400 m), SOM concentrations are the highest (Levin et al. 2002; Cardich et al. 2015), but free sulfide is only found deeper in the sediments because of its use by Thioploca spp (Suits and Arthur, 2000; Maltby et al., 2016), and/or its precipitation as metal sulphides (Froelich et al., 1988; Scholz et al., 2011). At the lower boundary of the OMZ $(\sim 600 \mathrm{~m})$, microxic conditions are present, nitrate penetrates deep into
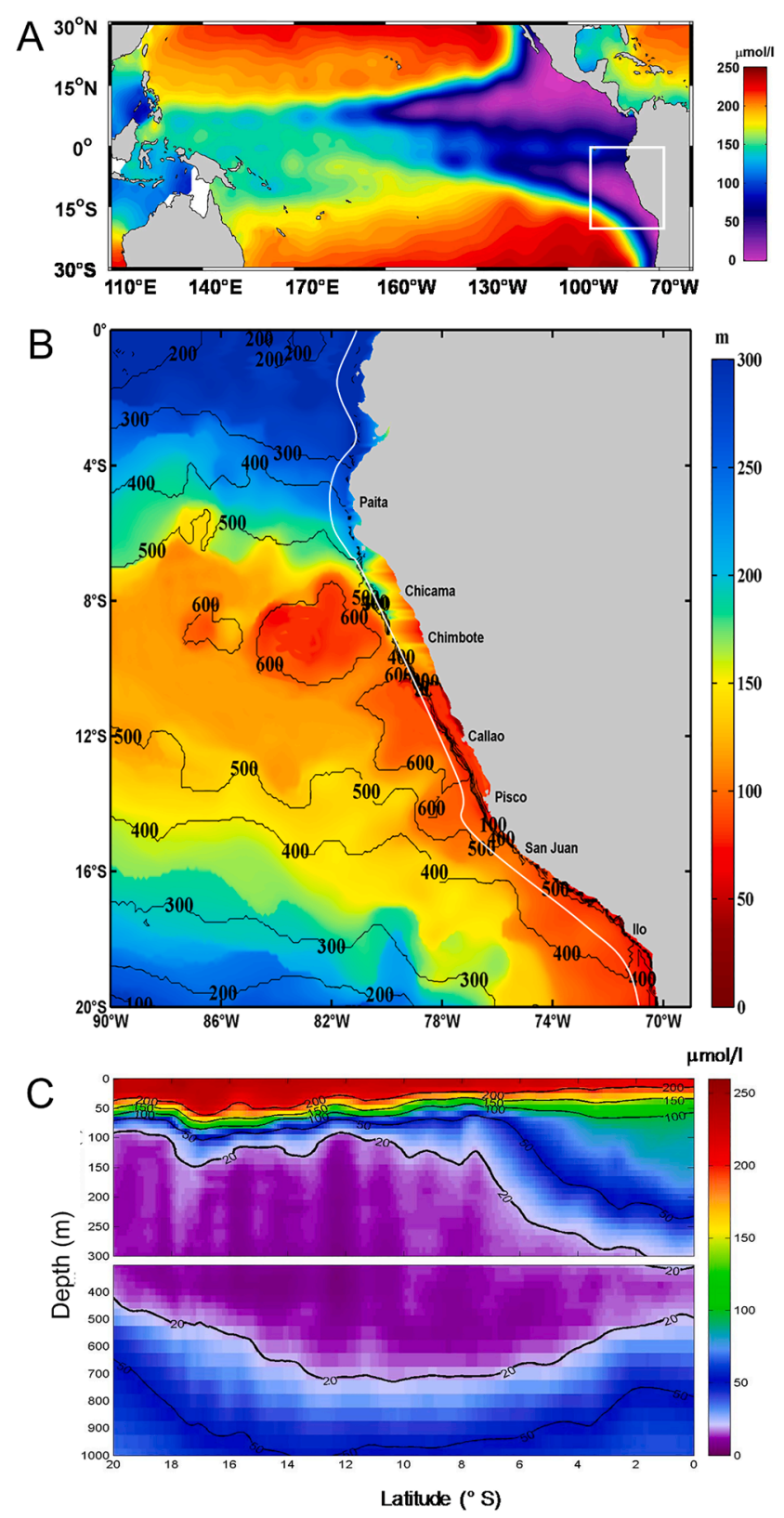

Fig.3.3.1. (a) Dissolved oxygen concentration at $150 \mathrm{~m}$ water depth in the Tropical Pacific (Gutiérrez et al., 2009); (b) mean upper limit depth (m, color bar) and thickness ( $m$, black contours) of the OMZ off the Peruvian coast; (c) climatological oxygen concentration for a meridional section at $100 \mathrm{~nm}$ from the coast, depicted as a grey line in (b). Both (b) and (c) derived for the period 1981-2010 (M Graco, pers. comm.). Date source: IMARPE and World Ocean Database (WOA; Boyer et al., 2013).

the sediment (Dale et al., 2016) and concentrations of SOM are lower (Fig. 3.3.2). Deeper down to $1000 \mathrm{~m}$, bottom oxygenation favours macrobenthic biomass, diversity and bioturbation (Rowe, 1971; Levin et al., 2002), as well as the presence of deep demersal fishes (Aramayo, 2016).

3.3.2. Drivers of oxygen deficiency at seasonal to interannual time-scales

The ETSP OMZ is sensitive to changes in the equatorial circulation (Montes et al., 2014; Espinoza-Morriberón et al., 2019), as the Equatorial Undercurrent (EUC) and the primary and secondary Tsuchiya Jets (Tsuchiya, 1975; Montes et al., 2010) ventilate the system by the eastward transport of more oxygenated waters towards the Eastern Pacific (Stramma et al., 2010a,b). The intense remineralization of organic 


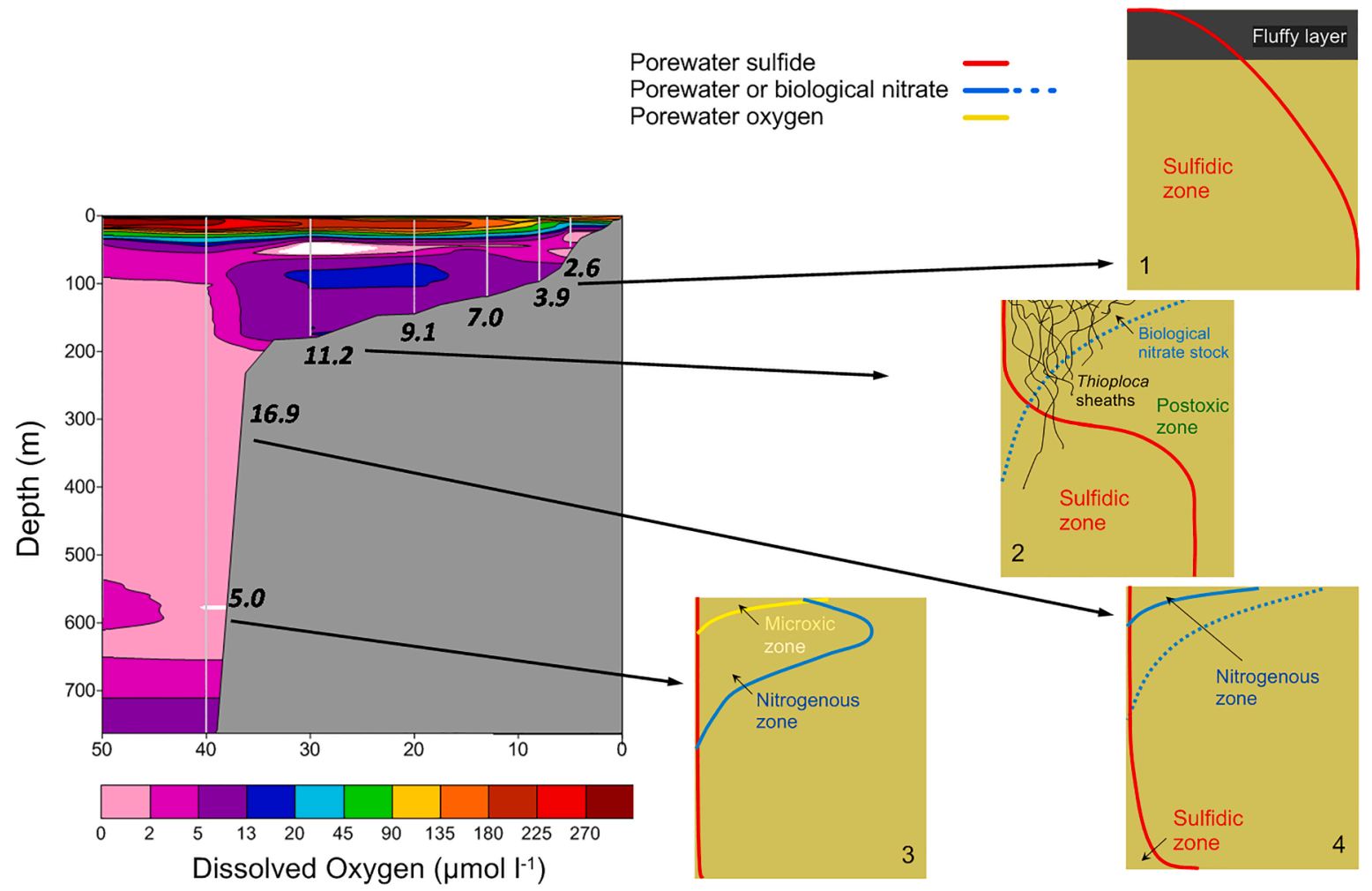

Fig. 3.3.2. Left: a section of dissolved oxygen off Callao ( $12^{\circ} \mathrm{S}$, distance in $\mathrm{nm}$ ) in April 2005, recorded on an MPI-IMARPE cruise onboard the RV Olaya (Lam et al., 2009), showing a weak oxygenation event over the shelf. Reference values of TOC for the shelf and slope are shown (Cardich et al., 2015; Levin et al., 2002, respectively). Right: Representative vertical profiles of sulphide and nitrate in the pore water across the shelf/upper slope; the black zone at the surface in 'case 1 ' depicts the fluffy layer (Gutiérrez et al., 2008). It should be noted that mats of Thioploca spp and benthic foraminifera store and use biological nitrate in the outer shelf and OMZ core, respectively (Dale et al., 2016).

matter, primarily in the oxycline, is the main process that consumes dissolved oxygen (Paulmier et al., 2006; Paulmier and Ruiz-Pino, 2009) within the region. The dynamics of the Peru-Chile undercurrent and intense mesoscale activity also contribute to the variability in oxygen deficiency (Vergara et al., 2016; Espinoza-Morriberón et al., 2019).

At seasonal timescales, stratification/mixing, productivity and export production, and mesoscale circulation govern the shallowing of the upper boundary of the OMZ in summer when it is able to enter the euphotic zone (Graco et al., 2017). In summer, vertical mixing and eddy diffusive flux are restricted to shallower depths, stratification is stronger and productivity increases (Echevin et al., 2008; Thomsen et al., 2016), leading to more oxygen depletion in the subsurface waters. By contrast, subduction of oxygenated waters, associated with mesoscale circulation (eddies and filaments), tends to be deeper during winter, when wind forcing and vertical mixing are stronger and primary productivity is lower due to light limitation (Echevin et al., 2008; Thomsen et al., 2016; Vergara et al., 2016;). Off Northern Peru, seasonal variability of the OMZ is influenced by the activity of the Equatorial Undercurrent, which is more intense in austral autumn, bringing relatively more oxygenated waters into the area (Czeschel et al., 2015).

Equatorial Kelvin Waves (EKWs) generated in the Equatorial Pacific and Coastal Trapped Waves (CTWs) play a major role in the ventilation of the water column in the region at intraseasonal to interannual timescales (Echevin et al., 2014; Espinoza-Morriberón et al., 2017). When EKWs reach the western coasts of America, they trigger downwelling/ upwelling CTWs, which propagate poleward. The passage of downwelling CTWs, which are more frequent and intense during El Niño in the Eastern Pacific (EN), deepen the OMZ upper limit (Gutiérrez et al., 2008; Graco et al., 2017), while upwelling CTWs have the opposite effect of causing the OMZ to shoal (Espinoza-Morriberón et al., 2019). Therefore, Eastern Pacific EN events are associated with a deepening of the OMZ, exposing the shelf off Peru and northern Chile to oxygenated waters (Morales et al., 1999; Sánchez et al., 1999; Gutiérrez et al., 2008; Graco et al., 2017).

Coastal upwelling and export production delivered from surface waters amplifies the depletion of oxygen near the coast, due to the upward advection of oxygen-poor waters from upwelling and from the enhanced oxygen consumption resulting from the production exported from the surface (Paulmier et al., 2006; Graco et al., 2007). However, the frequent intrusion of dissolved oxygen associated with mesoscale eddies, internal waves or coastal trapped-waves (Grados et al., 2016; Vergara et al., 2016; Espinoza-Morriberón et al., 2019), gives rise to a highly dynamic oxygen regime nearshore. These conditions favour the recycling of organic matter with low preservation of organic carbon in the surface sediments. Farther offshore, the outer continental shelf and upper slope are characterized by the highest accumulation rates of sedimentary organic matter (Muñoz et al., 2004; Gutiérrez et al., 2009; Cardich et al., 2015).

\subsubsection{Paleo-oxygenation and recent trends}

Proxies for water column denitrification, including sediment redox conditions, bioturbation and benthic foraminifera, among others, have been used to reconstruct past variation of subsurface oxygenation in the region (Higginson and Altabet, 2004; Morales et al., 2006; Gutiérrez et al., 2009; Salvatteci et al., 2014, 2016; Erdem and Schönfeld, 2017; Díaz-Ochoa et al., 2011; Castillo et al., 2017). At multidecadal to millennial timescales, the intensity and extension of the OMZ is modulated by changes in the Walker circulation, which controls the thermocline depth and thereby the productivity and respiration in the ETSP, as well as the subsurface ventilation associated with the equatorial currents (Agnihotri et al., 2008; Gutiérrez et al., 2009; Xu et al., 2015; Salvatteci et al., 2016). Farther south, the OMZ is likely to be influenced by the 
meridional shifts of the subtropical front controlling the ventilation at higher latitudes and by the intensity of the South Pacific Subtropical High (SPSH) that affects alongshore wind forcing (Strub et al., 1998).

After the Last Glacial Maximum, rapid deoxygenation took place following the Southern Hemisphere signature of deglacial warming, leaving a distinct imprint in $\delta^{15} \mathrm{~N}$ sediment records along the Peru-Chile margin that show maximal values during the Heinrich Stadial 1 period. Thereafter, an average positive trend of oxygenation characterised the late deglaciation, superimposed with millennial fluctuations (Higginson and Altabet, 2004; De Pol-Holz et al., 2014; Moffitt et al., 2015; Salvatteci et al., 2016). During this period, denitrification in the subsurface accelerated and the flooding of continental shelves subsequently increased denitrification at the seafloor (Galbraith et al., 2013).

During the warm mid-Holocene, the OMZ was weaker than during the early Holocene or the last millennia, as inferred by multiple proxies reported for the Peruvian slope (Xu et al., 2015; Salvatteci et al., 2016). This has been attributed to intensification of the eastward subsurface equatorial currents and the poleward undercurrent, as a consequence of a much stronger Walker circulation cell (Xu et al., 2015; Salvatteci et al., 2016; 2019b). For the late Holocene, proxy records of oxygenation and productivity provide evidence of significant shifts at multi-centennial time-scales, apparently associated with global 'cold' and 'warm' climatic periods (Fig. 3.3.3a, b). Thus, for the Little Ice Age (LIA, 1400-1850 CE), proxy records off Peru and Northern Chile indicate increased oxygenation in the water column and lower export production, under both weak Walker circulation and SPSH conditions. By contrast, for the late Medieval Climatic Anomaly (MCA, 1100 - 1350 CE) and after the LIA, the records indicate an increase in subsurface deoxygenation and higher export production with intensification of the Walker circulation and SPSH (Sifeddine et al., 2008; Gutiérrez et al., 2009; Salvatteci et al., 2014). A bi-decadal period around the 1870 s (characterized by strong ENSO activity; Gutiérrez et al., 2011) featured diatom-rich sedimentation events from Central Peru to Northern Chile. These events were associated with strong water column deoxygenation and bottom anoxia as inferred from $\delta^{15} \mathrm{~N}$ records in sedimentary organic matter and enrichment of redox-sensitive metals (Gutiérrez et al., 2009; Díaz-Ochoa et al., 2011; Salvatteci et al., 2014; Castillo et al., 2017).

For the twentieth century, in the subtropical region, shelf and slope records suggest increased subsurface and bottom oxygen with interdecadal fluctuations. At lower latitudes, a slight increase in oxygen near the OMZ core is noticeable for the last half century that seems decoupled from increased export production (Fig. 3.3.3c) (Gutiérrez et al., 2009; Salvatteci et al., 2014; Castillo et al., 2017). Further south, at $36{ }^{\circ}$ S, a decrease in the concentration of redox sensitive metals in the
A

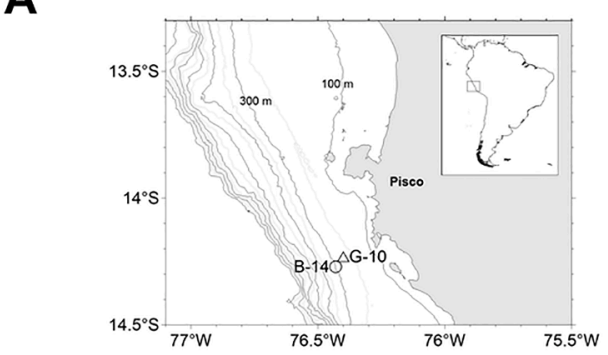

C

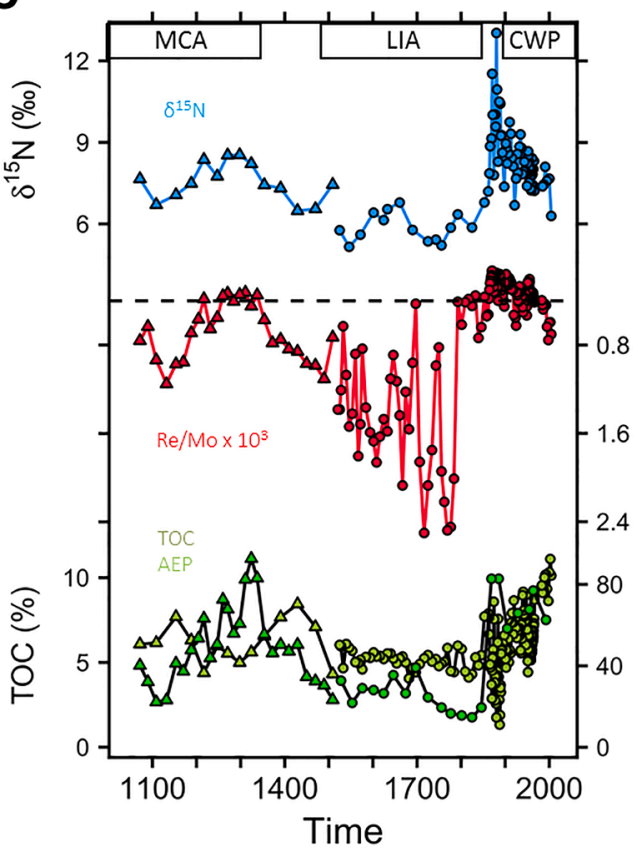

B

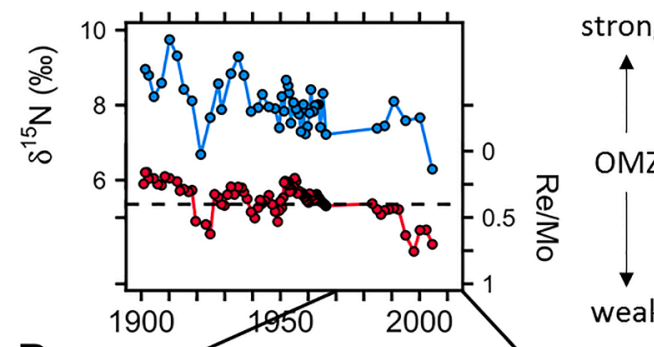

D

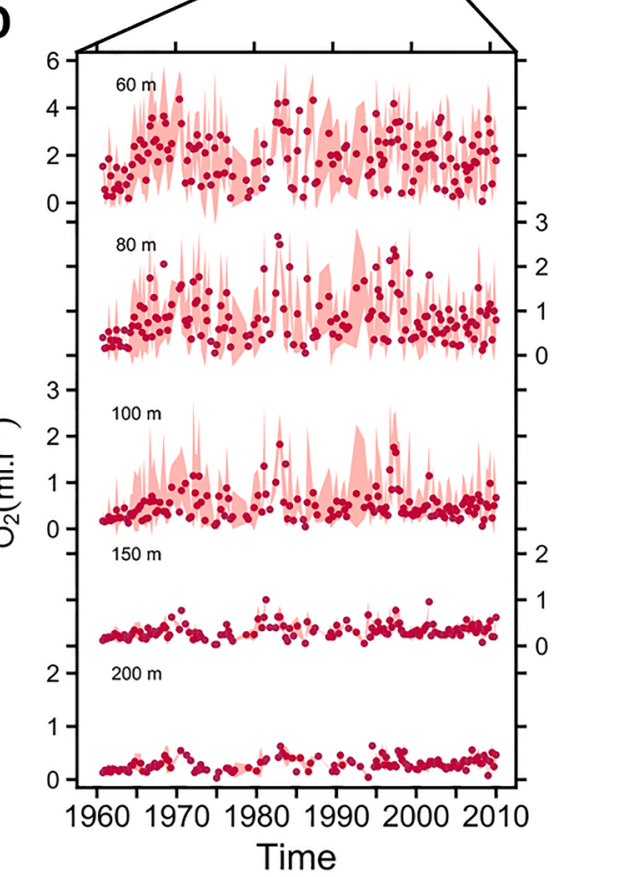

Fig. 3.3.3. (Paleo) oxygenation and (paleo) productivity records off central Peru. (A) Map of the sediment cores used for the records shown in figures B and C (Salvatteci et al., 2014, 2018). (B) Records of water column denitrification, sediment redox condition and export production for the last millennium. The latter is presented as percentage of total organic carbon (TOC\%) and as an average export production (AEP) obtained from the average of the Ni and Cu enrichment factors. Records from G-10 (triangles) were used for the period before 1500 CE, and records from B-14 (circles) were used for 1500 to 2005 CE. (C) Records of water column denitrification $\left(\delta^{15} \mathrm{~N}\right)$ and sediment redox conditions (authigenic Re/Mo ratio, y-axis inverted) for the last century. Data are from analysis of core B-14. (D) Average quarterly time series of instrumental dissolved oxygen data from several water column depths for the 1960 - 2010 period (IMARPE); shading corresponds to one standard deviation. The horizontal dashed line in B and C indicates the value of $0.4 \times 10^{-3}$ which corresponds to the ratio of the concentration of these metals in seawater; higher values indicate suboxic conditions, whereas equal or lower values indicate sulfidic conditions. 
continental shelf sediments from $\sim 1930$ to $\sim 2005$ (Srain et al., 2015), suggests a regional-level signature to the oxygenation trend (Castillo et al., 2017).

Proxy records are supported by historic shipboard oxygen measurements since the $1960 \mathrm{~s}$, which indicate a slight trend of ventilation close to the OMZ core over the upper continental slope (Cardich et al., 2019) (Fig. 3.3.3d). These observations contrast with those from the upper water column that exhibit strong regional interdecadal variability for the same period and a shoaling trend of the oxycline for the past few decades (Bertrand et al., 2011). Moreover, the shipboard measurements over the slope differ from oceanic observations off Northern Peru and in the Equatorial Eastern Pacific that indicate a trend of deoxygenation over the past decades (Czeschel et al., 2012, 2015). A modeling study suggests that the shoaling of the oxycline from 1970 to 2008 was associated with a decrease of the oxygen fluxes of the subsurface equatorial undercurrents (Espinoza-Morriberón, 2018), although in nearshore subsurface waters, instrumental data since the 1990s off Central Peru reveal a slight trend of oxygenation (Graco et al., 2017).

Multiple sediment cores near the OMZ core in the North Eastern Pacific (NEP) show a decreasing trend in $\delta^{15} \mathrm{~N}$ from 1850 to 1990 and an increasing trend since 1990 (Deutsch et al., 2014). Thus, the records suggest that the OMZ in the NEP was shrinking for most of the 20th century but that this trend reversed to deoxygenation in the latest period (Deutsch et al., 2014). The latter records are therefore similar to those observed in the ETSP oxycline, but the deoxygenation trend for the past few decades is absent in the proxy records from the Peruvian slope and Chilean shelf. Several mechanisms could be responsible for these features. For instance, multidecadal variations in the intensity of trade winds, by forcing thermocline depth changes, may have influenced the oxygen demand below the oxycline (Deutsch et al., 2014). However, variation in the intensity of trade winds may also involve changes in the equatorward overturning circulation associated with the SubtropicalTropical cells, which can contribute to the ventilation of the tropical ocean (Duteil et al., 2014a,b). Different oxygen trends in the NEP and the ETSP could result from the variability of the Equatorial Undercurrent (EUC), which is at least partially modulated by the intensity of trade winds and the Walker cell. However, while an intensification of the EUC would contribute to ventilate the subsurface water column in the coastal ETSP (Montes et al., 2014; Espinoza-Morriberón et al., 2019), intensification would increase the inflow of more oxygen-depleted waters than the local subsurface water in the NEP (Bograd et al., 2008; 2015; Ren et al., 2018). Furthermore, the trend of weak oxygenation near the OMZ core of the ETSP may reflect an intensification of the Chile-Peru Deep Coastal Current, which transports relatively fresh, oxygenated and cold Antarctic Intermediate Waters from the south (Pietri et al., 2014; Cardich et al., 2019).

\subsubsection{Future oxygen deficiency under climate change}

Current regional projections of ocean deoxygenation remain uncertain, especially relating to changes in oxygen in and around the ETSP OMZ. In fact, current global ocean models have limitations in accurately simulating the present-day oxygen distribution, and in reproducing measured changes in oxygen concentrations over the past 50 years (IPCC, 2013; Cabré et al., 2015; Oschlies et al., 2017; Schmidtko et al., 2017).

Climate change is likely to influence critical drivers of ventilation off Peru. In contrast with initial predictions of the likely response of upwelling systems to climate change (Bakun, 1990), recent downscaling of climate change scenarios show that surface winds off Peru are likely to decrease during summer (Goubanova et al., 2012; Belmadani et al., 2014; Chamorro et al., 2021) and on average stratification of the upper layers will increase (Echevin et al., 2020). As surface stratification is enhanced by ocean warming and oxygen saturation decreases with rising temperatures, surface layers are expected to experience reduced ventilation. Moreover, the impacts of increased nearshore stratification may differ with season. During summer, coastal upwelling may weaken, and thus productivity and the export of organic matter are likely to be reduced, leading to lower consumption of oxygen in subsurface layers through respiration. In winter, the depth of the surface mixed layer may be reduced due to the enhanced stratification, which may reduce light limitation (Echevin et al., 2008), favor primary production and the export of organic matter, and thus increase the biological consumption of oxygen. At a larger scale, potential changes in the circulation of Walker and Hadley cells (Lu et al., 2007; Vecchi and Soden, 2007; Yim et al., 2017) could affect the ventilation of the OMZ. Mechanisms may include the advection of source waters by the eastward equatorial currents in the north (Duteil et al., 2014a,b), and in the south, the inflow of more oxygenated subsurface or intermediate waters (Stramma et al., 2010a,b; Llanillo et al., 2013).

The projected increase in nearshore mesoscale activity (Echevin et al., 2011; Oerder et al., 2016) could enhance eddy-driven ventilation over the shelf and slope (Vergara et al., 2016). Modifications of the equatorial current systems (EUC and SSCCs, Montes et al., 2010, 2014; Espinoza-Morriberón 2018; Espinoza-Morriberón et al., 2019) may also change the volume of oxygenated waters of equatorial origin that are transported into the coastal system. Overall, ventilation processes also depend on the oxygen and nutrient content of the source waters upwelled near the coast (Rykaczewski and Dunne, 2010; EspinozaMorriberón et al., 2017; Echevin et al., 2020), which are not well constrained in CMIP models of the Eastern Equatorial Pacific (Cabré et al., 2015). A detailed analysis of the respective impact of these processes using regional downscaled simulations of CMIP earth system models is warranted.

To summarize, subsurface oxygen deficiency is an intrinsic feature of the ETSP and life cycles and biodiversity are adapted to the current patterns of oxygen deficiency and its spatial and temporal variability. Past records show that the ETSP OMZ intensity is modulated by climate variability through complex remote and local physical and biogeochemical processes that are not completely understood. Thus, predicting future trends of the ETSP OMZ and consequent ecological impacts face two important challenges. First, there is a need to improve our scientific understanding and modelling of the feedbacks among processes and scales that affect both ventilation and the consumption of oxygen. Secondly, there is a requirement for improved knowledge of biogeochemical, ecological and physiological thresholds that affect benthic, demersal and pelagic communities, as well as changes in benthic-pelagic coupling of nutrient regeneration, productivity and the export of organic matter. In the upper water column, a shallowing of the oxycline may amplify the negative effects of thermal stratification on the coastal retention of zooplankton and fish larvae (Brochier et al., 2013), and cause further vertical compression of the habitat of pelagic nekton. These mechanisms need to be investigated by combining experimental and bioenergetics studies with high-resolution modelling of coastal circulation and biogeochemistry.

\subsection{Southern shelf of the Canary Current}

\subsubsection{Shelf description and present oxygen conditions}

The OMZ of the Eastern Tropical North Atlantic (ETNA), similar to some other oceanic basins, lies in the weakly ventilated shadow zone between the well-ventilated subtropical gyre and the equatorial oxygen maximum with its core located around $10^{\circ} \mathrm{N}$ and $20^{\circ} \mathrm{W}$ at $\sim 400 \mathrm{~m}$ depth. The ETNA OMZ has expanded since the 1960s (Stramma et al., 2008, 2010a,b; Brandt et al., 2015) and has shoaled in the last decade (Hahn et al., 2017). However, regional modelling suggest that the connection between this deep OMZ and upwelling waters is very weak as only $\sim 1 \%$ of the surface waters originate from the waters of the OMZ (Glessmer et al., 2009). Along North-West Africa, waters upwelling onto the shelf north and south of the Cape Verde peninsula originate from relatively shallow water masses (Capet et al., 2017; Ndoye et al., 2017). Hence, oxygen conditions over the shelf are more constrained by the shallow water oxygen minimum located at $\sim 100 \mathrm{~m}\left(\sim 26.6 \mathrm{~kg} \mathrm{~m}^{-3}\right)$ 
depth off Mauritania and Senegal (Fig. 3.4.1a; Voituriez and Chuchla, 1978; Brandt et al., 2015; Klenz et al., 2018; Tall et al., In Press).

Along the southern part of the Canary Upwelling System, changes in the shape of the continental shelf and the presence of the Cape Verde peninsula result in a change in upwelling dynamics moving from the north to the south of the Cape (Ndoye et al., 2017). Along Mauritania, extensive sampling $\sim 18^{\circ} \mathrm{N}$ has shown dissolved oxygen concentrations of $60-70 \mu \mathrm{mol} \mathrm{kg}{ }^{-1}$ during the upwelling season in March on the outer edge of the shelf, with hypoxic conditions (e.g., $30 \mu \mathrm{mol} \mathrm{kg}{ }^{-1}$ ) associated with relaxation following the upwelling season (Gier et al., 2017). Over the southern Senegalese shelf, oxygen concentrations of nearbottom upwelling waters are $\sim 60 \mu \mathrm{mol} \mathrm{kg}{ }^{-1}$ during the upwelling season (Fig. 3.4.1c,d; Capet et al., 2017) and $\sim 200 \mu \mathrm{mol} \mathrm{kg}^{-1}$ during the warm season (Tall et al., In Press). Although the longer residence times characteristic of the wide and shallow southern Senegalese shelf favour the development of hypoxia, the first evidence of anoxia has only recently been documented (Machu et al., 2019). However, hypoxic conditions have previously been proposed to explain the occasional anomalous mortalities of demersal fish (Serranidae) that have been observed since the late 1980s (Caverivière and Touré, 1990).

\subsubsection{Causes and controls of low oxygen}

Oxygen-rich Tropical Surface Waters (TSW) dominate the upper ocean off West Africa. Central waters below the TSW comprise an upper and a lower layer, roughly delimited by the $26.8 \mathrm{~kg} \mathrm{~m}^{-3}$ isopycnal at around $300 \mathrm{~m}$ depth (El Moussaoui et al., 2005; Peña-Izquierdo et al., 2012; Klenz et al., 2018). The shelf is therefore subject to the influence of upper Central Waters that flow in a northward direction. Off the coast of Senegal, upper Central Water is made up primarily of South Atlantic Central Water (SACW), but is increasingly mixed with North Atlantic Central Water (NACW) as water moves towards the north. The characteristics of these source waters constrain the oxygen supply onto the shelf, with both physical and biologically-mediated processes subsequently modifying the oxygen content of shelf waters. Mean oxygen concentrations of the upper Central Water decrease northward presumably as a result of the degradation of the organic matter produced as a consequence of upwelling over the shelf (Peña-Izquierdo et al., 2012; Klenz et al., 2018). Off the Mauritanian coast, at $\sim 18^{\circ} \mathrm{N}$, Klenz et al. (2018) have shown that the lowest oxygen concentrations $\left(\sim 30 \mu \mathrm{mol} \mathrm{kg}{ }^{-1}\right)$ on the shelf are encountered following the upwelling season (June and August). During this time of upwelling relaxation, stratification strengthens and limits diapycnal oxygen supply from surface layers, which acts in combination with prolonged periods of high respiration $\left(\sim 10 \mathrm{mmol} \mathrm{O}_{2} \mathrm{~m}^{-3} \mathrm{~d}^{-1}\right.$; Dale et al., 2014) following the productive upwelling season, to reduce oxygen concentrations to their lowest values. During a cruise in 2014, Thomsen et al. (2019) showed that while some oxygen variability can be attributed to water mass composition, water mass characteristics are strongly modified by local

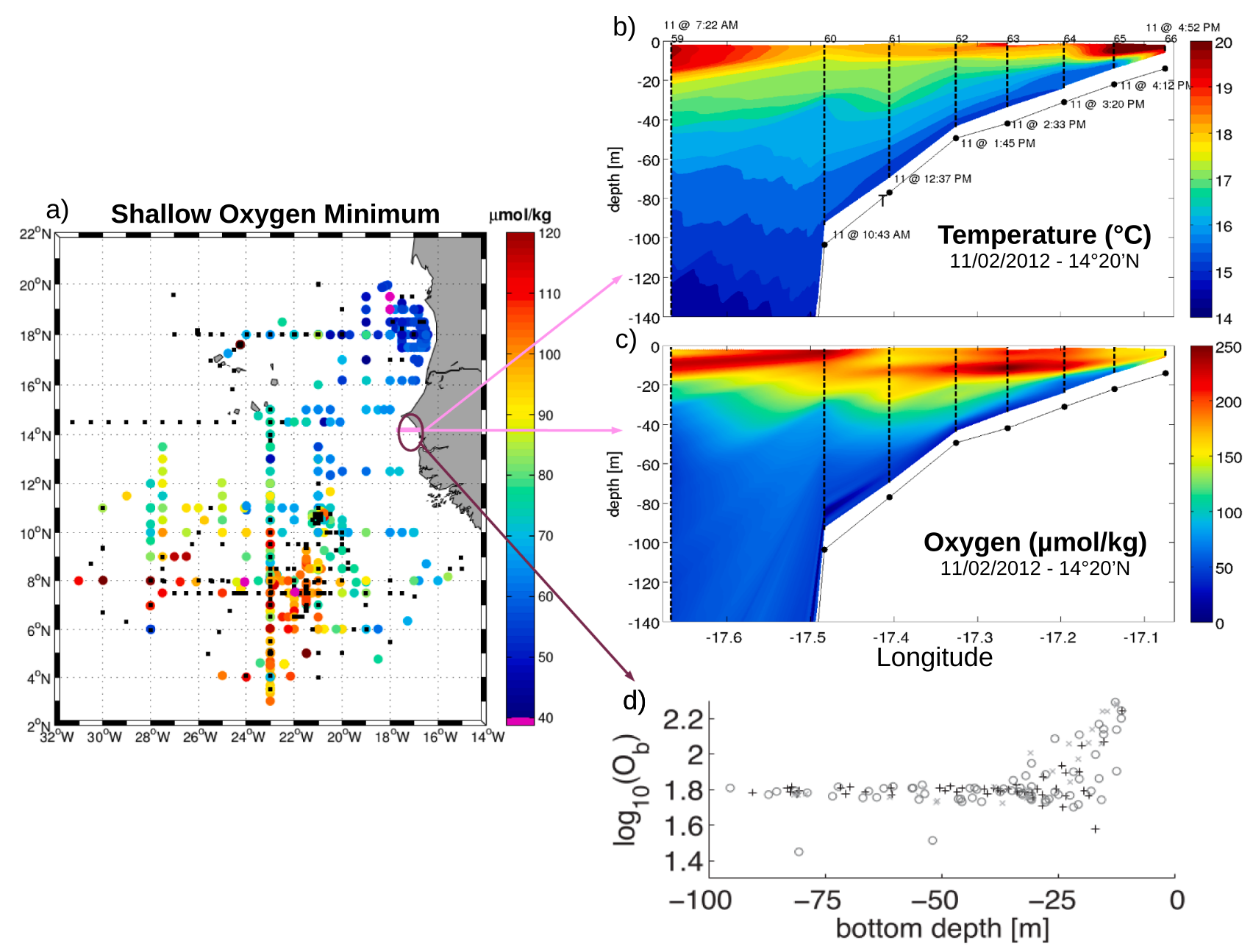

Fig. 3.4.1. (a) Minimum oxygen concentrations above $200 \mathrm{~m}$ in the southern Canary Upwelling region during the period 2006-2013 (black squares indicate profiles without a shallow oxygen minimum - i.e., the minimum oxygen concentration was found at the lower boundary of the chosen depth of $200 \mathrm{~m}$; from Brandt et al., 2015), (b) the vertical distribution of temperature and (c) of dissolved oxygen over the continental shelf of Senegal (transect along $14^{\circ} 20^{\prime} \mathrm{N}$ on 11 February 2012 during UPSEN1 (CTD cast numbers 59 to 66 ), and (d) bottom dissolved oxygen concentrations ( $\mu$ mol. $\mathrm{kg}^{-1}, \log$ scale), for all CTD casts along $\sim 14^{\circ} 30^{\prime} \mathrm{N}(+), \sim 14^{\circ} \mathrm{N}$ (circles), and $\sim 13^{\circ} 40^{\prime} \mathrm{N}(\mathrm{x})$ transects carried out during UPSEN2 and ECOAO 2013 field experiments (from Capet et al., 2017). 
oxygen consumption that occurs close to the coast near the seabed. Here, local oxygen respiration creates oxygen anomalies on time scales of 1-2 weeks that are of the same magnitude as those attributed to water mass variability.

Different advection and mixing processes have been proposed to explain the variability of oxygen in bottom waters of the southern Senegalese shelf (Fig. 3.4.1c; Tall et al., In Press). During the upwelling season, near hypoxic waters are advected onto the shelf (Capet et al., 2017; Machu et al., 2019). At the MELAX station $\left(14^{\circ} 20^{\prime} \mathrm{N}-17^{\circ} 13.5^{\prime} \mathrm{W}\right.$; $35 \mathrm{~m}$ depth), the oxygen content of bottom waters tends to be lower than that of upper slope water and can be partly attributed to the respiration of organic matter on the shelf (Tall et al., In Press). In addition to seasonal and intraseasonal variability in the slope current, coastal trapped waves (CTWs) can be generated from south of Senegal as far afield as the Gulf of Guinea (Diakhaté et al., 2016; Kounta et al., 2018). These CTWs modulate alongshore currents over the Senegalese continental slope and shelf (irrespective of local wind forcing) and, by vertically displacing isopycnals and oxygen gradients, modify the properties of source waters. During the upwelling season (December to May), currents are from the north, but reverse with the transition to the warm season in April and May, causing bottom oxygen concentrations to increase despite a strengthening of stratification. Stratification plays a crucial role in diurnal and semi-diurnal variability of oxygen by modulating the onshore propagation of internal waves and influencing mixing in the bottom layer, particularly during the transition period (August to November) from the warm and rainy monsoon season to the upwelling season (Tall et al., In Press). Remotely forced CTWs further impact oxygen concentrations by modulating the northward West African Boundary Current (Kounta et al., 2018) resulting in the transport of more oxygenated water from the south.

Anoxia recorded at mid-shelf during a period of relaxation of upwelling in March 2012 was attributed to the advection of a decaying diatom bloom that had developed in shallower waters. Coastal trapped waves triggered by remote wind fluctuations were considered the cause of the change in flow orientation and the advection of the decaying bloom (Machu et al., 2019). Other undocumented cases of severe hypoxia have been observed at different locations over the shelf from Dakar to Gambia during field experiments carried out over the last 7 years (Machu, pers. com.). These cases often involve high phytoplankton biomass and also occur during periods of relaxation and strong stratification that inhibits diapycnal oxygen supply.

\subsubsection{The future oxygen environment}

Many gaps remain in understanding oxygen variability along the coastal regions of the ETNA and on the low oxygen conditions that develop in this region. The duration and extension of hypoxic and anoxic events, their frequency of occurrence and their regional consequences on the nitrogen budget and the ecosystem, including through possible export of low oxygen waters toward the open ocean (Schütte et al., 2016a,b), are largely unknown.

The increase in the carbon-to-nitrogen ratio observed in particulate organic matter in high $\mathrm{CO}_{2}$ environments may lead to greater oxygen consumption resulting in a $50 \%$ increase in the suboxic water volume worldwide (Oschlies et al., 2008). Regionally, the shoaling by $-22 \pm 17 \mathrm{~m}$ of the deep OMZ observed by Hahn et al. (2017) over the last decade could modify the oxygen properties of water masses flowing over the continental slope and shelf of the ETNA. In Senegal, increases in the human population and in wastewater discharges (Diop et al., 2014) will play a role in affecting oxygen conditions. Coastal processes implicated in the production of local oxygen-depleted waters may also be affected by global climate change. The warming of surface waters as observed over the last decades (Vélez-Belchí et al., 2015; Gómez-Letona et al., 2017), and the accompanied reduction ( $10 \%)$ in wind stress as predicted to occur in the ETNA (Sylla et al., 2019), are likely to further influence stratification that plays an important role in generating low oxygen conditions over the shelf.

\subsection{Northern Benguela shelf}

\subsubsection{System description and established trends}

The Benguela Current region is a wind driven upwelling system that borders the west coast of southern Africa. The central upwelling cell near Lüderitz $\left(27^{\circ} \mathrm{S}\right)$ divides the system into two sub regions: the northern Benguela located off Namibia and southern Angola $\left(\sim 15-26^{\circ} \mathrm{S}\right)$ and the southern Benguela located off southern Namibia and the west coast of South Africa $\left(\sim 27-34^{\circ} \mathrm{S}\right)$. Bottom-water oxygen concentrations below $2.0 \mathrm{ml}^{-1}$ are perennial in the northern Benguela; in particular, between $19^{\circ} \mathrm{S}$ and $24^{\circ} \mathrm{S}$, the shelf exhibits persistent oxygen depleted bottom-waters with concentrations ranging from below 0.5 to $1.0 \mathrm{ml} \mathrm{l}^{-1}$ (Fig. 3.5.1; Bartholomae and van der Plas, 2007). Some seasonality is nevertheless evident, in that shelf hypoxia is most widespread during the warm, stratified conditions of summer and autumn, extending as far as $28^{\circ} \mathrm{S}$ (Fig. 3.5.1a). Hypoxia also occurs off the shelf as a seasonal midwater oxygen minimum feature at around 150 to $300 \mathrm{~m}$ water depth. Conversely, some re-oxygenation of shelf waters occurs during the winter into the spring upwelling period (Fig. 3.5.1b) when cool, fairly aerated Eastern South Atlantic Central Water (ESACW) flushes the northern Benguela shelf (Duncombe Rae, 2005).

Shelf anoxia in the northern Benguela is frequently accompanied by sulphidic water column conditions from anaerobic decomposition of organic matter (Brüchert et al., 2006; van der Plas et al., 2007; Lavik et al., 2009; Ohde and Mohrholz, 2011; Ohde and Dadou, 2018). Diatomaceous mud belts are specifically a major source of hydrogen sulphide. Here the rapid degradation of excess organic matter by bacterial sulphate reduction drives the diffusive flux of hydrogen sulphide from the sediment (Brüchert et al., 2006). The amount of hydrogen sulphide leaking into the water column is, however, limited by mats of a variety of sulphide-oxidizing bacteria, including Thiomargarita namibiensis (Schulz et al., 1999) and Beggiotoa, which cover the sediments and capture $\mathrm{H}_{2} \mathrm{~S}$ before it reaches the surface waters (Brüchert et al., 2006; Lavik et al., 2009). The limited availability of sulphate in the upper few centimeters of the sediments further promotes methanogenesis and the accumulation of free methane gas (Emeis et al., 2004). Both oxygen and methane concentrations on the shelf also exhibit variability at the event scale linked to local wind forcing (Monteiro et al., 2006).

Strong, longer-period fluctuations in oxygen are also evident in the northern Benguela forced by recurrent warm and cold events at interannual periods. Extreme warm events, referred to as Benguela Niños, are known to strengthen hypoxia and cool events (Benguela Niñas) are known to oxygenate the shelf (Shannon et al., 1986; Monteiro et al., 2008). Data from the near-monthly oceanographic monitoring transect off Walvis Bay $\left(23^{\circ} \mathrm{S}\right)$, which was re-initiated in 1999 , but has been sampled intermittently for dissolved oxygen since the late 1970s, show considerable inter-annual variability in water column oxygen (Fig. 3.5.2). This variability includes prolonged periods of shelf hypoxia from 1994 to 1995 and 2000-2001 associated with warmer subthermocline water (Hamukuaya et al., 1998; Bartholomae and van der Plas, 2007; Monteiro et al., 2008) and of shelf oxygenation from 1996 to 1998 associated with cooler waters (Fig. 3.5.2; Monteiro et al., 2008). In situ time series for the northern Benguela are not sufficiently long to resolve multi-decadal trends or patterns in oxygen variability. However, sedimentary core analyses have provided insight into past surface water temperatures, upwelling intensity and productivity over multi-decadal to glacial-interglacial time periods (e.g. Berger and Wefer, 2002; West et al., 2004; Meisel et al., 2011) from which inferences about the bottom-water oxygen condition can be made.

\subsubsection{Causes and controls of low oxygen}

The northern Benguela is a wind-forced coastal upwelling system in which southerly (trade) winds, linked to the position and circulation of the South Atlantic high pressure system, are an important driver of its productivity and variability on multiple time and space scales (Shannon, 1985; Boyd, 1987). The local equatorward wind forcing, which is 

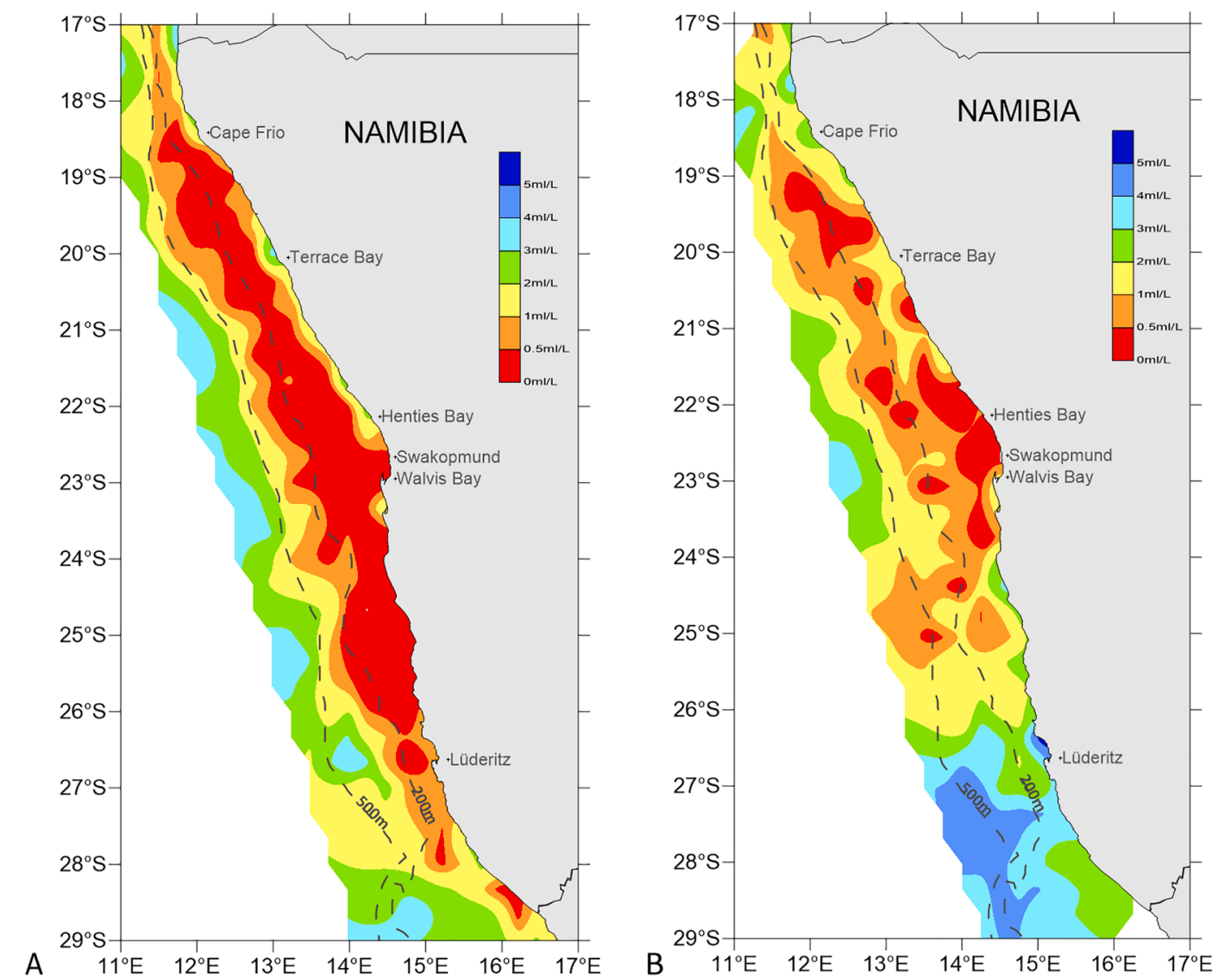

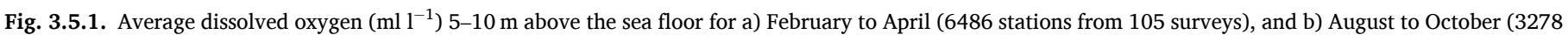
stations from 88 surveys) for the period 1976-2006 (data from Namibian Ministry of Fisheries and Marine Resources provided by Anja K. van der Plas).

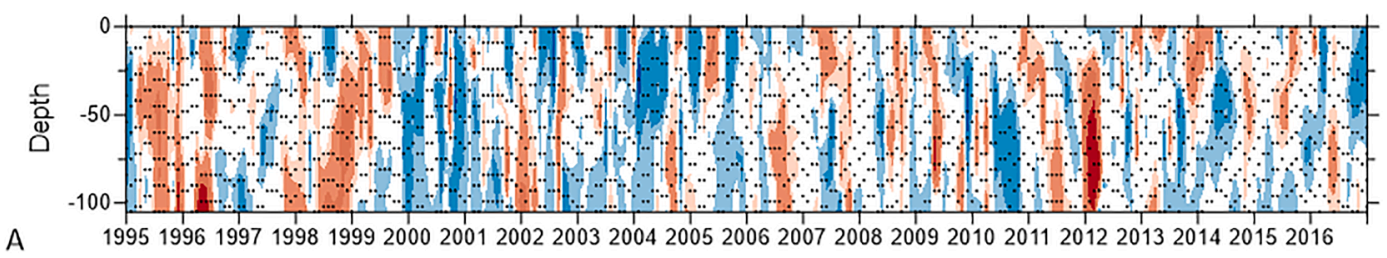

A

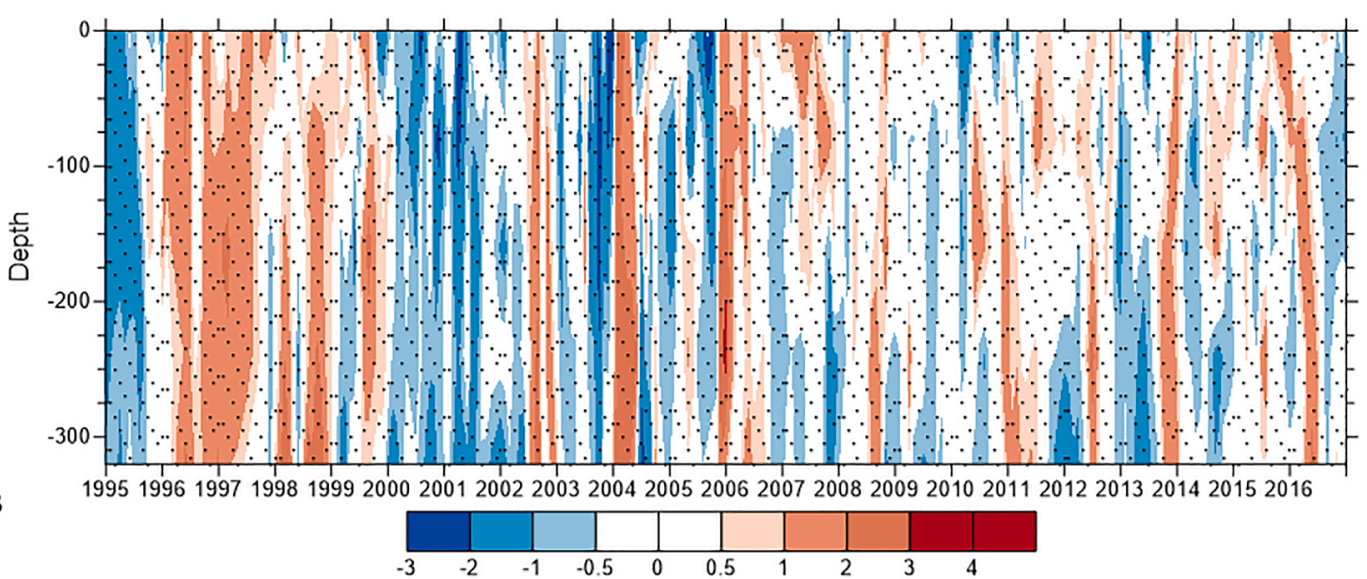

Fig. 3.5.2. In situ dissolved oxygen $\left(\mathrm{ml} \mathrm{l}^{-1}\right)$ standardized anomalies at a station a) 10 nautical miles (NM, $\left.23^{\circ} \mathrm{S}, 14^{\circ} 13.53^{\prime} \mathrm{E}\right)$ and $\left.\mathrm{b}\right) 70$ nautical miles $\left(23^{\circ} \mathrm{S}\right.$, $13^{\circ} 8.54^{\prime} \mathrm{E}$ ) offshore of Walvis Bay. The dots indicate sampling intervals and depths (data from Namibian Ministry of Fisheries and Marine Resources provided by Anja K. van der Plas). 
strongest during winter to spring, drives the cross-shelf advection and upwelling of nutrient-rich waters leading to high primary productivity on the inner northern Benguela shelf (Lass and Mohrholz, 2008; Fennel et al., 2012; Louw et al., 2016). The wide shelf ensures the retention of upwelling driven-shelf production and depositional characteristics, as influenced by the interaction between internal tides and the bathymetry, result in longshore alternating bands of high and low concentrations of particulate organic matter (Monteiro et al., 2005, 2011).

Aerobic remineralization of new production deposited on the inner shelf is expected to contribute to significant seasonal variability in oxygen drawdown. However, while the flux of new production peaks in early summer, the oxygen minimum over the northern Benguela occurs in late summer to autumn (Monteiro et al., 2006; Louw et al., 2016). This anomaly is attributed to changes in the physical ventilation of the shelf as controlled by the relative dominance of South Atlantic Central Water (SACW) flowing southward from the Angolan Dome, over the northward transport of Eastern South Atlantic Central Water (ESACW) from the Cape Basin.

The relaxation of equatorial trade winds during austral summer or the strengthening of the westerlies have been suggested as triggers for Kelvin waves that travel along the equatorial waveguide and, upon reaching the African continent, continue poleward as coastal trapped waves that deepen the thermocline and bring warm, saline Angola current water to the northern Benguela (Florenchie et al., 2003; Rouault et al., 2007; Junker et al., 2017). These sub-thermocline waters advecting southward as the so-called poleward undercurrent, both over the shelf and slope, originate from the pool of nitrate-rich, low-oxygen water in the Angola gyre (Duncombe Rae, 2005; Mohrholz et al., 2008). This Angola gyre central water primes the northern Benguela shelf with low oxygen and further biogeochemical activity that can lead to anoxia (Monteiro et al., 2006; Brüchert et al., 2006; van der Plas et al., 2007; Mohrholz et al., 2008). With the strengthening of the upwellingfavourable southerly winds in summer off Lüderitz and in winter and spring off central to northern Namibia (Boyd, 1987), the undercurrent reverses direction to equatorward. This reversal brings cold, more oxygenated ESACW originating from the Cape Basin off South Africa and ventilates the northern Benguela shelf, mainly via the strong Lüderitz upwelling cell, leading to an oxygen maximum during spring (Duncombe Rae, 2005; Monteiro et al., 2008; Mohrholz et al., 2008). These advective mechanisms driving oxygen supply are the primary controls of seasonal, interannual and decadal variations in the severity of oxygen depletion (Monteiro et al., 2006, 2008).

Using a regional coupled modelling approach incorporating the hydrodynamic ROMS model (Shchepetkin and McWilliams, 2005) and the biogeochemical model BioEBUS, Bachèlery et al. (2016) showed that oceanic remote equatorial forcing explains more than $85 \%$ of the interannual oxygen fluctuations along the Angolan and Namibian coasts, including the northern Benguela. Remotely forced coastal trapped waves propagate poleward along the African coast with strong subsurface signatures that can be detected in the northern Benguela to $24^{\circ} \mathrm{S}$. To describe the processes associated with the propagation of these coastal trapped waves, Bachèlery et al. (2016) analyzed coastal interannual biogeochemical budgets and found oxygen anomalies were controlled by physical advection processes. Changes in subsurface coastal biogeochemical characteristics were shown to translate into large variations of primary production in the euphotic layer. A sharp North $\left(0^{\circ}-22^{\circ} \mathrm{S}\right)$ - South $\left(23^{\circ}-28^{\circ} \mathrm{S}\right)$ contrast was evident in the biogeochemical signature of coastal waters (Fig. 3.5.3), including a sign inversion in the interannual anomalies in the Benguela upwelling system, in agreement with satellite-derived chlorophyll concentrations. This sign inversion is a function of weakened vertical advection associated with less intense vertical gradients of the biogeochemical tracers. The subsurface nutrient gain and associated oxygen loss in the Benguela upwelling system is explained by the horizontal advection of nitrate-rich water from the equator toward the pole, concomitant with vertical advection of deep nutrient-rich water.

Gutknecht et al. (2013a,b) have modelled the oxygen-dependent processes over the northern Benguela shelf in a climatological configuration using the coupled physical-biogeochemical ROMS-BioEBUS model and explored the model sensitivity to key biogeochemical parameters and nitrous oxide parameterizations. Biogeochemical parameters associated with organic matter decomposition, vertical sinking, and nitrification were shown through sensitivity analyses to play key roles in determining oxygen content, nitrogen loss, and nitrous oxide concentrations in the OMZ. Simulated minimum oxygen concentrations were driven by the poleward meridional advection of oxygen-depleted waters offshore of the $300 \mathrm{~m}$ isobath and by biogeochemical activity inshore of this isobath, highlighting a spatial dependence of the dominant processes maintaining minimum oxygen concentrations off Namibia (Fig. 3.5.4).

Interchanges between nutrient-rich, oxygen-depleted SACW and well-oxygenated ESACW in the Benguela create unique biogeochemical conditions on the shelf in that they drive the seasonality of nitrification, anammox and denitrification (Mashifane et al., 2016). Nitrite concentrations are key to understanding intermediate nitrogen processes and their implications for nitrogen loss in oxygen depleted waters. Understanding nitrite dynamics in oxygen depleted areas is nevertheless a challenge as nitrite represents an intermediary nitrogen species with a short turnover time. Further, nitrite is also reduced to nitrogen under conditions of oxygen depletion that prevents its accumulation. The modelling study of Mashifane et al. (2016) showed that primary and secondary nitrite maxima occur in the water column of shelf waters. The primary maxima are found in well oxygenated waters of the euphotic zone in response to nitrification and nitrate assimilation in the region of

\section{Coastal inter-annual oxygen anomalies $\left(\mathrm{mmolO}_{2} \cdot \mathrm{m}^{-3}\right)$}

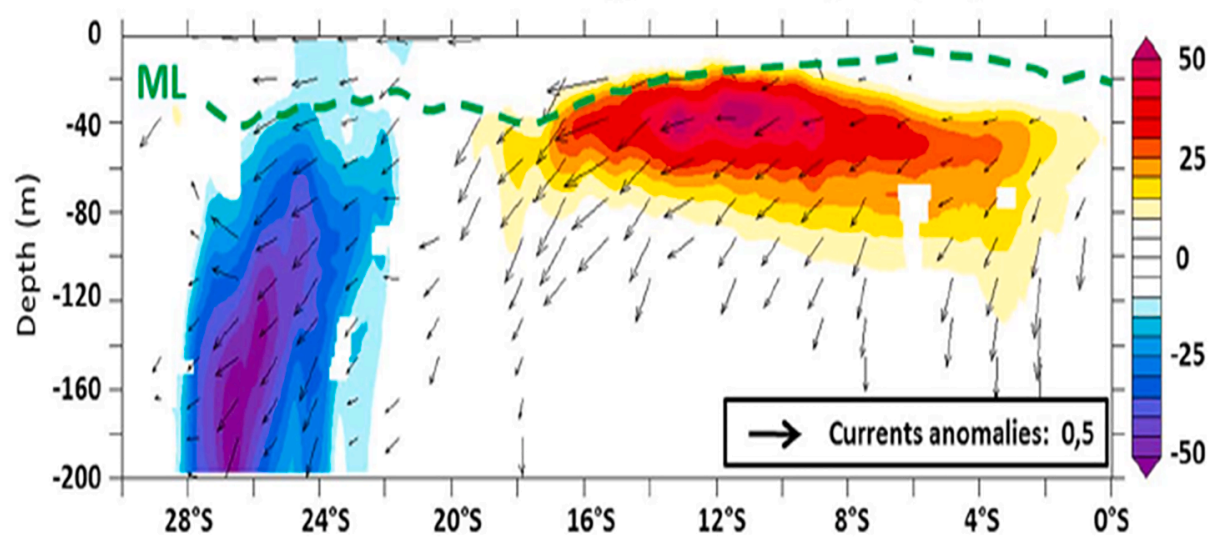

Fig. 3.5.3. Vertical section of oxygen anomalies as a function of latitude during an extreme warm event for the remote equatorial forcing simulation experiment with the ROMS-BioEBUS coupled model. The green dashed line indicates the mean position of the mixed layer and arrows correspond to mean (inter annual) vertical $\left(\mathrm{m} \mathrm{d}^{-1}\right)$ and alongshore $(0.1 \times \mathrm{m}$ $\mathrm{s}^{-1}$ ) currents for the period 2000-2008 (from Bachèlery et al., 2016). (For interpretation of the references to color in this figure legend, the reader is referred to the web version of this article.) 


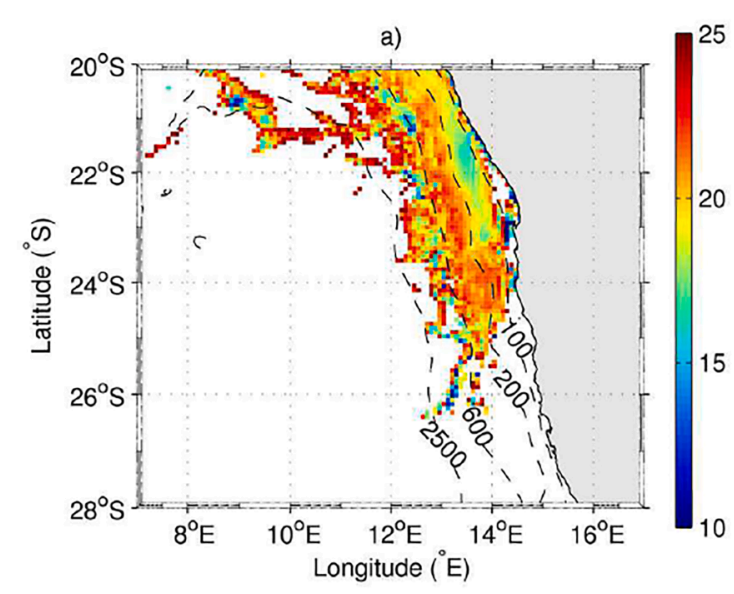

b)

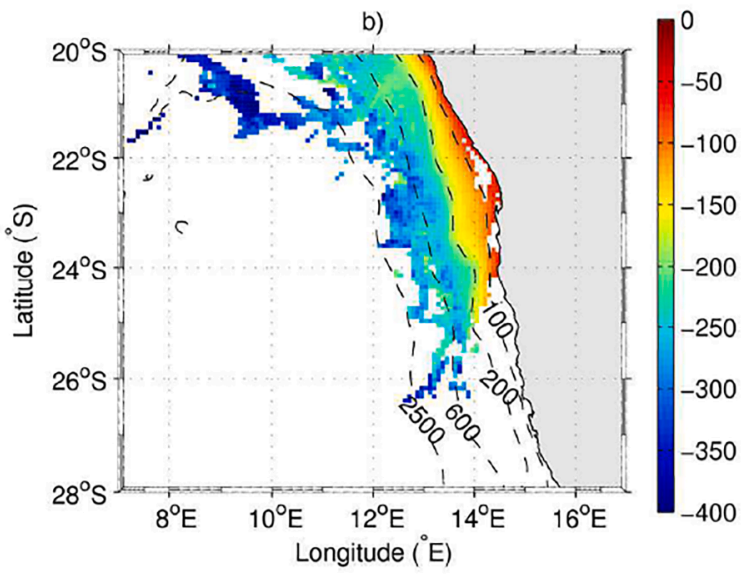

c)

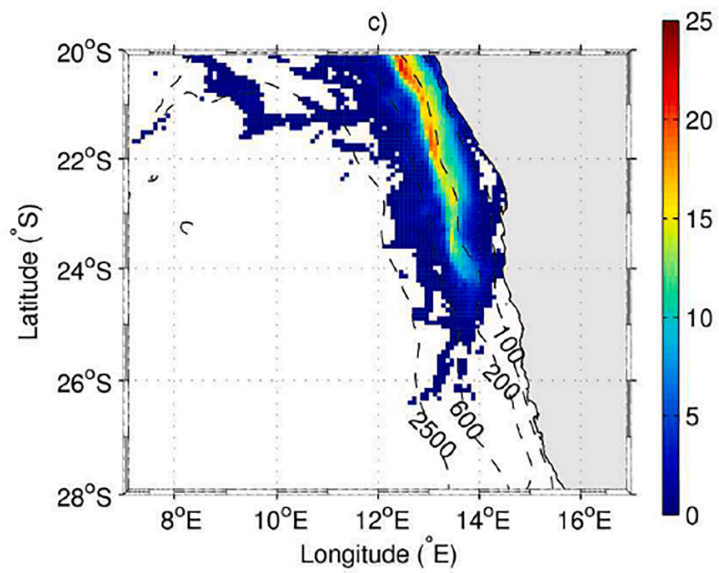

d)

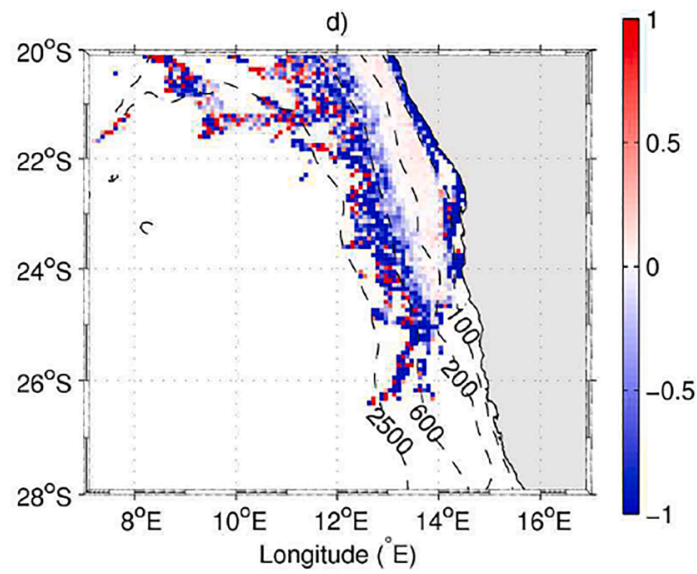

e)

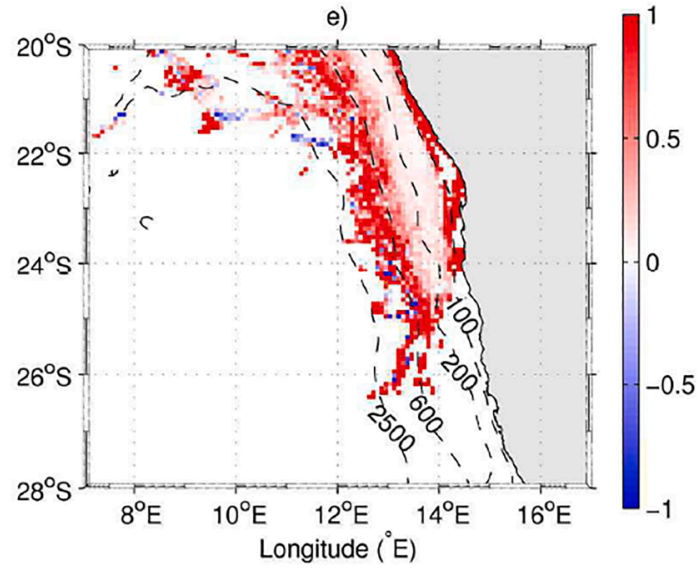

f)

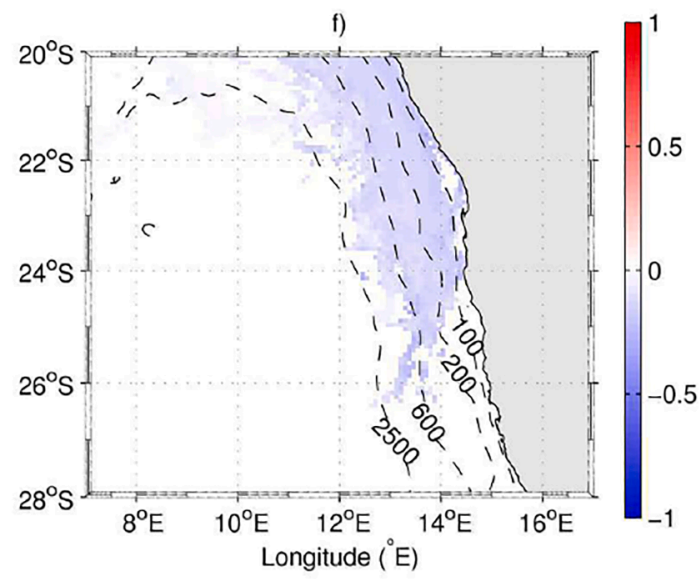

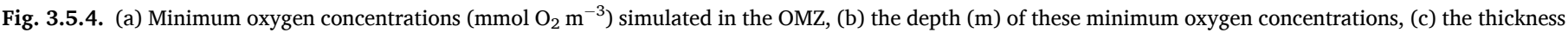

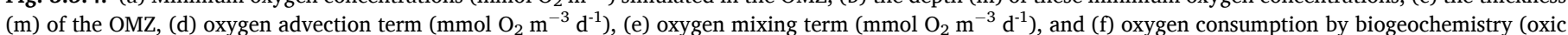

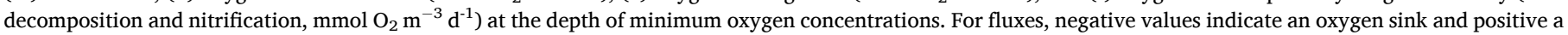
source (from Gutknecht et al., 2013a,b).

the nitracline. Secondary nitrite maxima are prominent in oxygen depleted waters in the Angola-Benguela Frontal (ABF) region at $100-200 \mathrm{~m}$ depth and are attributed to denitrification. South of the frontal region (off Walvis Bay), the secondary nitrite maxima are lower and indicate significant consumption through anammox (Kuypers et al., 2015). Subsequent nitrite reduction in the depleted bottom waters of the Benguela leads to nitrous oxide production, with high concentrations occurring in the $\mathrm{ABF}$ region as a result of nitrification and denitrification.

\subsubsection{Predictions of the future oxygen environment}

Various responses to climate change have been proposed for eastern boundary upwelling systems, including the northern Benguela, with a focus on changes in the trade wind system, upwelling intensity and sea surface temperatures. Proposed changes include an intensification of wind-induced coastal upwelling in response to increased land-sea temperature differences associated with global warming (Bakun, 1990; Sydeman et al., 2014). Responses to increased upwelling are increased productivity, higher sedimentation of organic material and increasing anoxia in bottom waters (Bakun 1990; Bakun and Weeks, 2004). 
However, ocean warming could counter stronger upwelling by increasing stratification and thus complicating forecasting of biogeochemical responses (Sydeman et al., 2014; García-Reyes et al., 2015). Further, coastal wind records for Lüderitz show weaker than average southerly wind stress since 2005 (Peard, 2007; CAF Grobler unpubl. data).

Model simulations have also revealed a likely poleward shift in atmospheric high-pressure systems that would result in upwelling weakening at low latitudes and strengthening at high latitudes (Rykaczewski et al., 2015; Wang et al., 2015). This may translate to a reduction in the extent of coastal upwelling in the northern Benguela, leading to increased hypoxia and anoxia over a large part of the shelf due to reduced ventilation from the main upwelling cell at Lüderitz. A change in frequency and severity of Benguela Niño events (Siegfried et al., 1990) would also affect dissolved oxygen levels as the tropical water is oxygen-poor and increased intrusion into the northern Benguela would lead to an increase in the areal extent and intensity of hypoxia (Monteiro et al., 2008).

For the Benguela, projected climate change and expected ecosystem responses by the end of the 21st century have been investigated using a regional coupled physical-biogeochemical model ROMS-AGRIF/ BioEBUS (Chust et al., 2014). The model was forced with climate simulations from the IPSL-CM4 Earth system model for the period 2080-2100 relative to 1980-2000 under the future climate scenario A1B representative of possible conditions between 2080 and 2100 under a business as usual emissions scenario. Wind downscaling following Goubanova et al. (2012) was necessary to correct SST seasonality, mixed layer depth, and to provide more realistic circulation and biogeochemical properties over the domain (Chust et al., 2014; Machu et al., 2015).
The Benguela upwelling system was projected to experience an increase in sea surface temperature $\left(+1.4^{\circ} \mathrm{C}\right)$ and a decrease in net productivity $(-12 \%)$ over the entire domain, and a decrease in the magnitude of trade winds $(-10 \%)$ and of minimum oxygen concentrations (-20 to $-30 \mathrm{mmol} \mathrm{m}^{-3}$ ) over the northern region and in areas of coastal upwelling (Chust et al., 2014). However, unexpected conditions characterised by increased production and plankton biomass could develop in the northern part of the Benguela upwelling system and along the coast, as a response to increased temperature and stratification and decreased mesoscale activity from weakening winds (Chust et al., 2014). Several studies using coupled models (Gruber et al., 2011) and satellite data (Rossi et al., 2008) show that decreased mesoscale activity over the continental slope can increase productivity in eastern boundary upwelling systems that may lead to an increase in the downward export of organic matter and a greater oxygen demand. In a future climate scenario, simulated $\mathrm{pH}$ decreased over the entire domain $(-0.24)$ due to an increase in atmospheric $\mathrm{CO}_{2}$ and the subsequent $\mathrm{CO}_{2}$ increase in seawater resulted in the acidification of the Benguela (MEECE, 2013).

\subsection{Continental shelves of the North Indian Ocean}

The two mesopelagic OMZs of the North Indian Ocean impinge upon a very large area of the continental margin. In fact, by being land-locked in the north, the Indian Ocean accounts for as much as two-thirds of the global continental margin area that is exposed to oxygen concentrations $<0.2 \mathrm{ml}^{-1}$ (Helly and Levin, 2004). However, as the upper boundary of the OMZ is generally between 100 and $150 \mathrm{~m}$ depths, the continental shelves only experience severe oxygen depletion during periods of upwelling. This process occurs on a large scale during the
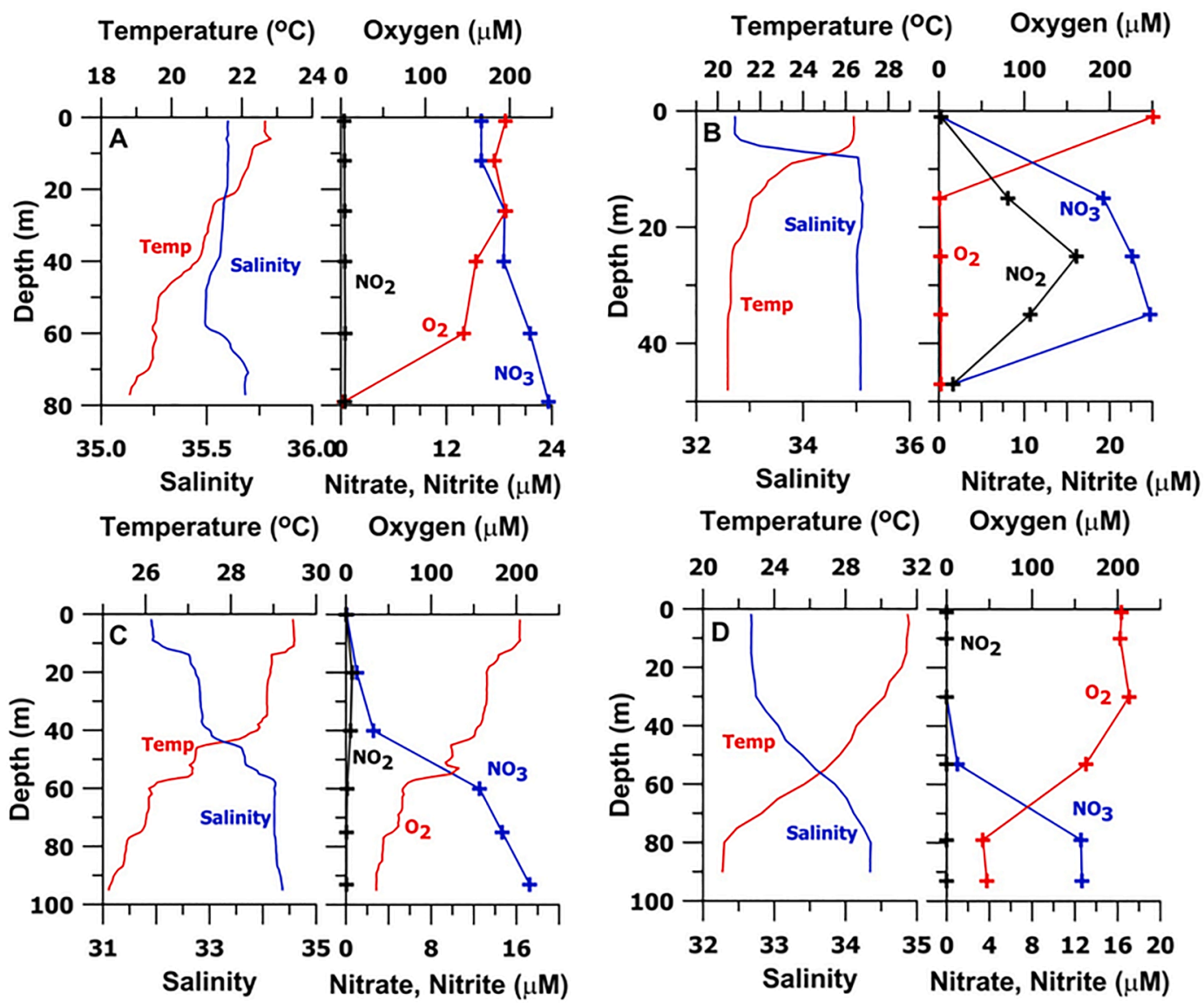

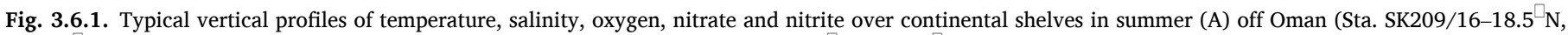

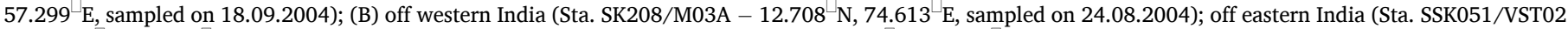
- 17.618 N, 83.754 E, sampled on 12.06.2013); and off Myanmar (Sta. SK175/76-14.502 N, 95.485 E, sampled on 09.05.2002). 
Southwest Monsoon (SWM) along both the western and eastern boundaries of the Arabian Sea, but with contrasting intensity and effects.

\subsubsection{Shelf susceptibility to low oxygen}

Temperature, salinity, oxygen, $\mathrm{NO}_{3}^{-}$and $\mathrm{NO}_{2}^{-}$profiles typically observed during summer upwelling over the western and eastern continental shelves in the Northwestern and Northeastern parts of the Indian Ocean are compared in Fig. 3.6.1. In the western Arabian Sea, upwelling driven by very strong southwesterly winds, forces subsurface waters of moderately low oxygen onto the shelf off the Somali and Arabian coasts. The thermohaline stratification is weak and nutrient concentrations are quite high in this region (Fig. 3.6.1a). However, the upwelled water is rapidly transported offshore and the short residence time over the narrow shelf does not allow the development of intense anoxia. Over the western Indian shelf, upwelling results from large-scale circulation, and except in the south, along the coasts of Kerala and western Sri Lanka where local winds are upwelling-favourable, the process is confined to a narrow (few tens of kilometers wide) coastal belt. Moreover, upwelled water is often prevented from reaching the surface due to the slow rate of upwelling and by a thin (5-10 m) lowsalinity lens that is formed because of the high rainfall in the coastal zone (Fig. 3.6.1b). Consequently, low oxygen $\left(<0.5 \mathrm{ml}^{-1}\right)$ conditions in bottom waters prevail over the entire Indian (and possibly most of the Pakistani) shelf (area $\sim 200000 \mathrm{~km}^{2}$ ), making it the largest shallow water oxygen-deficient zone in the world (Naqvi et al., 2000). The upwelled water, derived from the West India Undercurrent (WIUC), has low-oxygen to begin with, but is not anoxic. However, as it ascends over the shelf, WIUC waters further loses oxygen leading to clear watercolumn redox zonation: hypoxia over the outer shelf, "suboxia" (denitrifying conditions) over the mid-shelf and anoxia (sulphate reduction)
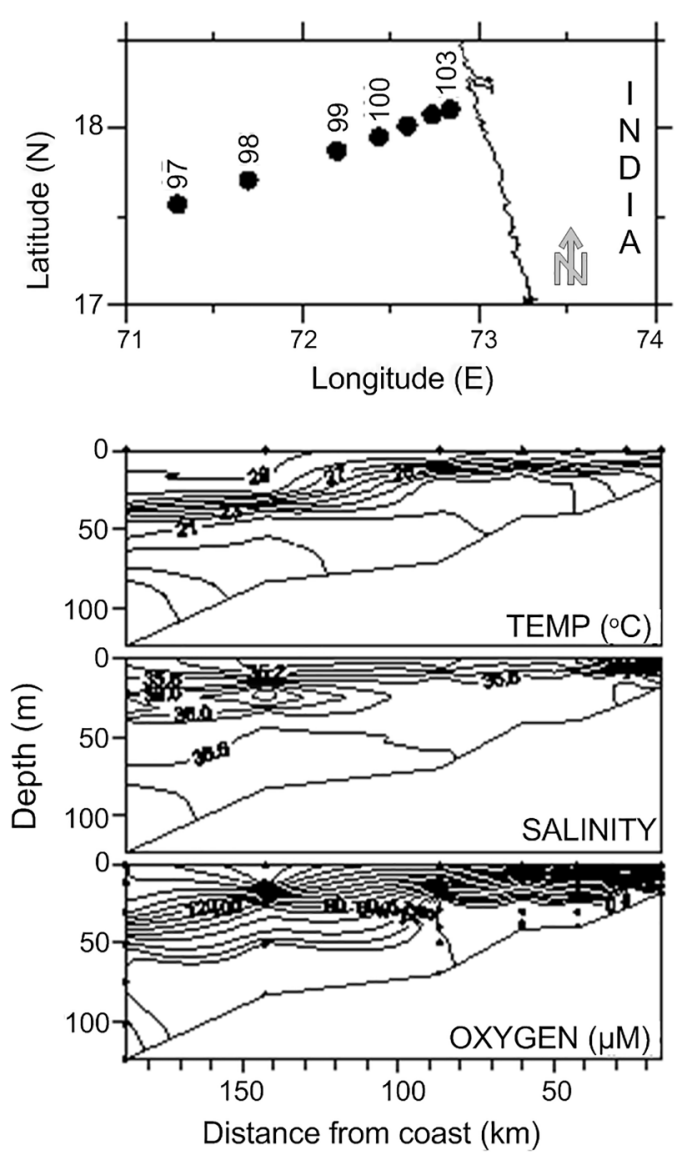

over the inner shelf (Fig. 3.6.2). Reducing conditions that culminate in sulphate reduction in near-bottom waters along an open coast have only been reported from the coastal upwelling systems off Namibia and Peru. However, while shelf anoxia off wetern India displays a number of similar chemical characteristics to the Namibia and Peru systems, including a build-up of high concentrations of hydrogen sulphide and nitrous oxide (off Peru but not off Namibia) (Brüchert et al., 2006; Schunck et al., 2013; Arévalo-Martínez et al., 2015), shelf anoxia off western India is different with respect to the forcing processes. That is, while excessive organic loading is a major cause of anoxia off Namibia and Peru, seasonal anoxia over the Indian shelf is predominantly due to initial low oxygen concentrations in upwelled waters and to their stagnation over the shelf. The extended residence time of these waters on the shelf is a consequence of a combination of the slow rate of upwelling and of very strong near-surface thermohaline stratification. The moderate organic loading over the Indian shelf is also reflected in the small accumulation of organic carbon, even over the inner shelf (2-3.5\%), and consequently low sulphate reduction rates, sedimentary methanogenesis and a much smaller accumulation of methane in the overlying waters (Naik et al., 2017; Shirodkar et al., 2018).

Unlike the Arabian Sea, anoxic conditions do not usually develop over the shelf in the Bay of Bengal, even though oxygen levels fall to quite low levels below the mixed layer (Fig. 3.6.1c,d; also see Sarma et al., 2013). This is also the case off the mouths of the major rivers, such as Ganges-Brahmaputra and Irrawaddy that enter the sea over wide shelves, causing strong stratification. The absence of anoxic conditions is largely because upwelling in the Bay of Bengal is much weaker than in the Arabian Sea, and the mesopelagic OMZ therefore rarely extends to shallow depths. However, an instance of very low oxygen $\left(\sim 0.1 \mathrm{ml}^{-1}\right.$ $1^{-1}$ ) was reported by Satpathy et al. (2013) in very shallow waters (59 m)

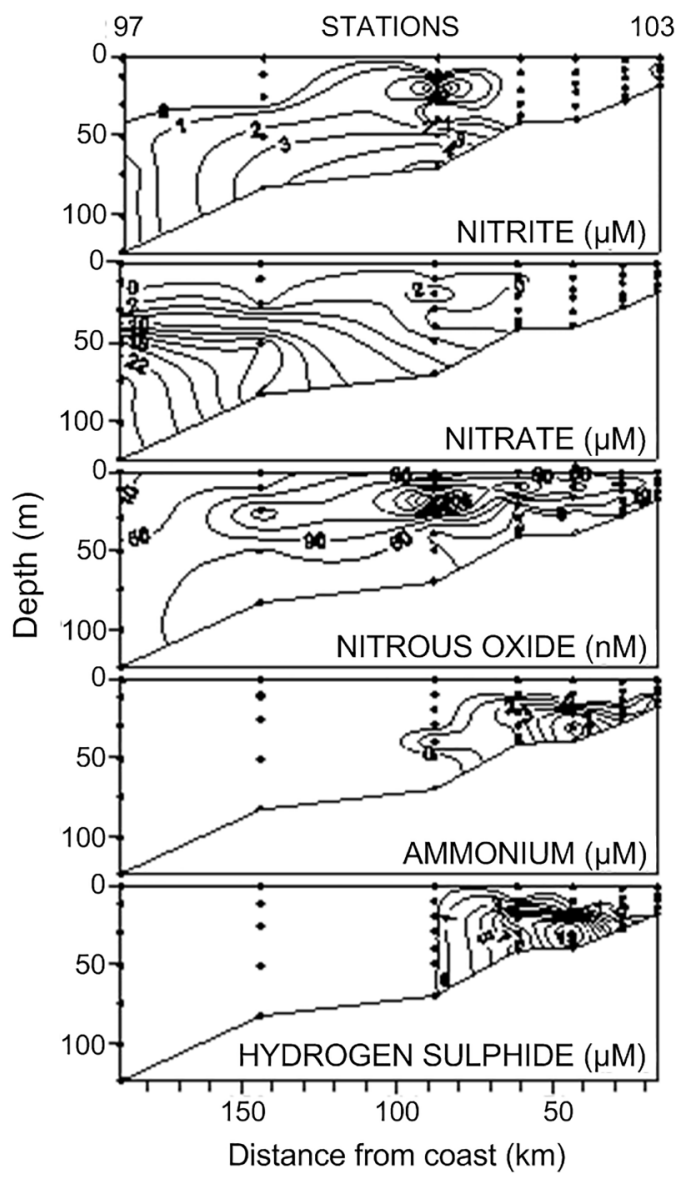

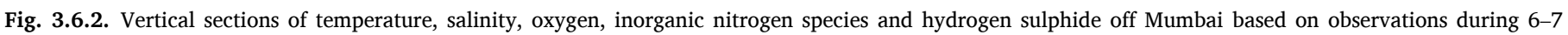
October 1999 (from Naqvi et al., 2000). 
off the south-east coast of India in September 2010. Although this event was attributed to land-based pollution, the data presented suggest an offshore origin of nearly-anoxic waters, possibly associated with an eddy.

\subsubsection{Human-induced deoxygenation trends}

Available data suggest a decrease in oxygen concentrations in the western Arabian Sea off Oman since the 1960s (Piontkovski and Al-Oufi, 2015; Piontkovski and Queste, 2016). However, more observations are needed from the Omani shelf to better assess this trend, its linkage to harmful algal blooms and fish kills and its potential socio economic impact (Piontkovski and Queste, 2016; Gomes et al., 2014). In comparison, the seasonally anoxic zone off the west coast of India, known since the 1950s (Banse, 1959; Carruthers et al., 1959), has been more thoroughly investigated, with initiation of time series observations off Goa (the Candolim Time Series, CaTS) and repeat samplings along several coastal transects in the 1990s (Naqvi et al., 2000, 2006c, 2009). Observations from the CaTS reveal large interannual changes in the duration and intensity of the oxygen deficiency without a clear longterm trend (Naqvi et al., 2009). However, the intensity of oxygen deficiency is apparently greater now than it was in the 1970s. Sulphidic conditions that have been observed during most years since 1997 were not encountered during the extensive surveys of the shelf conducted under the UNDP/FAO-sponsored Integrated Fisheries Project (IFP) from 1971 to 1975 when the oxygen concentrations in upwelled waters appear to have been significantly higher (Naqvi et al., 2006c). It has been proposed that the intensity of anoxia may be controlled by basin scale events such as the Indian Ocean Dipole (IOD) (Vallivattathillam et al., 2017). The year-long observations at a fixed site off Kochi revealed remarkably similar oxygen distribution to that observed by Banse (1968) who had sampled the same site from July 1958 to January 1960 (Gupta et al., 2016). However, it may be pointed out that 2012 was an IOD year with weaker than usual upwelling.

Despite the immense runoff from major rivers like the GangesBrahmaputra (Mitra et al., 2018) and Irrawaddy that are alleged to transport large quantities of nutrients into the Bay of Bengal (Seitzinger et al., 2002), large scale hypoxic zones near these river mouths, such as that evident off the Mississippi in the Gulf of Mexico, are not present (Fig. 3.6.1d). This supports the view that nutrient runoff by rivers flowing into the Bay of Bengal is likely smaller than predicted (Seitzinger et al., 2002). Unfortunately, recent, reliable oxygen data to assess the extent of oxygen change along the coasts of countries such as Bangladesh, Myanmar, Malaysia and Thailand does not exist.

\section{Enclosed seas}

Enclosed or semi-enclosed seas are characterised by limited exchange of water with adjacent seas or oceans and may be distinguished by euxinic deep layers. Case studies are presented for the Baltic Sea, the Black Sea and the Sea of Japan. Both the Baltic Sea and Black Sea show records of oxygen depletion following their transition from freshwater systems $\sim 8000$ years ago. While the Sea of Japan is presently welloxygenated, it has a history of oxygen depletion dictated by sea level changes that regulate seawater exchange and the relative inflow of freshwater.

\subsection{Baltic Sea}

The Baltic Sea is the largest anthropogenically induced hypoxic area in the world (Conley et al., 2009a). Over the last 115 years, observations document a 10-fold increase of hypoxia, primarily linked to the increased inputs of nutrients from land and with global warming contributing in recent years (Carstensen et al., 2014a). Hypoxia not only impacts bottom-living organisms and fish communities in the Baltic Sea, but also alters the breakdown of organic matter and the biogeochemical cycles of many biologically important elements such as nitrogen, phosphorus and iron (Carstensen et al., 2014b). Significant international efforts have been made to reduce anthropogenic nutrient inputs in order to restore good environmental status (HELCOM, 2018; Murray et al., 2019); although eutrophication has been reduced, hypoxia is still present and is near its maximum size $\left(>60000 \mathrm{~km}^{2}\right)$.

\subsubsection{System description}

The Baltic Sea is a strongly stratified, semi-enclosed postglacial sea with a surface area of $415000 \mathrm{~km}^{2}$, a volume of $21700 \mathrm{~km}^{3}$ and an average depth of $55 \mathrm{~m}$ with several deep $(>200 \mathrm{~m}$ ) basins. The catchment area is $1640000 \mathrm{~km}^{2}$, which gives a drainage area of around four times its surface area, with 9 countries having a coastline on the Baltic and 6 additional countries in the catchment. The salinity is controlled both by freshwater inputs from the watershed and by the exchange of saltwater with the North Sea. The exchange occurs through the shallow and narrow connections at the Danish Straits resulting in an estuarinelike circulation in the Baltic producing a strong salinity gradient from marine salinity conditions $\left(30 \mathrm{~g} \mathrm{~kg}^{-1}\right)$ at the entrance area to near freshwater $\left(2 \mathrm{~g} \mathrm{~kg}^{-1}\right)$ in the innermost parts of the northern reaches (HELCOM, 2018). Marine species are progressively replaced along this salinity gradient by freshwater species according to their salinity tolerances.

Water exchange is characterized by outflowing brackish water at the surface and inflowing salty and denser water through the Danish Straits. Although salinity inflows enter into the Baltic regularly (Meier, 2007), most studies have focused only on the dense inflows, the so-called Major Baltic Inflows (MBIs), that occur irregularly in response to meteorological conditions (Schinke and Matthäus, 1998). MBIs can transport large quantities of salinity and oxygen with significant potential to increase oxygen concentrations in the deep waters of the Baltic Proper (Schmale et al., 2016; Neumann et al., 2017).

There are large climatic gradients in the basin and the water temperatures vary significantly depending upon location, season and depth. During winter season, the northern Baltic Sea tends to be ice covered whereas surface temperatures during summer average $9-10^{\circ} \mathrm{C}$. In the southern Baltic, surface temperatures during winter range from 0 to $5^{\circ} \mathrm{C}$ and increase to $15-20^{\circ} \mathrm{C}$ during the peak of the summer (HELCOM, 2018). Temperatures in deep basins are around $5{ }^{\circ} \mathrm{C}$ with little seasonal variation. Both surface and bottom-water temperatures have increased by $1-2{ }^{\circ} \mathrm{C}$ over the past century.

\subsubsection{History of deoxygenation}

Sediment records show that hypoxia first occurred in the Baltic Sea soon after its transition from fresh water to brackish water $\sim 8000 \mathrm{BP}$ and hypoxia has been present intermittently throughout the Holocene (Zillén et al., 2008). Laminated sediments indicating hypoxic conditions can be seen primarily during three main intervals of the Holocene: the Holocene Thermal Maximum between c. 8 000-4 000 BP, the Medieval Climate Anomaly between $1200-750$ BP and the modern hypoxic interval (AD 1800 to present) (Fig. 4.1.1a). Sedimentary records signal intermittent euxinic (i.e., sulfidic) conditions in the bottom waters of the deep basins during the Holocene. The hypoxic intervals are characterized by enhanced cyanobacteria blooms and high organic carbon contents in sediments, attributed to both greater preservation of organic matter under reducing conditions and enhanced primary productivity during the hypoxic intervals (Funkey et al., 2014). Perturbation of trace metal cycles during the modern hypoxic interval is more intense than past hypoxic intervals indicating that euxinic bottom water conditions are more common today than during past hypoxic intervals (van Helmond et al., 2018).

Historical records of dissolved oxygen concentration from research cruises and monitoring programs show that low water-column dissolved oxygen concentrations have been observed since $\sim 1900$ with a 10-fold increase of hypoxia in the Baltic Sea during the last 115 years (Carstensen et al., 2014a). The area of oxygen-deficient waters has expanded from $5000 \mathrm{~km}^{2}$ to over $60000 \mathrm{~km}^{2}$ with large decadal fluctuations over 

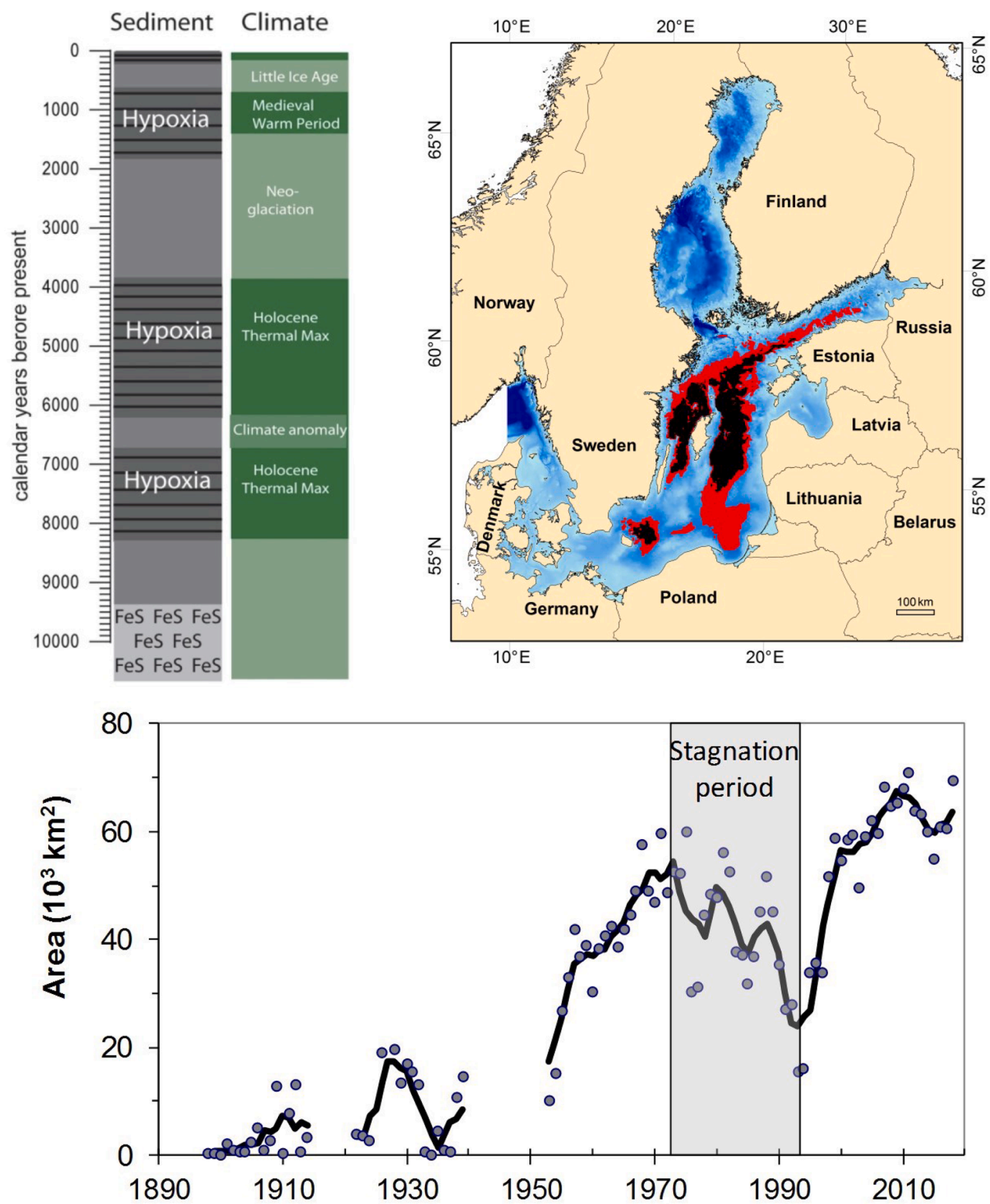

Fig. 4.1.1. Hypoxic conditions in the Baltic Sea. (a) The occurrence of laminated sediments as an indicator of hypoxia during different periods of the Holocene. (b) Areal extent of hypoxia in the Baltic Sea for the period 2001-2017. Black shading indicates anoxia, whereas red shading indicates hypoxia. (c) Annual average areal extent of hypoxia during the time period calculated from oxygen measurements (Carstensen et al. 2014a).

the last century (Fig. 4.1.1b,c). The maximum extent of hypoxia is increasingly controlled by the area below the pycnocline, and during most of the last decade nearly the entire bottom area below this layer is hypoxic. The modern data also show that the deepest depressions have experienced intermittent hypoxia during most of the Holocene, which corresponds well with what is observed in the palaeo data (Zillén et al., 2008; van Helmond et al., 2018).

Coastal hypoxia is widespread in the coastal zone of the Baltic with $\sim 35 \%$ of all coastal ecosystems having experienced hypoxia during the period 1955-2009 (Conley et al., 2011). Most of the sites investigated have experienced episodic hypoxia, which is a precursor to development of seasonal hypoxia (Conley et al., 2009b).

Episodic re-oxygenation can occur during strong MBI events and deep water oxygenation events can occur if inflows are dense enough to penetrate below the pycnocline. Recent studies have clearly demonstrated a complex response to inflow events both during the inflow period (Neumann et al., 2017; Schmale et al., 2016) and thereafter (Carstensen et al., 2014a). These events are strongly dependent upon volume of inflowing waters and density conditions in both the inflowing water and in the bottom waters. Subsequent changes in vertical mixing across the pycnocline with changes in salinity stratification, in nutrient biogeochemistry and consequent primary productivity (Funkey et al., 2014) all impact long-term oxygen dynamics in bottom waters after the occurrence of inflows of denser water.

\subsubsection{Causes of deoxygenation}

The expansion of hypoxia over the last century in the Baltic Sea has been primarily attributed to enhanced nutrient input from land and the atmosphere increasing algal production and thereby creating an oxygen demand upon degradation, and due to global warming (Carstensen 
et al., 2014a). Warming with climate change has caused the bottom waters to become increasingly oxygen depleted by decreasing the solubility of oxygen as a result of increasing temperature and through enhanced respiration of organic matter.

Nutrient pollution due to intense agriculture in the watershed together with discharges from wastewater resulted in an increase in nutrient loads to the Baltic Sea from the 1950s to the 1980s (Fig. 4.1.2), but then loads decreased substantially thereafter (Gustafsson et al., 2012). The Baltic Sea provides one of the rare examples in coastal marine ecosystems where successful management has led to a trend reversal in nutrient loading (Carstensen et al., 2006). Unfortunately, there are large pools of nutrients stored in sediments found in the watershed (e.g., agricultural fields, lakes) as well as nutrients buried in the Baltic sediments. These nutrients can be stored in the ecosystem on decadal or even centennial scales, or can be released and recycled. For example, phosphorus release from sediments will continue for several decades after load reductions, with hypoxia allowing for the retention of phosphorus in the water column (Reed et al., 2011).

Numerous results indicate that temperature and salinity changes were the key drivers of past hypoxia and imply that ongoing climate change will delay recovery from the modern, nutrient-driven hypoxia (Papadomanolaki et al., 2018). During the hypoxic periods observed in the past (e.g., the Holocene Thermal Maximum and the Medieval Climate Anomaly, Zillén et al., 2008; Papadomanolaki et al., 2018), changes in salinity and sea surface temperature were key causes of hypoxia, underscoring their possible importance in facilitating the spread of oxygen-depleted bottom waters in a future Baltic Sea. However, while shifts in climate and physical circulation are important factors modulating the extent of hypoxia, further nutrient reductions will be necessary to reduce the ecosystem impacts of deoxygenation.

\subsubsection{Modeling}

Several physical-biogeochemical ocean circulation model simulations have been used to disentangle the drivers of hypoxia (Eilola et al., 2009; Meier et al., 2011; Lehmann et al., 2014; Meier et al., 2018) and the role of eutrophication and atmospheric forcing functions on hypoxia. Most projections agree that rainfall will increase with global warming causing the average salinity to decrease over the coming century, presumably weakening stratification. However, decreased oxygen concentrations are predicted due to enlarged nutrient loads with increased runoff (Meier, 2007). Additional projected decreases in oxygen concentrations occur due to the reduced oxygen flux from the atmosphere to the ocean caused by increasing temperature and intensified internal nutrient cycling (Meier et al., 2011). Decadal to centennial changes in eutrophication, and the resulting hypoxia, have been primarily caused by changing river borne nutrient loads and atmospheric deposition (Carstensen et al., 2014b; Meier et al., 2018). All simulations to date agree that during the past 150 years, hypoxia would not have developed if nutrient conditions had remained at pristine levels. It is the increases in nutrient inputs (Gustafsson et al., 2012) that stimulated biological production and subsequent eutrophication, and thereby enhanced oxygen consumption (and hypoxia) in bottom waters during the last century.

Saltwater inputs and MBIs can modulate the duration and extent of hypoxia. MBIs are characterized by two phases: (1) sustained high pressure over the Baltic with easterly winds followed by (2) several weeks of strong zonal wind and pressure fields over the North Atlantic and Europe (Schinke and Matthäus, 1998). While these weather conditions can be observed, they cannot be predicted. Therefore, projections are not able to predict the timing of future impacts of MBIs and saltwater exchange, and indicate that mitigation schemes must also accommodate these changes in salinity and temperature and their possible effect on oxygen concentrations.

Finally, despite a reduction in external nutrient loads, the ecological status for large parts of the Baltic Sea is showing only gradual improvement (Andersen et al., 2017). Recovery from eutrophication is a slow process due to shifting baselines and non-linear responses of biogeochemical processes to reduced nutrient inputs (Duarte et al., 2009). This can also be attributed to the internal storage of nutrients in sediments and the recycling of phosphorus under hypoxic conditions. Model simulations suggest that once the goals of the Baltic Sea Action Plan (BSAP) for nutrient reduction are met, conditions could improve substantially within decades, but that fully achieving the management goals could take longer (HELCOM, 2018).

\subsection{Black Sea}

\subsubsection{System description and history of anoxia}

The Black Sea is a semi-enclosed sea with restricted exchange of water with the Mediterranean Sea through the Bosporus Strait. The

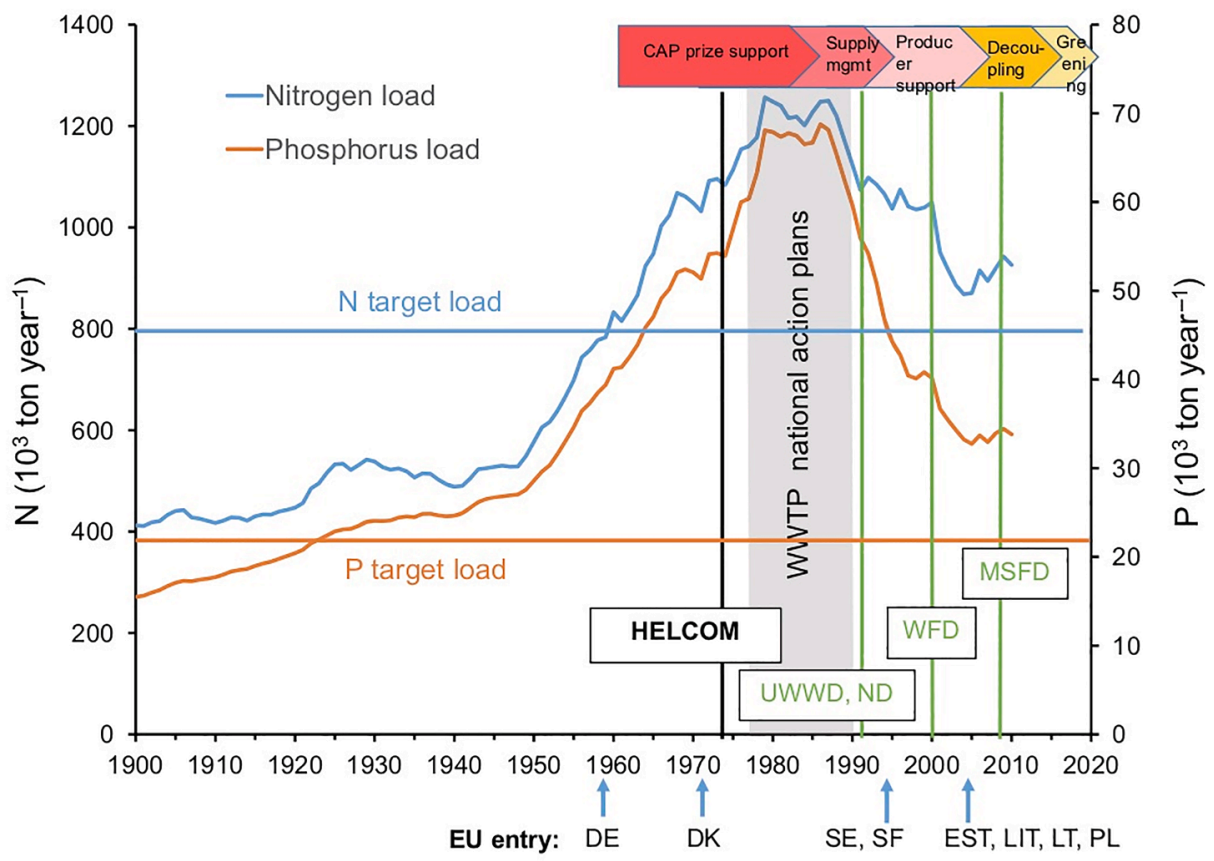

Fig. 4.1.2. Five-year moving average values of $\mathrm{N}$ and $\mathrm{P}$ loads (in 1000 metric tons per year) to the Baltic Sea together with the Baltic Sea Action Plan targets. Along the $\times$ axis, the timing of countries joining the $\mathrm{EU}$ and the introduction of key $\mathrm{EU}$ environmental legislation are shown. WWTP, wastewater treatment plans; HELCOM, signing of the Helsinki Convention; UWWD, urban wastewater directive. Key developments of the EU Common Agricultural Policy (CAP) are indicated by arrows at the top of the diagram (from Reusch et al., 2018). 
northwestern region of the sea consists of an almost $200 \mathrm{~km}$ wide shelf that comprises about $20 \%$ of the total surface area of the sea and that receives a large freshwater input mainly from the Danube River. The ratio of drainage area to the surface area of the Black Sea is particularly large ( $\sim 5.21$, Ludwig et al., 2009) leading to the discharge of a massive amount of fresh water $\left(\sim 350-400 \mathrm{~km}^{3}\right.$ year $\left.^{-1}\right)$ into the Black Sea. Consequently, the hydro-physical structure of the sea is particularly sensitive to river flows. The central Black Sea is $\sim 2000 \mathrm{~m}$ deep and interacts with the shelf along the continental slope.

During the Last Glacial Maximum, the Black Sea was a fully enclosed freshwater lake without any exchange with the Mediterranean Sea (Degens and Ross, 1972). With rising sea levels, water of the Mediterranean Sea entered the Black sea around 8000 years ago. As the salinity of Mediterranean water was high $(\sim 36)$, the Mediterranean water sank to the bottom as it entered the Black Sea resulting in the progressive formation of a permanent halocline that inhibited vertical ventilation of subsurface waters (Fig. 4.2.1). This resulted in the creation of deep anoxic, and ultimately sulfidic waters, thereby transforming the oxic Pleistocene freshwater lake into a permanently sulfidic marine basin.

\subsubsection{Physical controls of anoxia and recent trends}

Due to the presence of the permanent halocline (Fig. 4.2.1), the vertical circulation in the deep part of the Black Sea is currently less than a tenth of the integrated horizontal circulation (Stanev, 1990) and two main ventilation mechanisms come into play. Winter cooling and mixing oxygenate the upper layer forming dense waters that sink to the layer of the permanent pycnocline and form the well-oxygenated Cold Intermediate Layer (CIL); this is characterized by a temperature minimum at a depth between 50 and $100 \mathrm{~m}$ (Fig. 4.2.1). The other ventilation mechanism is intermittent, occurs below the CIL and is associated with the penetration of salty well-oxygenated Mediterranean waters through the Bosporus Strait. As a result, only the first $\sim 100 \mathrm{~m}$ of the water column is regularly ventilated, while waters below $100-150 \mathrm{~m}(\sim 87 \%$ of the volume corresponding to $\sim 4.7 \times 10^{5} \mathrm{~km}^{3}$ ) are essentially stagnant, deprived of oxygen and contain massive amounts of hydrogen sulfide. The Black Sea is the largest sulfidic basin in the world. The only transport influencing the deep waters is associated with convective motions driven by geothermal heat fluxes leading to the formation of the largest bottom convective layer (400-500 m) in the world's ocean (Top et al., 1991). The water residence time increases from a few years in the surface layer, subject to seasonal variability, to several hundreds of years for the deep waters. Together, the vertical structure and semi-enclosed character ensure that the Black Sea is naturally poorly ventilated and particularly sensitive to any modification of its hydrological balance.

The vertical biogeochemical structure of the Black Sea water column therefore consists of a well oxygenated surface layer (roughly 0-50 m), an oxycline where the oxygen concentration decreases sharply with depth to trace levels, a suboxic layer characterized by very low concentrations of oxygen and $\mathrm{H}_{2} \mathrm{~S}$ (i.e., $\mathrm{O}_{2}<10 \mu \mathrm{M}$ and $\mathrm{H}_{2} \mathrm{~S}<5 \mathrm{nM}$ ) (Murray et al., 1995), and a sulfidic layer extending from roughly below $100 \mathrm{~m}$ to the bottom (forming a large pool of reduced components like $\mathrm{H}_{2} \mathrm{~S}, \mathrm{NH}_{4}$, $\mathrm{Mn}^{2+}, \mathrm{Fe}^{2+}$ ) (Fig. 4.2.2). The upper interface of the suboxic layer corresponds to the base of the oxycline and its position depends on the flux of particulate organic matter sinking from the surface and the volume of the CIL formed by seasonal winter cooling. The lower interface is determined by the intensity of the upward flux of reduced substances from the anoxic layer (mainly $\mathrm{H}_{2} \mathrm{~S}$ ) and their oxidation by oxygen (mainly laterally injected from the Bosporus Strait), nitrate and metal oxides such as $\mathrm{MnO}_{2}$ and $\mathrm{FeOOH}$ (e.g., Konovalov and Murray, 2001) (Fig. 4.2.2).

The volume of new cold water formed each year depends on atmospheric conditions, especially atmospheric temperature. An increase in winter atmospheric temperature is expected to modify the rate of formation of the CIL that will impact the ventilation of the lower oxic layer. As the deep basin oxygen inventory is positively related with formation of the CIL, a reduced CIL is expected to lead to a reduction in the basin oxygen inventory (Capet et al., 2016a). The analysis of long-term time series data (ship-based and BGC-Argo floats) collected in the deep basin (1955 to 2016) revealed that the oxygen penetration depth (i.e., the depth where the oxygen concentration reaches $20 \mu \mathrm{moll}^{-1}$ ) decreased from $140 \mathrm{~m}$ to less than $90 \mathrm{~m}$ with a consequent reduction in the oxygen inventory of $44 \%$ (Capet et al., 2016a). This shoaling of the oxycline and reduction in total water column oxygen has been interpreted as a response to changes in the basin-wide nutrient load and climatic
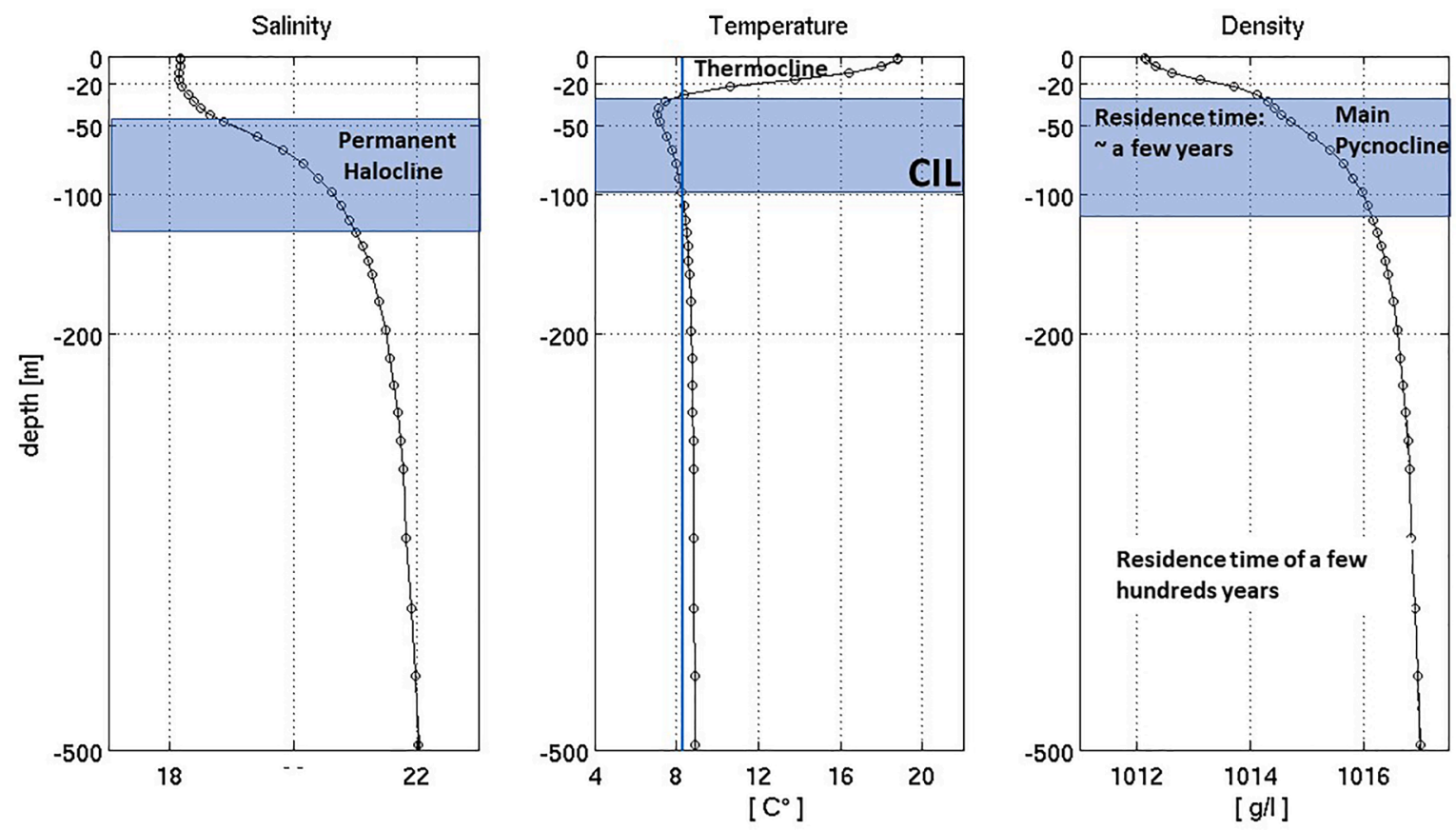

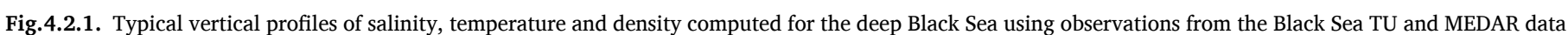

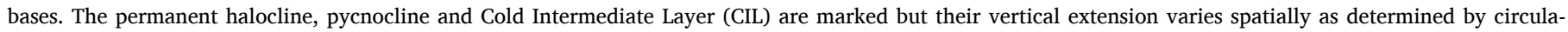
tion patterns. 


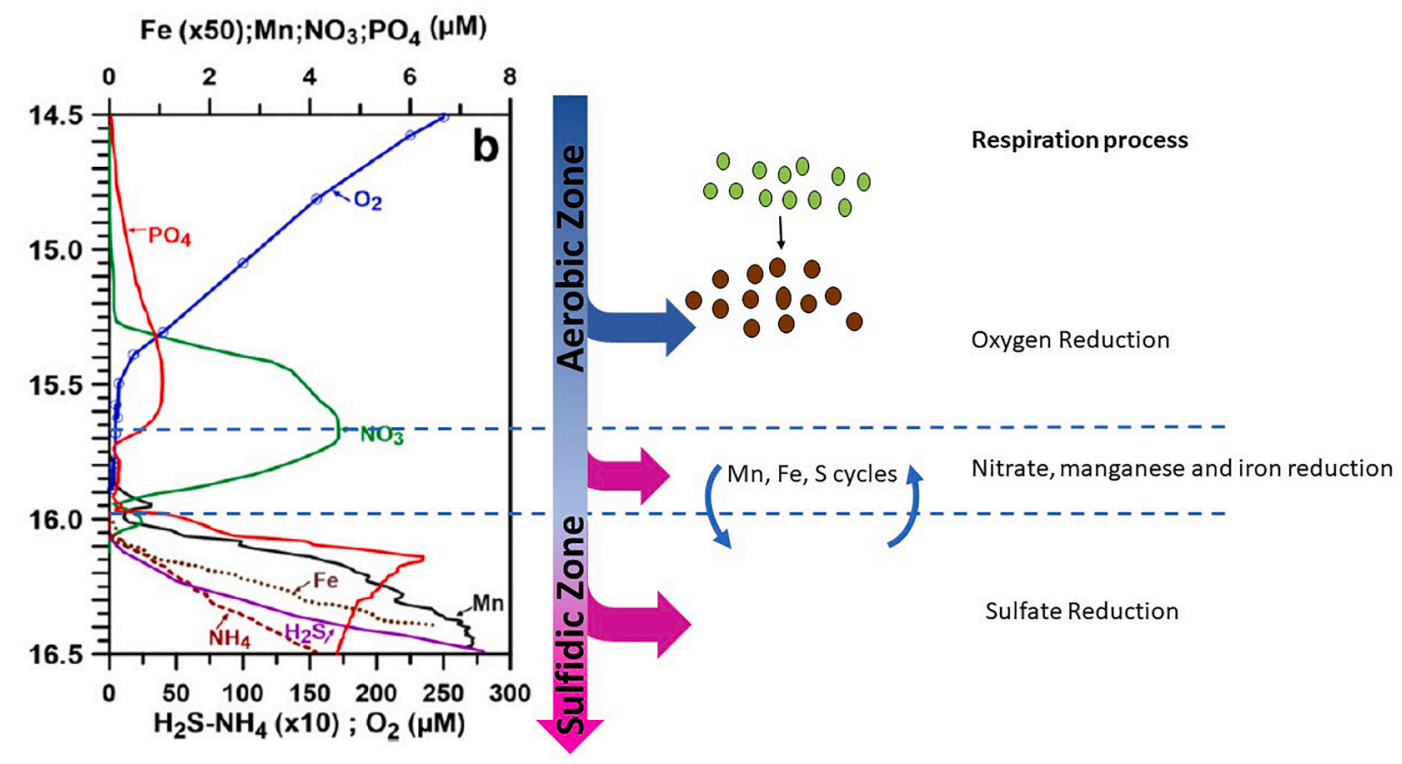

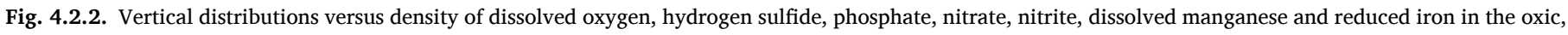

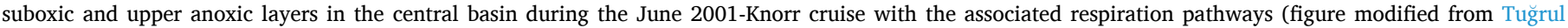
et al., 2014).

variability (Konovalov and Murray, 2001). The eutrophication process that impacted the north-western shelf of the Black Sea in the late 1960s also led to an increased input of organic matter into the deep sea and consequently higher oxygen consumption. After 1996, climate warming led to a reduction in the volume of the CIL, which serves as an essential vector for ventilation.

\subsubsection{Eutrophication and reduced ventilation of the continental shelf}

In addition to the presence of the large sulfidic pool in the deep portion, the Black Sea has also been subject to seasonal bottom hypoxia on its northwestern shelf located along the Romanian and Ukrainian coasts. In the late 1960s and early 1970s, urban expansion and agricultural and industrial development increased the nitrogen and phosphorus loads onto the shelf of the Black Sea to the extent that the ratio of inorganic nitrogen runoff of $6-8 \times 10^{5} \mathrm{t} \mathrm{N} \mathrm{yr}^{-1}$ to the shelf area $(\sim 80$ $000 \mathrm{~km}^{2}$ ) was significantly higher than that usually observed in the global ocean coastal zone (e.g., Wollast, 1998). This massive increase in nutrients resulted in the eutrophication of shelf waters and the development of large phytoplankton blooms that contributed to a significant increase in the accumulation of organic matter in the sediments. Further, the development of an anticyclonic current during the summer transports waters discharged from the Danube over the shelf to the north of the river mouth. These waters only leave the shelf in the northwestern region of the Black Sea, thereby significantly extending the area of high productivity. During the summer the water column is strongly stratified by the formation of a seasonal thermocline that combines with the halocline associated with the river plume. This strong stratification prevents the ventilation of bottom waters and the concurrent consumption of large amounts of oxygen with the degradation of bottom detritus leads to large areas of hypoxia on the shelf. Mee (2006) estimated that the resulting dead zone extended over a surface area of 40 $000 \mathrm{~km}^{2}$ at its extreme in the 1990s, which represents more than half of the shelf surface area. The occurrence of these hypoxic zones is thought to have killed thousands of tons of fish and benthos (Mee, 2006).

In the 1990s, nutrient runoff dropped off sharply due to a slow-down in agricultural and industrial activities following the collapse of the communist regime in Eastern Europe. Although it was argued by some that the shelf of the Black Sea had subsequently recovered from bottom hypoxia following the reduction in nutrient input, Capet et al. (2013) showed that bottom hypoxia was still prevalent during summer on the northern shelf and this finding has been corroborated by Ukrainian data sets. The cause of the prolonged hypoxia is considered to be the continued consumption of large quantities of oxygen due to the remineralization of organic matter accumulated over a number of years. This "sediment inertia" has been identified as a factor in delaying the reduction in hypoxia from reduced nutrient inputs and complicates prediction of the time required for ecological restoration of the system. For the Black Sea, the restoration period is expected to be extended by $\sim 9$ years due to the buildup of organic material during the period of eutrophication (Capet et al., 2013).

Since the mid-90s, coupled physical-biogeochemical models have been developed and used to understand the biogeochemical structure and cycling of the Black Sea. The modeling has focused on the oxygen dynamics at seasonal and interannual scales in order to establish whether the oxygen budget is balanced or has been disrupted by eutrophication and climate warming. Yakushev and Neretin (1997) initiated the building of a one dimensional chemical model of the transition zone between the oxygenated and anoxic zone describing the oxygen, nitrogen and sulfur cycles. This model was the precursor to the Redox-Layer Model (ROLM) that has been applied in the Black Sea and in various other oxygen deficient environments such as the Baltic and Arabian Seas (e.g., Yakushev et al., 2007). In particular, ROLM has been used by Stanev et al. (2014) for investigating the impact of lateral mixing processes on the dynamics of the redox layer. The first verticallyresolved planktonic model describing primary production, export and degradation was developed by Oguz et al. (2000) by coupling oxygen and nitrogen dynamics with a simplified representation of the manganese and sulfur cycle. This model was extended by Oguz et al. (2001) and Oguz (2002) to include representation of gelatinous carnivores and fish dynamics. Konovalov et al. (2006) investigated the importance of the lateral injection of oxygen from the Bosporus Strait using a onedimensional model that represented the lateral transport of oxygen. In a three-dimensional framework, Grégoire et al. (1997) developed the first coupled hydrodynamic-biogeochemical model of the Black Sea with a simple Fasham-type model that was extended by Grégoire and Lacroix (2001) to include oxygen. This model was refined by Grégoire et al. $(2008,2010)$ to give rise to the Biogeochemical Model for Hypoxic and Benthic Influenced areas (BAMHBI), which is the only Black Sea model that fully and explicitly simulates biogeochemical processes in the deep anoxic waters down to the sediments. This model has been extended by 
Capet et al. (2016b) to include representation of the sediments and is currently used in an operational mode in the European Copernicus Marine Environment Monitoring Service (CMEMS, http://marine. copernicus.eu/) delivering 10-day forecasts and 25-year reanalyses.

\subsection{Sea of Japan}

\subsubsection{System description and drivers of deoxygenation}

The Sea of Japan is a semi-enclosed marginal sea between the Japanese archipelago, the Korean Peninsula and the Eurasian Continent (Fig. 4.3.1). The seafloor bathymetry incorporates shallows in straits $(<130 \mathrm{~m})$ and deep areas in basins $(>3500 \mathrm{~m})$, such as in the Japan and Yamato Basins. Adjacent marine waters are connected to the sea through the shallow straits. The connections to the Sea of Japan include the East China Sea through the Tsushima Strait (sill depth $130 \mathrm{~m}$ ), the Pacific Ocean through the Tsugaru Strait (sill depth $130 \mathrm{~m}$ ), and the Okhotsk Sea through the Mamiya (sill depth $12 \mathrm{~m}$ ) and Soya Straits (sill depth $55 \mathrm{~m}$ ) (Itaki, 2016). The Tsushima Warm Current from the East China Sea flows in through the Tsushima Strait, and is the major seawater influx to the Sea of Japan (Talley et al., 2006). As the Tsushima Warm Current flows towards the polar front, it cools down and sinks to form a homogenous layer called the Japan Sea Proper or Deep Water (Minoura et al., 2012). This unique process of deep-water formation drives the circulation and presently sustains high oxygen levels in the Sea of Japan.

However, although the Sea of Japan is now classified as a welloxygenated marginal sea (Talley et al., 2006), it presents an interesting history of deoxygenation. Due to its semi-enclosed setting and shallow sill depths $(\sim 130 \mathrm{~m})$, the Sea of Japan is highly sensitive to sea level changes and activities of inflow from adjacent waters (Gallagher et al., 2015). As the sea level dropped during glacial periods (maximum $130 \mathrm{~m}$ ), the Sea of Japan was gradually isolated from adjacent oceans. When sea level drop exceeded $90 \mathrm{~m}$, sea circulation was notably altered in the absence of inflow from the Tsushima Warm Current. Consequently, the Sea of Japan received relatively higher inputs of freshwater from precipitation and river runoff leading to strong ocean stratification (Watanabe et al., 2007). This led to deoxygenation occurring in almost the entire deep-sea basin (Tada et al., 1999; Kido et al., 2007; Tada et al., 2015; Watanabe et al., 2007).

These oxygen dynamics of the Sea of Japan are clearly recorded as centimeter- to decimeter-scale alternations of dark- and light-coloured layers in basin-wide sediment depositions during the Quaternary (Kido et al., 2007; Tada et al., 1999; Tada et al., 2015; Watanabe et al., 2007). Light-coloured layers were deposited under conditions of intense bioturbation and represent well-oxygenated periods. In contrast, thick dark-coloured sulfur-rich layers ( $\sim 20$ to $40 \mathrm{~cm}$ thick) were deposited under euxinic conditions caused by strong ocean stratification and correspond with sea level drops of $>90 \mathrm{~m}$ during glacial maxima (Kido et al., 2007; Tada et al., 1999; Watanabe et al., 2007; Tada et al., 2015).

The sea circulation and oxygen dynamics are controlled by complex mechanisms influenced by global and regional dynamics, including orbital-scale glacial-interglacial cycles, suborbital-scale climate changes, the East Asian Monsoon system, and the activities of inflows from adjacent waters. The interplay of these systems has resulted in various degrees of deoxygenation. In addition to the thick dark-colored sulfur-rich layers during glacial maxima, thinner dark layers during interstadials reflect millennial scale changes in the East China Sea coastal waters that join the Tsushima Warm Current influx (Watanabe et al., 2007). The influx of low-salinity, nutrient-rich East China Sea coastal waters also enhance stratification and surface productivity, leading to bottom water deoxygenation (Tada et al., 1999; Tada et al., 2018). These millennial scale changes in the coastal waters of the East China Sea, and consequent changes in the oxygen dynamics of the Sea of Japan, probably reflect variability in the East Asian Summer Monsoon associated with abrupt climatic changes of the suborbital Dansgaard-

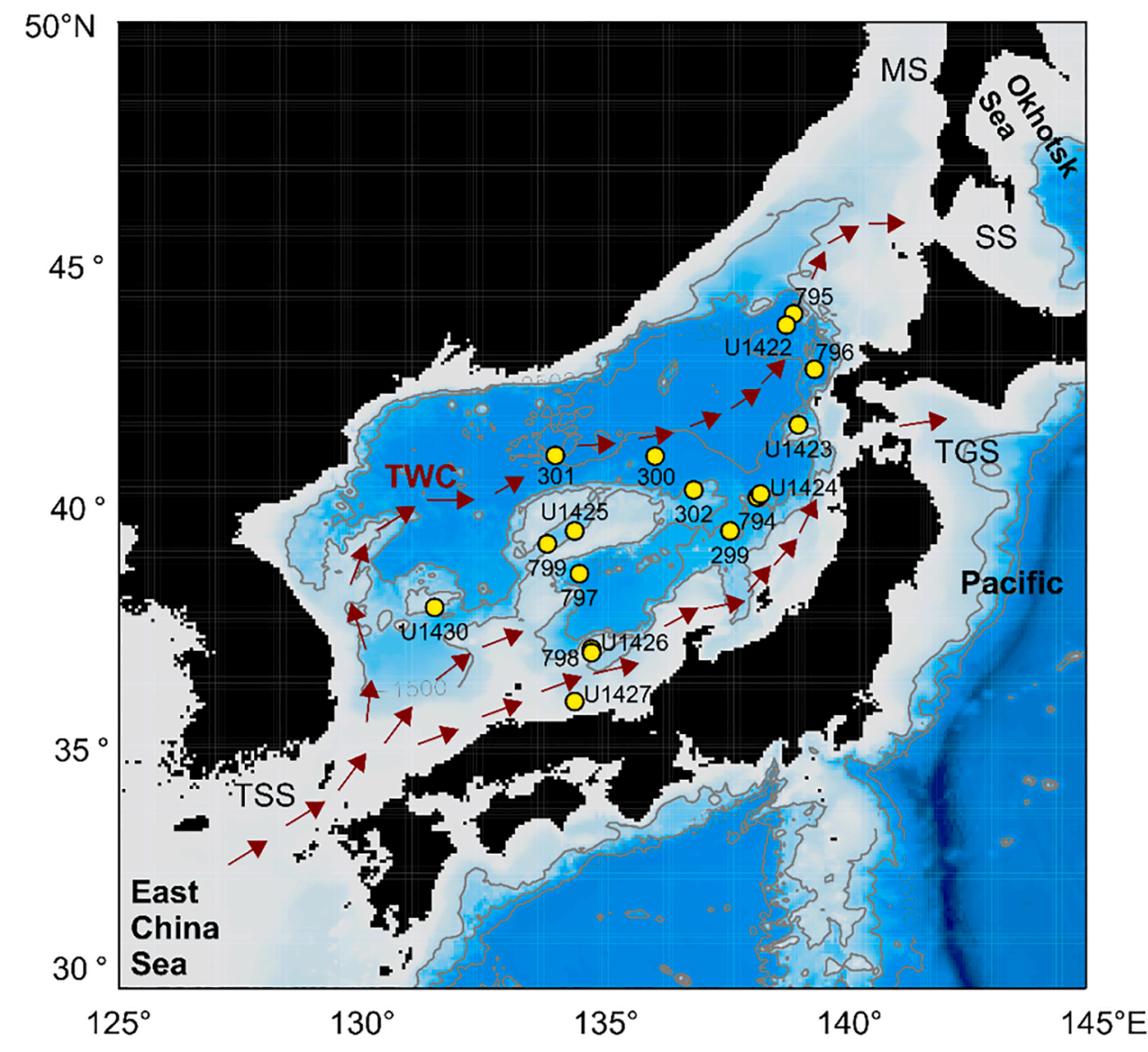

Fig. 4.3.1. A map of the Sea of Japan showing (1) the semi-enclosed nature of the marginal sea, (2) the Tsushima Warm Current (red arrows), and (3) basin-wide deep-sea drilling sites (yellow points). The deep sea drilling sites are from Deep Sea Drilling Program Leg 31, Ocean Drilling Program Leg 127 and 128, and the Integrated Ocean Discovery Program Expedition 346. Sediment cores obtained from these sites are characterised by alternations of dark- and light-coloured sediment layers. Abbreviations: TWC, Tsushima Warm Current; MS, Mamiya Strait; SS, Soya Strait; TGS, Tsugaru Strait; TSS, Tsushima Strait. The bathymetric data were downloaded from the NOAA ETOPO1 database (Amante and Eakins, 2009). The map was generated with the $R$ package "marmap" (Pante and Simon-Bouhet, 2013). (For interpretation of the references to color in this figure legend, the reader is referred to the web version of this article.) 
Oeschger Cycle (Tada et al., 1999, 2018).

\subsubsection{Biological impacts of deoxygenation on benthic fauna}

The Sea of Japan provides a natural laboratory for understanding biotic responses during cycles of deoxygenation. Recent deep-sea drillings (IODP Expedition 346) have recovered continuous high-resolution sediment cores in multiple key locations (Tada et al., 2015). Multidisciplinary studies, including sedimentology, biostratigraphy, tephrostratigraphy, magnetostratigraphy, and isotopic stratigraphy, on these cores has advanced our understanding on the regional Quaternary stratigraphy (Irino et al., 2018; Sagawa et al., 2018; Tada et al., 2018). High-resolution and high-precision stratigraphy has established a robust foundation to investigate the biological impacts of deoxygenation processes.

Microfaunal analyses on sediment cores have revealed extirpation events caused by deoxygenation (Fig. 4.3.2). In intermediate water depths, barren intervals of benthic ostracods and benthic foraminifera are found in striking synchrony with the thick dark-layer events (Gallagher et al., 2018; Huang et al., 2018a). These extirpation events were documented during glacial maxima (i.e., sea level minima) in Marine Isotopic Stages 2, 6, 10, 12 and 16, immediately before ice age terminations I, II, IV, V and VII (Huang et al., 2018a). In deeper waters $(>900 \mathrm{~m}$ ), the abundance and diversity of ostracods are lower than in the intermediate water depths. Nevertheless, statistical analyses also show that oxygen variability was important in controlling deeper-water faunal changes (Huang et al., 2018b; Yamaguchi et al., 2017). Other major taxonomic groups, such as the foraminifera and radiolarians, show consistent patterns in that the anoxic conditions resulted in their absence from the deep-sea fauna (Gallagher et al., 2018; Itaki et al., 2004).

Orbital-scale ostracod records from Marine Isotopic Stages 1 to 17 showed oxygen-driven patterns of extirpation and succession in the deep-sea benthic faunal community (Fig. 4.3.2; Huang et al., 2018a). The non-barren intervals between glacial extirpation events were characterized by alternating dominance of low-oxygen tolerant taxa (e.g., Krithe sawanensis) and oxygen-demanding taxa (e.g., Cytheropteron hyalinosa) (Huang et al., 2018a). The low-oxygen tolerant taxa were dominant during hypoxic conditions before and after extirpation events (i.e., entering and exiting the thick dark-layer events) (Huang et al., 2018a) and oxygen-demanding taxa were dominant during periods of high sea level (Huang et al., 2018a).

\subsubsection{Future prospects of deoxygenation in the Sea of Japan}

The Sea of Japan provides useful insights into the deoxygenation of deep sea ecosystems, which are important and understudied systems (Thurber et al., 2014). The deoxygenation process in the Sea of Japan is

1427, water depth $330 \mathrm{~m}$ )

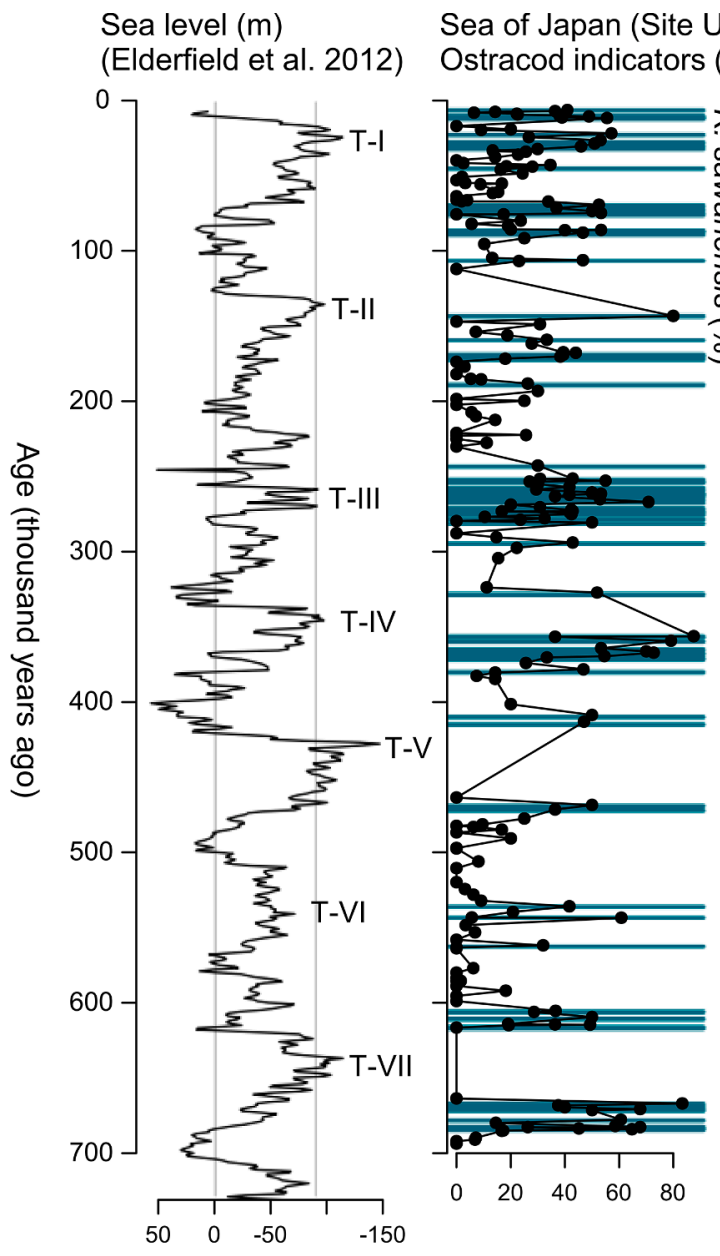

Sea level $(m)$

(E)

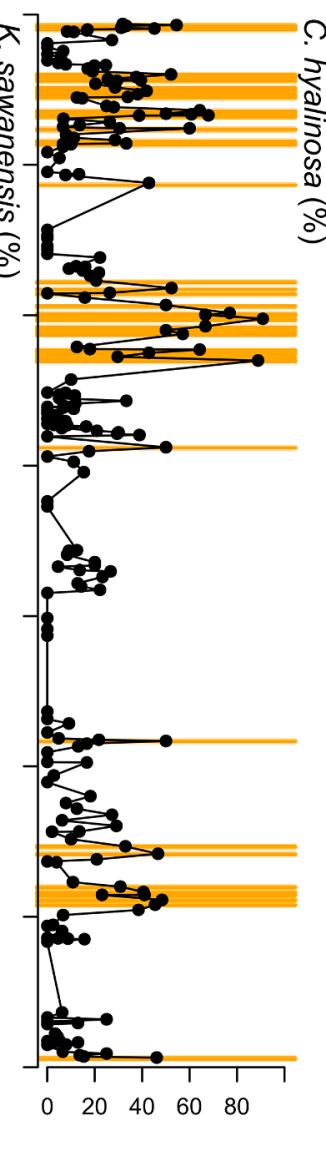

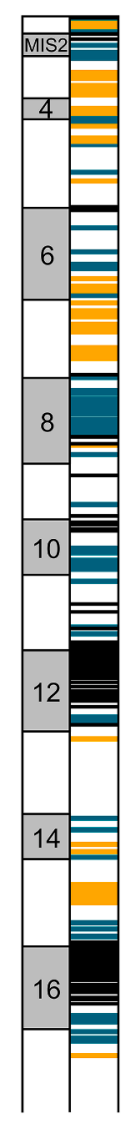

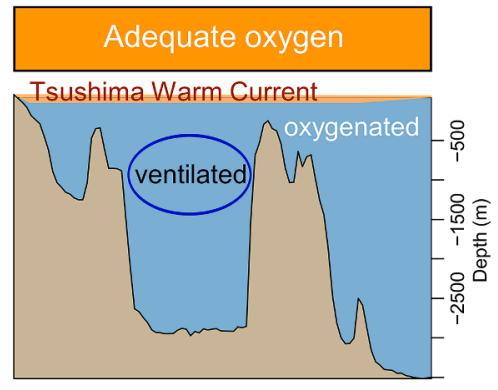

Moderate oxygen depletion

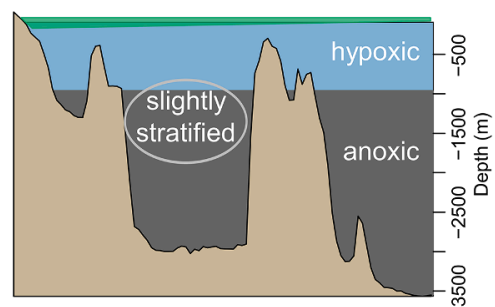

Extirpation events

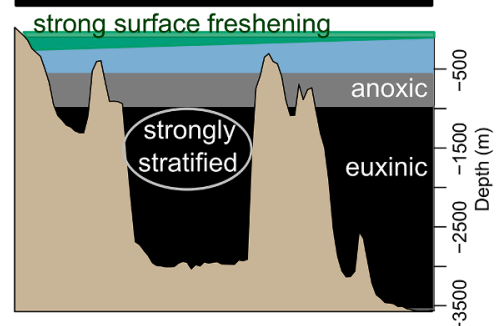

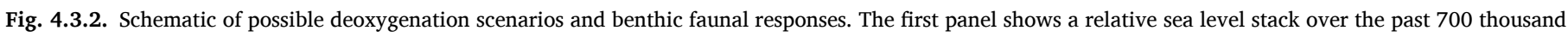

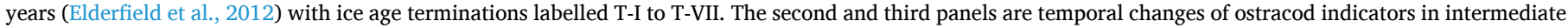

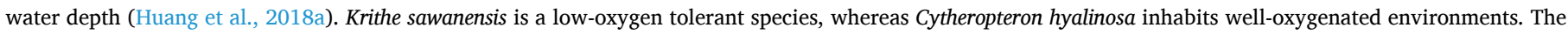

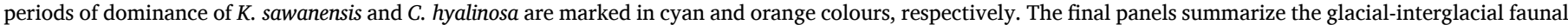

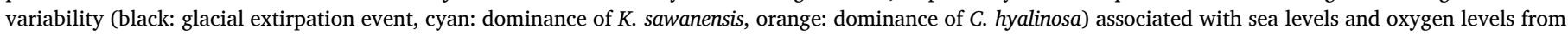

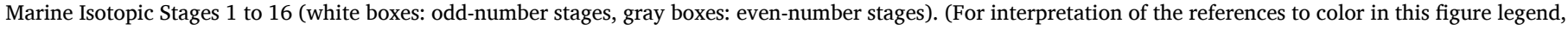
the reader is referred to the web version of this article.) 
complex and influenced by both climate change and by regional East Asian Monsoon activity. Based on continuous measurements, the bottom-water oxygen levels in the Sea of Japan have indeed declined by $>8 \%$ in the past 30 years (Gamo, 2011). Several paleoecological studies across multiple taxonomic groups have shown that marine ecosystems in intermediate and deep water are highly sensitive to oxygen variability (Gallagher et al., 2018; Huang et al., 2018a,b; Itaki et al., 2004; Yamaguchi et al., 2017) and severe deoxygenation will lead to extirpation of benthic fauna. These findings provide evidence of how potentially weakened ocean circulation in response to global warming can affect the oxygen dynamics in the Sea of Japan and other deep-sea ecosystems.

\section{Coastal zone}

The inner-shelf environment is subject to variable coastal geomorphology that serves to create areas of high susceptibility to low oxygen. Changes in coastline configuration and orientation, and changing bottom topography, strongly affect circulation and the properties of stratification and retention. These features also serve to influence inner shelf productivity, all of which impact rates of oxygen supply and consumption. Included in the spectrum of coastline configurations are headlands, capes, peninsulas, fjords, bays and estuaries, representing systems of increasing isolation from the open coast and consequently also increasing retention times. These systems are, in turn, subject to a wide range of temporal patterns in oxygen depletion associated with varying atmospheric conditions such as winds and precipitation. Coastal zone case studies presented here include Chesapeake Bay, Limfjorden Estuary in Denmark, the Changjiang and Zhujiang estuaries located in China, Tokyo and Osaka Bay of Japan, and Paracas Bay and St Helena Bay located in the Humboldt and Benguela eastern boundary upwelling systems.

\subsection{Chesapeake Bay}

\subsubsection{System description and history of deoxygenation}

Chesapeake Bay, located in the mid-Atlantic coastal region of the
United States, is the largest estuary in North America (Fig. 5.1.1). The mainstem bay is approximately $300 \mathrm{~km}$ long, $74 \mathrm{~km}^{3}$ in volume and has a 20-30 m deep but narrow (1-4 km) center N-S channel with shallow $(<10 \mathrm{~m})$ flanks to the east and west. Average depth is only $6 \mathrm{~m}$. The mainstem bay and its tidal tributaries have a surface area of approximately $11500 \mathrm{~km}^{2}$ and are bounded by almost $19000 \mathrm{~km}$ of shoreline.

Chesapeake Bay has one of the largest ratios of watershed area to surface area among estuaries worldwide (14.3:1) and a high watershed area to volume ratio (2.2:1) (www.chesapeakebay.net; Kemp et al., 2005). The water quality of the estuary is therefore particularly sensitive to land-based activities. The approximate $165000 \mathrm{~km}^{2}$ watershed is $65 \%$ forested, $24 \%$ agriculture and $11 \%$ developed land (Shenk and Linker, 2013), includes the urban areas of Washington, DC and Baltimore, and is home to $>18$ million people. The $1949-2000$ average water temperature ranged from $2.5^{\circ} \mathrm{C}$ in February to $26^{\circ} \mathrm{C}$ in August in the central channel of the mesohaline mainstem bay (Cronin et al., 2003). Surface water temperature can vary seasonally from 0 to $30^{\circ} \mathrm{C}$ or more in some shallow parts of the system; a long-term record near Solomons, $\mathrm{MD}$, indicates that annual average surface water temperatures increased by about $1.5^{\circ} \mathrm{C}$ between 1940 and 2005 (Najjar et al., 2010).

On average, Chesapeake Bay receives $2300 \mathrm{~m}^{3} \mathrm{~s}^{-1}$ of freshwater flow of which $>50 \%$ is from the Susquehanna River (Schubel and Pritchard, 1986). In addition, 8 major tributaries, and numerous smaller tributaries provide freshwater inflow laterally along the entire length. This freshwater input drives a gravitational estuarine circulation (Pritchard, 1956, 1967) with a buoyant surface net seaward flow and a denser lower-layer counter flow toward the head of the estuary. This 2layer circulation results in residence times of 90 to 180 days for freshwater and nutrients. The density stratification in the central channel, combined with relatively long residence times, promotes oxygen depletion in the deep waters of the Bay during the summer (Boicourt, 1992). In recent years (2014-2018), the maximum hypoxic volume (DO $<2.0 \mathrm{mg}^{-1}$ ) ranged from 7.1 to $10.8 \mathrm{~km}^{3}$, or about $10-16 \%$ of the total bay volume (VIMS, 2018).

The spatial and temporal extent of deoxygenation in the bottom waters of Chesapeake Bay increased dramatically during the 20th century due to cultural eutrophication (e.g., Kemp et al., 2005); however,

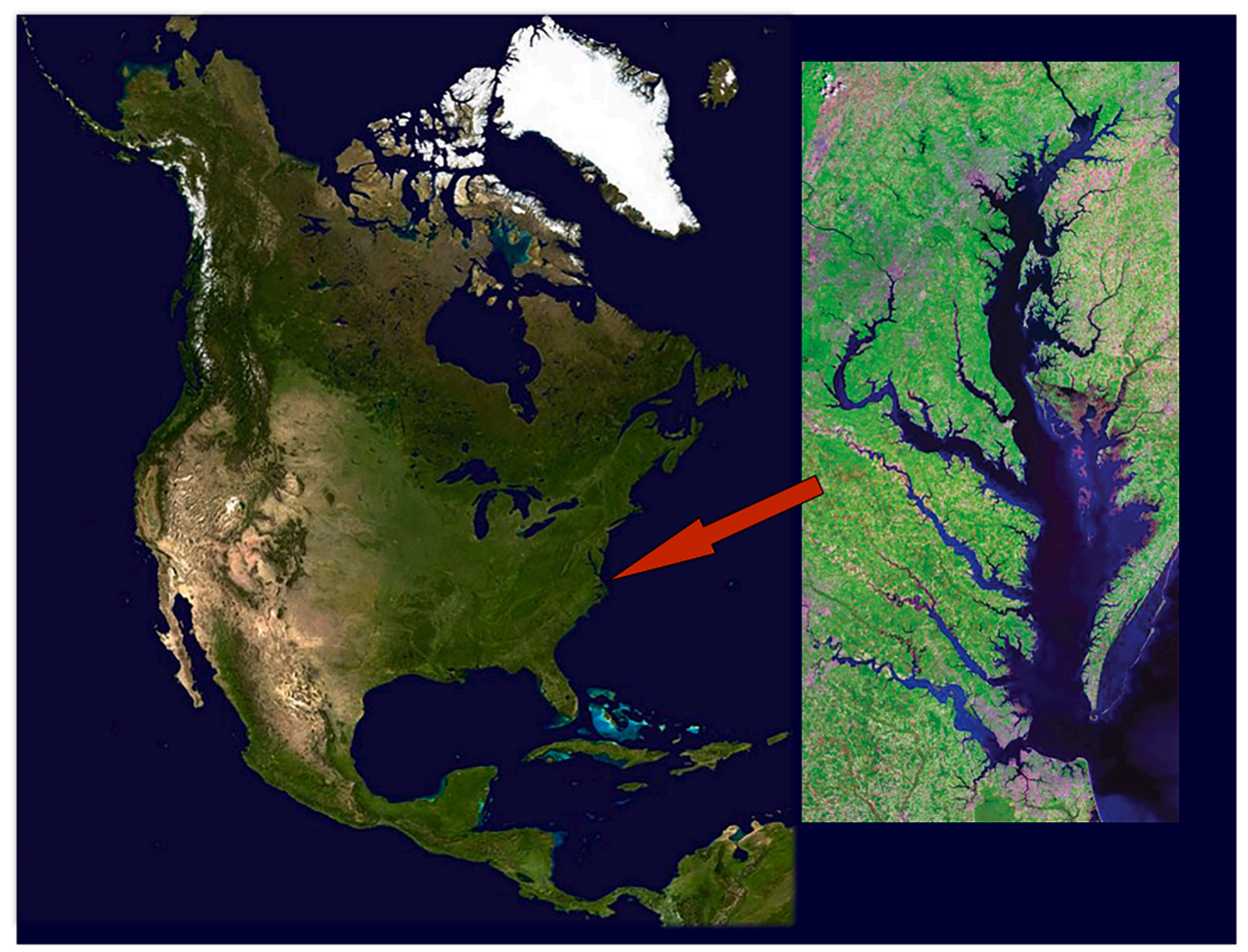

Fig. 5.1.1. Map showing location of Chesapeake Bay in North America. 
the geometry and circulation of the Bay naturally facilitate oxygen depletion in bottom waters. Microfossil and geochemical proxies from sediment cores in the mainstem Bay and tributaries show evidence of hypoxia estimated at between 0.5 and $2 \mathrm{ml} \mathrm{l}^{-1}$ over $2000 \mathrm{yr} \mathrm{BP}$, followed by greater deoxygenation with extensive land clearing in the watershed from 1700 to 1900 (Cooper and Brush, 1991; Willard et al., 2003; Cronin and Vann, 2003; Fig. 5.1.2a). The degree of pyritization of iron beginning around 1940 indicates that sediment in parts of the mainstem bay were deposited in low oxygen or anaerobic conditions (Cooper and Brush, 1993); a timeframe also supported by an abrupt change in sulphur speciation (Zimmerman and Canuel, 2000). Direct measurements of bottom water low oxygen were first reported in 1917 in the lower Potomac River (Sale and Skinner, 1917) and in 1938 in the center deep channel of Chesapeake Bay (Newcombe and Horne, 1938). Since these early observations, more regular monitoring programs have allowed investigators to assess the physical and biogeochemical controls of low oxygen waters in Chesapeake Bay.

\subsubsection{Causes and controls of deoxygenation}

Sub-pycnocline waters in the central deep region of Chesapeake Bay exhibit an annual cycle of maximum dissolved oxygen concentration in the winter and minimum during the summer (e.g., Taft et al., 1980; Malone et al., 1996; Fig. 5.1.2b). The decrease in bottom water oxygen begins in spring with stratification and reverses in fall with seasonal cooling of surface water and increased wind-induced mixing. The decrease in bottom water oxygen begins at the northern limit of the

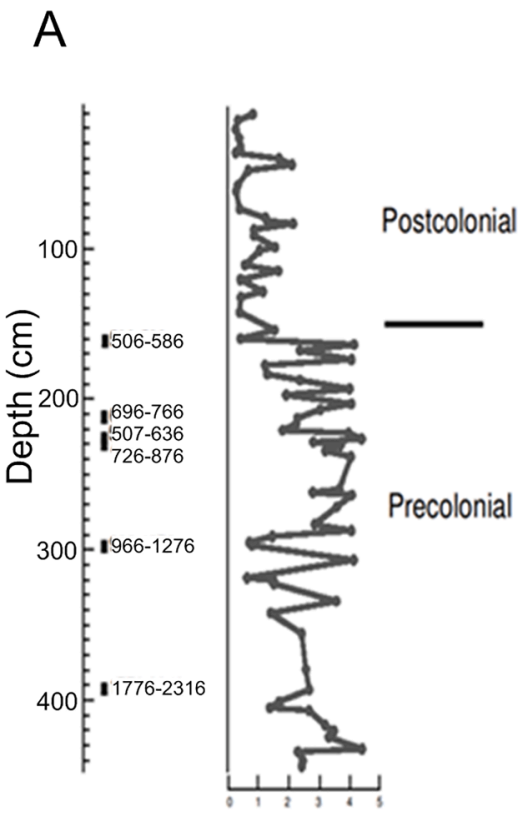

Dissolved oxygen $\mathrm{ml} \mathrm{l}^{-1}$
C

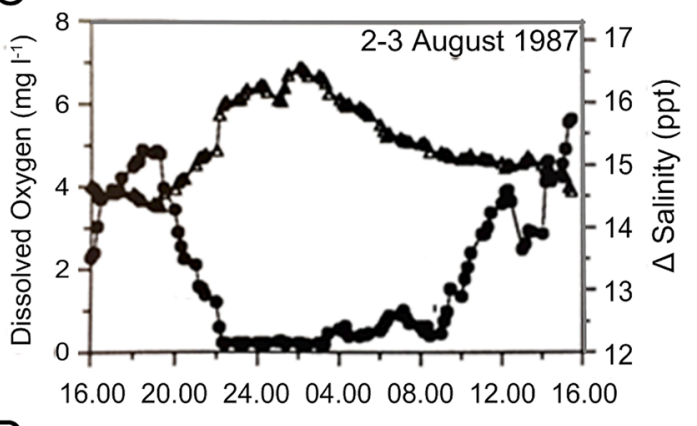

D

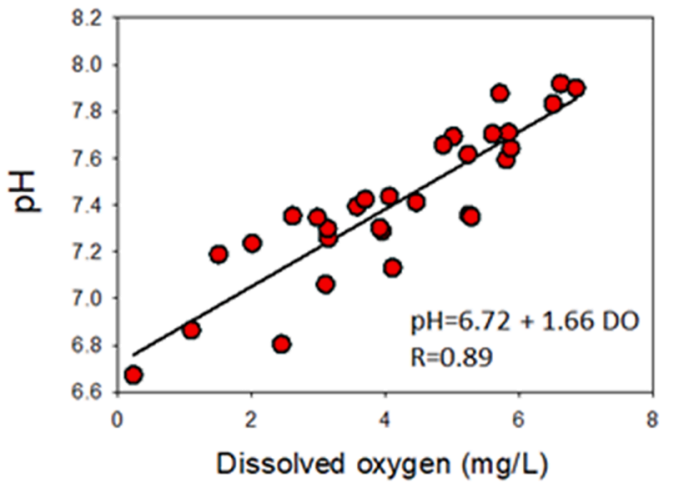

Fig. 5.1.2. Patterns of low dissolved oxygen in Chesapeake Bay. A. Estimated minimum dissolved oxygen based on dinocyst fossils in the mainstem bay near the mouth of the Potomac River. Note the occurrence of hypoxia prior to European colonization of the Chesapeake region (modified from Willard et al., 2003). B. Seasonal and spatial patterns of hypoxia and anoxia in Chesapeake Bay. Left map shows bottom dissolved oxygen during summer 2005. Right shows monthly vertical profiles along the long axis of the bay (mouth of the bay is to the right in each image). (Source: www1.udel.edu, downloaded 24 May 2018). C. Intrusion of low oxygen, higher salinity water onto a 4-m deep nearshore oyster reef along the western shore of Chesapeake Bay. Although these upwelling events are short-lived, they result in intense local mortality of both benthic and pelagic species (modified from Breitburg, 1990). D. Mean minimum July-August dissolved oxygen and $\mathrm{pH}$ from 28 shallow water sites in Chesapeake Bay. The correlation between $\mathrm{pH}$ and dissolved oxygen indicates that the pattern is driven by respiration (modified from Miller et al., 2016).

B

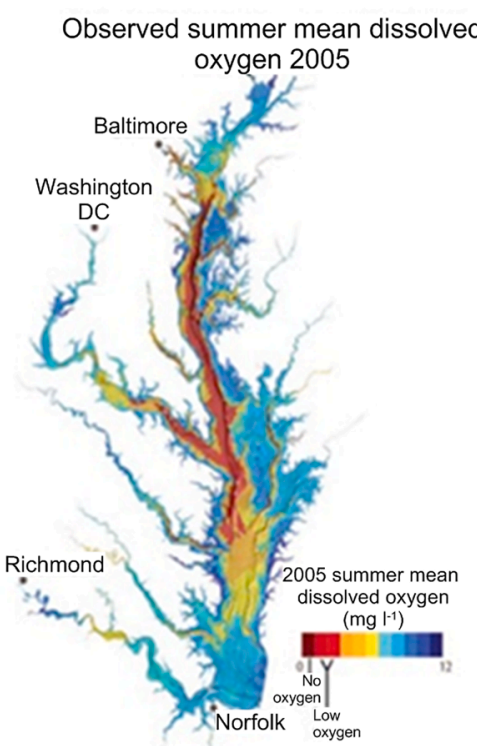

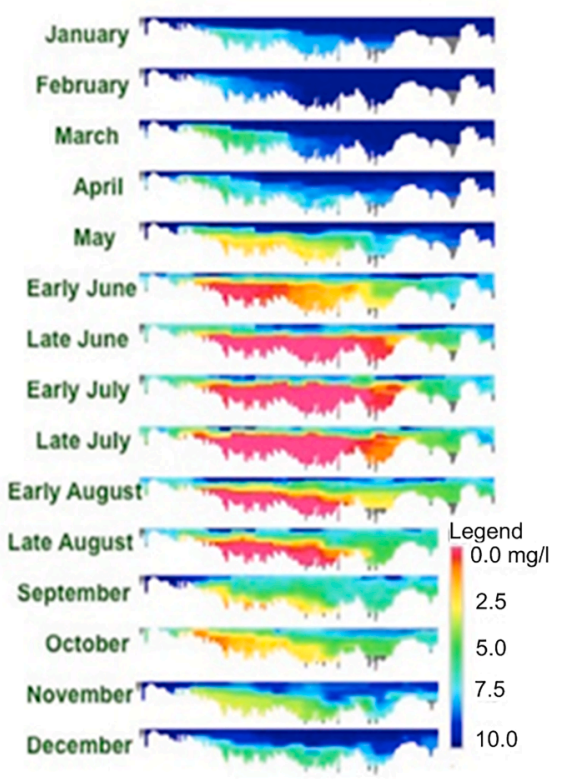


stratified flow and expands southward over the summer. Methane concentrations of $40 \mu \mathrm{mol}$ have been measured in near-bottom anoxic water of the central channel of the mesohaline mainstem bay (Gelesh et al., 2016).

Annual differences in freshwater input control the strength, spatial and temporal extent of density stratification in Chesapeake Bay and the extent of hypoxia by isolating bottom waters from the atmosphere. Thus, early analyses of the proximate causes of inter annual variations in bottom water deoxygenation suggested that inter-annual variations in the major source of freshwater to the Bay, the Susquehanna River, during winter-spring was the best predictor of the volume of hypoxic $\left(<2 \mathrm{mg} \mathrm{l}^{-1}\right.$ ) bottom water in summer (e.g., Taft et al., 1980; Seliger and Boggs, 1988; Hagy et al., 2004). However, because freshwater input influences both nutrient delivery and stratification, longer-term observations and analyses have been necessary to assess the relative importance of these two factors in controlling bottom water low oxygen in Chesapeake Bay. These more extensive analyses have shown that increases in the severity and extent of summer bottom water deoxygenation could not be explained solely by variation in freshwater inputs and the magnitude of stratification. Instead, Chesapeake Bay-wide increased volumes of low oxygen waters were also related to nutrient inputs, consistent with cultural eutrophication in other coastal systems (e.g., Kemp et al., 2005; Murphy et al., 2011; Testa and Kemp, 2014; Li et al., 2016; Testa et al., 2018a,2018b). Initial springtime rates of oxygen decline have varied little since 1938 (Hagy et al., 2004). This suggests that the initial spring decline in oxygen is driven by stratification, while the late spring oxygen decline and the extent of summer hypoxia are more closely related to eutrophication (Hagy et al., 2004; Kemp et al., 2005; Testa et al., 2018a,2018b). Inter-annual variations in spring nutrient loading are also correlated with rates of organic deposition to sediments that increase oxygen demand (Boynton and Kemp, 2000). Analysis of the monitoring data from 1985 to 2013 have shown that flow-corrected nitrogen loads and bottom water ammonium concentration have been reduced in Chesapeake Bay and that anoxia and latesummer low-oxygen in bottom waters have declined somewhat (Li et al., 2016; Testa et al., 2018a,2018b).

Prevailing wind speed and direction can influence the supply of oxygen to Chesapeake Bay bottom waters. Southerly winds enhance oxygen supply to bottom waters whereas westerly winds can lower oxygen supply to bottom waters (Scully, 2010a). Longer-term changes in bottom water oxygen concentration could result from large-scale climate patterns (i.e., NAO) that influence these local wind conditions (Scully, 2010b). Short-term erosion of the pycnocline and reaeration of low oxygen bottom waters can occur as a result of sub-tropical storms and hurricanes, but the gravitational circulation of the Bay rapidly (days) reestablishes stratification leading to the re-development of hypoxic bottom waters (Roman et al., 2005).

In addition to the dominant signal of seasonally persistent bottomlayer hypoxia and anoxia in the mainstem Bay, the diverse bathymetry of Chesapeake Bay is reflected in a wide range of other temporal and spatial patterns of hypoxia.These other patterns of hypoxia include episodically interrupted seasonal hypoxia, wind and tide-driven upwelling that advects hypoxia into shallow waters, and diel and tidalcycling low oxygen. Wind- and tide-forced oscillations of the pycnocline advect oxygen-depleted sub-pycnocline water towards shore in the mainstem Chesapeake Bay and into the mouths of some of its tributaries (Sanford et al., 1990; Breitburg, 1990; Fig. 5.1.2c). In the mesohaline mainstem Bay, for example, persistent winds blowing northward for several days can result in upwelling that advects oxygen-depleted water onto shallow nearshore oyster reefs on the western flanks of the Bay. Dissolved oxygen concentrations $<0.5 \mathrm{mgl}^{-1}$ have been reported in 2-4 m water depths (Breitburg, 1990). Dissolved oxygen concentrations in the surface layer water, both along the exposed mainstem Bay (Breitburg et al., 2009) and in shallow creeks and sub-estuaries (Breitburg et al., 2015; MD-DNR 2019), also fluctuate on diel cycles and with tides, as a result of variation in the balance between oxygen production through photosynthesis and oxygen consumption through aerobic respiration. Fluctuations in $\mathrm{pH}$ accompany these oxygen fluctuations and the severity of hypoxia and acidification are highly correlated both among (Fig. 5.1.2d, Miller et al., 2016) and within (Breitburg et al., 2015) sites. There is large variation among sites in the amplitude of the cycle, even within a single small tributary.

\subsubsection{Three-dimensional modeling}

The Chesapeake Bay has been the subject of decades of intensive water quality modeling by a variety of investigators (Testa et al., 2017). The various models have been designed and used to assess the causes (including physical versus biological) of hypoxia and to guide management actions about the responses of hypoxia to changes in nutrient loadings from the rivers. Examples of these analyses are highlighted that provide evidence of physical versus biological controls on hypoxia and projections on the effects of management actions under an expected future climate.

The relative role of physical versus biological controls of hypoxia is fundamental to effective management and restoration. Management actions in Chesapeake Bay are designed to reduce nutrient and sediment loadings from the watershed (NRC 2011; Lefcheck et al., 2018), which targets eutrophication and biological controls (biological productivity). The restoration plan of reducing nutrient and sediment loadings is a multi-decadal plan (Aiken, 2017) and therefore assessing the effectiveness of the reductions into the future is needed to ensure the restoration is viable and sustainable.

Modeling has shown the importance of both physical controls and biological controls, and the mix of results suggests that both play important roles in controlling summertime hypoxia in the Chesapeake Bay. Scully (2016) used a 3-D hydrodynamic model coupled to a simple oxygen model and showed a strong influence of summer winds on hypoxia for 1984-2013, with river discharge and nitrogen loading also being correlated to summer time hypoxia volume. Challenges in separating the effects of river flow (physical) and nutrient loadings (biological) were evident because of their dependency. Using a budget modeling approach, Du and Shen (2015) showed that when biological controls were removed, there was good agreement between predicted and observed bottom oxygen over 1985-2012, with oxygen being correlated with the magnitude of the vertical exchange time (VET). VET was estimated using 3-D tracer modeling and the concept of water age; VET is the elapsed time since the water parcel was last in contact with the surface. The degree of biological control in the Du and Shen analysis was indexed by the oxygen consumption rate and was correlated with chlorophyll-a concentrations (both spatially and temporally), thereby linking biological controls to the subsequent decline in bottom oxygen as the production decays. Both of these analyses focused on physical controls and demonstrated their importance in affecting hypoxia.

In contrast, Li et al. (2016) used the Regional Ocean Modeling System (ROMS) hydrodynamic model coupled to the Rossby Center Atmospheric (RCA) water quality model and determined that biological controls played a dominant role in affecting summertime hypoxia in the Chesapeake Bay. They quantified the effects on oxygen of longitudinal and vertical advective fluxes, horizontal and vertical diffusive fluxes, water column biogeochemical uptake (including algal and microbial respiration) and sediment oxygen demand. They developed an oxygen budget with these terms for the year 2000 and then used the multi-year simulation (1996-2005) to assess the relative role of these different physical and biological factors in influencing interannual variability in hypoxic volume. When examined within the year, the physical terms were mostly positive (i.e., caused an increase in oxygen), while the water column biogeochemical uptake was the largest sink term of oxygen. Over the 10-year simulation, water column biogeochemical uptake had the highest correlation with bottom oxygen and was also correlated to nutrient loadings and primary productivity.

Irby et al. (2018) used a ROMS 3-D hydrodynamic model coupled to a relatively simple water quality model (Estuarine-Carbon- 
Biogeochemistry, ECB) to assess the effects of nutrient reductions under a future climate. The model represents single phytoplankton and zooplankton groups and one limiting nutrient (nitrogen). They compared the most recent nutrient reduction targets $(38-45 \%$ reductions) for the Chesapeake Bay imposed for 1993-1995 and then the same 1993-1995 simulation but under climate conditions expected for 2050. Future climate for 2050 was warmer, had higher sea level and had changed monthly river flows that affected nutrient delivery to the Bay. The warming effect was imposed by increasing water temperatures by $1.75^{\circ} \mathrm{C}$ throughout the Bay that then affected biogeochemical processes and oxygen solubility. Sea level effects were imposed by adding $0.5 \mathrm{~m}$ to the free-water surface layer at the outer boundary of the model grid along the continental shelf. River flows were altered by multiplying monthly flows by $\sim 1.16 \mathrm{x}$ for January, February, and December, by $1.093 \mathrm{x}$ for November, and by 0.96 to $1.035 \mathrm{x}$ for the remaining months. The three years were simulated under baseline, baseline plus all climate change factors (temperature, sea level, precipitation), and with the nutrient reductions plus temperature, sea level, and precipitation imposed individually and all together.

The modeling results of Irby et al. (2018) showed that, overall, nutrient reductions had a larger effect on oxygen then the effects of climate change included in the model scenarios; however, climate change did reduce some of the gains in oxygen that resulted from the reductions in nutrient loadings. Climate change was predicted to result in an earlier onset of hypoxia by about 7 days and an increase in the cumulative hypoxic volume $\left(\mathrm{km}^{3} \times\right.$ days) with dissolved oxygen concentrations between 2.0 and $5.0 \mathrm{mg} \mathrm{l}^{-1}$. Climate change (all three effects) did not exacerbate the volume of hypoxia in the main hypoxic zone during the summer months (dissolved oxygen was already consistently low). Temperature had the largest individual factor effect (negative) among the climate change variables evaluated, and decreased oxygen solubility accounted for a large fraction of the temperature effect. The negative effect of increased river flow (which increased stratification and nutrient delivery), and positive effect of sea level rise (which decreased residence time) on cumulative hypoxic volume were smaller than those of temperature and approximately cancelled each other out.

In summary, the mainstem hypoxia of Chesapeake Bay has been extensively studied using long-term monitoring, process-level studies and coupled hydrodynamics-water quality modeling. Data analysis and modeling suggests that stratification drives the initial spring decline in oxygen and eutrophication influences the extent of the summer hypoxia. The diverse bathymetry of Chesapeake Bay results in hypoxia on multiple scales: (1) seasonally persistent bottom-layer hypoxia in the mainstem Bay, (2) episodic seasonal patchy hypoxia, (3) shallow-water hypoxic events due to wind and tide-driven upwelling, and (4) diel and

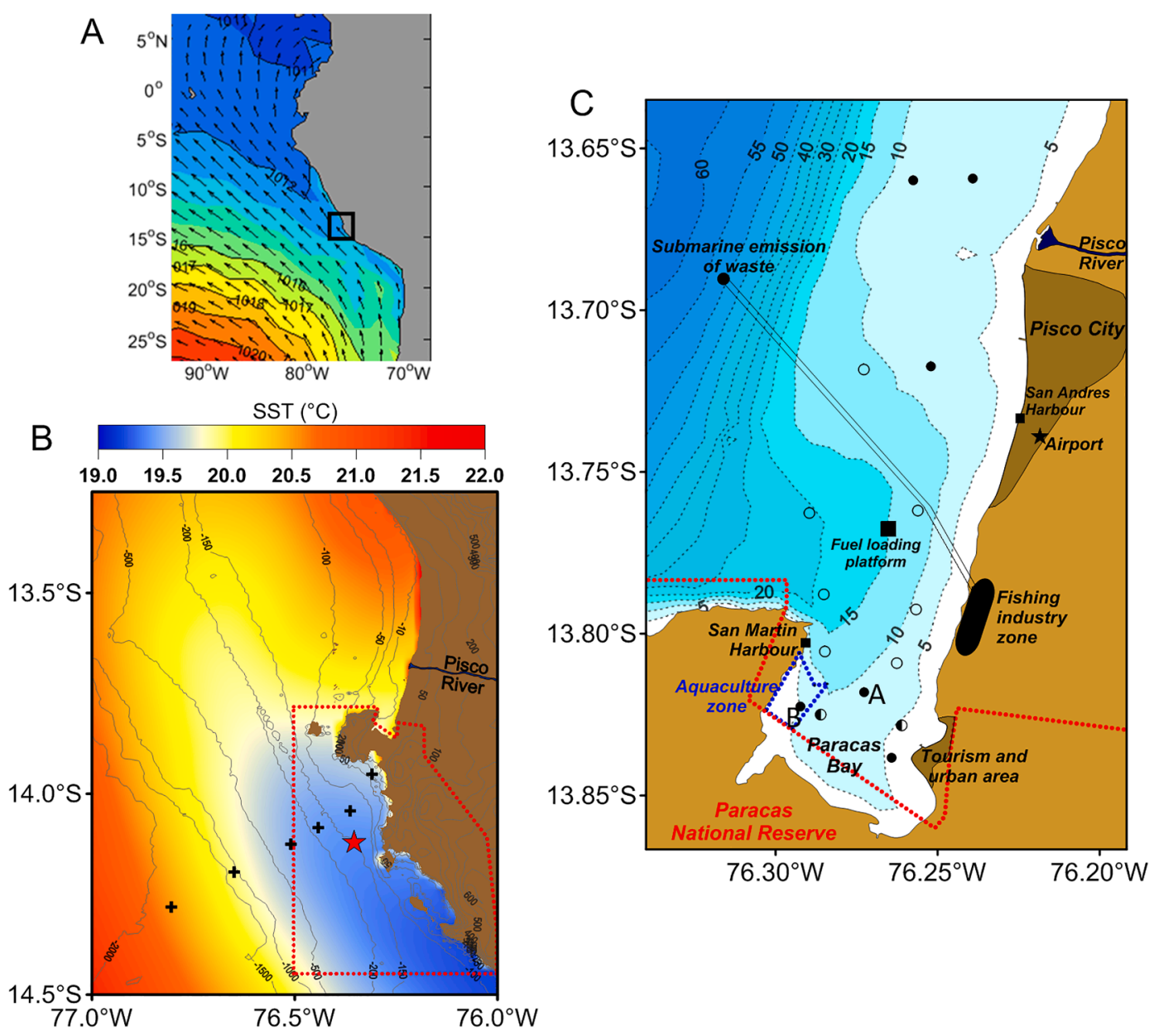

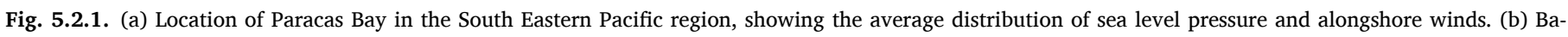

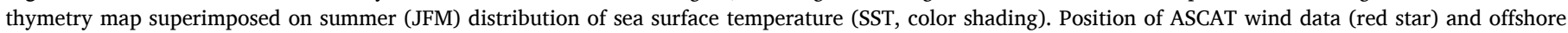

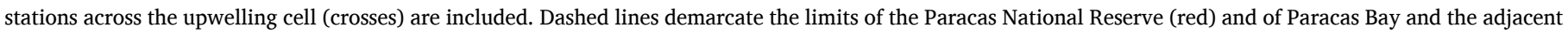

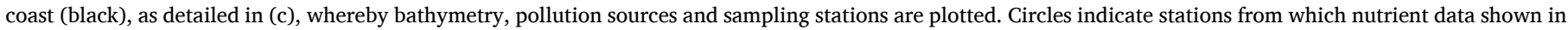

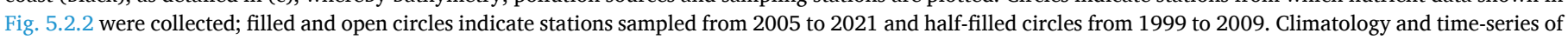

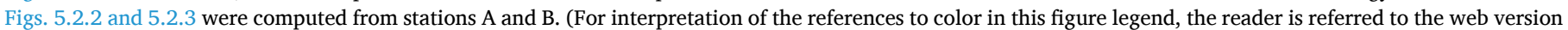
of this article.) 
tidal-scale oxygen cycling. Modeling has shown the importance of both physical controls and biological controls, and the mix of results suggest that both play important roles in controlling summertime hypoxia in the Chesapeake Bay. Explicit modeling of hypoxia under possible future conditions enabled quantification of how global climate change would affect, and partially dampen, the hypoxia response to proposed nutrient reductions. Chesapeake Bay serves as an example of extensive use of both data and modeling to inform and evaluate a large-scale restoration effort designed to reduce nutrient loadings to reduce hypoxia. Restoration efforts are continuing with a spatial approach that defines water quality goals and targets on local scale, which then leads to the development of implementation plans to achieve these goals (Batiuk et al., 2013). The large-scale of the effort has fueled ever-evolving developments and advances in coupled watershed-estuarine hydrodynamic and water quality modeling in response to new scientific issues and management needs (Hood et al., 2019).

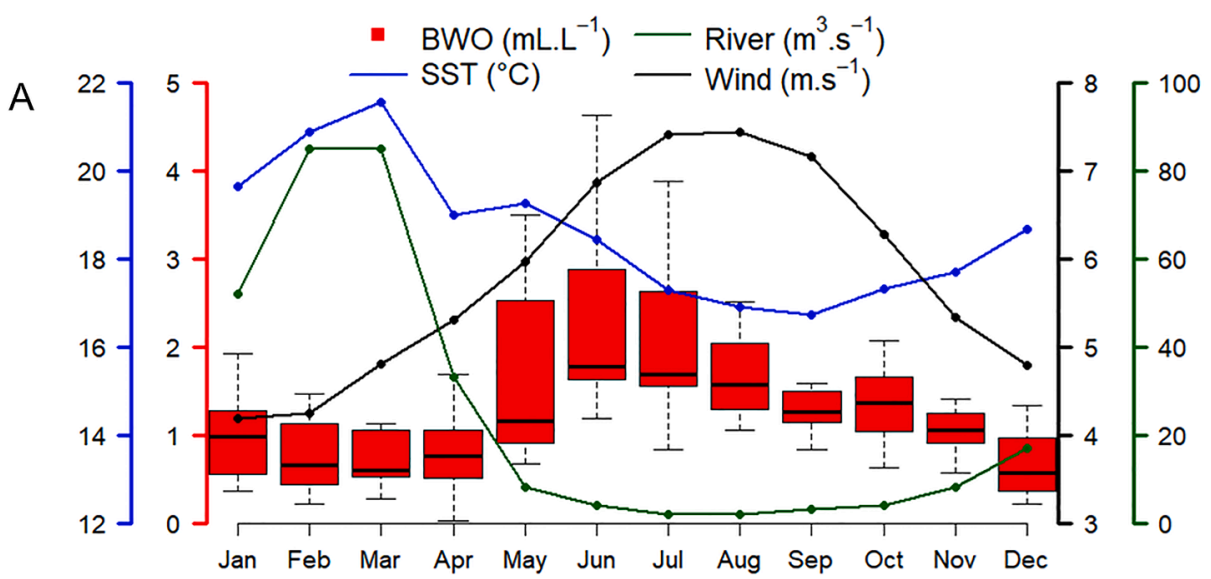

B

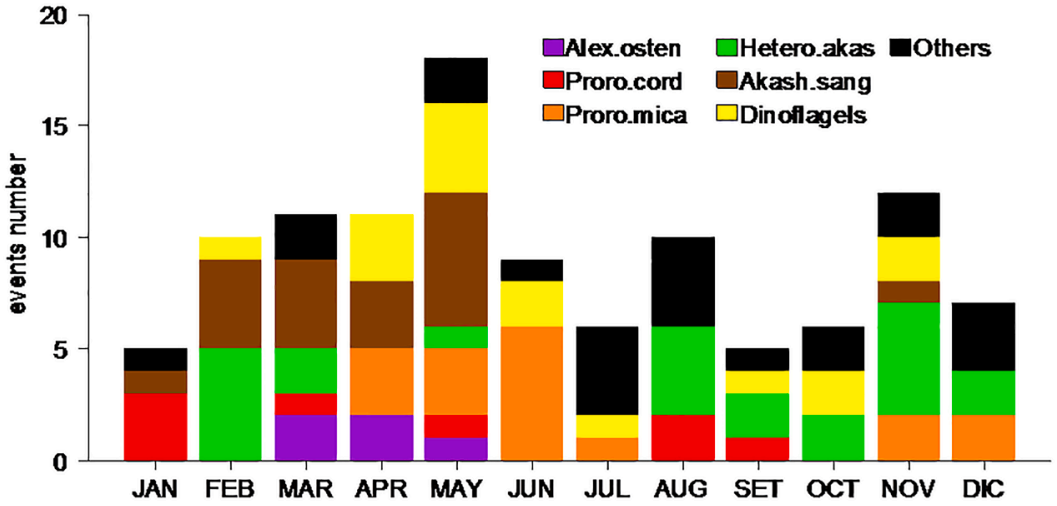

Fig. 5.2.2. (a) Annual cycles of bottom water dissolved oxygen (BWO $\mathrm{ml} \mathrm{l}^{-1}$, boxes median, quartiles and percentiles 1 and 99) and sea surface temperature (SST, mean) at bay station A, velocity $\left(\mathrm{m} \mathrm{s}^{-1}\right)$ of upwelling-favorable winds (ASCAT, see Figure 1b for position) and Pisco river discharge $\left(\mathrm{m}^{3} \mathrm{~s}^{-1}\right)$; (b) frequency of HABs recorded in Paracas Bay (2005-2017) by the species Alexandrium ostenfeldii, Heterosigma akashiwo, Prorocentrum cordatum, Akashiwo sanguinea, $P$. micans, other dinoflagellates and other species; and (c) bottom water N:P ratios in Paracas Bay (stations shown in Figure 1c), for winter (July), spring (October/November) and late summer (March), compared with ratios from water column records $(0-500 \mathrm{~m})$ at offshore stations across the upwelling cell (CRIO) during early fall (April 2005-2015); the Redfield ratio (16:1) is depicted by the black line. Data in (a) are from 2005-2015, except for ASCAT winds which are from 2006-2015.

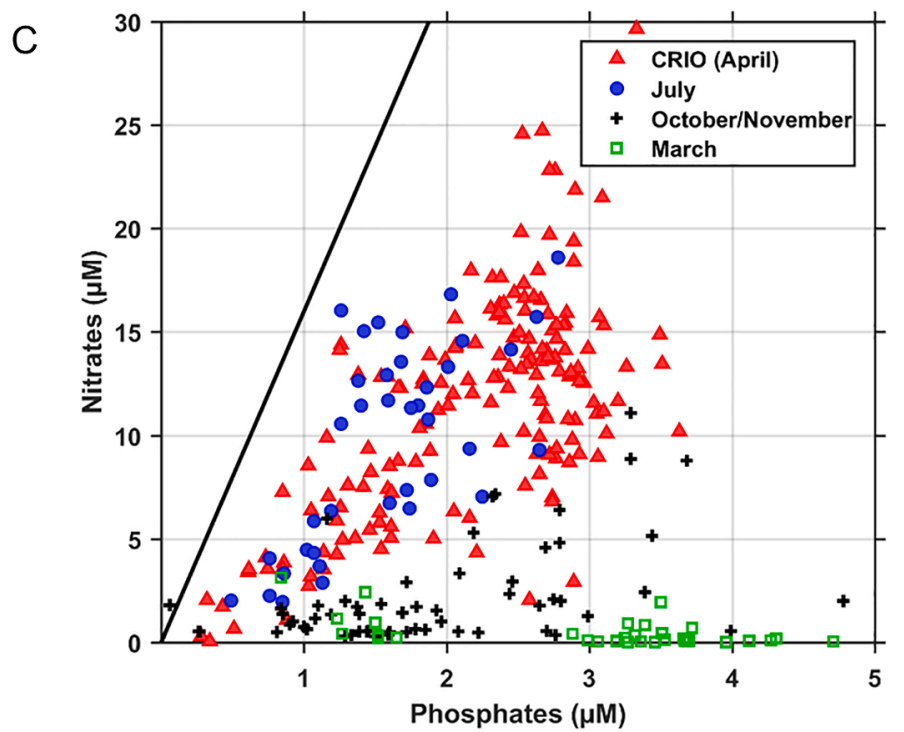




\subsection{Paracas Bay}

\subsubsection{Bay description}

Paracas Bay $\left(14^{\circ} \mathrm{S}\right)$ is a small $\left(35 \mathrm{~km}^{2}\right)$, shallow ( $<15 \mathrm{~m}$ depth) embayment located downstream of the main coastal upwelling center off Peru (Fig. 5.2.1a-c). Paracas Bay has a semi-enclosed geomorphology, partially isolated from the open waters by a peninsula on the western side of the bay, with the bay mouth oriented towards the north-east. The peninsula protects both the bay and the adjacent coast north-east of the bay from upwelling winds. The geomorphology and bathymetry result in the convergence of upwelled and inshore waters within the bay (Maldonado, 1988; Yzocupe, 2002). An upwelling shadow develops north of the bay, allowing the persistence of relatively warm temperatures (SSTs) compared to the upwelled waters off the peninsula, while the bay itself exhibits intermediate SSTs (Fig. 5.2.1b). The Pisco River discharges $15 \mathrm{~km}$ north of the mouth of the bay and its flow is highly seasonal, being low in winter and reaching its peak in summer. The seafloor exhibits a mosaic of sediment types, from fine sand to silty mud. The sedimentary organic matter and total organic carbon contents exhibit values up to nearly $16 \%$ and $6 \%$, respectively, with the highest values within the bay (Velazco and Solís, 2000).

The oceanographic regime in Paracas Bay exhibits a clear seasonal signature. During winter and early spring, when alongshore equatorward winds are prominent, the intrusion of cold upwelled waters and vertical mixing characterize the water column. In contrast, during summer and early fall, thermal stratification intensifies, coastal upwelling is reduced and freshwater input from the Pisco River increases (Cabello et al., 2002) (Fig. 5.2.2a). The topographic protection offered by the bay increases stratification of the water column when winds relax, which in turn, supports higher primary productivity in the bay particularly during summer (Gutiérrez et al., 2016). During winter, spring and early summer, diatoms dominate the phytoplankton community, with a shift in mid-summer to flagellates that persist until autumn. These flagellates may include harmful algal blooms (HABs) most often formed by Heterosigma akashiwo, Akashiwo sanguinea and Prorocentrum micans (Cabello et al., 2002; López, 2008) (Fig. 5.2.2b).

Episodes of hypoxia and the emergence of bottom anoxia occur primarily during summer and autumn (Cabello et al., 2002; AguirreVelarde et al., 2019) and correspond to conditions of low pH (Merma, 2016). In some cases, these episodes are followed by the presence of discoloured "white waters" associated with the oxidation of free sulphide to colloidal elemental sulphur (Schunk et al., 2013). These hypoxic conditions during summer-autumn trigger an intense nitrate deficit in the bottom waters, likely due to denitrification in the water column and the release of phosphate from the surface sediments (Fig. 5.2.2c).

Benthic fauna in Paracas Bay exhibit strong bathymetric zonation. For macrofauna, species richness is greatest in shallow $(<5 \mathrm{~m})$ mixed hard-soft bottoms, composed of filter feeders like bivalves, cirripeds and anemones, and large predators and grazers, like crabs and urchins (Ibarra, 2015). With increasing depth, the bottom becomes muddy and the benthic community becomes dominated by deposit-feeding and predatory polychaetes, followed by small crustaceans and mollusks bearing well-developed gills to withstand oxygen deficiency (Ibarra, 2015; Lomovasky et al., 2011). At depths around $10 \mathrm{~m}$, the muddy bottom in the bay is almost devoid of macrofauna. Few calcareous benthic foraminifera species inhabit these sediments, along with some soft-shelled species, which may outnumber the calcareous foraminifera in conditions prone to the dissolution of carbonates (Merma, 2016).

Paracas Bay forms a buffer zone to the marine protected area of Paracas, which extends from the peninsula to Independencia Bay in the south and up to $53 \mathrm{~km}$ offshore (Fig. 5.2.1b). The coastal population of about 100000 people is concentrated in the town of Pisco and the harbor district San Andres, both located to the north of the bay. For the past decade, total fish landings in Pisco-Paracas have averaged 33000 tons per annum, with the Peruvian anchovy Engraulis ringens comprising about $75 \%$ of the catches. Shellfish harvests have reached 1569 tons per annum during the same period, and include mainly scallops, marine snails, mussels, crabs and macroalgae. The aquaculture sector is based primarily on bottom culture and secondarily on suspended culture of the Peruvian scallop Argopecten purpuratus, with an annual production of around 1000 tonnes from the Paracas region.

Several other anthropogenic activities directly or indirectly impact the water quality of the bay and adjacent coast (Fig. 5.2.1c). Treatment of domestic waters from the town of Pisco and San Andrés harbour was initiated in 2000, but the treated sewage waters are nonetheless discharged into the Pisco River. The river also transports high loads of nitrate and nitrite, derived from agriculture use, and silicates, at concentrations up to $59 \mu \mathrm{M}, 22.5 \mu \mathrm{M}$ and $186 \mu \mathrm{M}$, respectively, according to IMARPE records, well above the concentrations found in coastal waters. Until 2004, waste waters from fish meal and fish oil industries were also disposed directly into the bay and adjacent coast with minimal treatment, which is likely to have increased the organic content in the shallow surface sediments adjacent to the factories (Velazco and Solís, 2000; Cabello et al., 2002). In 2004, a new waste treatment system was established for these industries and a sewage pipe was built that discharges outside of the bay into water of $50 \mathrm{~m}$ depth (Fig. 5.2.1c). Since 2004 , shipping of gas products has also taken place in a marine berth located north of the bay.

\subsubsection{Drivers of coastal hypoxia and emergence of anoxia}

At least three mechanisms drive the development of coastal hypoxia and anoxia in Paracas Bay; these include the advection of oxygendepleted upwelled waters into the bay, in situ oxygen depletion following thermohaline stratification, and in situ oxygen depletion by the decay of HABs.

During summer and autumn, abrupt drops in temperature down to $8{ }^{\circ} \mathrm{C}$ can be recorded in a few hours with coincident drops in bottom water oxygen often reaching anoxic conditions (Aguirre-Velarde et al., 2019). These episodes are occasionally accompanied by "white water" discolourations (Fig. 5.2.3b, d-e). A shallow oxygen minimum zone, local bathymetry and the orientation of the bay all favour the advection of the oxygen-depleted upwelled waters into the bay resulting in low oxygen conditions for several days. Remote-sensing of ocean colour has shown that "white waters" are more frequent in autumn (Chauca, 2018; Ohde, 2018), just after the annual peak in productivity and when upwelling winds become stronger. These observations indicate that coastal upwelling is able to transport anoxic, sulphidic waters into the bay.

In situ depletion of oxygen in Paracas Bay has also been linked to thermohaline stratification. The seasonality of coastal winds leads to a general intensification of upwelling and vertical mixing of the upper water column during winter and spring and a weakening of these processes during summer and autumn. Reduced winds during this latter period, with increased insolation, promote thermal stratification of the coastal and bay waters (Sears, 1954). In addition, river discharge increases from nearly zero in winter and spring to $200-800 \mathrm{~m}^{3} \mathrm{~s}^{-1}$ in summer following rains in the Andean mountains (Fig. 5.2.2a). This freshwater input causes a drop in surface salinity to $30 \mathrm{ppm}$ and these waters may extend several miles from the river mouth, enhancing stratification and oxygen depletion. Wind relaxation events also promote the southward flow of these waters into the bay (Yzocupe, 2002), whereby local stratification and respiration may further deplete oxygen through the water column and down into bottom waters (Fig. 5.2.3a-d). This mechanism is likely to be more dominant in late summer, when river discharge and SST reach their peaks, and wind intensity is generally lowest.

HABs are often followed by anoxic events in Paracas Bay (Cabello et al., 2002; López, 2008). The development of HABs has a weaker seasonal signature compared to wind and river discharge, although HABs are more frequent in autumn (Fig. 5.2.2b). In fact, any window of wind relaxation, particularly following coastal upwelling events, may trigger phytoplankton growth, profiting from the enrichment of surface waters (Pitcher et al., 2010). The senescence and decay of blooms leads 

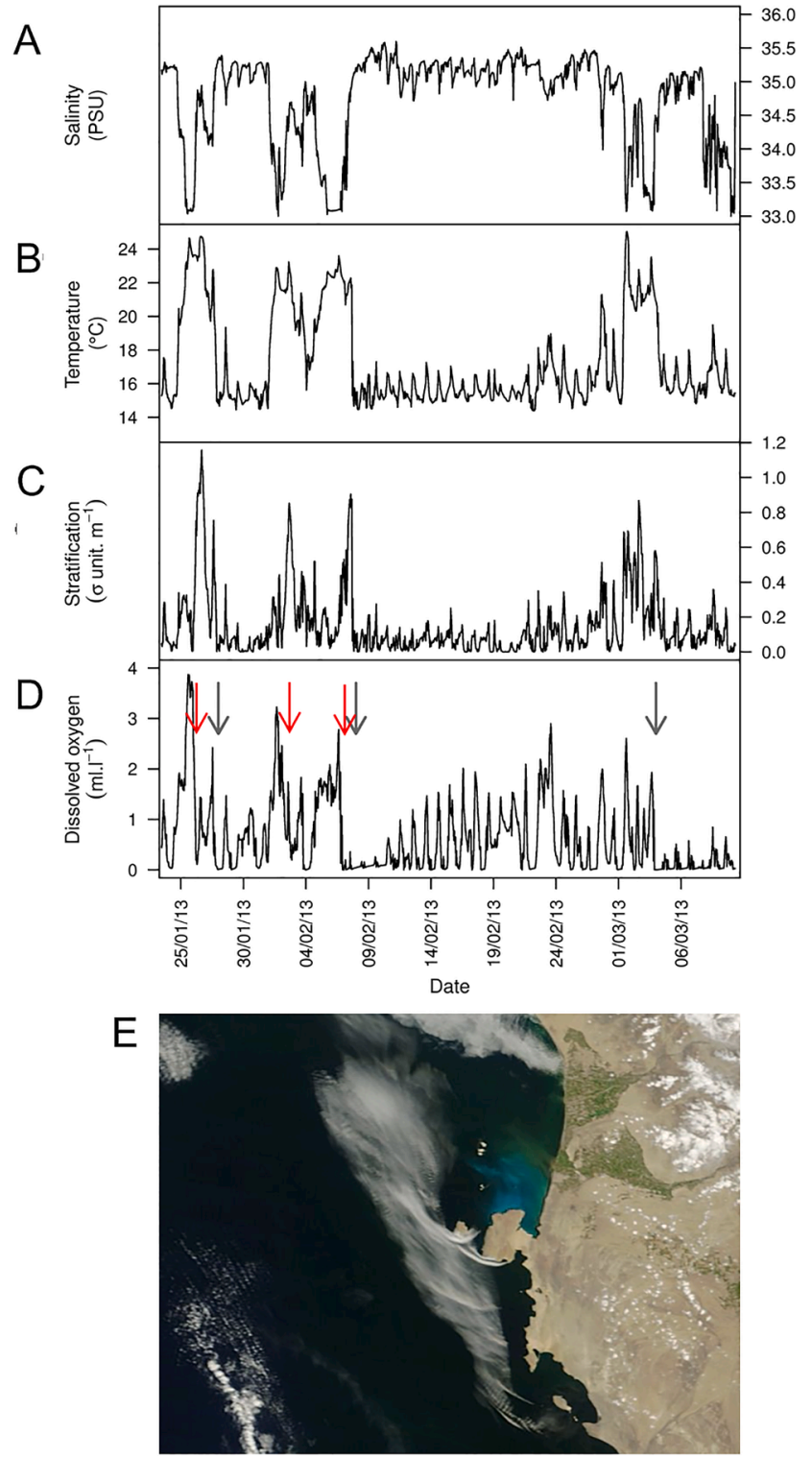

Fig. 5.2.3. (a) Hourly time-series of sea surface salinity, (b) SST $\left({ }^{\circ} \mathrm{C}\right),(\mathrm{c})$ stratification (vertical density gradient, $\mathrm{s}$ units $\mathrm{m}^{-1}$ ), and (d) bottom water dissolved oxygen $\left(\mathrm{ml} \mathrm{l}^{-1}\right)$ at station B (shown in Figure 1) from 23/01/19 - 11/ 03/13). Red arrows indicate bottom hypoxia associated with stratification and black arrows depict the occurrence of 'white waters' affecting Paracas Bay; (e) a 'white water' event detected on 11/02/2013 (satellite image from MODIS). The identification was done by analysis of reflectance at $488 \mathrm{~nm}$ (related to high sulphur concentrations in seawater from the oxidation of hydrogen sulfide). (For interpretation of the references to colour in this figure legend, the reader is referred to the web version of this article.)

to the sedimentation of large quantities of phytodetritus followed by anaerobic respiration and possible anoxia. HABs formed by Prorocentrum ordatum and $H$. akashiwo are observed along adjacent coastal waters and within the bay, coincident with the distribution of stratified, hypoxic waters following wind relaxation events. Other HABs, including A. sanguinea and Alexandrium ostenfeldii, have mostly been observed inside the bay and in summer and autumn, when HAB decay can contribute a greater fraction to sedimentary organic enrichment and the development of anoxia.

The three mechanisms described above are not mutually exclusive, so that a hypoxic or anoxic event may result from a combination of these drivers (Fig. 5.2.3d). Two other anthropogenic factors may amplify the development hypoxia or anoxia through the eutrophication of coastal waters. Firstly, the nutrient input and the transport of organic matter by the Pisco River has yet to be quantified. Secondly, the input of organic matter linked to maritime traffic, including fishing, and the fish meal and oil industries, needs to be considered. Importantly, the lowest bottom oxygen concentrations were recorded before the construction of a new waste treatment system and sewage pipe in 2004 .

\subsubsection{Inter annual variability and recent trends}

Bottom water oxygen (BWO) in the bay has been measured by IMARPE since 1999 and in 2005 these measurements were extended to the adjacent coast north of the bay (Fig. 5.2.4). From these records, it is possible to infer a pattern in BWO which can be roughly split into two periods: the first period is characterized by a trend of oxygenation that reached a plateau in 2007, and the second period reveals a reversal of this trend.

For the first period (1999-2007), oxygen trends were positive in the bay, but varied seasonally, from $+0.11 \mathrm{mll}^{-1} \mathrm{y}^{-1}$ (or $+4.7 \mu \mathrm{mol} 1^{-1} \mathrm{y}^{-1}$ ) in early spring to $+0.28 \mathrm{mll}^{-1} \mathrm{y}^{-1}$ (or $+12.4 \mu \mathrm{moll}^{-1} \mathrm{y}^{-1}$ ) in late summer. By contrast, for the second period (2008-2019), trends were significant only for winter and early spring, but negative, reaching $-0.10 \mathrm{ml} \mathrm{l}^{-1} \mathrm{y}^{-1}$ (or $-4.5 \mu \mathrm{mol}^{-1} \mathrm{y}^{-1}$ ). For the northeastern adjacent coast, trends after 2007 were not significant.

The oxygenation of bay bottom waters during the first period is at odds with reported coastal cooling along Central and Southern Peru from the late 1970s to the late 2000s (Gutiérrez et al., 2011, 2016), as the cooling trend is indicative of enhanced upwelling and thereby likely to increase the advection of oxygen-depleted waters into the bay. On other hand, during the first period, a strong La Niña (1999-2001) and two Modoki El Niños (2002-2003 and 2006-2007) occurred, the former associated with a shoaling of the oxycline and the latter, with weak oxygenation of the water column within the region (Gutiérrez et al., 2008; Dewitte et al., 2012; Graco et al., 2017). Then, an ENSO-related contribution for the observed oxygenation in the bay could not explain the higher BWO values already measured in the summers of 2005 and 2006, before the occurrence of the last Modoki El Niños. It is more likely that the trend of oxygenation was the result of reduced oxygen consumption owing to the reduced input of organic matter following the construction of the sewage pipe in 2004 (Fig. 5.2.4).

For the second period, the trend of winter deoxygenation suggests an increase in the advection of oxygen-depleted upwelled waters into the bay, though enhanced vertical mixing during winter precludes the development of anoxia in winter. The absence of deoxygenation off the northeastern adjacent coast might be explained by its lower exposure to the advection of upwelled waters. Ohde (2018) has proposed that the occurrence of sulphidic events, which are related to the advection mechanism for hypoxia (see above), are associated with La Niña conditions, but the period of observation is too short to verify this hypothesis. Also, better understanding of the roles of the recent variability of upwelling-favorable winds or upwelling source waters on the oxygen trends is needed.

\subsubsection{Susceptibility to deoxygenation under climate change}

Future projections of the oceanographic conditions off the Peruvian coast indicate that coastal upwelling winds will show a moderate decrease during summer with climate change (Goubanova et al., 2012; Belmadani et al., 2014; Chamorro et al., 2021). However, thermal stratification is expected to intensify (Echevin et al., 2011, 2020; Brochier et al., 2013), which is likely to result in reduced ventilation of the subsurface layers, particularly in summer. Increased stratification is also likely to increase the occurrence of HABs that may also lead to further hypoxia or anoxia in the bay. Irrespective of changes in coastal upwelling, the advection of oxygen-depleted waters into the bay also depends on changes in the upwelling source waters. Recent studies highlight the role of circulation changes (Llanillo et al., 2013; Duteil et al., 2014a,b; Montes et al., 2014; Espinoza-Morriberón, 2018) and nearshore mesoscale activity (Echevin et al., 2011; Oerder et al., 2016; 

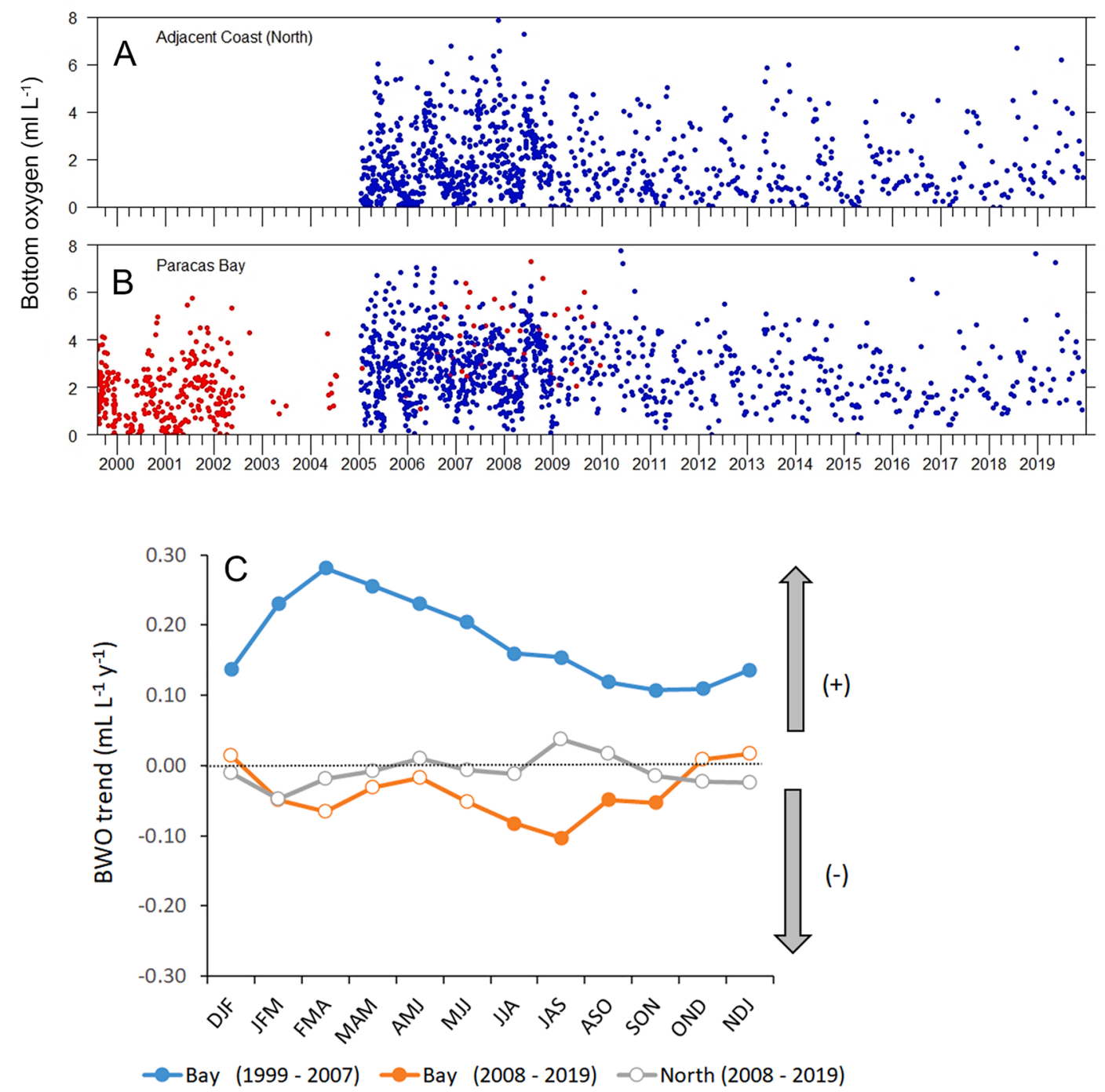

Fig. 5.2.4. Time series of average bottom water dissolved oxygen (BWO, $\mathrm{ml} \mathrm{l}^{-1}$ ) at selected stations (a) located north of Paracas Bay and (b) within Paracas Bay. Red circles correspond to monitoring stations sampled from 1999 to 2009, and blue circles to monitoring stations sampled since 2005 (see also Figure 1c). Trends of BWO $\left(\mathrm{ml}^{-1} \mathrm{y}^{-1}\right)$ are shown in (c), computed by quarterly time series (e.g., DJF means December/January/February). Significant trends correspond to filled symbols. Data source: IMARPE. (For interpretation of the references to colour in this figure legend, the reader is referred to the web version of this article.)

Vergara et al., 2016) on increasing or decreasing the ventilation of upwelling source waters in the region.

Bay susceptibility to deoxygenation will also depend on future changes in river discharge and pollution. Hydrological scenarios predict an average $6 \%$ increase in rainfall upstream of the Pisco River by 2030 , reaching a 16\% increase in summer (Oria and Avalos, 2013; MINAM, 2016). Since the Peruvian coast is characterized by steep, narrow slopes, rainfall and river discharge are closely linked (Olsson et al., 2017). Increased river discharge will contribute directly by intensifying summer stratification in the bay, and may also contribute to increase nutrient and organic matter inputs, particularly if current deficiencies in the management of waste waters persist. Also, the ongoing expansion of the San Martin harbour at the bay mouth has modified local bathymetry in order to increase its operating capacity, which will escalate maritime traffic and the possibility of increased local pollution. Again, further research is needed to establish the future scenarios for coastal hypoxia, ecosystem health and management options in Paracas Bay, taking into account the multiple drivers involved.

In conclusion, events of coastal hypoxia and anoxia currently characterize Paracas Bay, particularly during summer and autumn. These events are favoured by bay topography, coastal upwelling and local circulation; and wind variability is important in the development of thermohaline stratification, HABs and their subsequent decay, and the advection of oxygen-poor upwelled waters into the bay. The occurrence of hypoxia is amplified by river discharge, which introduces freshwater into the system, increases nutrient and organic matter content in the bay, and serves as a source of pollutants. The vulnerability of the bay to anthropogenic influences is evidenced by time-series of near bottom oxygen, which shows the lowest oxygen conditions prior to the construction of a sewage pipe in 2004. Future scenarios at the regional level suggest increasing susceptibility to deoxygenation under climate change, as the stratification of Peruvian coastal waters is predicted to increase, leading to reduced bottom ventilation and an increase in coastal HABs.

\subsection{Masfjorden and the Bergen fjords}

More than 1000 fjords are located on the rugged west coast of Norway, and they vary in size, shape and environmental conditions. The deepest and longest fjord is Sognefjorden, which is $205 \mathrm{~km}$ in length and has a maximum depth of $1308 \mathrm{~m}$. Other countries with numerous fjords include Alaska, Canada, Greenland, Iceland and Scotland in the northern hemisphere, and Argentina, Chile and New Zealand, and Antarctica, in the southern hemisphere. Some Norwegian fjords are naturally hypoxic 
or anoxic, either recurrently or permanently, and are often characterised by sulphidic water masses and sediments (Gaarder, 1916). Other Norwegian fjords, particularly those in the south, have shown a loss of oxygen in their basin waters since the 1980s (Sætre et al., 2010). Masfjorden and the Bergen fjord system on the southwest coast of Norway are the location of large Atlantic salmon Salmo salar farms (Svåsand et al., 2017) that require well-oxygenated water.

\subsubsection{System description and history of deoxygenation}

Fjords are typically long and narrow, with steep sides and deep inlets carved out by glaciers, and were filled with seawater after the last glacial maximum around 17000 years ago (Syvitski et al., 1987). The outer areas of fjords can be several kilometers wide, and they narrow to a few hundred meters at their heads. A topographic barrier in the form of a sill is typically found at the entrance of a fjord, and this serves to isolate the deep basin waters from waters outside of the fjord (Inall and Gillibrand, 2010; Darelius, 2020; Aksnes et al., 2019; Fig. 5.3.1a). These sills strongly influence water structure, circulation, sediment distribution and the biology of fjords. Variation in density stratification between fjords and adjacent coastal waters is important in determining the

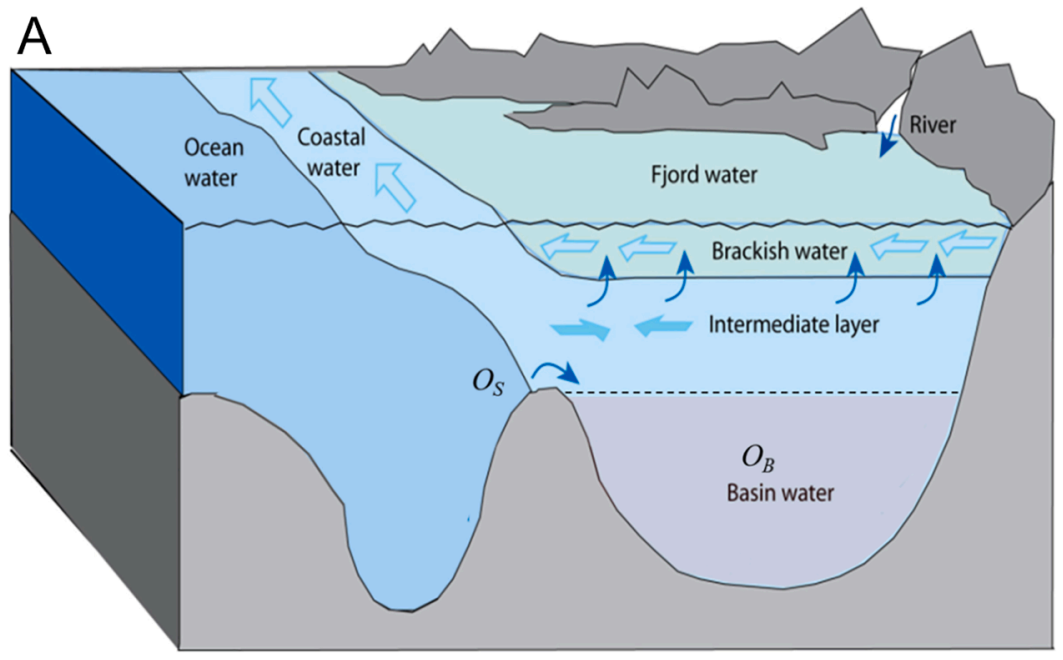

B

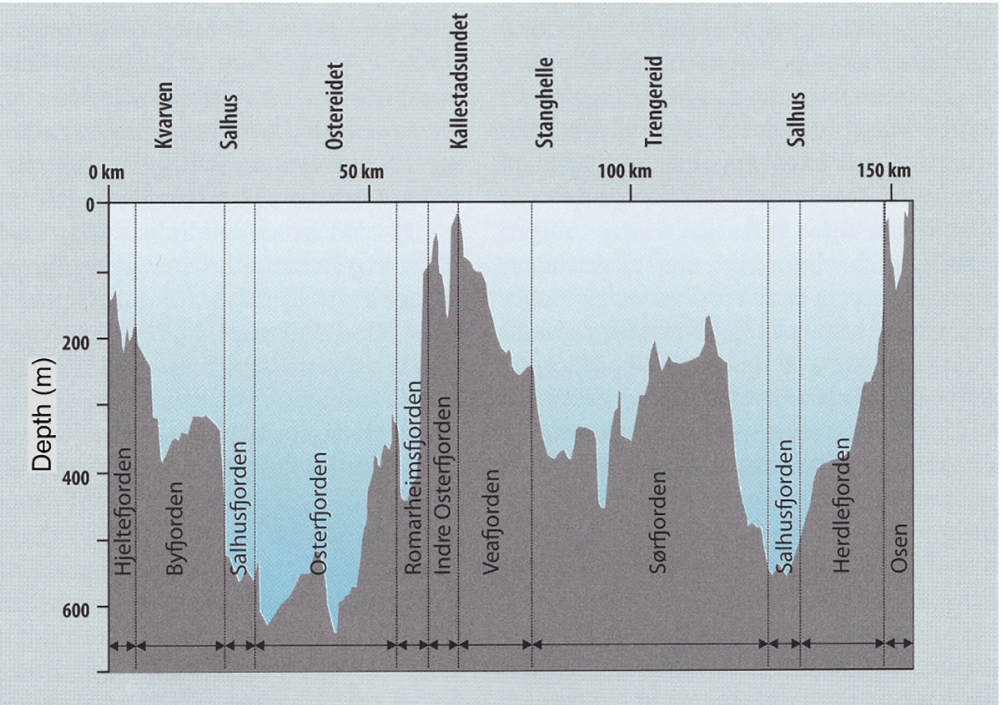

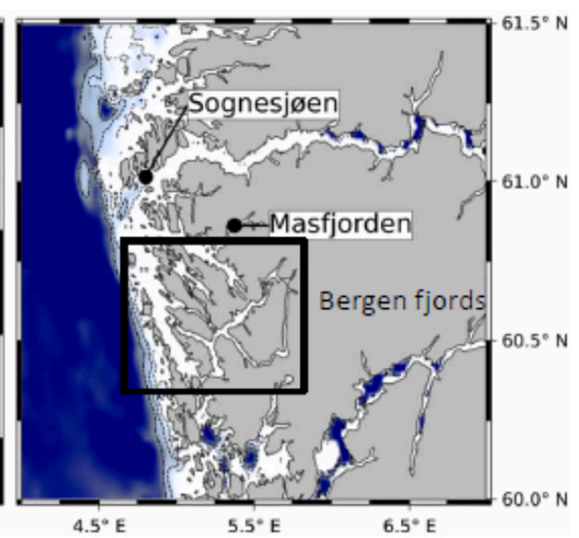

Fig. 5.3.1. (a) A simplified illustration of fjord topography with three vertical layers: a thin brackish layer at the top, a dynamic intermediate layer which extends down to the sill depth, and the basin water below sill depth. OB refers to dissolved oxygen of basin water and OS to dissolved oxygen of oceanic water (open access under the CC BY license: Aksnes et al., 2019); (b) basin depths as depicted by a transect of the Bergen fjords, starting at the sill at the entrance of Hjeltefjorden, via Byfjorden, the fjords surrounding Osterøy, and exiting at Herdlafjorden (Copyright John Grieg, from Sætre et al., 2010); (c) location of Masfjorden and the Bergen fjords. The North Atlantic Current (NAC) is a northern branch of the Gulf Stream that transports North Atlantic Waters (NAW, salinity $>35^{\circ} \%$ ) into the Norwegian Sea, and the Norwegian Coastal Current (NCC) forms a wedge of less saline Norwegian Coastal Water (NCW, salinity $<34.5^{\circ} \%$ ) along the Norwegian coast (modified from open access figure under the CC BY license: Aksnes et al., 2019). 
renewal of water masses below the sill depth (Inall and Gillibrand, 2010).

The water masses of fjords consist of three distinct layers: a brackish layer at the top formed by freshwater supplied from the local watershed, an intermediate layer between the brackish water and the sill depth (Stigebrandt, 2012), and basin water (Aksnes et al., 2019; Fig. 5.3.1a). Circulation within Norwegian fjords is influenced by the wedge-like Norwegian Coastal Current (NCC) comprising North Atlantic Water (NAW, salinity $>35 \%$ ) and Norwegian Coastal Water (NCW, salinity $<34.5^{\circ} \%$ ) (Fig. 5.3.1c). The thickness of the surface layer is typically 1 to $5 \mathrm{~m}$ depending on the volume of freshwater supply relative to the fjord volume (Aksnes et al., 2019). The intermediate layer consists of low saline NCW $\left(<34.5^{\circ} \% 0\right)$, and if the sill is deep enough, the intermediate layer also contains the more saline NAW $(>35 \%$ ) below the layer of NCW. In the intermediate layer, there is normally a significant exchange of water between the fjord and oceanic water; non-local forcing by winds along the Norwegian coast regulate this advective transport (Aksnes et al., 1989; Asplin et al., 1999; Sætre, 2007). Estuarine circulation in fjords, including Masfjorden, is minor compared to the circulation of the intermediate layer (Aksnes et al., 1989; 2019). Deep water renewal typically occurs intermittently and is mainly influenced by fjord topography and connections with NAW, tidal circulation and diapycnal mixing (Gade and Edwards, 1980; Aure and
Stigebrandt, 1989; Sætre et al., 2010). Seasonal variations are evident in the depth of NCW that is narrow and deep in winter but shallow and broad during the summer. When the NCW is shallow and broad, fjord basin waters on the west coast of Norway are renewed (Sætre et al., 2010; Fig. 5.3.2).

Shallow sills restrict free exchange of basin waters with the open ocean, resulting in the stagnation of basin waters (Syvitski et al., 1987). Many fjords in the Bergen system have shallow sills and the basin water below the sill depth can only be renewed if the density of the water outside the fjord exceeds that of the density of the basin water (Gade and Edwards, 1980; Syvitski et al., 1987). Temperature and oxygen vary seasonally, as is evident in Byfjorden where changes in temperature and oxygen of the deep basin waters are driven mainly by the annual inflow of deep coastal water over the sill (Sætre et al., 2010). During the inflow period in late spring to early summer, the mean temperature at $300 \mathrm{~m}$ depth is shown to drop from 7.35 to $7.10^{\circ} \mathrm{C}$ and the oxygen increases from 5.3 to $5.9 \mathrm{mll}^{-1}$ (Fig. 5.3.2).

The length, width and depth of fjords, along with their sill depths, dictate their susceptibility to the development and persistence of hypoxic conditions. Some fjords, including the Bergen fjords, have several basins and sills (Syvitski et al., 1987). The Bergen fjords stretch from Korsfjorden $\left(60^{\circ} 10^{\prime} \mathrm{N} ; 5^{\circ} 10^{\prime} \mathrm{E}\right)$ in the south to Fensfjorden $\left(60^{\circ} 50^{\prime} \mathrm{N}\right.$; $5^{\circ} 10^{\prime} \mathrm{E}$ ) in the north and have a total surface area of $240 \mathrm{~km}^{2}$ (Sætre
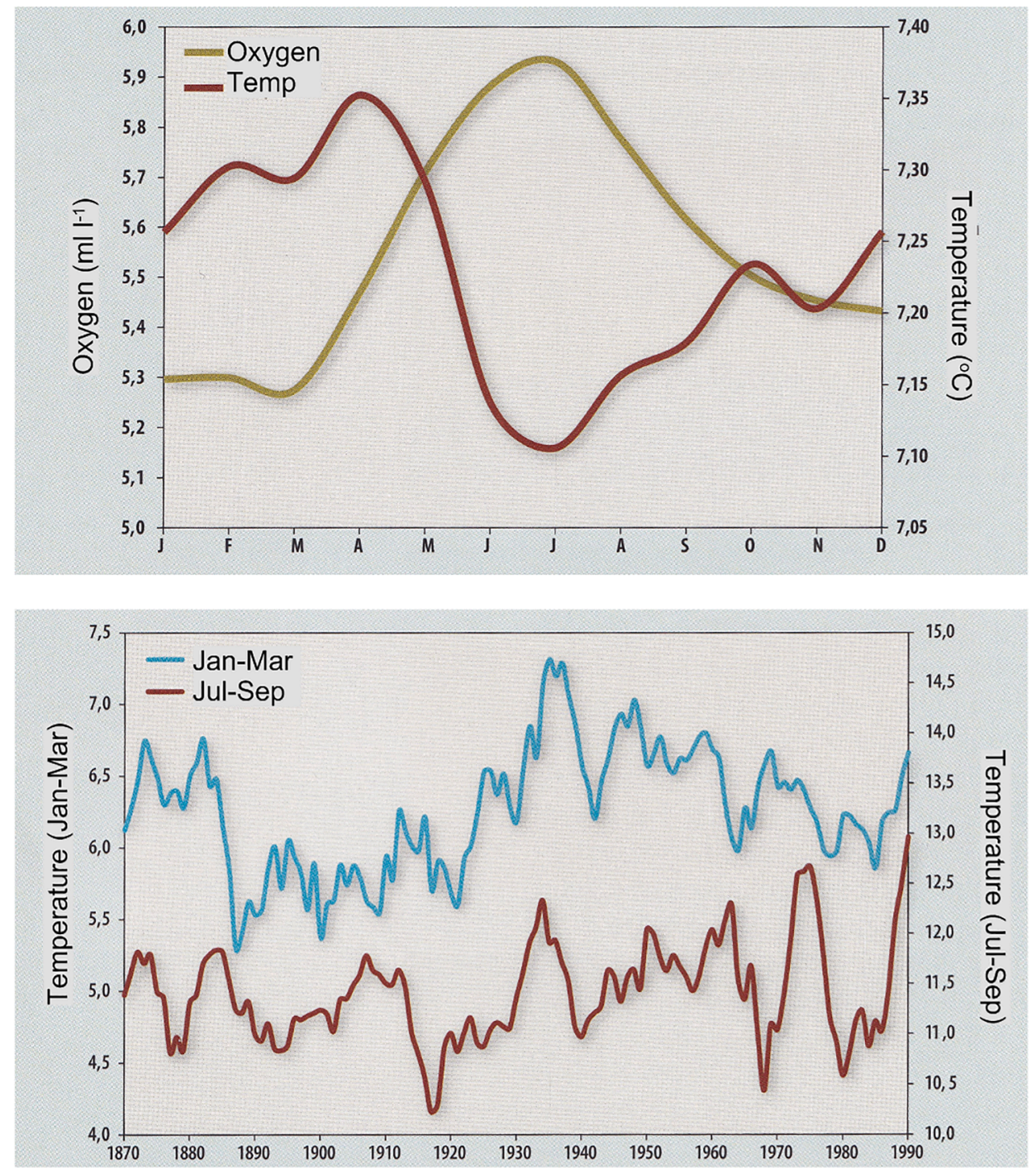

Fig. 5.3.2. (a) Mean annual variation (1981-2004) in oxygen and temperature at $300 \mathrm{~m}$ depth in Byfjorden of the Bergen fjords; (b) Mean surface temperature in winter (January - March) and summer (July - September) at the Hellisøy light house station from 1870 to 1990 (from Sætre et al., 2010, copyright John Grieg). 
et al., 2010). The outer sill depth is $130 \mathrm{~m}$ deep, located at the entrance to Hjeltefjorden, which connects the ocean with the $350 \mathrm{~m}$ deep Byfjorden. Further inland is the $550 \mathrm{~m}$ deep Salhusfjorden with an inward connection to the $650 \mathrm{~m}$ deep Osterfjorden, and so forth (moving from left to right in Fig. 5.3.1b). Inside Osterfjorden is the $8 \mathrm{~km}$ long, $0.5 \mathrm{~km}$ wide and $200 \mathrm{~m}$ deep Mofjorden, located behind a very shallow 2-2.5 m deep and $700 \mathrm{~m}$ long sill. Hydrographic measurements dating back to 1903 show that Mofjorden is a pristine and remote fjord with naturally anoxic and sulphidic basin waters. These measurements reported severe hypoxia with oxygen concentrations $<0.2 \mathrm{ml}^{-1}$ at depths between 50 and $200 \mathrm{~m}$ and increasing concentrations of $\mathrm{H}_{2} \mathrm{~S}$ with depth with a maximum of $0.9 \mathrm{ml} \mathrm{l}^{-1}$ at the bottom (Gaarder, 1916). Natural anoxia was also reported by Gaarder (1916) in another shallow sill fjord in a more populated area close to Bergen, Nordaasvannet, with stagnant deep basin waters ( $80 \mathrm{~m}$ depth) containing $\mathrm{H}_{2} \mathrm{~S}$ between $15 \mathrm{~m}$ and the bottom.

The total annual exchange of intermediate water above the outer $130 \mathrm{~m}$ sill to the Bergen fjords is estimated at $375 \mathrm{~km}^{3} \mathrm{yr}^{-1}$, of which $60 \%$ is driven by the horizontal density difference (baroclinic exchange) between coastal waters and fjord waters above the sill (Inall and Gillibrand, 2010; Sætre et al., 2010). Exchange driven by estuarine circulation and freshwater runoff in the Bergen fjords is $\sim 15 \%$ of the total exchange across the sill (Sætre et al., 2010). Field studies and model simulations also show that the advection of intermediate water masses is dampened with increasing distance from the coast, and this dampening reduces the transport of zooplankton into the inner regions of fjords and decreases the carrying capacity of these inner regions for higher trophic levels (Salvanes et al., 1995).

Long-term monitoring programmes were established in the Bergen fjords, including Fensfjorden and Masfjorden, in the 1970s. These programmes aimed to (i) monitor domestic effluent from Bergen; (ii) evaluate seabeds for mining deposits; (iii) evaluate the consequences of floating bridges; (iv) monitor pollution from fish farms; and (v) monitor environmental influences on fish recruitment and distribution along the coast (since 1935) and in fjords (since 1975) along the Norwegian coast (Sætre et al., 2003). These programmes have generated valuable time series that have also been used for studies of the responses of water quality and benthos to climate variability. The data show a clear increase in temperature and a clear loss of oxygen at $300 \mathrm{~m}$ depth since 1980 in Byfjorden (1926-2005) and Fensfjorden (1975-2008) (Fig. 5.3.3). Signals of oxygen loss are also apparent in the benthic deep water macrofauna, which is now dominated by opportunistic species characteristic of areas of hypoxia and high organic matter in their sediments (Johansen et al., 2018).

Masfjorden branches off towards the north from within the inner part of Fensfjorden. Masfjorden has a $75 \mathrm{~m}$ deep sill at its entrance, is $22 \mathrm{~km}$ long, ranges in width from 0.3 to $1.3 \mathrm{~km}$ and has a maximum depth of $494 \mathrm{~m}$. Haugsværfjorden, in turn, branches off the inner part of Masfjorden over a sill that is $20-30 \mathrm{~m}$ deep and $67 \mathrm{~m}$ wide into a basin with a maximum depth of $120 \mathrm{~m}$. The majority of freshwater enters at the head of Masfjorden, where the outlet from a hydroelectric power plant is located (Aksnes et al., 1989). The volume of Masfjorden is $5.36 \mathrm{~km}^{3}$, the surface area is $28.5 \mathrm{~km}^{2}$, and the tidal amplitude is 0.5 to $1 \mathrm{~m}$. The daily exchange due to tides is $\sim 0.5 \%$ and the total freshwater supply varies between 30 and $60 \mathrm{~m}^{3} \mathrm{~s}^{-1}$ (Aksnes et al., 1989).

For Masfjorden, Aksnes et al. (2019) recently reported a multidecadal declining trend in oxygen concentration of $2.0 \mathrm{mll}^{-1}$ over 42 years. Over the same time period, the data show a decline in the density of the basin water and a $1{ }^{\circ} \mathrm{C}$ increase in temperature (Fig. 5.3.4a). The salinity was in the range $34.85-35.10 \%$ (Aksnes et al., 2019; Fig. 5.3.4b). The water is defined as North Atlantic Water (NAW) if salinity $>35.0 \%$ and as Norwegian Coastal Water (NCW) if the salinity $<34.5 \%$.

Since 2011, annual monitoring at a fixed station in Masfjorden has shown a decline in deep basin oxygen. During this period (2011 to 2017), oxygen concentrations below $300 \mathrm{~m}$ depth dropped below $2 \mathrm{mll}^{-1}$, but have subsequently partially recovered (Fig. 5.3.4d). Coincident measurements of nutrients in 2019 showed increasing nutrients with depth that paralleled the decrease in oxygen concentrations with depth (Elin Darelius and Are S Olsen, University of Bergen, unpublished data; Fig. 5.3.4c). Although particulate organic matter (POM) in the water column has not been measured, published data on sediment samples from $470 \mathrm{~m}$ depth in 2014 showed the sediment to be $65 \%$ silt (grain size $<0.063 \mathrm{~mm}$ ) and $44 \%$ total organic carbon (TOC) (Tveranger
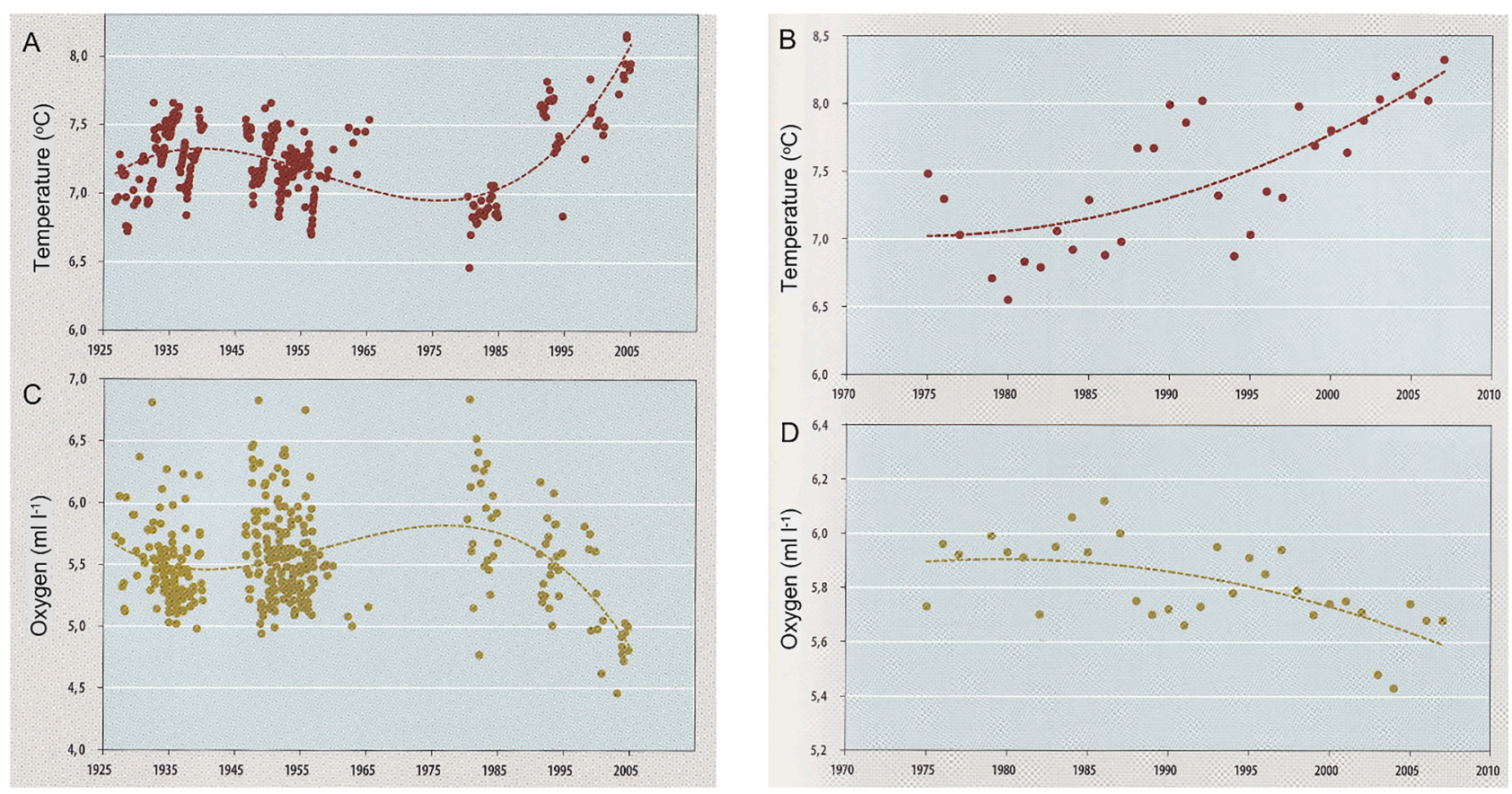

Fig. 5.3.3. Long-term monitoring at $300 \mathrm{~m}$ depth of (a) temperature $\left({ }^{\circ} \mathrm{C}\right)$ and (c) oxygen $\left(\mathrm{ml}{ }^{-1}\right)$ at hydrographical station 4 in Byfjorden from 1926 to 2005 ; and annual autumn measures of (b) temperature $\left({ }^{\circ} \mathrm{C}\right)$ and (d) oxygen $\left(\mathrm{ml} \mathrm{l}^{-1}\right)$ at the Fensfjorden hydrographical station from 1975 to 2008 (from Sætre et al., 2010 , copyright John Grieg). 

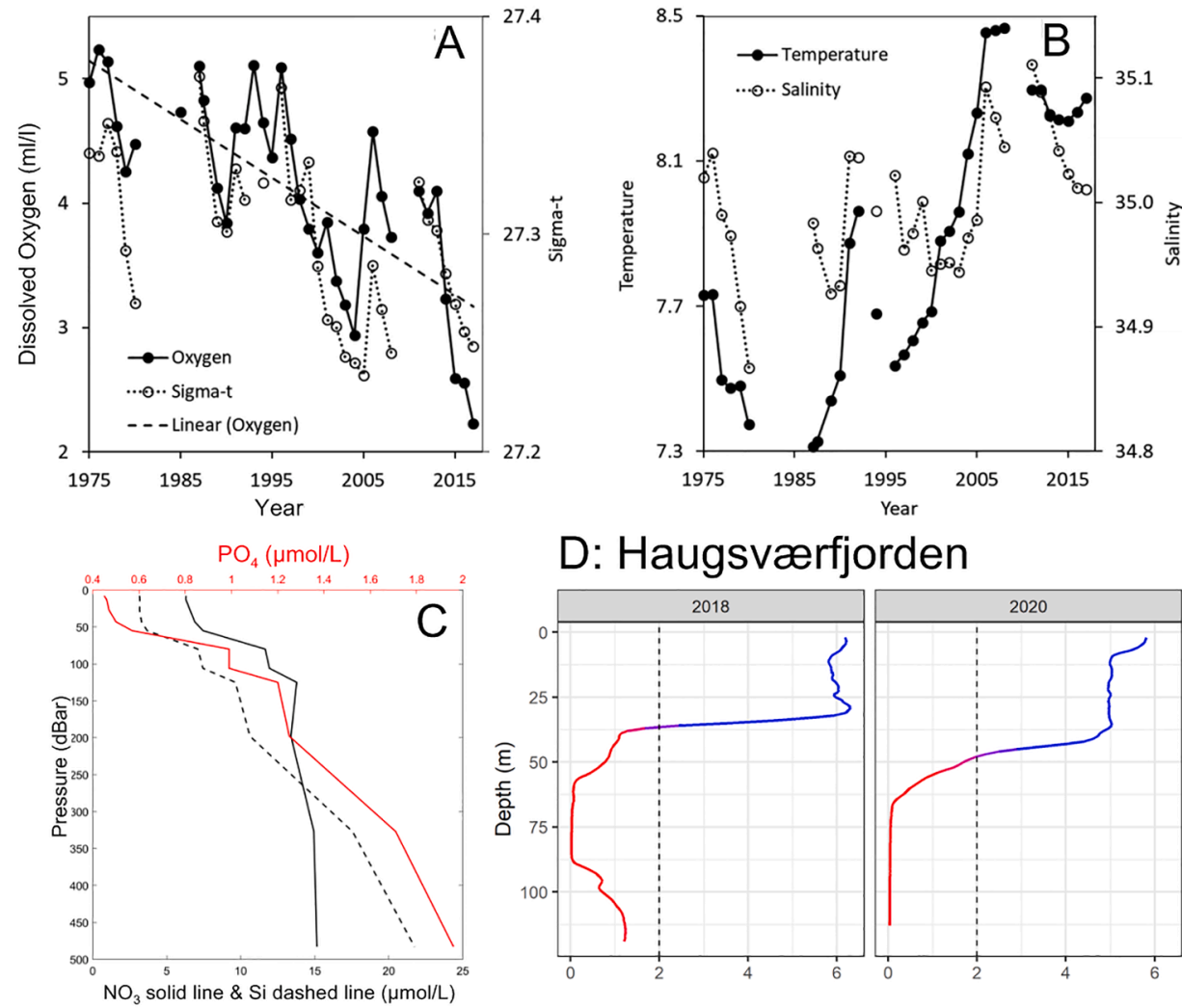

\section{D: Haugsværfjorden}

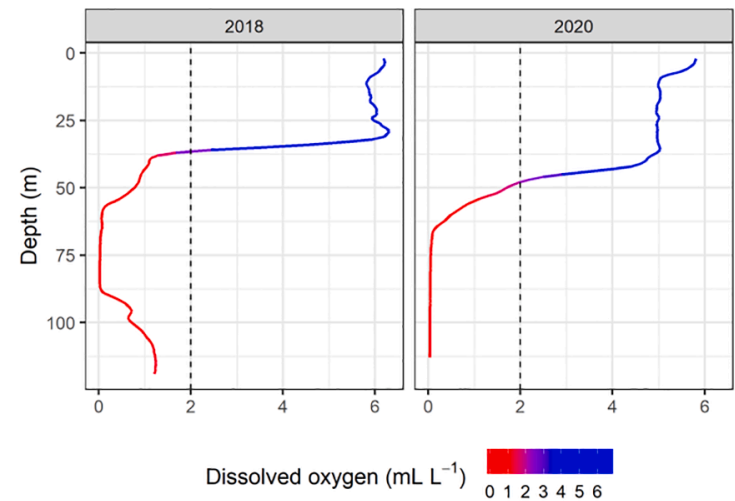

D: Masfjorden
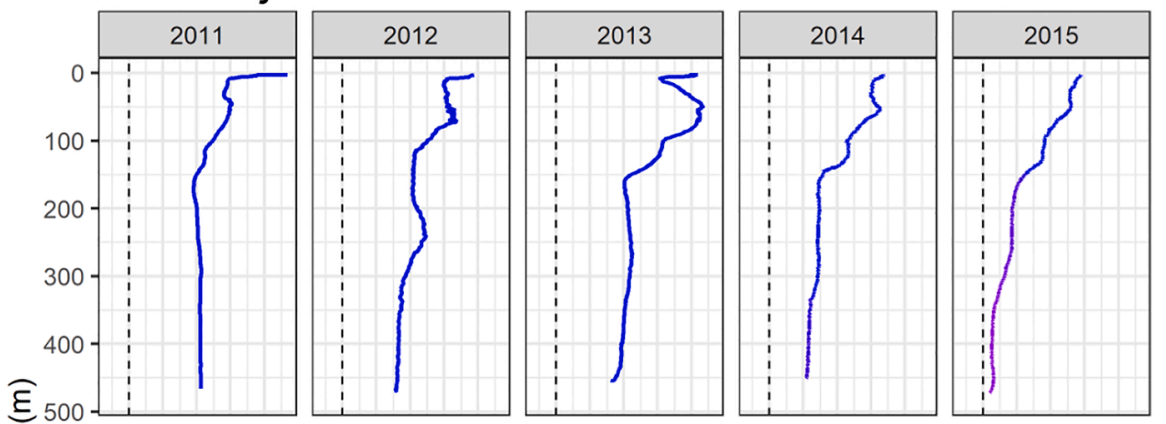

营
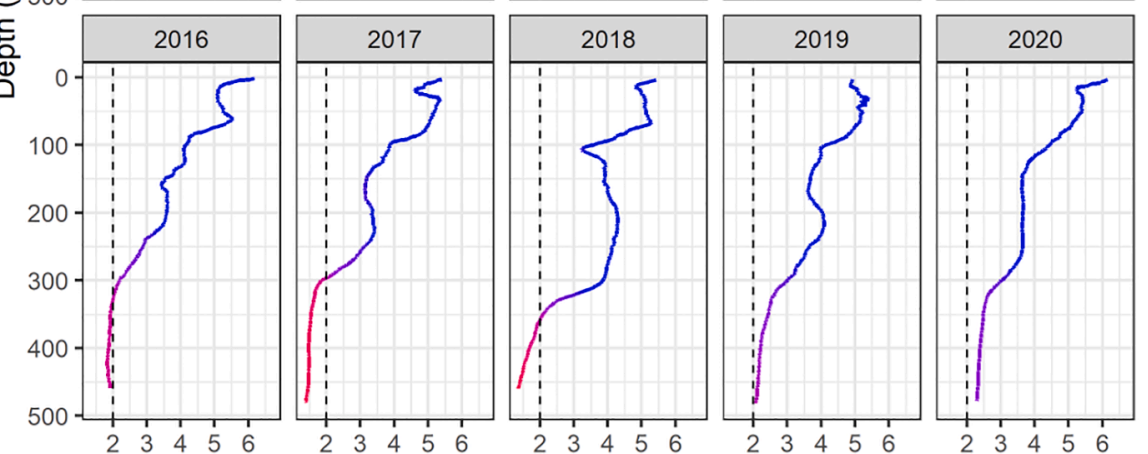

Fig. 5.3.4. Measurements in the basin water of Masfjorden from 1975 to 2016 of (a) dissolved oxygen ( $\mathrm{ml} \mathrm{l}^{-1}$ ) and density (sigma-t); and (b) temperature $\left({ }^{\circ} \mathrm{C}\right.$ ) and salinity (\%o) (data are presented as averages of measures from 200, 300 and $400 \mathrm{~m}$ depth in October or November) (open access under the CC BY license: Aksnes et al., 2019); (c) nutrient profiles from 2019 (Copyright: Elin Darelius and Are S Olsen, Geophysical Institute, University of Bergen, unpublished data); and (d) vertical profiles of oxygen from CTD-casts in the autumn in Masfjorden from 2011 to 2019 and in March 2020, and in Haugsværfjorden in August 2018 and March 2020 (Copyright: Martine Røysted Solås and Anne Gro Vea Salvanes, Department of Biological Sciences, University of Bergen, unpublished data).

\footnotetext{
Dissolved oxygen $\left(\mathrm{mL} \mathrm{L}^{-1}\right) \quad \begin{array}{lllll} & 0 & 123456\end{array}$
}

et al., 2019), indicative of a high sedimentation rate and sluggish bottom currents.

Haugsværfjorden, a branch of Masfjorden, has shown a greater loss in oxygen than the main fjord, with concentrations below $50-60 \mathrm{~m}$ depth declining to $0.066 \mathrm{ml} \mathrm{l}^{-1}$ in 2018 and 2020 (Martine Røysted Solås and Anne Gro Vea Salvanes, University of Bergen, unpublished data; Fig. 5.3.4d). Studies of deep-water exchange in Masfjorden have just begun (Aksnes et al., 2019; Darelius, 2020), but for other similar sill 
fjord systems, it has been shown that hypoxia is achieved by the net effects of intrusions of well oxygenated deep water across the sill, the degradation of organic matter by microbial respiration and vertical turbulent diffusivity (e.g., Gade, 1973; Aure and Stigebrandt, 1989; Aure et al., 2007; Stigebrandt, 2012).

\subsubsection{Causes and controls of deoxygenation}

Dissolved oxygen content in fjord basin waters, when sill depths are deeper than the euphotic zone, depends on three main processes (Aure and Stigebrandt, 1989; Aksnes and Lie, 1990): (1) basin water renewal from the intrusion of water masses of higher density than that of the basin water, (2) oxygen consumption from biological activity, and (3) vertical turbulent diffusivity. The isolation and stagnation of basin water typically leads to the depletion of dissolved oxygen resulting in hypoxia and sometimes anoxia (Aure and Stigebrandt, 1989; Gillibrand et al., 1996). This may affect the sedimentary environment, particularly if the water at the sediment interface and basin waters become anoxic (Inall and Gillibrand, 2010).

Intruding water masses from outside of fjords originate from depths at, or shallower than, the sill depths (Aksnes et al., 2019), or when stratified barotropic flow accelerates denser water from below the sill depth up and over the sill to a depth of equivalent density inside the fjord (Gade and Edwards, 1980; Inall and Gillibrand, 2010). The residence time of the basin water depends on three factors (Stigebrandt, 2012): (i) the spectral distribution of the temporal density fluctuations of the water just above the sill depth outside the fjord, (ii) the rate of the density reduction of basin water due to diapycnal mixing, and (iii) the time it takes to fill the basin with new water. For many fjords, the time scale for filling the basin with new water is long relative to the time scale for density variations and numerous partial exchanges that might take place (Aksnes et al., 2019). For example, studies of deep-water exchange in Sognefjorden, which has a deep sill of $165 \mathrm{~m}$ at its entrance, show that water flow into the fjord, with a density sufficiently high to reach the bottom of the fjord, lasts for only a few days. This indicates that bottom water renewal is episodic, and occurs only when water outside of the fjord is sufficiently heavy and there is an inward current able to move this water across the sill (Lars Asplin, Institute of Marine Research, personal communication).

Vertical mixing and diffusion reduce the density of water in the fjord basin with time. The energy needed to mix light water downwards is mainly supplied by the tides; for example, tidal currents interacting with the sill to generate internal waves that break against the fjord walls (Aure and Stigebrandt, 1989). A northward increase in tidal amplitudes and a reduction in vertical density gradients along the Norwegian coast result in an increase in the renewal rate of fjord basin waters to the north (Sætre et al., 2010). Consequently, some fjord basin waters in northern Norway are renewed and re-oxygenated annually (Sælen 1950), while renewal in fjords in southern Norway may take several (8-9) years (Gade, 1973; Sælen, 1976; Aure et al., 2007). In fjords with deep basins and also in fjords with deep sills, the oxygen consumption is lower than in shallow fjords, so even when the time between deep water renewal events is long, it may take several years before the basin waters turn hypoxic or anoxic (Gade, 1973; Aure and Stigebrandt, 1989).

The rate of oxygen consumption from biological activity depends largely on fjord topography. Aure and Stigebrandt (1989) estimated the rate of oxygen consumption for 29 fjords in the mid-Norway region, north of the Bergen fjords. Their estimates show that the rate of oxygen consumption was inversely proportional with the depth of the fjord basin, and that the oxygen consumption rate decreased with increasing sill depth. Thus, oxygen is depleted faster in fjords with shallow basin water and/or shallow sills than in fjords with deep basin water and/or deep sills (Aure and Stigebrandt, 1989). For example, in Nordaasvannet, which has a shallow $10 \mathrm{~m}$ deep sill and a basin depth of $80 \mathrm{~m}$, it took only 6-7 months after water renewal for anoxic conditions to again develop from $20 \mathrm{~m}$ depth to the bottom at $80 \mathrm{~m}$ (Gaarder, 1916). This was assumed to be caused by resuspension of particulate organic matter
(POM) from the soft-bottom sediments into the water column resulting from the intrusion of well oxygenated water from outside the fjord (Gaarder, 1916). As the POM sank back to the bottom, oxygen was stripped from the water column due to heterotrophic activity and degradation by microbial respiration (Gaarder, 1916). During stratification in both Nordåsvannet and Lindåspollane (part of the Bergen fjords) in the 1980s, the sedimentation rate decreased below the euphotic zone and with increasing depth, which was contrary to what was found in other areas (Wassmann, 1983,1985).

If the time required to consume all oxygen is shorter than the time period between renewals, then the fjord basins will lose oxygen and may turn anoxic. Aksnes et al. (2019) identified five three-year periods in Masfjorden after 1977 when basin water oxygen concentrations dropped at rates between 0.42 and $0.75 \mathrm{ml} \mathrm{O}_{2} \mathrm{l}^{-1} \mathrm{yr}^{-1}$. Fjord basin waters can contain high levels of POM resulting in high oxygen demand, especially if fish farming is occurring in the fjord. The decline reported by Aksnes et al. (2019) includes the biochemical oxygen demand attributed to feces and excess feed on salmon farms, estimated in Masfjorden annually as $0.065 \mathrm{ml} \mathrm{O}_{2} 1^{-1}$ per 1000 metric tons fish produced. Aksnes et al. (2019) thereby estimated that $\sim 9 \%$ of the total oxygen consumption was due to the effects of fish farming. These estimates indicated a time scale of 7-12 years of stagnant conditions for the Masfjorden basin water to turn anoxic.

\subsubsection{Modelling renewal frequency of basin water in sill fjords}

Darelius (2020) revisited the data used by Aksnes et al. (2019) and applied the statistical approach of Gade (1973) to evaluate the effect of the observed negative trend in the density of shelf waters on the renewal rate of the basin waters of Masfjorden and other fjords. The observed negative trend $\left(-0.006 \mathrm{~kg} \mathrm{~m}^{-3} \mathrm{yr}^{-1}\right)$ after 1990 in the annual maximum density observed at Sognesjøen (a hydrological station on the west coast of Norway visited bimonthly since 1935) has, in all likelihood, reduced the renewal frequency and increased the stagnation period of its basin waters. Darelius (2020) estimates that the probability of stagnation periods longer than 10 years has increased since 1990 from 0.02 to between 0.13 and 0.19 . The negative trend in the density of surface waters appears uncorrelated with sea surface temperature and the Atlantic Multidecadal Oscillation (Darelius, 2020). Rather, the observed simultaneous warming and freshening of the upper $1000 \mathrm{~m}$ of the Norwegian Sea from 2011 to 2018 may be explained by reduced ocean heat loss and the advection of fresher Atlantic water into the Norwegian Sea (Mork et al., 2019).

Furthermore, the high temperatures and salinities along the coast in the 1990s were ascribed by Sætre et al. (2003) to an increase of Atlantic inflow in the late 1980s and early 1990s combined with a strengthening of the North Atlantic Oscillation (NAO). Ten years later (2000-2009), Albretsen et al. (2012) report an increase in temperature of more than $0.6^{\circ} \mathrm{C}$ (compared with the mean for 1961-1990) along the Norwegian coast both for surface and deeper $(200 \mathrm{~m})$ waters. Observations of negative trends in the annual maximum density at most hydrographical stations along the coast of Norway suggest that the renewal frequency of the basin waters of many Norwegian fjords may have been reduced during the last 30 years, leading to steady declines in oxygen (Darelius, 2020). If the trend of deoxygenation continues in fjords, then this will impact fjord ecosystems and negatively impact the fish farming sector.

\subsubsection{Summary of temporal influences on hypoxia in fjords of western Norway}

The main influences on hypoxia in fjords of western Norway are: (1) renewal frequencies of basin water below sill depth; (2) the amount of particulate organic matter (POM) and consumption from biological activity; and (3) vertical turbulent diffusivity (Aure and Stigebrandt, 1989; Aksnes and Lie, 1990). Renewal of fjord basin waters is mainly driven by tidal circulation, diapycnal mixing, the cross-sectional area at the sill, the sill depth and the basin depth below the sill (Aure and Stigebrandt, 1989; Sætre et al., 2010). Renewals occur in the spring-summer season 
when the North Atlantic Water (NAW) is shallow. The wedge-shaped Norwegian Coastal Current (NCC) overlaying the NAW is deep and narrow during winter and wide and shallow during summer, and the dynamics of these water masses are driven by monsoon-like wind patterns along the Norwegian coast (Sætre et al., 1988); with winds from the south-west dominant in the winter and winds from the north dominant in April-August.

The warming of the interior of the North Atlantic Ocean has, through increased stratification and reduced ventilation, contributed to recent deoxygenation of the mesopelagic zone of Masfjorden, a typical west coast Norwegian fjord. Aksnes et al. (2019) suggest that the North Atlantic "Great Salinity Anomalies" in the 1980s, combined with warming, have led to a decreased frequency of high-density water-intrusions and have thereby reduced the renewal rate of Masfjorden basin water. Despite a gradual increase in salinity after 1980, the density of the water at the sill depth has decreased due to increasing temperatures (Aksnes et al., 2019). The probability of stagnation periods longer than
10 years is now six times higher than before 1990 due to reduced density at the sill depth (Darelius, 2020).

The recent warming along the Norwegian coast appears to be associated with large-scale phenomena of the North Atlantic. Hydrographic studies report high correlations with the NAO decadal cycle and precipitation (Sætre et al., 2003; Albretsen et al., 2012) and a simultaneous trend of warming and freshening in the upper $1000 \mathrm{~m}$ attributed to reduced ocean heat loss and the advection of fresher Atlantic water into the Norwegian Sea (Mork et al., 2019). Since the circulation of fjord basins is tightly connected with coastal water masses via tidal circulation and coastal wind conditions (Sætre et al., 2003), future climate changes in the North Atlantic will likely propagate into the fjords. A continued decrease in the density of coastal water masses at fjord sill depths may increase the probability of long stagnation periods with implications of ongoing deoxygenation of fjord basin waters.

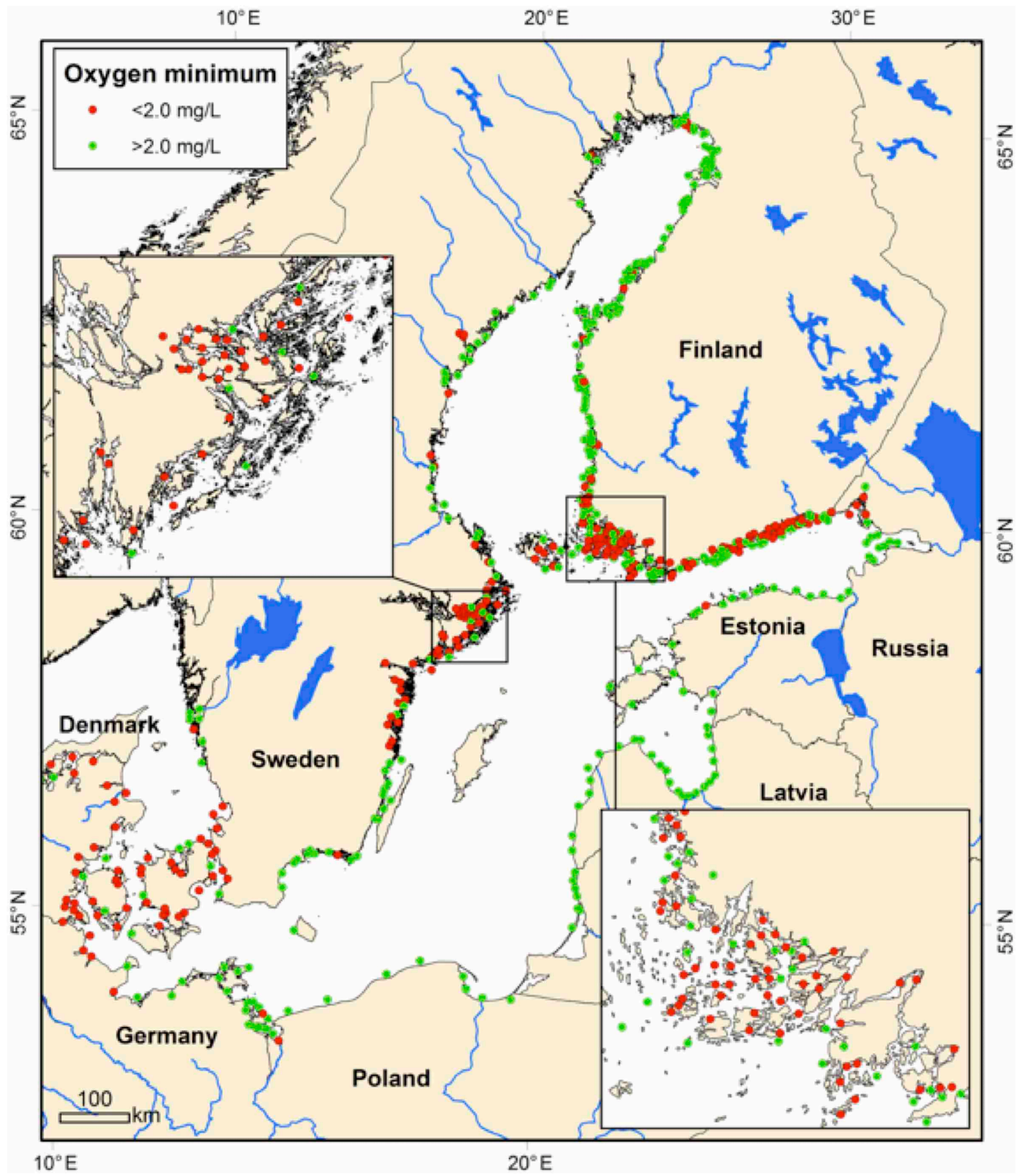

Fig. 5.4.1. Lowest oxygen concentration at all monitoring locations throughout the period (1955-2009) in the entire Baltic Sea. Insets show details for the Stockholm Archipelago (upper left) and the Finnish Archipelago Sea (lower right). Oxygen concentration in bottom waters was divided into two categories (hypoxic $<2 \mathrm{mg}^{-1}$ and oxic $>2 \mathrm{mg}^{-1}$ ). 


\subsection{Limfjorden Estuary}

Hypoxia is widespread in the coastal zone of the Baltic Sea (Fig. 5.4.1), with an estimated $\sim 35 \%$ of all coastal ecosystems having experienced hypoxia during 1955 to 2009 (Conley et al., 2011), and with the overall frequency of hypoxia increasing. However, improved oxygen conditions have also been observed in coastal ecosystems receiving significant nutrient inputs from urban areas in the past after their sewage treatment was upgraded, such as the inner Stockholm Archipelago (Norkko et al., 2012). Restricted water circulation is an important feature for many of the hypoxic coastal ecosystems, especially in the Swedish and Finnish archipelagos.

Phytoplankton growth stimulated by nutrient inputs from urban and agricultural sources is the primary cause of hypoxia in most Baltic coastal ecosystems. Hypoxia can be generated by local nutrient sources enhancing productivity in the coastal ecosystem, or it can be imported through advection of hypoxic bottom waters from deeper open areas, where perennial or seasonal hypoxia prevails. This is typically the case for coastal ecosystems in the outer archipelagos, experiencing spillovers of hypoxic water from the central Baltic Sea, and some estuaries in the western Baltic where strong westerly winds can drive seasonally hypoxic water from the Danish Straits into shallower waters.

In the shallow Limfjorden estuary, hypoxic conditions are observed nearly every year during the warm summer months; however, frequent wind mixing breaks down stratification such that development of persistent seasonal hypoxia does not occur (Conley et al., 2009b). Nutrient inputs from the local watershed are the main cause of hypoxia in the Limfjorden, and these nutrients sustain high productivity in the system.

\subsubsection{System description of Limfjorden}

Limfjorden is the largest estuary in Denmark. It has two inlets, one connecting to the North Sea to the west and the other connecting to the Kattegat to the east. The area of the Limfjorden is $1500 \mathrm{~km}^{2}$ and the catchment area is $7500 \mathrm{~km}^{2}$, of which $62 \%$ is intensively farmed with a high livestock density. Limfjorden consists of a mosaic of basins with different nutrient status, and due to large nutrient inputs, the estuarine system is highly eutrophic. The estuary has a mean water depth of $4.6 \mathrm{~m}$ and consists of several shallow broads (up to 5-8 $\mathrm{m}$ deep) linked by deeper channels (18-22 m). Stratification occurs following intrusions of saline North Sea water through the western inlet that then propagate to the other broads; stratification in the shallow areas is easily broken down by wind mixing. The western part has broad shoals on both sides of the central channel and is more exposed to wind than other basins (Carstensen et al., 2007, 2013). The estuary has a large mussel fishing industry based on bottom dredging, and the stones and shells that are removed are not returned to the estuary resulting in alterations to the bottom habitat.

Nutrient discharges to the Baltic Sea and to the Danish coastal waters peaked in the 1980s (Carstensen et al., 2006). In the past two decades, several nutrient management plans have been implemented and significant measures have been taken to reduce nitrogen and phosphorus discharges. Overall nutrient inputs from Denmark since 1990 have been reduced by $\sim 50 \%$ for nitrogen $(\mathrm{N})$ and $56 \%$ for phosphorus (P) (Riemann et al., 2016) and the dominant phosphorus input from land changed from point to diffuse sources (Krause-Jensen et al., 2012). Both nutrient and chlorophyll concentrations have responded with decreasing trends over the period from 1985 to 2008 for all basins in Limfjorden (Krause-Jensen et al., 2012), although nutrient levels remain high in many parts of the Limfjorden (Carstensen et al., 2013). Furthermore, analysis of nutrient inputs from 1990 to 2017 show only moderate long-term declines for $\mathrm{N}$ (Fig. 5.4.2a), but not for $\mathrm{P}$ (Fig. 5.4.2b); however, major reductions occurred earlier in the 1980s when most sewage treatment plants were upgraded (Krause-Jensen et al., 2012).
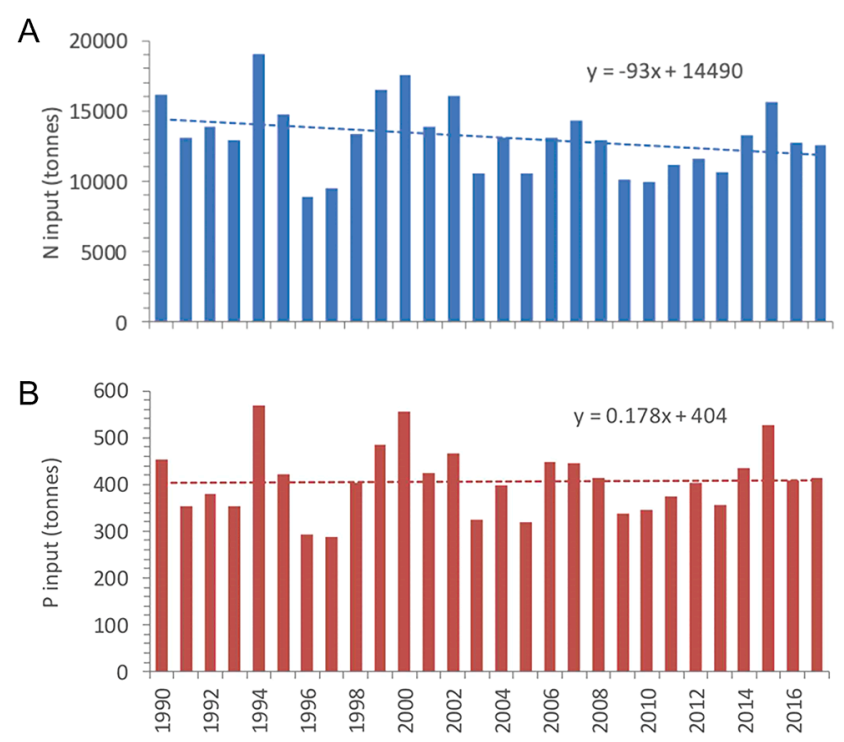

Fig. 5.4.2. Long-term nutrient loading to the Limfjorden from 1990 to 2016 for (A) nitrogen (N) and (B) phosphorus (P).

\subsubsection{History of deoxygenation}

The first reports of oxygen deficiency in the Limfjorden date back to around 1940, showing low oxygen concentrations in the same basins that experience hypoxic conditions today. Water quality monitoring was initiated in 1980 and since 2003 spatially extensive monitoring cruises have been carried out with the aim to map the extent of hypoxia. Enormous annual variation in the extent of hypoxic waters $\left(\mathrm{O}_{2}<2 \mathrm{mg} \mathrm{l}^{-1}\right)$ is observed in the Limfjorden (Fig. 5.4.3a). Hypoxia can occur in early June and extend until early October, with large areas of the sea bottom affected by hypoxia, particularly in the nutrient-rich southeastern basins (Krause-Jensen et al., 2012). The maximum bottom area affected by hypoxia during the period 2004-2017 varies between years by over an order of magnitude, ranging between $13 \mathrm{~km}^{2}$ in 2015 and $282 \mathrm{~km}^{2}$ in 2011 (Fig. 5.4.3b). Although it appears that the maximum extent of hypoxia has decreased through time, this trend is partly due to reduced monitoring effort over time, which varied from sampling almost every week in the earlier years to monthly surveys in recent years. Annual reports on oxygen concentrations below the pycnocline during stratified conditions show no long-term changes in oxygen concentration (Hansen and Carstensen, 2019).

Examples of the appearance and disappearance of hypoxia show a wide range of area covered during the summer months with no consistent pattern in the geographic distribution of oxygen (Fig. 5.4.3b). Peak hypoxia can occur in any summer month with the duration dependent upon wind conditions. Carstensen et al. (2007) observed that Skive Fjord, a small enclosed basin in the Limfjorden, was only stratified about $40 \%$ of the time due to the shallowness and the wind-exposed character of its inlet.

\subsubsection{Causes and consequences of deoxygenation}

Hypoxia can develop within a few days after saltwater intrusions cause the water column to stratify. While saltwater intrusions from the North Sea are saturated in oxygen as they enter the Limfjorden, they also form a thin bottom layer $(\sim 2-3 \mathrm{~m})$ in the most productive basins. The relatively small total oxygen content in the bottom layer offers little resistance to the large sediment oxygen demand during the warm summer months and consequently, bottom waters become deoxygenated after a few days with calm winds and persistent stratification. Moreover, this deoxygenated water mass can move around between basins by shifting winds that are not sufficiently strong to mix the entire water column. The Limfjorden ecosystem is sensitive to eutrophication owing to its physical setting. It is possible that hypoxia occurred in the 

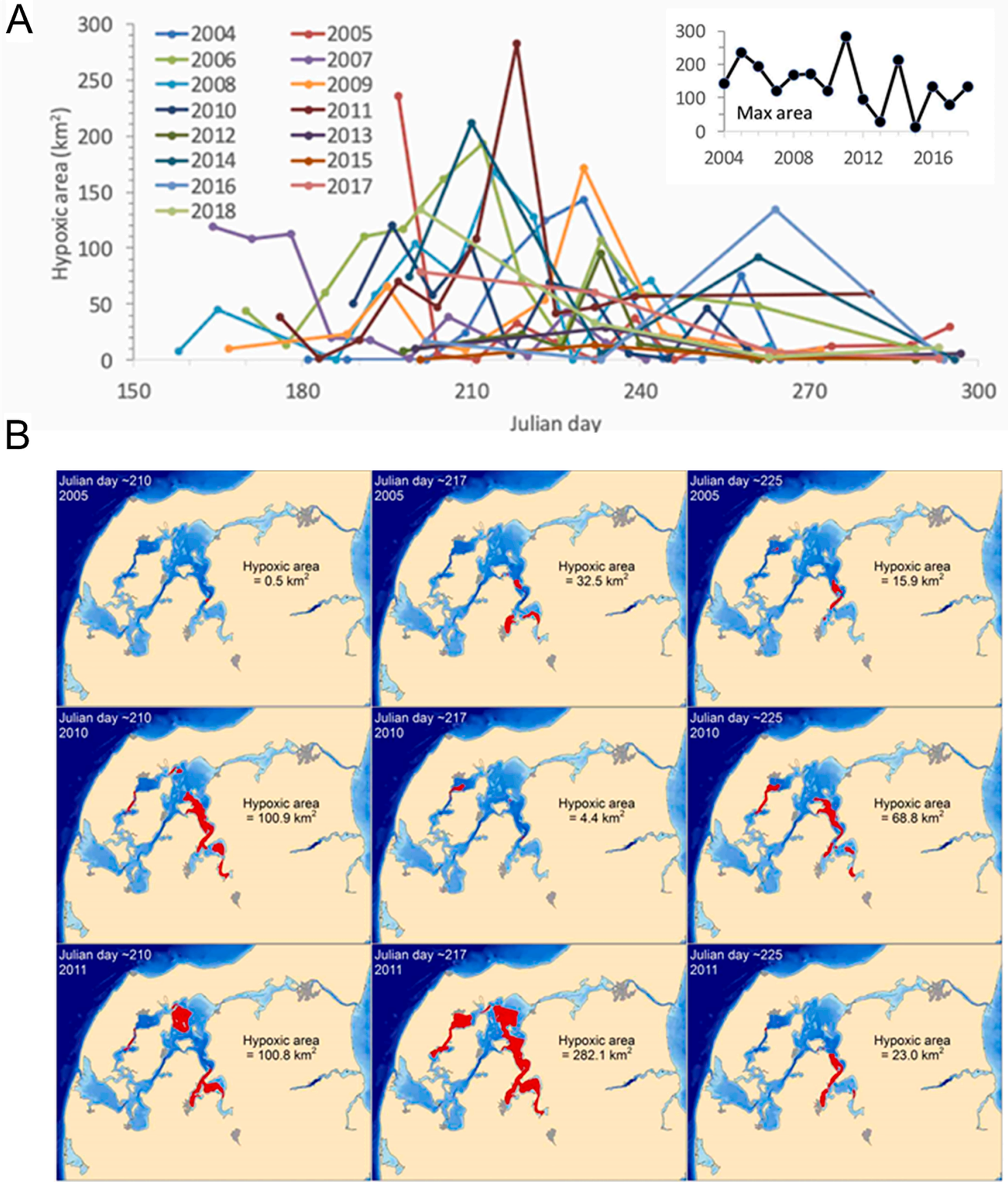

Fig. 5.4.3. Annual variation in the extent of hypoxic waters $\left(\mathrm{O}_{2}<2 \mathrm{mg} \mathrm{l}^{-1}\right)$ in the Limfjorden. A. Extent of hypoxic waters during different times of the year for different years. The inset defines the maximum area of hypoxia observed during a particular year. B. Spatial variation in the extent of hypoxia in 2005,2010 and 2011 demonstrating the strong variability in the coverage of hypoxic area.

past, before nutrient inputs started to accelerate in the 1950s (Conley et al., 2007), but oxygen demands have increased with nutrient enrichment rendering the ecosystem more vulnerable to hypoxia. Hence, in the past it would likely require unusual meteorological conditions for hypoxia to develop, whereas today meteorological conditions supporting the development of hypoxia occur multiple times each summer.

The connection between nutrient inputs and the poor ecological status of the Limfjorden was realized in the 1980s, when the first management measures to address eutrophication were taken. Due to reductions in nutrient inputs from wastewater treatment plants in the early 1980s, all basins in Limfjorden have responded with decreasing trends in both nutrient and chlorophyll concentrations over the period from 1985 to 2008 (Krause-Jensen et al., 2012). However, oxygen concentrations have not improved showing a small, albeit not significant, decrease over time (Hansen and Carstensen, 2019). This unexpected result may be due to increasing temperatures enhancing respiration and increasing the frequency of stratification (Riemann et al., 2016). In fact, oxygen conditions would have been much worse during the peak of eutrophication in the 1980s, if wind conditions and stratification had been similar to that in more recent decades.

Increases in particulate inorganic matter have been observed from enhanced sediment resuspension in response to the removal of blue mussels by dredging and to declining eelgrass cover (Carstensen et al., 2013). Although both blue mussels and eelgrass can sustain low oxygen concentrations for days, it is also possible that severe events of hypoxia 
will affect these populations and therefore contribute to the observed increase in sediment resuspension (Carstensen et al., 2013). Furthermore, nutrients stored in sediments are probably more easily mobilized during resuspension events in the absence of blue mussel and eelgrass populations.

Hypoxia under stratified conditions also leads to high accumulation of inorganic nutrients in bottom waters in Limfjorden. These nutrients can then sustain phytoplankton blooms in the surface after stratification breaks down by wind. Carstensen et al. (2007) showed that the magnitude of the surface blooms is significantly related to prior hypoxic conditions.

Limfjorden has been a test case for the use of long-line mussel farming as a mitigation tool in eutrophic coastal areas (Holmer et al., 2016). Model analyses show that mitigation farming decreases chlorophyll $a$ concentrations and increases Secchi depth, especially in the local surroundings of the mussel farms (Timmermann et al., 2019). However, nutrient regeneration from mussel farms is high and enhances nutrient availability, primarily ammonium, and thereby increases the pool of nutrients in the water column with the contribution increasing with increasing biomass of the farmed mussels. In addition, sediment respiration is enhanced showing a significant contribution of mussels to the consumption of oxygen (Holmer et al., 2016). Hence, mussel farms may overall reduce some of the symptoms of eutrophication in the estuary, but they also concentrate organic sediment loading locally with ramifications for development of hypoxia and nutrient cycling.

Low oxygen concentrations leading to hypoxia enhance sediment-water fluxes of ammonium and phosphate, increasing nutrient concentrations in the water column and stimulating additional phytoplankton production (Conley et al., 2007). Therefore, recommendations are that mussels should be harvested within the first year of the production cycle when the sediments change from a net sink of $\mathrm{N}$ due to uptake of $\mathrm{N}$ in the sediments to a source of $\mathrm{N}$ to the estuary.

\subsubsection{Future perspectives}

Over-enrichment of nutrients leads to serious and negative effects on ecosystems such as algal blooms, habitat loss, biodiversity changes, fishery loss and bottom water oxygen depletion (Scavia and Yong, 2009). In addition, hypoxia reduces the ability of marine systems to bury phosphorus or to lose nitrogen through denitrification (Asmala et al., 2017). Changes and reductions in benthic communities after hypoxic events alter the processing of organic matter within the sediments, and by reducing sediment mixing by organisms and can lead to increases in the anaerobic decomposition of organic matter. Repeated hypoxic events, such as observed in Limfjorden, thus increase the susceptibility of Danish waters to eutrophication and further hypoxia (Conley et al., 2007).

Decades of fertilizer use have created nutrient legacies in the catchment of the Baltic Sea and in its sediments. These nutrient pools result in time lags between the implementation of conservation measures that reduce land-based nutrient loads and the expected improvements in water quality (McCrackin et al., 2018); these delays can frustrate efforts for a cleaner Baltic Sea.
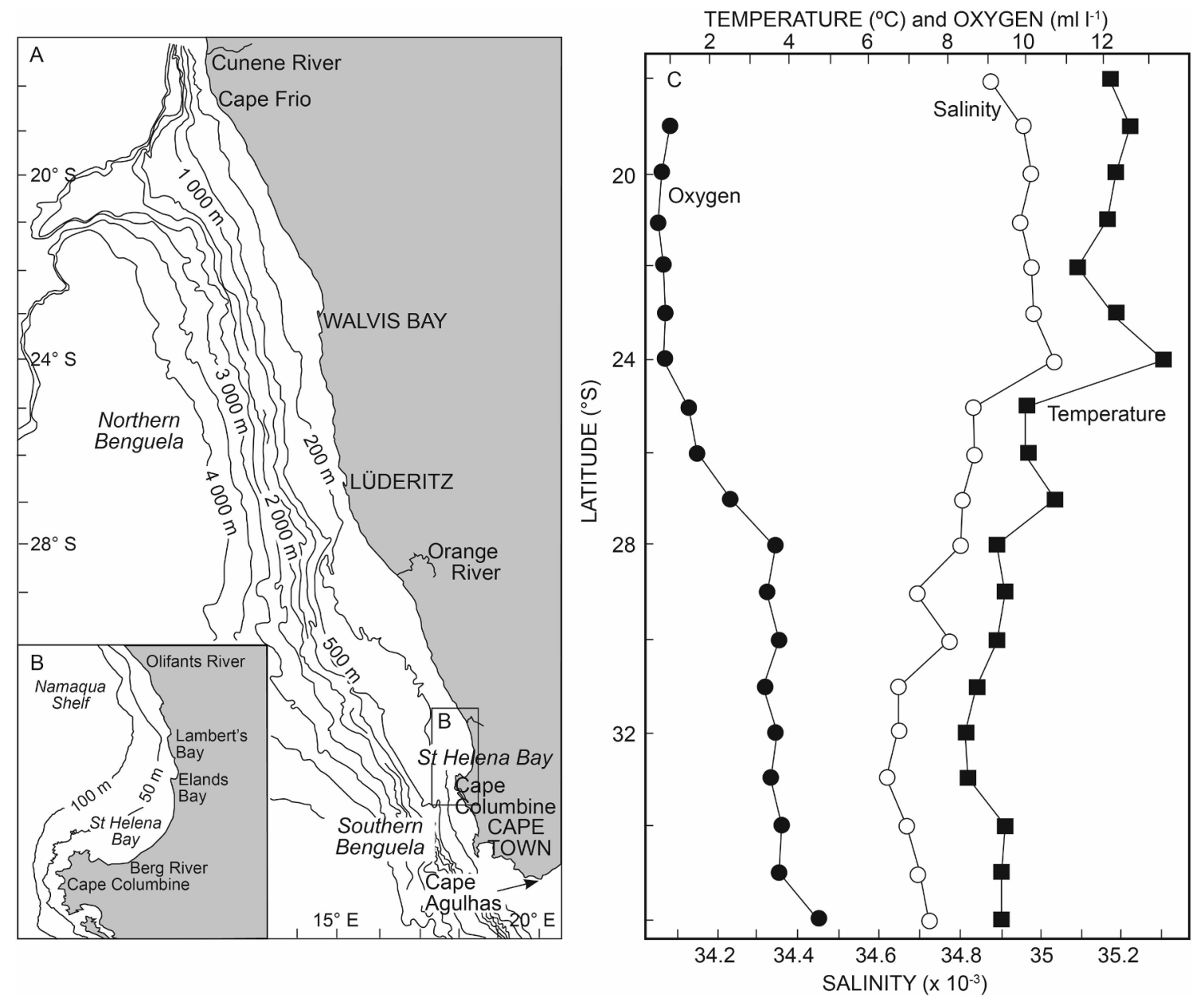

Fig. 5.5.1. Bathymetry of the (a) Benguela eastern boundary upwelling system and (b) St Helena Bay, and (c) along-shelf values of temperature, salinity and oxygen on the $200 \mathrm{~m}$ isobath.

Adapted from Dingle and Nelson (1993) 


\subsection{St Helena Bay}

The Benguela eastern boundary upwelling system is partitioned into northern and southern subsystems by a major upwelling cell off Lüderitz that creates a hydrographic disjuncture (Duncombe Rae, 2005). In the northern Benguela subsystem, oxygen depletion is more severe and widespread compared to that in the southern Benguela and this contrast in the oxygen regime is evident from the progressive increase in bottom oxygen values along the $200-\mathrm{m}$ isobath south of the Lüderitz upwelling cell (Fig. 5.5.1; Dingle and Nelson, 1993). The greater severity in oxygen depletion in the northern subsystem is largely dictated by differences in the character and source of the waters that feed wind-induced upwelling on the shelf to the north and south of the Lüderitz discontinuity. North of the Lüderitz upwelling cell, sub-thermocline waters originate from the oxygen-depleted Angola gyre, whereas south of Lüderitz these waters come from the interior of the well-ventilated Cape Basin (Duncombe Rae, 2005). Consequently, in contrast to the northern Benguela which is primed with remotely sourced low oxygen water, oxygen depletion in the southern Benguela is primarily a function of local drawdown. Here, oxygen-depleted waters are generally confined to the Namaqua shelf where oxygen concentrations have been shown to be lowest in St Helena Bay (Fig. 5.5.1; De Decker, 1970; Bailey and Chapman, 1985, 1991; Monteiro and van der Plas, 2006; Jarre et al., 2015).

\subsubsection{Bay setting within the southern Benguela}

St Helena Bay is formed by Cape Columbine, a promontory that modulates the seasonal upwelling process by influencing the across-shelf structure in alongshore flow, thereby creating a zone of retention in the lee of the Cape (Duncan and Nel, 1969; Holden, 1985; Penven et al., 2000; Fawcett et al., 2008). Additionally, intensification of upwelling off Cape Columbine, and the resulting cold water plume that forms off the promontory, tends to create a dynamic boundary isolating bay waters from the offshore domain (Penven et al., 2000). The resulting cyclonic circulation and increased residence time within the bay gives rise during the upwelling season to a strongly stratified, highly productive, twolayer system, sustained with cold upwelled bottom water and a sunwarmed surface layer (Waldron and Probyn, 1991).

The high productivity of St Helena Bay, and its isolation from the shelf region through limited across-shelf exchange, lead to very high levels of phytoplankton biomass within the bay particularly during late summer and early autumn (Pitcher and Weeks, 2006; Weeks et al., 2006). Increasingly stratified conditions at this time promote the succession of phytoplankton communities leading often to dinoflagellatedominated communities, which may accumulate nearshore forming red tides following relaxation or reversal of upwelling favourable winds (Pitcher and Nelson, 2006). Under conditions of persistent downwelling, development of an inshore poleward counter-current on the Namaqua shelf promotes alongshore delivery of these blooms into the southern reaches of the bay (Pitcher and Probyn, 2011; Pitcher et al., 2014). Within this environment of elevated primary production and high levels of organic matter two conspicuous categories of oxygen depletion have been identified with their own set of drivers and scales of variability, namely: (1) seasonal sub-thermocline hypoxia-anoxia and (2) episodic nearshore anoxia.

\subsubsection{Seasonal sub-thermocline hypoxia-anoxia}

Many investigations have reported the seasonal development of subthermocline hypoxia in St Helena Bay that is attributed to the retentive characteristics of the bay, to the high summer productivity in surface waters and a corresponding high rate of sedimentation of labile organic matter from these waters, and to summer stratification of the bay that impedes the exchange of oxygen between surface and bottom waters (De Decker, 1970, Bailey, 1991; Monteiro and van der Plas, 2006; Pitcher et al., 2014). Isolation of bay from shelf waters as simulated using a barotropic model (Penven et al., 2000), and as evident in the surface distribution of phytoplankton (Pitcher and Nelson, 2006), is also apparent in the bottom oxygen regime in that bay waters are clearly more depleted of oxygen than mid-shelf waters (Pitcher et al., 2014). These observations are considered indicative of local drawdown rather than that of advective exchange and the markedly different relationship between oxygen and temperature within and outside the bay further reinforces the notion of local depletion (Pitcher et al., 2014; Lamont et al., 2018). Spatially, the seasonal depletion of bottom oxygen is most evident in the southern reaches of the bay coincident with the highest surface chlorophyll $a$ concentrations (Pitcher and Probyn, 2017). In these high chlorophyll $a$ areas, retention as a function of cyclonic circulation is at a maximum and the consistently lower oxygen concentrations in this part of the bay are also responsible for a local shift in biogeochemical cycling. Only in this region of the bay is there evidence of fixed-N loss via denitrification and/or anammox with a resulting clear nitrate deficit in autumn (Pitcher and Probyn, 2017).

A high resolution time series of bottom oxygen in the southern region of the bay at $50 \mathrm{~m}$ depth for 2013-2014 showed that the seasonal decline in oxygen concentration is marked by sharp sub-seasonal variability. This subseasonal variability reflects events of hypoxia or anoxia that are often associated with periodic deposition of organic matter, as indicated by coincident increases in bottom chlorophyll $a$ concentrations (Pitcher and Probyn, 2017). The deposition of fresh organic matter as indicated by large spikes in bottom fluorescence is considered indicative of rapid vertical flux to the sediment and alludes to abrupt termination of blooms. A more recent time series of temperature, oxygen and chlorophyll $a$ from the same locality for July 2016 - June 2017 similarly depicts many of these sub-seasonal variations (Fig. 5.5.2). The elevated bottom temperatures $\left(>11^{\circ} \mathrm{C}\right)$ and oxygen concentrations $\left(>2 \mathrm{ml} \mathrm{l}^{-1}\right)$ characteristic of winter, decline with the transition to spring, and an increasingly stratified environment forced by the incursion of cold bottom waters and sun-warming of surface waters. The hypoxic conditions that consequently characterize most of spring and summer are interspersed with events of anoxia clearly linked with periodic increases in bottom water chlorophyll $a$ concentrations. Two such events leading to anoxia are evident during the course of the 2016-17 upwelling season, one in spring (late September - early October) and the other in autumn (March) (Fig. 5.5.2). These events were separated by several similar events, but of lesser magnitude, while the second event was followed by a period of sustained anoxia. Bottom waters are abruptly ventilated by deep mixing with the onset of winter (June), as revealed by a coincident increase in bottom temperatures (Fig. 5.5.2).

\subsubsection{Episodic nearshore anoxia}

A category of episodic oxygen-deficiency is recognized in association with high biomass dinoflagellate blooms in the nearshore waters of St Helena Bay (Pitcher and Probyn, 2011, 2012, 2016; Pitcher et al., 2014; Pitcher and Jacinto, 2019). The blooms are known as red tides and the northern shores of St Helena Bay are often subject to these blooms where they accumulate under conditions of downwelling during late summer and autumn (Pitcher and Probyn, 2011, 2012; Pitcher et al., 2014). These events have often been associated with large marine mortalities and have also been found to coincide with corrosive low $\mathrm{pH}$ conditions and, in some cases, with the production of hydrogen sulphide $\left(\mathrm{H}_{2} \mathrm{~S}\right)$ (Matthews and Pitcher, 1996; Pitcher and Probyn, 2012).

Overnight development of anoxia in St Helena Bay has been shown to be achievable owing to the exceptional rates of respiration of these blooms due to their magnitude and the inherently high respiration rates of dinoflagellates (Pitcher and Probyn, 2016). Night-time respiration rates of $1.71 \mathrm{ml} \mathrm{l}^{-1} \mathrm{~h}^{-1}$ have been recorded and far exceed replenishment via air-sea exchange, and result in the subsequent removal of oxygen from the entire water column within a few hours of sunset. Bloom senescence and its subsequent decay within the confines of shallow, low volume, nearshore environments also lead to the complete stripping of oxygen from the water column. Nutrient stressors are considered important in driving bloom-to-post-bloom transitions important in determining the biogeochemical fate of the bloom and the onset of 

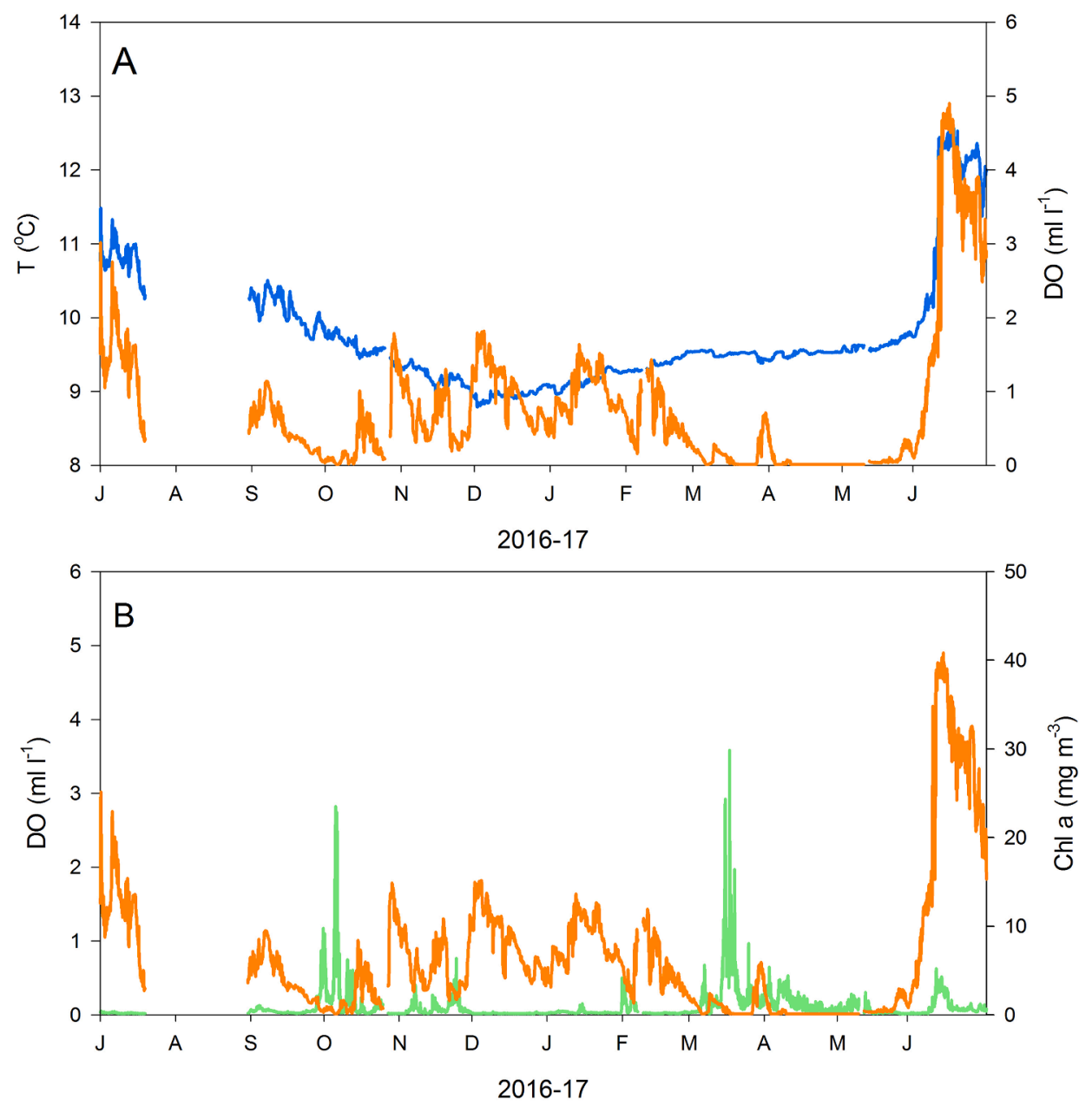

Fig. 5.5.2. A time series of (a) bottom temperature and oxygen, and (b) bottom oxygen and chlorophyll $a$ in St Helena Bay at $50 \mathrm{~m}$ depth from 1 July 2016 to 30 June 2017 (data from Department Forestry, Fisheries and Environment, South Africa provided by Grant C. Pitcher).

anoxia (Pitcher and Probyn, 2016). Concurrent measurements of nutrients and nutrient uptake within red tides have shown that nutrient concentrations are unlikely to meet the demands of these blooms. Nutrient inaccessibility, particularly during periods of extended downwelling when sub-thermocline nutrients are unavailable, is therefore likely to trigger cell death and bloom mortality thereby fueling the microbial food web and the consumption of oxygen (Pitcher and Probyn, 2011).

Observations of anoxia attributed to the dinoflagellate Prorocentrum triestinum in St Helena Bay in February 2015 demonstrate the scales of variability associated with such events (Fig. 5.5.3; Ndhlovu et al., 2017). The bloom distribution and magnitude was captured by satellite observations of ocean colour, and profiles of oxygen at four stations demonstrate the extreme variability of oxygen concentrations between stations and throughout the water column. Warm surface waters with high biomass characterized all of the stations. Anoxic conditions were evident through the entire water column at the shallow inner station a, anoxic surface waters were found to overlay oxygenated deeper waters at station b, near-surface and bottom hypoxia were evident at station c, while station $\mathrm{d}$ was characterized by saturated oxygen concentrations at the surface and bottom water hypoxia (Fig. 5.5.3). This extreme variability is dictated by bloom patchiness, varying metabolism (oxygen production/consumption) and ultimately bloom senescence leading to high microbial respiration and a rapid transition from net autotrophy to net heterotrophy.

\subsubsection{The superposition of drivers of hypoxia-anoxia}

Multiple mechanisms drive oxygen depletion in St Helena Bay and their importance vary somewhat between the two categories of seasonal sub-thermocline depletion and episodic nearshore depletion. The extent and rate of development of hypoxia and anoxia is always a function of competing physical and biogeochemical processes with the trade-off between flushing and respiration clearly important. The superposition of processes, some additive and others subtractive in the net outcome of hypoxia or anoxia, makes attribution to any particular mechanism challenging. Although oxygen depletion results from the sum of a number of processes serving in the direct production or consumption of oxygen, these processes are indirectly controlled by a complex interplay of hydrographic and biological factors.

Upwelling-supplied nutrients are fundamental in determining the high productivity of St Helena Bay; however, coastline configuration and the resulting three-dimensional circulation are equally important in creating a zone of retention of high biomass (Pitcher and Nelson, 2006). Through the generation of a cyclonic eddy within the bay, retention also serves to increase residence time and reduce flushing of the bay by oxygen replete shelf waters (Pitcher et al., 2014). Further, the development of strongly stratified bay waters within the wind shadow of Cape Columbine serves both to reduce the ventilation of bottom waters and to promote the development of red tides, in that the growth of dinoflagellates is favoured in a low turbulence environment (Figueiras et al., 2006). Finally, periods of relaxation of upwelling are required for the development and concentration of nearshore red tides, and the manifestation of an inshore poleward counter current during periods of 

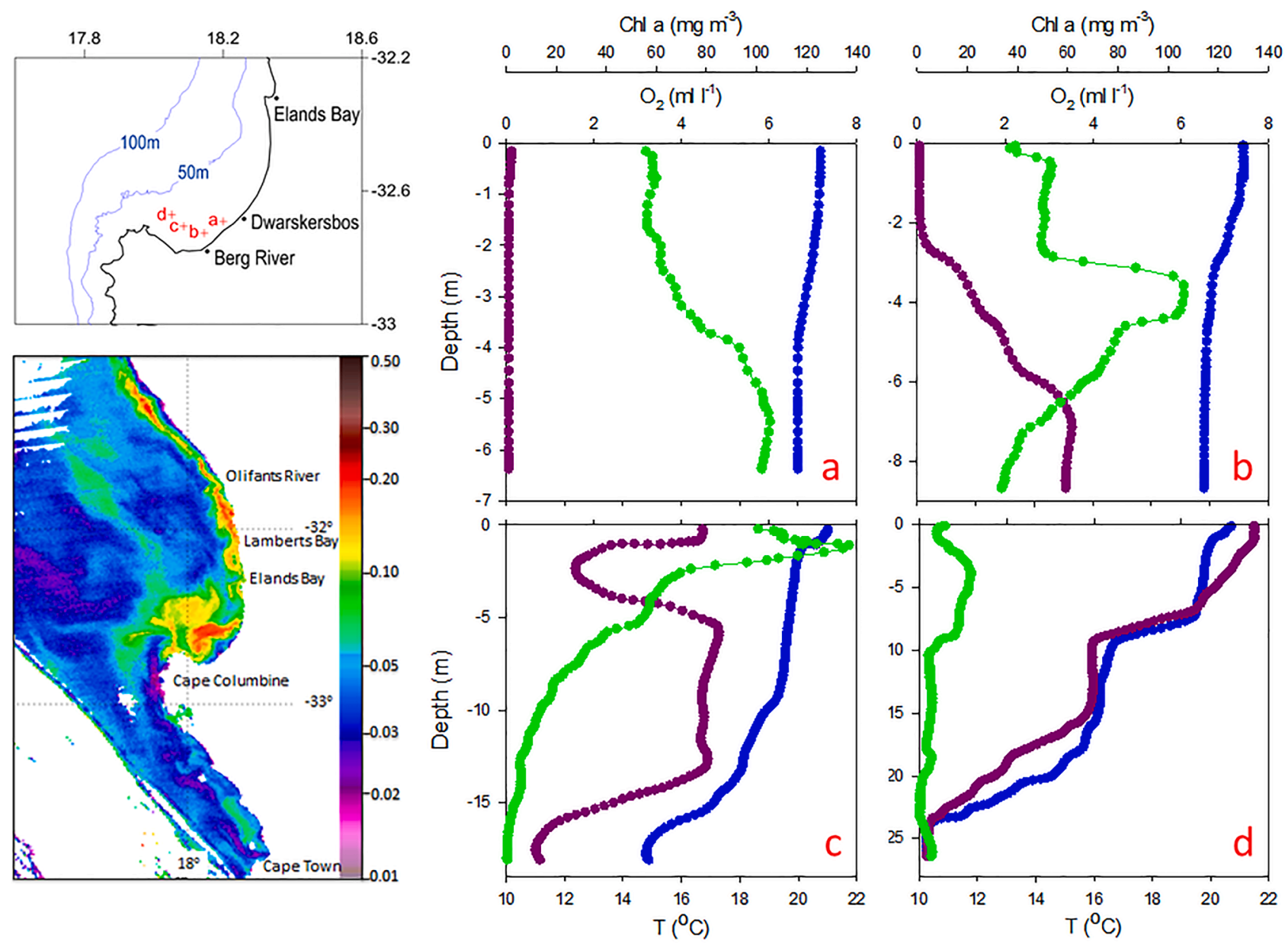

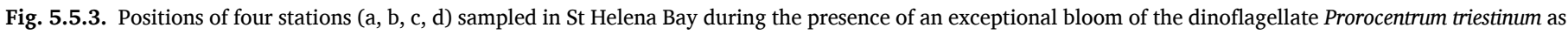

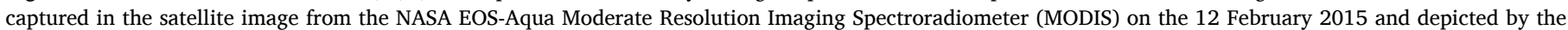

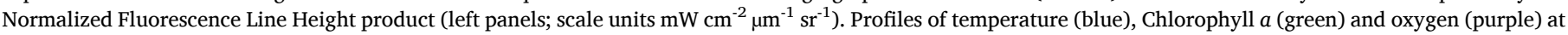

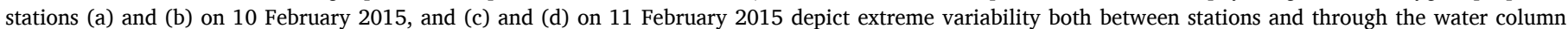
(adapted from Ndhlovu et al., 2017). (For interpretation of the references to color in this figure legend, the reader is referred to the web version of this article.)

downwelling further concentrates these blooms within the confines of the bay (Pitcher and Nelson, 2006).

Ultimately, all oxygen consumption is driven by the supply of organic matter and bloom senescence is an important process in fueling this supply. In the episodic events of anoxia linked to red tide, the respiration of organic matter by microbes and microzooplankton is shown to far exceed oxygen supply through air-sea exchange (Pitcher and Probyn, 2016). This is a function of the extraordinary amounts of phytodetritus produced by these blooms and the small volume of water from which oxygen needs to be consumed in shallow nearshore environments. For the development of seasonal hypoxia or anoxia in bottom waters, the rate of sedimentation of labile organic matter and the resulting consumption of oxygen through its degradation by microbial respiration needs to exceed the supply of oxygen from surface waters. Supply from surface waters is dictated by the strength of the thermocline and from the advection and subsequent retention of shelf waters into the bay. Oxygen consumption in bottom waters appear closely linked to subseasonal events of elevated deposition of organic matter as indicated by spikes in bottom chlorophyll $a$ concentrations (Pitcher and Probyn, 2017). These spikes in bottom fluorescence are considered indicative of rapid vertical flux dictating rapid increases in oxygen utilization and imply abrupt termination of blooms in response to one or another stressor. The observations in St Helena Bay thereby serve to demonstrate the increasing relevance of biological, as opposed to hydro-physical, drivers of low oxygen with increasing productivity and production of organic matter. Within the spectrum of physical versus biological control, the episodic events of anoxia associated with red tides represent the extreme in biological control of oxygen depletion.

\subsubsection{Known trends and susceptibility to further deoxygenation}

The response of eastern boundary upwelling systems to climate change is likely to include an increase in upwelling owing to intensified winds driven by increased temperature differences between land and sea (Bakun, 1990; Sydeman et al., 2014). The likelihood of increased upwelling in the southern Benguela is further supported by predictions of a poleward shift in atmospheric high pressure systems that will strengthen upwelling winds at high latitudes (Rykaczewski et al., 2015; Wang et al., 2015). The timing, evolution, intensity and duration of coastal upwelling all have important ecosystem consequences, as demonstrated by year to year differences in winds in the St Helena Bay region and their influence on upper-ocean warming, stratification, productivity and the development of red tides (Pitcher et al., 2014). The observations of high bay productivity and a higher prevalence of red tides during years of increased cumulative wind stress suggest a greater risk of declining oxygen concentrations with intensified upwelling.

Several assessments of long-term changes in bottom oxygen concentrations in St Helena Bay have been undertaken. Hutchings et al. (2009) reported a long-term decline in oxygen concentrations in subthermocline waters of St Helena Bay of about $1 \mathrm{mll}^{-1}$ over the period 1961-2007 and this decline in oxygenated waters was implicated as the 
cause of a southward shift in the distribution of rock lobster (Cockcroft et al., 2008). However, in extending this time series back to 1957, Hutchings et al. (2012) claimed only a muted biogeochemical response to climate in sub-thermocline waters, and attributed changes in oxygen concentrations to marked decadal variability. Pitcher et al. (2014) considered these time series to be compromised by temporal and spatial biases, and in undertaking a comparison of data collected at similar intervals and from stations of close proximity, between 1957 and 1962 and 2008-2011, was unable to detect any notable change in bottom oxygen concentrations. These studies demonstrated the very clear need for implementation of a consistent sampling protocol with respect to sampling intervals and station locations to enable meaningful analyses of trends. Nevertheless, in the absence of any detected change in bottom oxygen concentrations, it is likely that the decline of rock lobsters on the west coast be attributed to an increase in events of episodic anoxia due to an increased occurrence of red tides (Augustyn et al., 2018).

\subsection{Changiiang and Zhujiang estuaries}

There are many sites along the coast of mainland China where hypoxia has been observed but these observations are seldom reported in the scientific literature. Terrestrial input typically plays an important role in the development of hypoxia at these sites ultimately effecting ecosystem functions. Consequently, the largest areas of hypoxia along the coast of China are found in regions impacted by large river systems. The two largest rivers in China, as measured by annual water discharge, are the Changjiang (Yangtze River) and Zhujiang (Pearl River). Both exhibit hypoxia within their respective estuaries (Fig. 5.6.1a). The Changjiang flows into the East China Sea (and partially into the southern Yellow Sea), and the Zhujiang (including parts of the lower reaches of the Humen outlet, the Lingding Yang and waters off Hong Kong) flows into the northern South China Sea (Fig. 5.6.1b,c). Another well-known large river is the Huanghe (Yellow River) that empties into the Bohai, where decreasing oxygen concentrations have also been reported in recent years (Zhai et al., 2019).

\subsubsection{Comparison of the Changiiang and Zhujiang estuaries}

Both the Changjiang and Zhujiang are subject to high-levels of freshwater runoff with high sediment loads. The coastal environments off the Changjiang and Zhujiang are also highly eutrophic, and characterized by very high dissolved inorganic nitrogen (DIN) relative to phosphate (DIP) (Table 5.6.1). Consequently N:P ratios for both river systems are extremely high (Yin et al., 2001). The Changjiang River is very turbid, and plumes of water off the river mouth with high total suspended matter (TSM) result in a strongly light limited environment. The turbidity of the Zhujiang is much lower, as is evident from the lower annual sediment discharge of $26.9 \times 10^{6}$ ton versus $152 \times 10^{6}$ ton for the Changjiang (Table 5.6.1). For the Changjiang Estuary, phytoplankton growth is at a maximum and high concentrations of chlorophyll $a$ are evident in the waters beyond the turbid light-limited river plume but inshore of the nutrient-limited offshore oligotrophic waters (i. e., between $122.5^{\circ} \mathrm{E}$ to $123.0^{\circ} \mathrm{E}$; Zhu et al., 2009). This area of high chlorophyll is influenced by Changjiang Diluted Waters (CDW) and reports of algal blooms in the estuary and adjacent East China Sea have increased dramatically since 1985 from $<5$ per year in the 1980 s to over 50 per year in the 2000s (Wang, 2006). Owing to the combined effects of high river discharge in summer and the dominance of southwesterly winds induced by the East Asia Monsoon, the impact of the Changjiang waters can extend as far as Cheju Island, about $400 \mathrm{~km}$ from the river mouth, where the salinity can decline to $<30$ in surface waters (Lie et al., 2003).

Hypoxia typically occurs off the Changjiang Estuary in August each year, with the first records dating back to the 1950s, when the hypoxic zone was around $1900 \mathrm{~km}^{2}$ (Data of the national integrated oceanographic survey, 1961). Later in the 1970s, a low oxygen area was identified in the southern Yellow Sea with oxygen concentrations as low
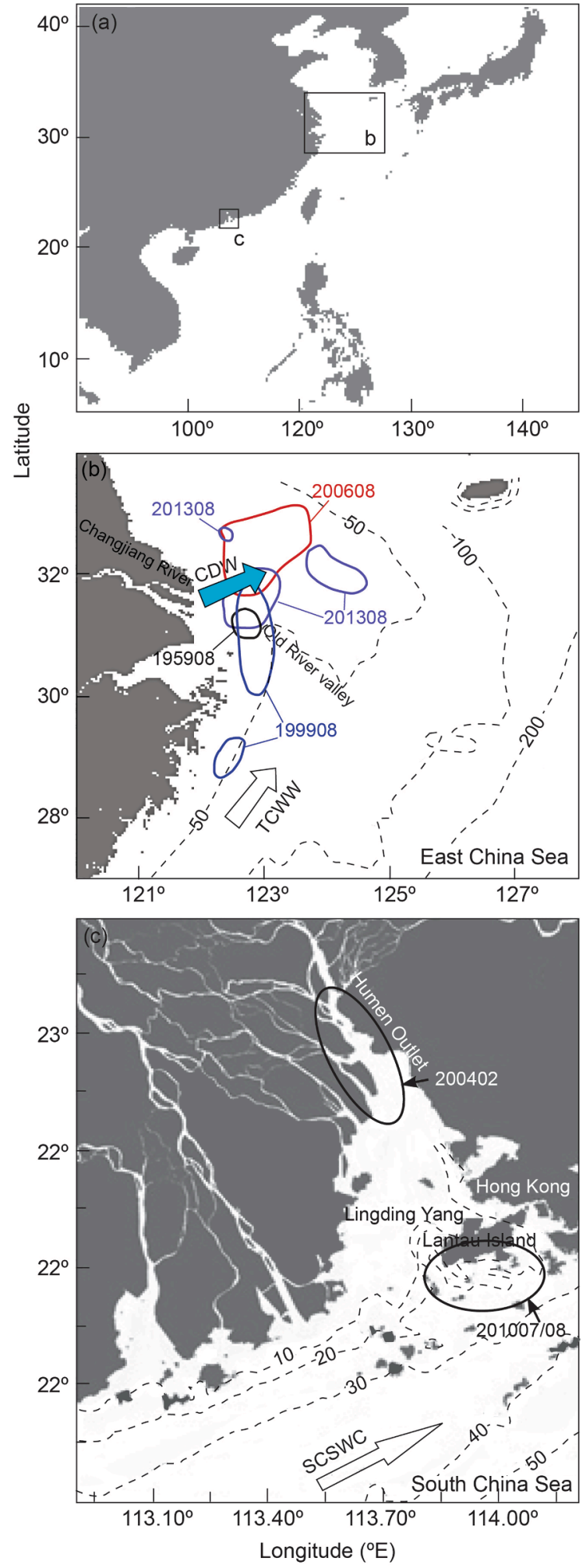

Fig. 5.6.1. (a) The location of China's two largest estuaries (b) the Changjiang and (c) the Zhujiang. Demarcated areas of hypoxia $\left(\mathrm{O}_{2}<2 \mathrm{mg} \mathrm{l}^{-1}\right)$ are labeled by year/month. For plot $b$, blue and hollow arrows indicate the flow directions in surface and bottom layers, respectively. CDW $=$ Changjiang Diluted Water; TCWW = Taiwan Current Warm Water. Modified from Zhu et al. (2011). For plot c, the arrow indicates summer flow in the offshore region (SCSWC = South China Sea Warm Current). For the Lingding Yang region flow patterns are strongly influenced by the tides, undergoing reversals as determined by the tidal phase. (For interpretation of the references to color in this figure legend, the reader is referred to the web version of this article.) 
Table 5.6.1

A comparison of the Changjiang and Zhujiang.

\begin{tabular}{llll}
\hline & Units & Changjiang & Zhujiang \\
\hline Basin area & $10^{6} \mathrm{~km}^{2}$ & $1.94[1]$ & $0.45[2]$ \\
Population & billion & $0.4[1]$ & $0.09[2]$ \\
Annual water discharge & $10^{9} \mathrm{~m}^{3}$ & $970[1]$ & $395[2]$ \\
Annual sediment discharge & $10^{6}$ ton & $152[3]$ & $26.9[3]$ \\
Silica (summer) & $\mu \mathrm{M}$ & $150[4]$ & $115[5]$ \\
Nitrate (summer) & $\mu \mathrm{M}$ & $100[4]$ & $90[5]$ \\
DIP (summer) & $\mu \mathrm{M}$ & $1.5[4]$ & $0.6[5]$ \\
\hline
\end{tabular}

(1) The Changjiang water resources bulletin (2015).

(2) The Peal River water resources bulletin (2016).

(3) China River Sediment Bulletin (2016).

(4) Zhang et al. (2007).

(5) Yin et al. (2001).

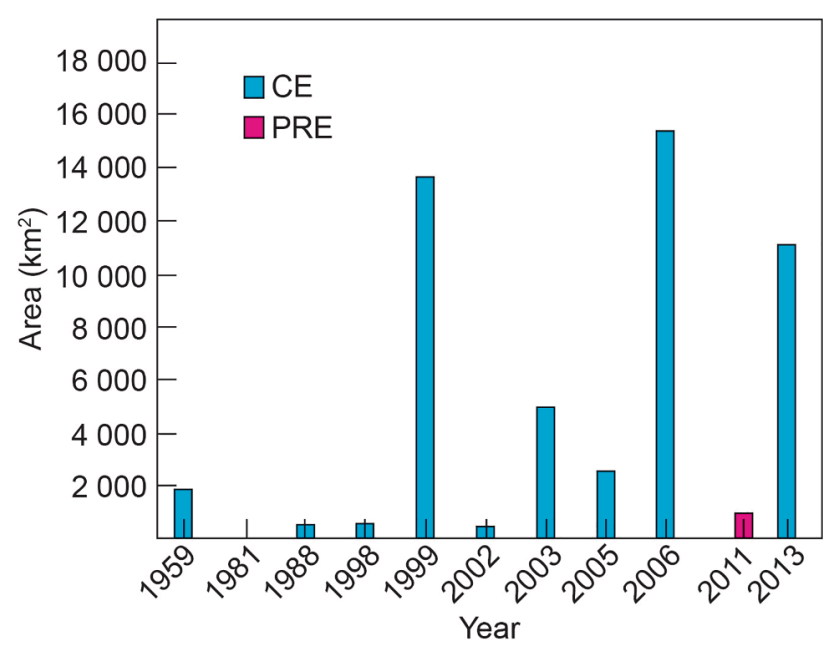

Fig. 5.6.2. Hypoxic zone area in the Zhujiang Estuary (PRE) and off the Changjiang Estuary (CE). Note the x-axis is not proportional. Data source, for CE: 1959 (Office of integrated oceanographic survey, 1961), 1981 (Limeburner et al., 1983), 1988 (Tian et al., 1993), 1998 (Wang and Wang 2007), 1999 (Li et al., 2002), 2002 (Wang, 2009), 2003 (Wang, 2009), 2005 (our unpublished data), 2006 (Zhu et al., 2011), 2011 and 2013 (Zhu et al., 2017); for PRE: 2011 (Yin et al., 2004; Qian et al., 2018).

as $1.8 \mathrm{ml}^{-1}$ in near-bottom waters ( $\mathrm{Gu}, 1980$ ). During the 1980 s and 1990s, further studies identified areas of hypoxia (Limeburner et al., 1983; Tian et al., 1993), although the exact areas were not determined. Increased attention was given to hypoxia off the Changjiang Estuary in the late 1990s, and in 1999 the area of hypoxia was determined to be $13.8 \times 10^{3} \mathrm{~km}^{2}$ (Li et al., 2002). By 2006, the area of hypoxia had increased to $15.4 \times 10^{3} \mathrm{~km}^{2}$ (Zhu et al., 2011) and was similarly large in 2013 at $11.2 \times 10^{3} \mathrm{~km}^{2}$ (Zhu et al., 2017) (Fig. 5.6.2). The oxygen minimum decreased over the three major hypoxic events from $0.96 \mathrm{mg} \mathrm{l}^{-1}$ in 1999 and $0.94 \mathrm{mg} \mathrm{l}^{-1}$ in 2006 to $0.73 \mathrm{mg} \mathrm{l}^{-1}$ in 2013 (Zhu et al., 2017). The East China Sea has a wide continental shelf with a strong tidal influence, and high-frequency measurements over $25 \mathrm{~h}$ in summer showed a sinusoidal signal in bottom oxygen, with a period of $12-13.5 \mathrm{~h}$ that was close to the tidal period (i.e., $12.5 \mathrm{~h}$ ) (Zhu et al., 2017). The influence of the tide was nevertheless unable to alleviate bottom hypoxia, largely due to the bottom topography and the strongly stratified conditions forced by the buoyancy of the river plume. Moreover, the center of hypoxia is typically located in the area where the residual current is slowest (i.e., the net transport due to tidal currents is at a minimum) (Zhu et al., 2016).

Hypoxia in the Zhujiang Estuary is located at a shallower depth $(10-30 \mathrm{~m})$ than the hypoxia off the Changjiang Estuary $(20-50 \mathrm{~m})$ (Fig. 5.6.1b,c). Hypoxia in the Zhujiang Estuary is also much smaller in extent, is located much closer to the mainland and islands, and may even occur in the river channel in the upper reaches of the estuary (Humen outlet; Fig. 5.6.1c) in winter (Dai et al., 2006). The summer hypoxia near Lantau Island (Fig. 5.6.1c) is similar in character to hypoxia offshore of the Changjiang Estuary, and may extend into the East China Sea and Yellow Sea (Yin et al., 2004). Observations in the Zhujiang Estuary and adjacent offshore region between 1990 and 2000 showed that bottom oxygen concentration was low, but usually $>2 \mathrm{mgl}^{-1}$. Only one station located in the region of maximum turbidity showed bottom oxygen concentrations $<2 \mathrm{mg}^{-1}$ (Yin et al., 2004). After 2000, an increasing number of hypoxic sites were reported in the Zhujiang Estuary and adjacent coastal environment, including both the Estuary head (the Humen outlet) and downstream of the Zhujiang Estuary in the Lantau Island area off Hong Kong (Fig. 5.6.1c) (Dai et al., 2006). In the vicinity of the Humen outlet, oxygen concentrations of $<2 \mathrm{mg} \mathrm{l}^{-1}$ were observed and in the dry season (February) conditions were close to anoxic (Dai et al., 2006; Harrison et al., 2008). Downstream of the Zhujiang Estuary off Hong Kong, hypoxic bottom waters have been recorded with an oxygen minimum as low $\approx 1 \mathrm{mg}^{-1}$ (Qian et al., 2018). Overall, hypoxia in the Zhujiang Estuary is less extensive, but more persistent than the hypoxia associated with the Changjiang Estuary in that, during the dry season, the hypoxia in the Zhujiang is located in the upper reaches of the estuary and in the wet season hypoxia is located in the lower reaches of the estuary. Monthly observations between 2010 and 2011 showed the presence of hypoxia in the lower estuary off Hong Kong with an area $\sim 1$ $000 \mathrm{~km}^{2}$ (Qian et al., 2018) (Fig. 5.6.2).

\subsubsection{Mechanisms important in the development of hypoxia}

Stratification of the water column is the basic physical attribute that drives hypoxia in both the Changjiang and Zhujiang estuaries (Zhu et al., 2016). For this reason, hypoxia in both estuaries occurs primarily in August, when water column stratification is strongest, while hypoxia is absent off the Changjiang in the dry and windy winter season (Zhu et al., 2017; Qian et al., 2018). Circulation is also important in controlling hypoxia and determines the residence time of bottom waters. For the Changjiang Estuary, the estimated bottom water residence time is 11 days, whereas for the Zhujiang Estuary the estimated residence time (for the area close to Lantau Island) is shorter at 3-5 days (Rabouille et al., 2008). These residence times are both considerably shorter than those of many other areas of coastal hypoxia, including the Gulf of Mexico where the estimated residence time is 95 days (Rabouille et al., 2008). Consequently, hypoxia in the Gulf of Mexico is found to be more stable than that off the Changjiang (Zhu et al., 2017) and Zhujiang estuaries (Qian et al., 2018). In the Chinese estuaries, wind and cyclones can temporally erode water column stratification and thereby ventilate bottom waters, but following these events, stratification is readily reestablished and bottom hypoxia can again develop within two weeks (Ni et al., 2016). Bottom topography is also considered to play a major role in the development of hypoxia, particularly in the submerged and old river valley off the Changjiang (Fig. 5.6.1b; Wang, 2009), where water is more isolated and not easily renewed or replaced. However, the bottom topography of the main zone of hypoxia further to the north is rather featureless (with area over $15400 \mathrm{~km}^{2}$; Fig. 5.6.1b) and consequently has a limited influence on the distribution of the hypoxic zone.

Kuroshio waters that intrude onto the shelf of the East China Sea determine the background oxygen concentrations of the Changjiang Estuary and its adjacent marine environment (Qian et al., 2017). These bottom oxygen concentrations of $\sim 4.7 \mathrm{mg}^{-1}$ are much lower than the saturated oxygen levels $\left(\sim 8 \mathrm{mg} \mathrm{l}^{-1}\right)$ in the surface waters. Despite the high input of terrestrially sourced organic matter, microbial respiration of the organic matter formed by enhanced marine primary production, attributed to eutrophication, is the dominant consumer of bottom oxygen resulting in hypoxia (Wang et al., 2016; Wang et al., 2017). Based on two independent isotope fractionation models that quantified the isotopic distillation of dissolved oxygen concentration and its $\delta^{18} \mathrm{O}$, the mean contributions of water column respiration and sedimentary respiration to total near-bottom oxygen utilization were calculated as 53 
and $47 \%$, respectively (Zhou et al., 2021). Beneath the pycnocline water column respiration contributions to total oxygen utilization increased with increasing oxygen utilization. Consequently, under hypoxic conditions water column respiration was shown to be the major oxygen consumption mechanism and therefore plays a vital role in driving the depletion of oxygen off the Changjiang Estuary. A high resolution time series of oxygen from a bottom-mounted sensor has shown that bottom hypoxia can develop within relatively short periods (e.g., two weeks) in summer and is closely related to patterns of stratification ( $\mathrm{Ni}$ et al., 2016). Every increase or decrease in oxygen was associated with a weakening or strengthening of stratification. Consequently, bottom oxygen and wind mixing were significantly correlated with oxygen lagging wind by $33 \mathrm{~h}$. Strong wind was shown to play a dual role in determining bottom oxygen concentrations. Wind induced mixing was able to ventilate bottom waters but also enhanced subsequent phytoplankton bloom development following the enrichment of surface waters (due to wind-driven vertical mixing). As a result, higher rates of organic deposition followed during ensuing periods of stratification, thereby accelerating the development of hypoxia (Ni et al., 2016).

The coupling of bottom oxygen depletion and nutrient regeneration in the northern and southern regions (separated by $30.5^{\circ} \mathrm{N}$ ) of the hypoxic zone off the Changjiang Estuary are distinctly different. In the southern region, apparent oxygen utilization and regenerated nutrients follow the Redfield ratio, whereas in the northern region there is a clear deviation from the Redfield ratio (Zhu et al., 2011). This difference in biogeochemical coupling is repeatedly observed each summer (Zhu et al., 2017). Possible reasons include differences between regions in the stoichiometry of deposited organic matter and in the removal or addition of nutrients by lateral advection or exchange at the sediment-water interface. Note that there is upwelling in the southern region, whereas upwelling is much weaker or absent in the northern region. Further, because hypoxia off the Changjiang Estuary is recurrent and occurs repeatedly within a single summer (Ni et al., 2016), nutrient regeneration and hence cycling is much greater.

For the Zhujiang Estuary, while extended periods of hypoxia are rare in Hong Kong waters, episodic events have been reported during late summer due to factors such as low wind, high rainfall and high river discharge that result in strongly stratified waters with dampened vertical mixing (Yin et al., 2004; Dai et al., 2006). As is the case in the Changjiang Estuary, summer upwelling and regional circulation transport relatively low oxygen bottom waters $\left(3-4 \mathrm{mg}^{-1}\right.$ ) into the Zhujiang Estuary and this increases the potential for hypoxia (Harrison et al., 2008). The development of low oxygen in this region is coupled to the presence of phytoplankton blooms in the surface waters (Qian et al., 2018). However, terrestrial organic matter is also considered an important source of organic matter (as high as 35\%) contributing to the generation of bottom hypoxia (Su et al., 2017). In the head of the Zhujiang estuary in the Humen outlet area, nitrification also plays an important role in depleting oxygen in the water column (Dai et al., 2006; Harrison et al., 2008).

The location of the hypoxic zone off the Changjiang Estuary is also reported to be moving northward (Fig. 5.6.1b) (Zhu et al., 2011). Given that the tidal excursion (the distance that water travels under tidal impact) is longer in the northern region (north of $30.5^{\circ} \mathrm{N}$; Fig. 5.6.1b) relative to that in the southern region, the impacts to the benthic ecosystem off the Changjiang Estuary may be greater (Zhu et al., 2017). Eutrophication is a key cause for coastal and estuarine hypoxia, and it is well established that eutrophication of the water bodies draining into the Changjiang has been increasing for the past several decades (Zhang et al., 1999; Yan and Zhang, 2003). Furthermore, preserved sedimentary phytoplankton pigments indicate that mild eutrophication may have been taking place since 1855 or possibly even earlier (Zhu et al., 2014). As a result, the reported areas of the hypoxic zone off the Changjiang Estuary have increased in recent decades, exceeding $10000 \mathrm{~km}^{2}$ in some years (Fig. 5.6.2); for comparison, hypoxia at various localities in the Zhujiang Estuary has recently been estimated as a combined area of $\sim 1$
$000 \mathrm{~km}^{2}$ (Fig. 5.6.2).

Finally, it has been suggested that nutrient ratios (N/P and N/Si) in the Changjiang estuary have changed during the last few decades (Zhang et al., 2007), and that dinoflagellates now play a more important role in the estuary and adjacent East China Sea (Zhu et al., 2014; Tang et al., 2006). Dinoflagellate-derived organic matter is hence expected to play an increasingly important role in the consumption of bottom oxygen. With respect to the Zhujiang, nutrient loads and ratios are also likely to change over the next several decades (Harrison et al., 2008) and these changes and their impact on hypoxia off both the Changjiang and Zhujiang Estuary require further study.

\subsection{Tokyo and Osaka bays}

Many Japanese embayments have experienced severe cultural eutrophication due to economic growth and expanding human populations and this has resulted in increasing depletion of oxygen in their bottom waters (Diaz and Rosenberg, 2008; Yasuhara et al., 2012; Yanagi, 2015b; Breitburg et al., 2018). Among these embayments, Tokyo Bay and Osaka Bay have been intensively studied in terms of their history of eutrophication and deoxygenation.

\subsubsection{Tokyo Bay}

Tokyo Bay is the largest bay in Japan in terms of the population of its catchment area, which includes Tokyo, the capital and the largest city of Japan (Furukawa, 2015). Approximately 28 million people live in the catchment area of Tokyo Bay $\left(7600 \mathrm{~km}^{2}\right)$, having increased from $\sim 10$ million in 1950. This is almost double the population of the Chesapeake Bay (USA) catchment area. Tokyo Bay is an enclosed bay with a surface area of $1400 \mathrm{~km}^{2}$ and an average water depth of $\sim 15 \mathrm{~m}$. The inner northeastern part of the bay is shallow, $<20 \mathrm{~m}$ water depth, but a channel runs south from the central bay gradually deepening to $\sim 600 \mathrm{~m}$ at the bay mouth. Surface water temperature ranges from $\sim 10$ to $27^{\circ} \mathrm{C}$, and surface salinity varies from $\sim 15$ to 33 , with more stable subsurface salinities (at $10 \mathrm{~m}$ ) ranging mostly from $\sim 30$ to 33 (Ramaiah and Furuya, 2002; Kubo et al., 2019). The tidal range is $\sim 1.5 \mathrm{~m}$. The freshwater input into Tokyo Bay is $\sim 400 \mathrm{~m}^{3} \mathrm{~s}^{-1}$ (Furukawa, 2015), and two major rivers, the Edo and Ara Rivers, provide $\sim 50 \%$ of the total freshwater supply to the bay (Furukawa and Okada, 2006). Seawater exchange with the ocean is dominated by estuarine circulation, and the residence time is about 20-30 days during summer (Sato et al., 2012; Yanagi, 2015a). Since the 1950s, Tokyo Bay has suffered various environmental problems with serious impacts on the ecosystem because of rapid industrial development and increasing human population (Matsumoto, 1981, 1983; Matsumoto and Saito, 1984).

Eutrophication and the resulting deoxygenation of bottom waters has been one of the most serious outcomes of development and economic growth, with an increase in algal blooms in the form of red tides and blue tide events (caused by the presence of colloidal sulfur formed by the oxidation of sulfides) following the upwelling of hypoxic bottom waters. In addition, $\sim 90 \%$ of the natural tidal flats of the bay have been lost to coastal development over the last 100 years. Consequently, loads between 1950 and 1980 increased from $\sim 200$ to $\sim 500$ tons $\mathrm{d}^{-1}$ for chemical oxygen demand (COD), from $\sim 80$ to $\sim 250$ for total phosphorus (TP) and from $\sim 10$ to $\sim 30$ for total nitrogen (TN). However, subsequent to these peaks in the 1970s and 1980s, these loadings subsequently decreased to nearly the 1950 values $(\sim 200, \sim 100$ and $\sim 10$ in 2001), owing to improved sewage treatment and more stringent legislation and environmental management. Nevertheless, since 1980, Tokyo Bay has consistently been subject to 3-4 months of bottom water hypoxia each summer that is mostly driven by eutrophication. Typically, hypoxic bottom waters cover the major part of the inner bay (Ando et al., 2005). Blue tides that follow the upwelling of this hypoxic bottom water are also associated with periodic events of hydrogen sulphide poisoning of marine organisms. Modeling studies have indicated that wind stress, river discharge and the intrusion of oceanic water are important in 
determining the seasonal dynamics of bottom water oxygen (Nakayama et al., 2010; 2013; Sato et al., 2012).

The key controls on bottom water oxygen concentrations are: (1) freshwater discharge; (2) northeast winds; (3) southwest winds; and (4) strong southwest winds (Nakayama et al., 2010). The tendency is for northeast winds to enhance exchange with the deep ocean (Nakayama et al., 2010). These winds, assisted by freshwater discharge into the bay, enhance estuarine circulation by increasing surface outflow, which is compensated by the intrusion of deeper oceanic waters that maintain high oxygen concentrations in the bay's bottom waters. In contrast, persistent southwest winds tend to suppress estuarine circulation and the exchange of oceanic waters, and thus, contribute to the onset of hypoxia (Nakayama et al., 2010). However, strong southwesterly winds above a threshold of $10 \mathrm{~m} \mathrm{~s}^{-1}$ cause rapid recovery from hypoxia due to the mixing of the inner bay water with oceanic water (Sato et al., 2012; Nakayama et al., 2010, 2013). Further, the recovery of oxygen concentrations is shown to be a function of the duration of these strong winds and of the antecedent oxygen concentrations.

Observational studies from repeated measurements from the bay head to bay mouth have been informative in describing oxygen distributions in response to the intrusion of oceanic waters (Fig. 5.7.1; Fujiwara and Yamada, 2002). The intrusion of dense oceanic water forces the bottom hypoxic waters to the northern bay head, where they are lifted to intermediate depth to form a subsurface hypoxic water mass in the region of the pycnocline. In summer, these subsurface hypoxic waters may spread out along the pycnocline towards the southern outer part of the bay (Fig. 5.7.1, top panel). When the dense oceanic bottom waters retreat from the bay, oceanic water may flow in at intermediate depth by way of compensation forming a 3-layered structure. At this time the bottom hypoxic water mass is shifted from the center of the bay towards the mouth of the bay (Fig. 5.7.1, bottom panel; Fujiwara and Yamada, 2002).

\subsubsection{Osaka Bay}

Osaka Bay is an enclosed bay with an ellipsoidal shape, being $\sim 60 \mathrm{~km}$ in length and $\sim 30 \mathrm{~km}$ wide, with a tidal range of $\sim 1 \mathrm{~m}$. The bay surface area is $\sim 1500 \mathrm{~km}^{2}$ and the average water depth is $\sim 20 \mathrm{~m}$. The Yodo River is the main source of freshwater flowing into the bay. Osaka
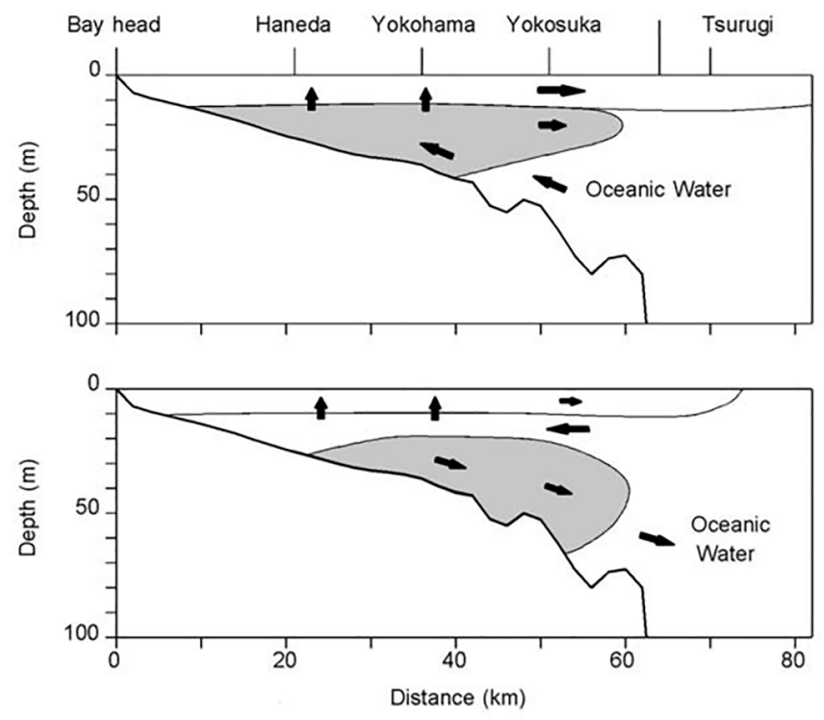

Fig. 5.7.1. Schematic illustration of circulation in Tokyo Bay and the corresponding movement of hypoxic water (grey area): top panel, intrusion of oceanic water into the bottom layer and development of subsurface hypoxic water; and bottom panel, withdrawal of the oceanic water and accompanying displacement of the hypoxic water towards the bay mouth (Fujiwara and Yamada 2002).
City, located within the catchment area of Osaka Bay, is one of the largest cities in Japan with a population of $\sim 2.7$ million. Like Tokyo Bay, Osaka Bay has experienced various environmental problems attributed to coastal development and expanding populations within the catchment area (Yasuhara et al., 2007; Yanagi, 2015c).

Environmental monitoring in the inner bay has provided an overview of the present status and of changes in the bay since the $1970 \mathrm{~s}$ (Figs. 5.7.2 and 5.7.3). These changes have included high chemical oxygen demand and total phosphorus values and low bottom water oxygen concentrations particularly during the summer in the inner northeastern parts of Osaka Bay (Fig. 5.7.2). In the summer, low surfacewater salinity and resulting stratification are attributed to higher precipitation and river discharge which also contributes the input of high organic matter into the inner part of the bay (Fig. 5.7.3).

Paleoecological investigation of sediment cores in Osaga Bay (Yasuhara and Yamazaki, 2005; Tsujimoto et al., 2006a, 2008a,b; Yasuhara et al., 2007; Hirose et al., 2008) identified the start of eutrophication in the early 1900s after the industrialization of Japan $\sim 100$ years ago (Fig. 5.7.4). After that, especially during post-World War II economic growth, eutrophication and resulting bottom water deoxygenation further deteriorated, reaching a low in the 1970 s. Since the early 1900s, and more specifically the mid-1950s, ostracod abundance at the inner bay sites (OBY, OS3) decreased due to bottom hypoxia driven by eutrophication, while abundances at the middle bay sites (OS4, OS5) increased due to a food-rich environment induced by eutrophication without oxygen depletion (Fig. 5.7.4). These observations were accompanied by increases in the benthic foraminifera Eggerella advena and Trochammina hadai, both known indicators of eutrophication and hypoxia (Fig. 5.7.4). During the 1950s, one-third of the bay was covered by hypoxic bottom waters (Joh, 1986) which seriously affected the benthic ecosystem. The situation has improved since the 1950s owing to better environmental regulation, specifically the Law Concerning Special Measures for Conservation of the Environment of the Seto Inland Sea enacted in 1973. Increases in the population of Osaka City, in the frequency of red tides (Tsujimoto et al., 2006a), and in COD, N and P discharge from the 1900s and their peaks in the 1970s are all consistent with the paleoecological reconstruction (Fig. 5.7.4; Yasuhara et al., 2007; Tsujimoto et al., 2008a).

\section{Discussion}

\subsection{Open ocean}

In the open ocean, the physical attributes of low ventilation or near stagnant waters, along with the accumulated removal of oxygen by heterotrophic respiration, has led to the development of major subsurface oxygen minimum zones (OMZs) in the eastern parts of the tropical Pacific and Atlantic oceans and in the northern Indian Ocean (Karstensen et al., 2008; Paulmier and Ruiz-Pino, 2009). Oxygen profiles in these regions are typically characterised by saturated surface oxygen concentrations, by an oxygen minimum zone at intermediate depths (100-1 $000 \mathrm{~m}$ ), and by higher oxygen levels at greater depths (Brandt et al., 2015). This vertical structure is the result of a delicate balance between oxygen supplied through varying ventilation and circulation patterns, the photosynthetic production of oxygen, and the consumption of oxygen by the remineralization of sinking organic matter (Brandt et al., 2015). These OMZs typically reach their lowest oxygen concentrations and shallowest depths in subtropical and tropical upwelling regions where thermocline waters have been isolated from the atmosphere for the longest time (Margolskee et al., 2019).

The case studies of the ETSP and ETNA reveal that OMZs are located in a shadow zone equatorward of the subtropical gyre, with the lowest oxygen levels near the shelf break (Brandt et al., 2015). Similarities in structure include an equatorial oxygen maximum driven by zonal advection and the relative importance of the different terms of their oxygen budgets. However, they are different in that the OMZ of the ETSP 

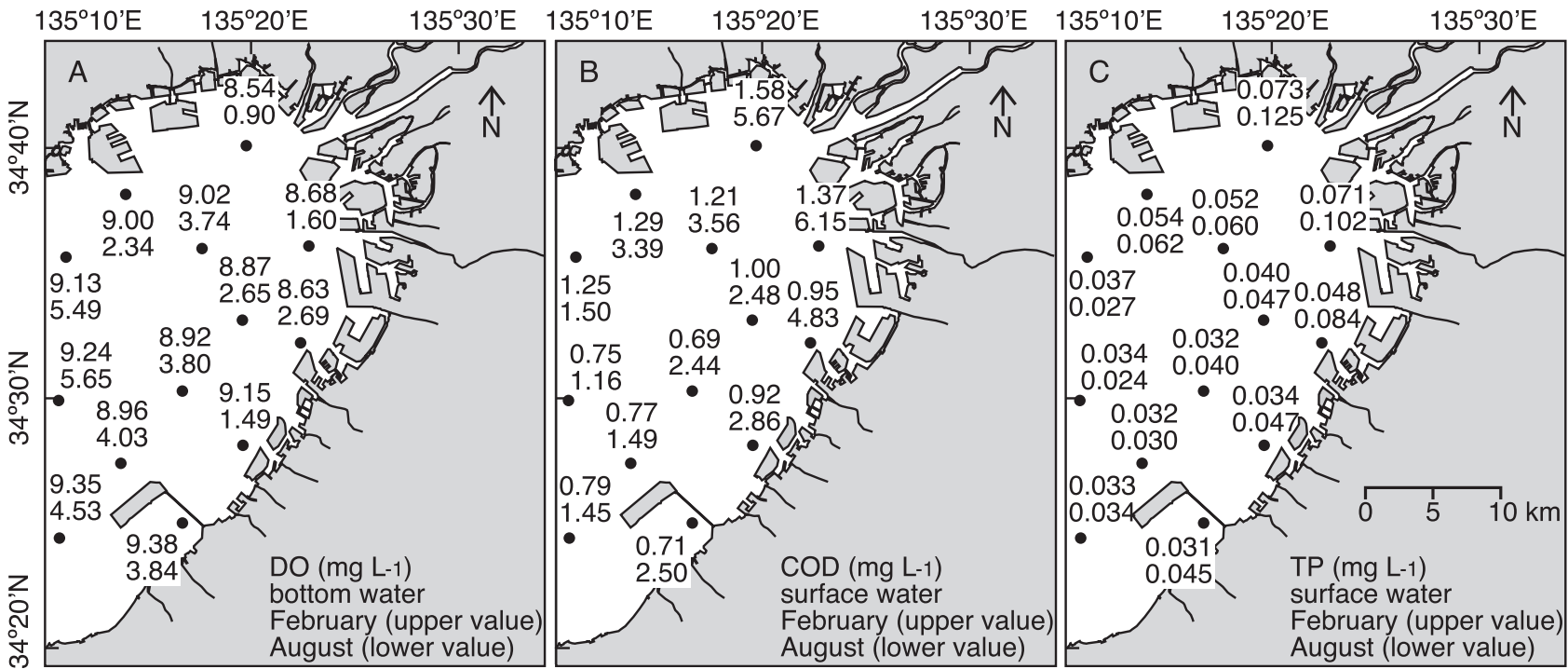

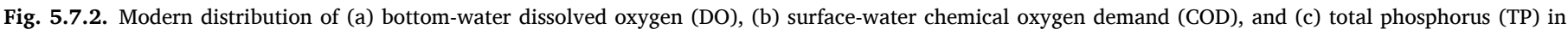
Osaka Bay (3-yr average from 2001 to 2003). From Yasuhara et al. (2007).

covers a much wider region and oxygen concentrations in its core are considerably lower than that of the OMZ of the ETNA (Karstensen et al., 2008). OMZ dynamics are particularly sensitive to open boundary conditions as dictated by equatorial circulation (Montes et al., 2014). For both OMZs, the dominant ventilation process is the eastward advection of oxygenated waters from the well-ventilated western boundary by subsurface equatorial zonal jets (Duteil et al., 2014a,b). As the zonal currents are of similar strength in both the tropical Pacific and Atlantic, it is the difference in basin width that results in greater water mass age and consequently lower oxygen concentrations in the eastern tropical Pacific compared to the eastern tropical Atlantic (Brandt et al., 2015). Other common ventilation processes in these OMZs include lateral fluxes from oxygen-rich waters of the subtropics through mesoscale activity and diapycnal oxygen fluxes from oxygen-rich layers above and below the thermocline. Oxygen consumption processes key to the development of OMZs are poorly constrained and are currently best estimated as the net consumption along the water mass path from subduction to the OMZ (Brandt et al., 2015).

The anomalous location of the OMZs of the Indian Ocean, in that they are not found on the eastern boundary, is the result of the connection of the Indian Ocean to the Pacific through the Indonesian seas and to the limited northern extension of the Indian Ocean as a result of the Eurasian landmass (Wyrtki, 1971). OMZs are found in the northern basins of the Indian Ocean, in the Arabian Sea and Bay of Bengal, and are attributed to the high productivity of the region owing to monsoon winds and to the very restricted oxygen supply by means of lateral advection (Swallow, 1984; Naqvi, 1987; Warren, 1994). As revealed in the case study of the OMZs of the north Indian Ocean, minimum oxygen concentrations within the Arabian Sea and Bay of Bengal are similar, but these systems are characterised by very different biogeochemical regimes. The Arabian Sea is more productive than the Bay of Bengal and is also better ventilated from oxygenated waters crossing the equator and entering the western Arabian Sea (McCreary et al., 2013). Higher productivity and better ventilation, together with the advection of waters from the Persian Gulf in the northern Arabian Sea, ensure that the most intense oxygen minima are confined in the Arabian Sea to the central and northeastern parts of the basin. These areas of intense oxygen minima further correspond to areas of active denitrification and nitrite maxima.

Lower oxygen concentrations in the Bay of Bengal compared to the Arabian Sea are expected based on their respective differences in circulation and reduced ventilation of the Bay of Bengal. However, the nitrite maximum observed in the Arabian Sea is seldom seen in the Bay of Bengal, where nitrate concentrations are also higher. The absence of denitrification in the Bay of Bengal is possibly attributed to lower respiration rates in the water column and a deeper remineralization depth that may be linked to higher lithogenic material from river input that is likely to facilitate more rapid sinking of aggregate material with less degradation in the water column (Naqvi et al., 1996; Al Azhar et al., 2017).

Quantitative assessment of the global oceanic oxygen content since 1960 has revealed a $>2 \%$ decrease throughout the water column and ocean models predict a further decline in the global dissolved oxygen inventory of $1-7 \%$ by the year 2100 (Stramma et al., 2008; Helm et al., 2011; Schmidtko et al., 2017). Global warming is considered the major driver of this decrease in the open oceans through a reduction in oxygen solubility (Bopp et al., 2013; Oschlies et al., 2018). Decreasing oxygen solubility associated with warming is estimated to account for $\sim 15 \%$ of current total global oxygen loss, and a much higher $>50 \%$ of the oxygen loss in the upper $1000 \mathrm{~m}$ of the ocean (Helm et al., 2011). The role of decreasing solubility in declining oxygen concentrations in the upper ocean is apparent for the period 1958-2015, in that, begining in the mid1980 s, oxygen and heat content were shown to be highly correlated with sharp increases in both deoxygenation and ocean heat content (Ito et al., 2017). It is estimated that a $1^{\circ} \mathrm{C}$ warming through the water column will create a $10 \%$ increase in the area of hypoxic zones and a threefold increase in the volume of suboxic waters (Deutsch et al., 2011).

Warming also acts to intensify thermal- and salinity-driven stratification, the latter through its effects on ice melt and precipitation, and both may significantly decrease the transport of oxygen into the ocean interior by diminishing ventilation processes (Oschlies et al., 2018). Changes in the transport of oxygen can be manifest through a slow-down in large-scale overturning circulation and reduced mixing, particularly with a reduction in mixed layer depth (Keeling et al., 2010; Schmidtko et al., 2017). Although current evidence suggests that biogeochemical processes contribute only a small portion to oceanic oxygen loss, the production and consumption of oxygen in the open ocean may also be influenced by various factors including temperature effects on metabolic rates (Oschlies et al., 2018). Warming tends to raise metabolic rates, thus accelerating the rate of respiration and oxygen consumption. Decomposition of sinking particles occurs faster, and remineralization of these particles is shifted toward shallower depths, affecting the vertical profile of oxygen consumption (Brewer and Peltzer, 2017), but not necessarily changing the magnitude of oxygen loss. 

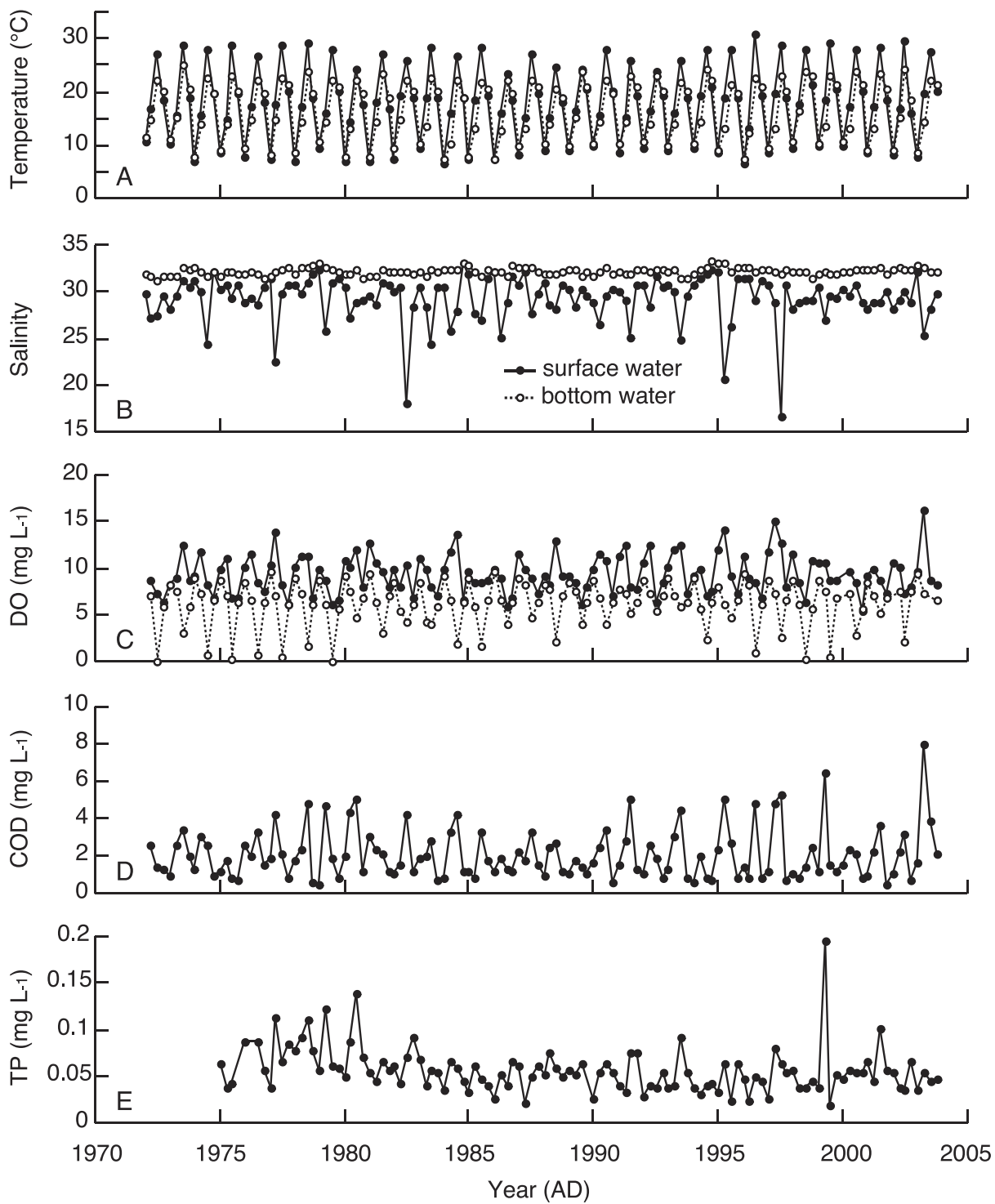

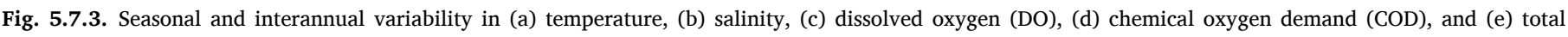
phosphorus (TP) in the inner part of Osaka Bay over the last 30 yr. From Yasuhara et al. (2007).

Although deoxygenation of the oceans is not restricted to low-oxygen environments, it is in oxygen deficient regions that a further decline in oxygen is likely to have a more immediate impact. However, the very low oxygen concentrations in some of the OMZs make it difficult to discern a decreasing trend. Nevertheless, observations have shown an intensification and expansion of OMZs in the tropical oceans, specifically the central and eastern tropical Atlantic and the equatorial Pacific (Stramma et al., 2008). The steeper oxygen declines in the tropical Atlantic may be owing to the higher oxygen concentrations in this region compared to the Pacific and Indian Oceans.

With reference to the case studies, decreases in oxygen in the upperpart of the OMZ of the ETSP over the past few decades, attributed to an expansion of the OMZ (Czeschel et al., 2012; Schmidtko et al., 2017; Ito et al., 2017), are highly sensitive to changes in equatorial circulation, specifically the intensity of zonal currents that ventilate the OMZ from the west. This physical contribution to the rate of change of oxygen is considered an order of magnitude greater than changes attributed to biogeochemical processes (Montes et al., 2014). Observations of slight oxygenation of waters near the OMZ core off Southern Peru suggest a source of ventilation associated with the deeper Intermediate Antarctic Waters, though the regional significance of this trend needs to be confirmed and the potential mechanism further studied (Duteil et al., 2020). In the OMZ of the ETNA, long-term changes were attributed to a decline in core concentrations and an increase in the vertical extent of the OMZ (Stramma et al., 2008). A more recent analysis of oxygen concentrations has shown that while oxygen concentrations have continued to decline in the upper oxycline, oxygen concentration below the OMZ core has increased (Hahn et al., 2017). Causes for this shoaling of the OMZ are not fully understood but suggested mechanisms include weakened ventilation and/or enhanced biological oxygen consumption. In the OMZs of the north Indian Ocean, rates of deoxygenation have been shown to be low (Stramma et al., 2008). However, given the very low oxygen concentrations in these waters, small declines may have a disproportionately large impact. Deoxygenation in the equatorial Indian Ocean appears to be highest along the western boundary, due to declining oxygen concentrations in the intermediate waters crossing the equator and entering the western Arabian Sea and also due to a change in the volume of these waters as a consequence of altered circulation.

There are notable model-data discrepancies in the simulation of ocean interior oxygen distributions in eastern tropical OMZs by Earth system models. The failure of the models to sufficiently resolve observed subsurface equatorial zonal jets, the exclusion of mesoscale eddies and 


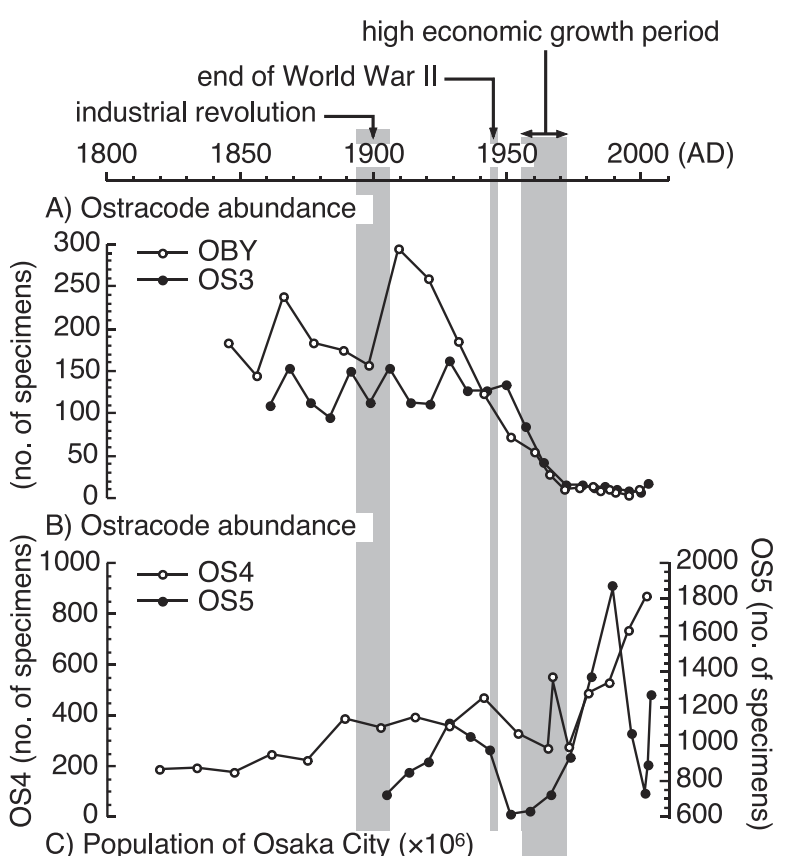

C) Population of Osaka City $\left(\times 10^{6}\right)$

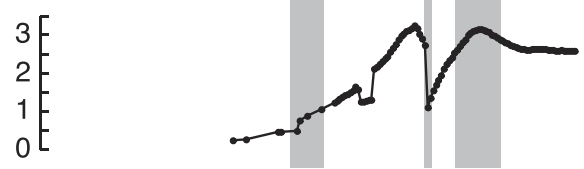

D) Relative abundance of foraminiferal species

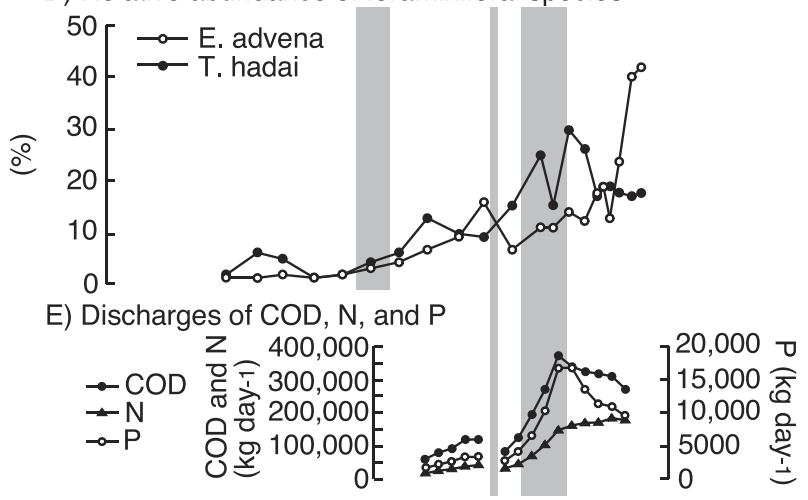

Fig. 5.7.4. The history of eutrophication of Osaka Bay. (a, b) Temporal distributions of ostracode absolute abundance (number of specimens per $10 \mathrm{~g}$ dry sediment), (c) the Osaka City population (Osaka City, 2002), (d) relative abundance of E. advena and T. hadai (agglutinated foraminifera) in the core OBY (Tsujimoto et al., 2006b), and (e) discharges of COD, nitrogen, and phosphorous from the Osaka Prefecture via the Yodo River (Nakatsuji et al., 1998). From Yasuhara et al. (2007).

inaccurate representation of isopycnal mixing, all of which are important ventilation processes, contribute to model biases (Gnanadesikan et al., 2013; Cabré et al., 2015; Fu et al., 2018). Nevertheless, recent Earth system models have served to demonstrate the inter-dependencies and feedbacks between drivers of oxygen depletion in open oceans in their prediction of a reversal of declining oxygen concentrations in the intermediate waters of the tropical oceans (Fu et al., 2018). Long-term computer simulations have reproduced observed declines in oxygen driven by reduced solubility and ventilation and these are projected to continue to around 2150 . However, the process of reducing the supply of oxygen to the interior of the ocean with increasing stratification also reduces the supply of nutrients to surface waters thereby limiting primary production and the export of organic matter to the deep ocean. Therefore, a shift from OMZ expansion to contraction is predicted to occur by these models after 2150 when biological effects of reduced export of organic matter become more prominent than the solubility effect. A reduced OMZ core is also likely to limit the production of the greenhouse gas nitrous oxide (Fu et al., 2018).

\subsection{Shelf systems}

The oxygen regime of the shelf may be strongly influenced by the adjacent environments of the coastal zone and the open ocean. Coastal ecosystems and their watersheds strongly impact the shelf environment through the input of freshwater and river-borne nutrient loadings that strengthen stratification and increase productivity and the supply of organic matter to the shelf. Conversely, the supply of oxygen onto the shelf is dictated by the origin of water masses advected onto the shelf, the properties of which are subsequently modified by both physically and biologically mediated processes on the shelf.

Shelf hypoxia is in many cases associated with large rivers that may exert a strong influence on the continental shelves over which they discharge, forming stratified and turbid plumes especially during periods of high discharge (Rabouille et al., 2008). The case study of the northern Gulf of Mexico clearly shows shelf hypoxia driven by the increased nutrient loads associated with many of these rivers, both in the initial development of hypoxia and in its worsening over time. Although physical attributes of the system, including the high volume of fresh water supply from the Mississippi River and the resulting stratified conditions, suggest the possible occurrence of natural hypoxia, paleo indicators in dated sediment cores indicate the appearance of hypoxia around the 1950s that was coincident with increasing eutrophication (Rabalais et al., 2007a; Gooday et al., 2009). The three-fold increase in nitrate loadings since 1950 has served to increase both the severity of hypoxia and also the areal extent. Consequently, the load of nitrate from the Mississippi River in May has been shown to be a good predictor of the area of hypoxia in mid-summer (Turner et al., 2008). Although some river-borne organic material may also contribute to the organic loading in bottom shelf waters, most organic matter is derived from phytoplankton growth stimulated by riverine-delivered nutrients (Turner and Rabalais et al., 1994; Rabalais et al., 2014). The greater persistence and severity of bottom water hypoxia in summer is attributed to the strengthening of the pycnocline as formed by freshwater and reinforced by thermal warming. Once established in mid-summer, wind-induced cross-shelf advection determines the distribution of hypoxic waters on the shelf (Rabalais et al., 1991).

Shelf waters of the North Indian Ocean provide a clear example of an environment impacted by low oxygen waters of the open ocean. The two mesopelagic OMZs of the North Indian Ocean impinge on a large area of the continental margin, which is consequently subject to severe hypoxia. However, because the upper boundary of the two OMZs is generally located between 100 and $200 \mathrm{~m}$, the continental shelf of the North Indian Ocean only experiences oxygen depletion on the western and eastern boundaries of the Arabian Sea at times of intense upwelling during the Southwest Monsoon. In the western Arabian Sea, short residence times on the shelf do not allow for development of intense anoxia. In contrast, on the western Indian shelf, the slow rate of upwelling and the formation of a low salinity surface lens formed by high coastal rainfall contribute to the formation of the largest shallow water oxygendeficient zone in the world (Naqvi et al., 2000). Upwelling in the Bay of Bengal is weaker than in the Arabian Sea and the OMZ in the Bay of Bengal rarely extends to shallow depths and therefore does not impact the shelf environment.

Continental shelves of eastern boundary upwelling systems (EBUS) are generally characterised by low oxygen environments generated by high productivity without any direct anthropogenic influence. However, here too the characteristics of source waters are important and the variation between oxygen regimes of EBUS is considered to be driven by differences in source waters. The fact that the spatial and temporal variability of hypoxia both within and between EBUS far exceeds observed variability in net production export fluxes bears testament to 
the important role of source waters in driving variability in hypoxia (Monteiro et al., 2011).

The upper boundary of the OMZ of the Eastern Tropical South Pacific is shallower than that of other OMZs, particularly off central Peru where it significantly impacts the shelf environment (Helly and Levin, 2004). This is in contrast to the southern shelf of the Canary Current that is poorly linked to the OMZ of the Eastern Tropical North Atlantic, in that only $1 \%$ of the ETNA OMZ waters upwell onto the shelf (Glessmer et al., 2009). Therefore, the numerous processes that drive variability of the OMZ in the ETSP also impact oxygen levels on the shelf. Seasonal and interannual variations are specifically driven by the shoaling or deepening of the upper boundary of the OMZ. At seasonal time scales, mixing-stratification, primary production and mesoscale circulation govern the shallowing of the upper boundary of the ETSP OMZ (Graco et al., 2017), whereas Equatorial Kelvin Waves and Coastal Trapped Waves impact the shoaling of the OMZ at intra seasonal and interannual timescales (Espinoza-Morriberón et al., 2019). At multi-decadal to millennial scales, shelf oxygen is influenced by the OMZ as modulated by changes in Walker circulation, which controls thermocline depth and thereby productivity and respiration, and by subsurface ventilation associated with equatorial currents (Gutiérrez et al., 2009; Salvatteci et al., 2016, 2019b).

The importance of source water is also clearly evident on the Namibian shelf as determined by the relative dominance of South Atlantic Central Water (SACW) flowing southward from the Angolan Dome over Eastern South Atlantic Central Water (ESACW) transported northward from the Cape Basin. The Angola gyre central water primes the northern Benguela shelf with low oxygen and then further consumption of oxygen over the shelf may lead to anoxia (Monteiro et al., 2008 , 2011). However, with the strengthening of upwelling-favourable southerly winds the undercurrent reverses direction to equatorward and thus, more oxygenated ESACW originating from the Cape Basin off South Africa ventilates the northern Benguela shelf, leading to an oxygen maximum during spring. These advective mechanisms driving oxygen supply for the Northern Benguela shelf are the primary controls of seasonal, interannual and decadal variations in the severity of oxygen depletion.

The California Current Ecosystem provides an excellent description of oxygen variability characteristic of EBUSs. Oxygen variability in the California Current is shown to span many orders of magnitude providing considerable insight into the drivers of this variability (Levin et al., 2015). These drivers include: expansions and contractions of low oxygen water over glacial-interglacial periods; regime shifts linked to the North Pacific Gyre Oscillations; interannual variations linked to changes in mixed layer depth and productivity driven by ENSO events; seasonal variability driven mostly by the respiration of primary production with local retentive circulation determining spatial patterns; event scale variability linked to the upwelling-downwelling cycle and longshore advection; semidiurnal fluctuations associated with internal tides; and diel cycling linked to photosynthesis. Superimposed on this variability is a longer-term trend of deoxygenation that manifests as shoaling oxyclines and declining oxygen concentrations at specific densities. Although it is generally believed that solubility and stratification effects of warming have lowered oxygen levels in California Current source waters in the subarctic and tropical Pacific, and that the low-oxygen California undercurrent has strengthened (Bograd et al., 2015), none of these declines have yet been mechanistically attributed to climate change.

Proposed changes in EBUSs in response to climate change include an intensification of wind-induced coastal upwelling in response to increased land-sea temperature differences associated with global warming (Bakun, 1990; Sydeman et al., 2014). Expected responses to increased upwelling are increased productivity, higher sedimentation of organic material and increasing anoxia in bottom waters. However, ocean warming could counter stronger upwelling by increasing stratification, complicating forecasts of biogeochemical responses (Sydeman et al., 2014; García-Reyes et al., 2015). Models have also revealed a likely poleward shift in atmospheric high-pressure systems with upwelling therefore likely to weaken at low latitudes and to strengthen at high latitudes. For the northern Benguela, this may translate to a reduction in the extent of coastal upwelling, leading to increased hypoxia and anoxia over a large part of the shelf due to reduced ventilation. For the Peruvian shelf waters, the fate of productivity and oxygenation will also be modulated by the changes in the intensity of the eastward Equatorial subsurface currents that ventilate and modify the nutrients' signature in the upwelling source waters (Espinoza-Morriberón 2018; 2019).

\subsection{Enclosed seas}

Enclosed or semi-enclosed seas are typically connected to the open ocean at the surface by one or more narrow straits that are also bounded at depth by a submarine ridge. The resulting restrictive mechanisms of exchange naturally drive oxygen depletion that can be amplified with large freshwater inputs that contribute to highly stratified and eutrophic systems. The case studies of the Baltic Sea and Black Sea both show records of oxygen depletion following their transition from freshwater systems $\sim 8000$ years ago as dictated by sea level height (Zillén et al., 2008). High freshwater input contributing to the stratified nature of these systems is attributed to large catchment areas and high precipitation. Water exchange in the Baltic is driven by outflowing brackish water at the surface and the inflow of dense, high salinity water from the North Sea through the Danish Straits. Sediment records indicate that hypoxia in the Baltic has been present intermittently throughout the Holocene with sulphidic conditions characterizing the bottom waters of its deep basins. The Black Sea was transformed from a freshwater lake after the entry of high salinity Mediterranean waters through the Bosporus Strait following rising sea levels (Degens and Ross, 1972). Subduction of these high salinity waters as they entered the Black Sea resulted in the development of a permanent halocline that inhibited ventilation of subsurface waters, resulting in the largest sulfidic basin in the world. Apart from upper layer mixing, mid-water intrusions through the respective straits serve as important ventilation mechanisms in both the Baltic Sea and Black Sea (Neumann et al., 2017).

Further oxygen depletion over the past several decades in both the Baltic Sea and Black Sea have been attributed to increased nutrient loading and more recently to climate change (Carstensen et al., 2014a). Model simulations indicate that hypoxia in the Baltic would not have developed over the past 150 years had nutrient levels remained pristine. The expansion of hypoxia in the Baltic over the last century has therefore been attributed primarily to enhanced nutrient input, increased algal production and higher oxygen demand following degradation (Gustafsson et al., 2012). As a result, the Baltic Sea is now considered the largest anthropogenically induced hypoxic area in the world. Similarly, agricultural and industrial development, alongside unban expansion in the late 1960s resulted in a reduction of water column oxygen in the Black Sea, specifically in bottom waters on its northwestern shelf. Interestingly, despite trend reversals in anthropogenic nutrient loading in the late 1980s and 1990s in both the Baltic and Black Sea, these have not been matched by similar increases in oxygen, and hypoxia remains near its maximum size in the Baltic (Capet et al., 2013; Carstensen et al., 2006). This prolonged hypoxia is attributed to large pools of nutrients and organic matter accumulated in the sediment during the years of higher nutrient input and is likely to delay restoration by many years. This recovery from modern, nutrient-driven hypoxia will be further compromised by global warming and its contribution to further declines in oxygen through reduced solubility (Carstensen et al., 2014a).

The Sea of Japan provides an interesting case study for enclosed seas in that it is presently well-oxygenated but has a history of oxygen depletion also dictated by sea level changes. Exchange with adjacent seas is through shallow straits thereby making exchange sensitive to changes in sea level (Gallagher et al., 2015). Specifically, flow of the 
Tsushima Warm Current from the East China Sea through the Tsushima Strait provides the major seawater influx. As this flow approaches the polar front, it cools and sinks thereby driving circulation and high oxygen levels in the Sea of Japan. However, sea level drops of $>90 \mathrm{~m}$ during glacial periods isolated the Sea of Japan from adjacent oceans, specifically eliminating inflow from the Tsushima Warm Current. The resulting relatively higher input of freshwater from river runoff caused stratification to strengthen, leading ultimately to both anoxic and sulphidic conditions through the entire deep-sea basin as reflected in sediment depositions (Tada et al., 1999; Watanabe et al., 2007).

\subsection{Coastal zone}

The spatial complexity of coastal environments, and the varying atmospheric conditions associated with them, leads to high spatial and temporal heterogeneity in the oxygen content of the coastal zone. Those environments with restricted circulation and long water residence times tend to be naturally prone to lower oxygen concentrations, and an elevated supply of inorganic nutrients as a consequence of either natural or cultural eutrophication further increases their susceptibility to hypoxia. Restricted circulation not only serves to limit ventilation but also aids in accumulating the products of enhanced primary and secondary production leading to greater delivery of degradable organic matter to bottom waters. These drivers of hypoxia are clearly evident in the coastal zone of the Baltic, where restricted circulation and elevated nutrient loads from urban and agricultural sources are the cause of enhanced hypoxia in the Swedish and Finish archipelagos (Conley et al., 2011). Here, complex bottom topography in the form of basins and shallow sills restricts circulation and creates conditions favourable for hypoxia, whereas on the eastern shores of the Baltic between Estonia and Poland, hypoxia is uncommon owing to increased circulation. Similarly oxygen content of the basin waters of the fjords of western Norway are largely dependent on deep water renewal times, which are in turn generally governed by fjord topography, specifically in terms of sill depth, the cross-sectional area at the sill, and the basin depth below the sill.

Temporal variations in oxygen content are evident at a number of scales and are usually associated with changing atmospheric conditions, specifically varying winds and precipitation that control stratification and the vertical exchange of oxygen within the water column. Seasonal variability is common and most often driven by seasonal warming and river discharge and their influence on stratification. But daily, interannual and longer-period variations are also observed in oxygen concentrations, hypoxic volume and duration. By way of example, water column stratification is the basic physical attribute that drives hypoxia in the both the Changjiang and Zhujiang estuaries and for this reason hypoxia is strongest in summer and absent in winter (Zhu et al., 2016, 2017; Qian et al 2018). Modeling studies have shown a clear reduction of hypoxic areas in the Zhujiang estuary associated with reduced river discharge and this is attributed to a reduction in the delivery of particulate organic matter to the estuary and a decrease in the strength of stratification that facilitates greater vertical diffusion of oxygen (Huang et al., 2019). Residence times in these estuaries are relatively short and wind events associated with summer cyclones can rapidly erode stratification and ventilate bottom waters. Nevertheless, stratification and bottom hypoxia are readily re-established leading to a close correlation of bottom oxygen and winds ( $\mathrm{Ni}$ et al., 2016). Oxygen concentrations also show considerable variation over the spring-neap tidal cycles with tidal mixing replenishing bottom oxygen in shallow areas (Huang et al., 2019). As in the open ocean, global warming is also expected to exacerbate oxygen depletion in many coastal systems through the same mechanisms of intensified stratification of increased duration, decreased oxygen solubility, and accelerated respiration. Currently the rate of oxygen decline in coastal areas is considered to exceed that of the open ocean reflecting the combined effects of increased warming and eutrophication (Gilbert et al., 2010).
Hypoxia or anoxia in most coastal systems is at least partially attributed to oxygen depletion in response to cultural eutrophication that has enhanced productivity. Consequently, systems such as Chesapeake Bay, in which oxygen depletion is naturally facilitated by bay geometry and circulation, have been subject to spatial and temporal increases in the extent of depletion due to cultural eutrophication (Kemp et al., 2005). In many cases, the size of the hypoxic area appears related to the nutrient load. Systems subject to cultural eutrophication are usually characterized by large catchment areas making them particularly sensitive to land-based activities that include increased agricultural production and fertilizer use, and increasing human populations, urbanization and associated sewage discharges. As an example, the population in the catchment area of Tokyo Bay is now 28 million having increased from 10 million in 1950. Coincident with this growth in the population, total nitrogen loading increased from 10 tons $\mathrm{d}^{-1}$ in 1950 to 30 tons $\mathrm{d}^{-1}$ in 1980 with a corresponding increase in chemical oxygen demand from 200 to 500 ton $\mathrm{d}^{-1}$. In Chesapeake Bay, variations in freshwater input have been shown to be the best predictor of the volume of low oxygen bottom water in summer, through its influence on stratification and nutrient input (Hagy et al., 2004).

Implementation of environmental legislation aimed at nutrient load reductions has been undertaken in several coastal environments in an attempt to restore oxygen concentrations to levels prior to eutrophication. Fundamental for effective management and restoration are models that are informative in determining the relative role of physical versus biological controls of oxygen depletion and can thereby guide management actions. However, as demonstrated in Chesapeake Bay, separating the effects of physical and biological control are challenging because of their interdependency, such as river discharge influencing both stratification and nutrient loading. Within Chesapeake Bay, the initial spring decline in oxygen is considered to be driven by stratification, while the late spring decline and the extent of summer hypoxia are more closely related to nutrient load (Hagy et al., 2004; Testa et al., 2018a,2018b). While nutrient reductions in Chesapeake Bay have been accompanied by a corresponding decline in low oxygen waters, the same success has not been observed in other coastal environments. In Tokyo Bay, despite the restoration of water quality parameters to those of the 1950 s, the bay remains subject to 3-4 months of bottom water hypoxia each summer with periodic events of hydrogen sulphide poisoning (Ando et al., 2005). Similarly, improvement of water quality in Limfjorden Estuary appears to be delayed by "nutrient legacies" in both the catchment areas and in the sediments of the estuary (McCrackin et al., 2018). In Chesapeake Bay, model scenarios have shown that nutrient reductions have a larger effect on oxygen than the effects of climate change; however, climate change is shown to reduce some of the gains in oxygen from reductions in nutrient loadings (Irby et al., 2018).

The eastern boundary embayments of the Humboldt and Benguela upwelling systems, namely Paracas Bay and St Helena Bay, classified as wide-open bays by Largier (2020), are differentiated from the other case studies in that they are subject to natural eutrophication and are also less dependent on freshwater input as a source of nutrients. Both Paracas Bay and St Helena Bay are formed by promontories that influence alongshore flow thereby creating a zone of retention in the lee of the promontory. The topographic protection somewhat isolates these bays from the offshore domain and increases stratification, which in turn supports high primary productivity within the bay and a high incidence of red tides or harmful algal blooms (Figueiras et al., 2006). Consequently, both systems are subject to hypoxia, and in some cases anoxia, particularly during summer and autumn and exhibit a nitrate deficit in bottom waters likely due to denitrification. Both bays incur local oxygen depletion in subsurface waters following seasonal thermohaline stratification. Superimposed on this seasonal decline in oxygen in St Helena Bay is subseasonal variability associated with periodic deposition of organic matter indicative of abrupt termination of blooms and rapid vertical flux into bottom waters (Pitcher and Probyn, 2017). Episodic events of oxygen depletion linked to HABs are also observed in both bays (Cabello 
et al., 2002; López, 2008). These events are attributed to the exceptional magnitude of these blooms and are often associated with extreme variability in the oxygen environment attributed to bloom patchiness, varying metabolism in terms of oxygen production and ultimately bloom senescence leading to high microbial respiration and a rapid transition from autotrophy to heterotrophy (Pitcher and Probyn, 2011; 2016). The bays differ in terms of their respective source waters in that upwelled waters advected into Paracas Bay are oxygen-depleted or even anoxic (Aguirre-Velarde et al., 2019), whereas waters advected into St Helena Bay are typically well ventilated. Therefore, while processes responsible for oxygen depletion in Paracas Bay are both remote and local, oxygen depletion in St Helena Bay is primarily a function of drawdown within the bay. Another difference between the two bays is that freshwater input into Paracas Bay is greater, as are major sources of anthropogenic influence such as treated waste water and maritime traffic all of which may further promote oxygen depletion in Paracas Bay.

\section{Conclusion}

Oxygen concentrations in marine systems exhibit significant spatial and temporal variations collectively regulated by physical and biogeochemical properties and processes, producing linked feedbacks that drive oxygen decline and recovery in response to global change and natural variability. The case studies central to this review serve to demonstrate the roles of these physical and biogeochemical processes in driving system variations in ventilation and respiration leading to open ocean and coastal environments characterised by low oxygen. However, separating the effects of these physical and biogeochemical drivers is challenging as they proceed simultaneously and have a high degree of interdependency. Oxygen concentration is determined by the net outcome of several processes that either supply or consume oxygen at different time scales. Attribution of low oxygen to a single driver is therefore unrealistic; hypoxia or anoxia is the net outcome of the superposition of a number of drivers acting in both additive and subtractive modes. Consequently, although system sources and sinks of oxygen may be individually well established, there is a need to appreciate multiple causality in determining changing oxygen concentrations (Brewer, 2018). The interdependencies and feedbacks between mechanisms mean that their individual effects on deoxygenation can be counteracted or exacerbated (Robinson, 2019), and require that all processes be incorporated in predictions as attempts to provide simple answers are likely to fail (Brewer, 2018).

Spatial distributions of oxygen and time series of oxygen data have provided the opportunity to identify trends in oxygen availability and, in so doing, have allowed various drivers of low oxygen to be distinguished through correlative and causative relationships. Such time series have also served to show that within a single system, the drivers of low oxygen may vary at different time-scales. Ultimately, system oxygen concentrations are determined by the tradeoff between ventilation and respiration, with respiration being a function of organic matter whose availability leads to widely varying rates of oxygen consumption between systems. When biogeochemical sinks are large (i.e., when the supply of organic matter is large), hypoxia or anoxia can be achieved at short timescales without a restriction in physical supply of oxygen. Alternatively, if biogeochemical sinks are small, then there is a greater requirement for restricted physical supply and the time required for hypoxia or anoxia to develop is likely to be longer (Fennel and Testa, 2019). System-specific models are required to achieve a quantitative understanding of these processes and of the feedbacks between processes at varying temporal and spatial scales.

Ocean deoxygenation as observed since the middle of the 20th century is generally attributed, particularly in the open ocean, to global warming affecting solubility, thermohaline stratification, circulation, mixing and rates of respiration, whereas deoxygenation in coastal systems is driven primarily through increased loadings of nutrients and organic matter related to human activities (Breitburg et al., 2018;
Oschlies et al., 2018). Oxygen in coastal systems is also influenced by the effects of climate change at the regional scale through changes in precipitation and winds. Where precipitation increases, both stratification and nutrient discharges are expected to increase, while the reverse is expected in regions where precipitation decreases. Documenting, understanding and predicting further declines in open ocean and coastal oxygen requires expanded and sustained observation efforts merged with improved models.

In the open ocean, solubility effects have been found to dominate deoxygenation near the surface and its role has been quantified; however, a quantitative understanding of the contribution of other drivers has yet to be achieved. As a result, current models perform poorly in depicting oxygen variability in the open ocean and underestimate deoxygenation owing to unresolved transport processes, unaccounted variations in respiratory oxygen demands or overlooked biogeochemical feedbacks (Oschlies et al., 2018). Closer to the coast, models may guide management actions in terms of responses of hypoxia or anoxia to changes in nutrient loadings. However, trajectories of oxygen depletion driven by eutrophication are not directly reversible, as nutrient reductions lead to convoluted trajectories often without returning to their reference status (Duarte et al., 2009). Conservation measures to reduce land-derived nutrient loads are further complicated by so-called nutrient legacies in catchment areas and in marine sediments causing time lags in the improvement of water quality. The current assumption of many coastal management plans of a direct response to altered nutrient inputs therefore needs to change to incorporate an ecosystem perspective that considers nutrient input with the other concurrent drivers of change and their interactions (Duarte et al., 2009). Nevertheless, the improvements in dissolved oxygen in coastal systems expected in response to management-dictated nutrient reductions are likely to be significantly greater than the potential decreases in oxygen attributed to climate change.

Our extensive review of deoxygenation was necessarily somewhat uneven in the information presented because these systems have been studied to different degrees and with different emphases placed on the various aspects of deoxygenation. This review and synthesis, with its focus on cross-system comparisons of drivers of deoxygenation, provides a strong scientific foundation for better understanding deoxygenation, and for positioning us for projecting deoxygenation in response to management actions and into the future under climate change, at local, regional and global scales.

\section{Declaration of Competing Interest}

The authors declare that they have no known competing financial interests or personal relationships that could have appeared to influence the work reported in this paper.

\section{Acknowledgements}

The undertaking of this review paper was an activity prioritized by the Global Ocean Oxygen Network $\left(\mathrm{GO}_{2} \mathrm{NE}\right)$ in an effort to synthesize our knowledge and to provide an inclusive perspective of the drivers of deoxygenation in both coastal and open ocean systems. We thank the IOC-UNESCO for initiating and supporting $\mathrm{GO}_{2} \mathrm{NE}$. VG and $\mathrm{BD}$ acknowledge support from the EU H2020 FutureMARES project (Theme LC-CLA-06-2019, Grant $\mathrm{N}^{\mathrm{o}}$ 869300) and BD also acknowledges support from ANID (Grants R20F0008-CEAZA and 1190276).

\section{References}

Agnihotri, R., Altabet, M.A., Herbert, T.D., Tierney, J.E., 2008. Subdecadally resolved paleoceanography of the Peru margin during the last two millennia. Geochem. Geophys. Geosyst. 9 (5), Q05013. https://doi.org/10.1029/2007GC001744.

Aguirre-Velarde, A., Thouzeau, G., Jean, F., Mendo, J., Cueto-Vega, R., KawazoDelgado, M., Vasquez-Spencer, J., Herrera-Sanchez, D., Vega-Espinoza, A., FlyeSainte-Marie, J., 2019. Chronic and severe hypoxic conditions in Paracas Bay, Pisco, 
Peru: Consequences on scallop growth, reproduction, and survival. Aquaculture 512, 734259.

Aiken, J.D., 2017. Validity of Chesapeake Bay total maximum daily load upheld. J. Soil Water Conserv. 72 (4), 87A-92A.

Aksnes, D.L., Aure, J., Johansen, P.-O., Johnsen, G.H., Salvanes, A.G.V., 2019. Multidecadal warming of Atlantic water and associated decline of dissolved oxygen in a deep fjord. Estuar. Coast. Shelf Sci. 228, 106392 https://doi.org/10.1016/j. ecss.2019.106392.

Aksnes, D.L., Aure, J., Kaartvedt, S., Magnesen, T., Richards, J., 1989. Significance of advection for the carrying capacities of fjord populations. Mar. Ecol. Prog. Ser. 50, 263-274.

Aksnes, D.L., Lie, U., 1990. A coupled physical biological pelagic model of a shallow sill fjord. Estuar. Coast. Shelf Sci. 31, 459-486.

Al-Ansari, E.M.A.S., Rowe, G., Abdel-Moati, M.A.R., Yigiterhan, O., Al-Maslamani, I., Al Yafei, M.A., Al-Shaikh, I., Upstill-Goddard, R., 2015. Hypoxia in the central Arabian Gulf Exclusive Economic Zone of Qatar during summer season. Estuar. Coast. Shelf Sci. 159, 60-68.

Al Azhar, M., Lachkhar, M., Lévy, M., Shafer-Smith, K., 2017. Oxygen minimum zone contrasts between the Arabian Sea and the Bay of Bengal implied by differences in remineralization depth. Geophys. Res. Lett. 44, 11106-11114.

Albretsen, J., Aure, J., Sætre, R., Danielssen, D.S., 2012. Climatic variability in the Skagerrak and coastal waters of Norway. ICES J. Mar. Sci. 69, 758-763. https://doi. org/10.1093/icesjms/fsr187.

Alegre, A., Bertrand, A., Espino, M., Espinoza, P., Dioses, T., Niquen, M., Navarro, I., Simier, M., Ménard, F., 2015. Diet diversity of jack and chub mackerels and ecosystem changes in the northern Humboldt Current system: a long-term study. Progr. Oceanogr. 137(Part A), 299-313, https://doi.org/10.1016/j. pocean.2015.07.010.

Alexander, R.B., Smith, R.A., Schwarz, G.E., Boyer, E.W., Nolan, J.V., Brakebill, J.W., 2008. Differences in phosphorus and nitrogen delivery to the Gulf of Mexico from the Mississippi River basin. Environ. Sci. Technol. 42 (3), 822-830.

Al-Said, T., Naqvi, S.W.A., Al-Yamani, F., Goncharov, A., Fernandes, L., 2018. High tota organic carbon in surface waters of the northern Arabian Gulf: implications for the oxygen minimum zone of the Arabian Sea. Mar. Pollut. Bull. 129, 35-42.

Altabet, M.A., Higginson, M.J., Murray, D.W., 2002. The effect of millennial-scale changes in Arabian Sea denitrification on atmospheric $\mathrm{CO}_{2}$. Nature 415, 159-162.

Álvarez-Salgado, X.A., Doval, M.D., Borges, A.V., Joint, I., Frankignoulle, M. Woodward, E.M.S., Figueiras, F.G., 2001. Off-shelf fluxes of labile materials by an upwelling filament in the NW Iberian upwelling system. Prog. Oceanogr. 51, 321-337.

Álvarez-Salgado, X.A., Arístegui, J., Barton, E.D., Hansell, D.A., 2007. Contribution of upwelling filaments to offshore carbon export in the subtropical Northeast Atlantic Ocean. Limnol. Oceanogr. 52, 1287-1292.

Al-Yamani, F., Naqvi, S.W.A., 2019. Chemical oceanography of the Arabian Gulf. DeepSea Res. II 161, 72-80.

Amante, C., Eakins, B.W., 2009. ETOPO1 1 Arc-Minute Global Relief Model: Procedures, Data Sources and Analysis. NOAA Technical Memorandum NESDIS NGDC-24: 1-19, http://www.ngdc.noaa.gov/mgg/global/relief/ETOPO1/docs/ETOPO1.pdf.

Anderson, C., Hepner-Medina, M., 2020. Southern California Coastal Observing System. Red Tide Bull.

Andersen, J.H., Carstensen, J., Conley, D.J., Dromph, K., Fleming-Lehtinen, V., Gustafsson, B.G., Josefson, A.B., Norkko, A., Vilnäs, A., Murray, C., 2017. Long-term temporal and spatial trends in eutrophication status of the Baltic Sea. Biol. Rev. 92 135-149. https://doi.org/10.1111/brv.12221.

Ando, H., Kashiwagi, N., Ninomiya, K., Ogura, H., Kawai, T., 2005. Changes in the state of water pollution in Tokyo Bay since 1980 - trend analysis of water quality using monitoring data obtained by Local Governments. Ann. Report Tokyo Metropolitan Res. Instit. Environ. Protection 2005, 141-150.

Antezana, T., 2009. Species-specific patterns of diel migration into the Oxygen Minimum Zone by euphausiids in the Humboldt Current Ecosystem. Prog. Oceanogr. 83, $228-236$

Aramayo, V., 2016. Breve síntesis sobre el recurso bacalao de profundidad Dissostichus eleginoides en Perú. Revista de Biología Marina y Oceanografía 51 (2), 229-239.

Arévalo-Martínez, D.L., Kock, A., Löscher, C.R., Schmitz, R.A., Bange, H.W., 2015. Massive nitrous oxide emissions from the tropical South Pacific Ocean. Nat. Geosci. $8,530-533$

Arntz, W.E., Gallardo, V.A., Gutiérrez, D., Isla, E., Levin, L.A., Mendo, J., Neira, C. Rowe, G.T., Tarazona, J., Wolff, M., 2006. El Niño and similar perturbation effects on the benthos of the Humboldt, California, and Benguela Current upwelling ecosystems. Adv. Geosci. 6, 243-265.

Asmala, E., Carstensen, J., Conley, D.J., Slomp, C.P., Stadmark, J., Voss, M., 2017. Efficiency of the coastal filter: nitrogen and phosphorus removal in the Baltic Sea. Limnol. Oceanogr. 62, S222-S238. https://doi.org/10.1002/lno.10644.

Asplin, L., Salvanes, A.G.V., Kristoffersen, J.B., 1999. Nonlocal wind-driven fjord-coast advection and its potential effect on plankton and fish recruitment. Fish. Oceanogr. 8, 255-263.

Augustyn, J., Cockcroft, A., Kerwath, S., Lamberth, S., Githaiga-Mwicigi, J., Pitcher, G. Roberts, M., van der Lingen, C.D., Auerswald, L., 2018. South Africa. In: Philips, B.F., Péres-Ramírez, M. (Eds.), Climate change impacts on fisheries and aquaculture. John Wiley and Sons Ltd, pp. 479-522.

Aure, J., Asplin, L., Sætre, R., 2007. Coast/fjord water exchange. In: Sætre, R. (Ed.), The Norwegian Coastal Current. Tapir Academic Press, Trondheim, pp. 115-124.

Aure, J., Stigebrandt, A., 1989. On the influence of topographic factors upon the oxygen consumption rate in sill basins of fjords. Estuar. Coast. Shelf Sci. 28, 59-69.
Bachèlery, M.-L., Illig, S., Dadou, I., 2016. Forcings of nutrient, oxygen and primary production interannual variability in the southeast Atlantic Ocean. Geophys. Res. Lett. 43, 8617-8625.

Bailey, G.W., 1991. Organic carbon flux and development of oxygen deficiency on the modern Benguela continental shelf south of $22^{\circ} \mathrm{S}$ : spatial and temporal variability. In: Tyson, R.V., Pearson, T.H. (Eds.), Modern and Ancient Continental Shelf Anoxia. Geological Society, London, pp. 171-183.

Bailey, G.W., Chapman, P., 1985. The nutrient status of the St Helena Bay region in February 1979. In: Shannon, L.V. (Ed.), South African Ocean Colour and Upwelling Experiment. Sea Fisheries Research Institute, Cape Town, South Africa, pp. 125-145.

Bailey, G.W., Chapman, P., 1991. Short-term variability during an anchor station study in the southern Benguela upwelling system: Chemical and physical oceanography. Prog. Oceanogr. 28, 9-37.

Bakun, A., 1990. Global climate change and the intensification of coastal upwelling. Science 247, 198-201.

Bakun, A., Weeks, S.J., 2004. Greenhouse gas buildup, sardines, submarineeruptions and the possibility of abrupt degradation of intense marine upwelling ecosystems. Ecol. Lett. 7, 1015-1023. https://doi.org/10.1111/j.1461-0248.2004.00665.x.

Bange, H.W., Freing, A., Kock, A., Löscher, C.R., 2010. Marine pathways to nitrous oxide. In: Smith, K.A. (Ed.), Nitrous oxide and climate change. Earthscan, London, pp. 36-62.

Banse, K., 1959. On upwelling and bottom-trawling off the southwest coast of India. J. Mar. Biol. Assoc., India 1 (1), 33-49.

Banse, K., 1968. Hydrography of the Arabian Sea Shelf of India and Pakistan and effects on demersal fishes. Deep-Sea Res. 55 (1), 45-48.

Banse, K., Naqvi, S.W.A., Narvekar, P.V., Postel, J.R., Jayakumar, D.A., 2014. Oxygen minimum zone of the open Arabian Sea: variability of oxygen and nitrite from daily to decadal timescales. Biogeosciences 11, 2237-2261.

Bartholomae, C.H., van der Plas, A.K., 2007. Towards the development of environmental indices for the Namibian shelf, with particular reference to fisheries management. Afr. J. Mar. Sci. 29 (1), 25-35.

Batiuk, R.A., Linker, C.C., Cerco, C.F., 2013. Featured collection introduction: Chesapeake Bay total maximum daily load development and application. J. Am. Water Resources Association (JAWRA) 1-5. https://doi.org/10.1111/jawr.12114.

Belmadani, A., Echevin, V., Codron, F., Takahashi, K., Junquas, C., 2014. What dynamics drive future wind scenarios for coastal upwelling off Peru and Chile? Clim. Dyn. 43, 1893-1914. https://doi.org/10.1007/s00382-013-2015-2.

Bennett, E.M., Carpenter, S.R., Caraco, N.F., 2001. Human impact on erodable phosphorus and eutrophication: a global perspective. Bioscience 51, 227-234.

Berger, W.H., Wefer, G., 2002. On the reconstruction of upwelling history: Namibia upwelling in context. Mar. Geol. 180, 3-28.

Bertrand, A., Chaigneau, A., Peraltilla, S., Ledesma, J., Graco, M., Monetti, F., Chavez, F. P., 2011. Oxygen: a fundamental property regulating pelagic ecosystem structure in the coastal Southeastern Tropical Pacific. PLoS ONE 6 (12). https://doi.org/ 10.1371/journal.pone.0029558.

Bettencourt, J.H., López, C., Hernández-García, E., Montes, I., Sudre, J., Dewitte, B. Paulmier, A., Garçon, V., 2015. Boundaries of the Peruvian oxygen minimum zone shaped by coherent mesoscale dynamics. Nat. Geosci. 8, 937-940. https://doi.org/ $10.1038 /$ ngeo 2570

Bograd, S.J., Castro, C.G., Di Lorenzo, E., Palacios, D.M., Bailey, H., Gilly, W., Chavez, F. P., 2008. Oxygen declines and the shoaling of the hypoxic boundary in the California current. Geophys. Res. Lett. 35 https://doi.org/10.1029/2008GL034185.

Bograd, S.J., Pozo Buil, M., Di Lorenzo, E., Castro, C.G., Schroeder, I.D., Goericke, R., Anderson, C.R., Benitez-Nelson, C., Whitney, F.A., 2015. Changes in source waters to the Southern California Bight. Deep-Sea Res. II 112, 42-52.

Bograd, S.J., Schroeder, I.D., Jacox, M.G., 2019. A water mass history of the Southern California Current System. Geophys. Res. Lett. 46, 6690-6698. https://doi.org/ 10.1029/2019GL082685.

Boicourt, W.C., 1992. Influences of circulation processes on dissolved oxygen in the Chesapeake Bay. In: Smith, D.E., Leffler, M., Mackiernan, G. (Eds.), Oxygen Dynamics in Chesapeake Bay: a synthesis of recent research. Maryland Sea Grant Publication, College Park, Maryland, pp. 7-59.

Bopp, L., Resplandy, L., Orr, J.C., Doney, S.C., Dunne, J.P., Gehlen, M., Halloran, P., Heinze, C., Ilyina, T., Séférian, R., Tjiputra, J., Vichi, M., 2013. Multiple stressors of ocean ecosystems in the 21st century: projections with CMIP5 models. Biogeosciences 10, 6225-6245. https://doi.org/10.5194/bg-10-6225-2013.

Boyd, A.J., 1987. The oceanography of the Namibian shelf. PhD thesis. University of Cape Town, South Africa, p. 190 pp.

Boyer, T.P., Antonov, J.I., Baranova, O.K., Coleman, C., Garcia, H.E., Grodsky, A. Johnson, D.R., Locarnini, R.A., Mishonov, A.V., O’Brien, T.D., Paver, C.R., Reagan, J. R., Seidov, D., Smolyar, I.V., Zweng, M.M., 2013. World Ocean Database 2013 , Levitus, S. (Ed.) and Mishonov, A. (Technical Ed.), NOAA Atlas NESDIS 72, 209 pp., https://doi:10.7289/V5NZ85MT.

Boynton, W.R., Kemp, W.M., 2000. Influence of river flow and nutrient loads on selected ecosystem processes. In: Hobbie, J.E. (Ed.), Estuarine Science: A Synthetic Approach to Research and Practice. Island Press, Washington, DC, pp. 269-298.

Brandes, J.A., Devol, A.H., Yoshinari, T., Jayakumar, D.A., Naqvi, S.W.A., 1998. Isotopic composition of nitrate in the central Arabian Sea and eastern tropical North Pacific: a tracer for mixing and nitrogen cycles. Limnol. Oceanogr. 43, 1680-1689.

Brandt, P., Bange, H.W., Banyte, D., Dengler, M., Didwischus, S.-H., Fischer, T., Greatbatch, R.J., Hahn, J., Kanzow, T., Karstensen, J., Körtzinger, A., Krahmann, G., Schmidtko, S., Stramma, L., Tanhua, T., Visbeck, M., 2015. On the role of circulation and mixing in the ventilation of oxygen minimum zones with a focus on the eastern tropical North Atlantic. Biogeosciences 12, 489-512. 
Brandt, P., Hormann, V., Körtzinger, A., Visbeck, M., Krahmann, G., Stramma, L., Lumpkin, R., Schmid, C., 2010. Changes in the ventilation of the Oxygen Minimum Zone of the Tropical North Atlantic. J. Phys. Oceanogr. 40, 1784-1801.

Breitburg, D.L., 1990. Near-shore hypoxia in the Chesapeake Bay: patterns and relationships among physical factors. Estuar. Coast. Shelf Sci. 30 (6), 593-609.

Breitburg, D.L., Hondorp, D.W., Davias, L.A., Diaz, R.J., 2009. Hypoxia, nitrogen, and fisheries: integrating effects across local and global landscapes. Ann. Rev. Mar. Sci. 1 (1), 329-349.

Breitburg, D., Levin, L.A., Oschlies, A., Grégoire, M., Chavez, F.P., Conley, D.J., Garçon, V., Gilbert, D., Gutiérrez, D., Isensee, K., Jacinto, G.S., Limburg, K.E., Montes, I., Naqvi, S.W.A., Pitcher, G.C., Rabalais, N.N., Roman, M.R., Rose, K.A., Seibel, B.A., Telszewski, M., Yasuhara, M., and Zhang, J., 2018, Declining oxygen in the global ocean and coastal waters. Science 359 , eaam7240, https://doi.org/10.1126/science. aam7240.

Breitburg, D.L., Salisbury, J., Bernhard, J.M., Cai, W.-J., Dupont, S., Doney, S.C., Kroeker, K.J., Levin, L.A., Long, W.C., Milke, L.M., Miller, S.H., Phelan, B. Passow, U., Seibel, B.A., Todgham, A.E., Tarrant, A.M., 2015. And on top of all that... coping with ocean acidification in the midst of many stressors. Oceanography 28 (2), 48-61.

Bretagnon, M., Paulmier, A., Garçon, V., Dewitte, B., Illig, S., Leblond, N., Coppola, L., Campos, F., Velazco, F., Panagiotopoulos, C., Oschlies, A., Hernandez-Ayon, J.M., Maske, H., Vergara, O., Montes, I., Martinez, P., Carrasco, E., Grelet, J., Desprez-DeGesincourt, O., Maes, C., Scouarnec, L., 2018. Modulation of the vertical particle transfer efficiency in the oxygen minimum zone off Peru. Biogeosciences 15, 5093-5111. https://doi.org/10.5194/bg-15-5093-2018.

Brewer, P., 2018. Multiple choices for changing ocean oxygen concentrations. Eos 99. https://doi.org/10.1029/2018E0098367.

Brewer, P.G., Peltzer, E.T., 2017. Depth perception: the need to report ocean biogeochemical rates as functions of temperature, not depth. Phil. Trans. R. Soc. A $375,20160319$.

Bristow, L.A., Callbeck, C.M., Larsen, M., Altabet, M.A., Dekaezemacker, J., Forth, M., Gauns, M., Glud, R.N., Kuypers, M.M.M., Lavik, G., Milucka, J., Naqvi, S.W.A., Pratihary, A.K., Revsbech, N.P., Thamdrup, B., Treusch, A.H., Canfield, D.E., 2017. $\mathrm{N}_{2}$ production rates limited by nitrite availability in the Bay of Bengal oxygen minimum zone. Nat. Geosci. 10, 24-29.

Brochier, T., Echevin, V., Tam, J., Chaigneau, A., Goubanova, K., Bertrand, A., 2013. Climate change scenarios experiments predict a future reduction in small pelagic fish recruitment in the Humboldt Current system. Glob. Change Biol. 19 (6), 1841-1853. https://doi.org/10.1111/gcb.12184.

Broenkow, W.W., Cline, J.D., 1969. Colorimetric determination of dissolved oxygen at low concentrations. Limnol. Oceanogr. 14 (3), 450-454.

Brüchert, V., Currie, B., Peard, K.R., Lass, U., Endler, R., Dübecke, A., Julies, E., Leipe, T. Zitzmann, S., 2006. Biogeochemical and physical control on shelf anoxia and wate column hydrogen sulphide in the Benguela coastal upwelling system off Namibia. In: Neretin, L. (Ed.), Past and Present Water Column Anoxia. NATO Science Series, IV Earth and Environmental Sciences 64, Springer, Netherlands, pp. 161-193.

Bulow, S.E., Rich, J.J., Naik, H.S., Pratihary, A.K., Ward, B.B., 2010. Denitrification exceeds anammox as a nitrogen loss pathway in the Arabian Sea oxygen minimum zone. Deep-Sea Res. I 57, 384-393.

Cabello, R., Tam, J., Jacinto, M.E., 2002. Procesos naturales y antropogénicos asociados al evento de mortalidad de conchas de abanico ocurrido en la bahía de Paracas (Pisco, Perú) en junio del 2000. Revista Peruana de Biología 9 (2), 94-110.

Cabré, A., Marinov, I., Bernardello, R., Bianchi, D., 2015. Oxygen minimum zones in the tropical Pacific across CMIP5 models: mean state differences and climate change trends. Biogeosciences 12, 5429-5454.

Canfield, D.E., Stewart, F.J., Thamdrup, B., De Brabandere, L., Dalsgaard, T., Delong, E. F., Revsbech, N.P., Ulloa, O., 2010. A cryptic sulfur cycle in oxygen-minimum-zone waters off the Chilean coast. Science 330, 1375-1378.

Capet, A., Beckers, J.-M., Grégoire, M., 2013. Drivers, mechanisms and long-term variability of seasonal hypoxia on the Black Sea northwestern shelf - is there any recovery after eutrophication? Biogeosciences 10, 3943-3962.

Capet, X., Colas, F., McWilliams, J.C., Penven, P., Marchesiello, P., 2008. Eddies in eastern boundary subtropical upwelling systems. In: Hecht, M.W., Hasumi, H. (Eds.), Ocean Modeling in an Eddying Regime. AGU, Washington, D.C., pp. 131-147

Capet, X., Estrade, P., Machu, E., Ndoye, S., Grelet, J., Lazar, A., Maríe, L., Dausse, D., Brehmer, P., 2017. On the dynamics of the southern Senegal upwelling center: observed variability from synoptic to superinertial scales. J. Phys. Oceanogr. 47 $155-180$.

Capet, A., Meysman, F., Akoumianaki, I., Soetaert, K., Grégoire, M., 2016a. Integrating sediment biogeochemistry into 3D oceanic models: a study of benthic-pelagic coupling in the Black Sea. Ocean Model. 101, 83-100.

Capet, A., Stanev, E.V., Beckers, J.-M., Murray, J.W., Grégoire, M., 2016b. Decline of the Black Sea oxygen inventory. Biogeosciences 13, 1287-1297.

Cardich, J., Gutiérrez, D., Romero, D., Pérez, A., Quipúzcoa, L., Marquina, R., Yupanqui, W., Solís, J., Carhuapoma, W., Sifeddine, A., Rathburn, A., 2015. Calcareous benthic foraminifera from the upper central Peruvian margin: control of the assemblage by pore water redox and sedimentary organic matter. Mar. Ecol. Prog. Ser. 535, 63-87.

Cardich, J., Sifeddine, A., Salvatteci, R., Romero, D., Briceño-Zuluaga, F., Graco, M. Anculle, T., Almeida, C., Gutiérrez, D., 2019. Multidecadal changes in marine subsurface oxygenation off Central Peru during the last ca.170 years. Frontiers in Marine. Science 6, 270. https://doi.org/10.3389/fmars.2019.00270.

Carruthers, J.N., Gogate, S.S., Naidu, J.R., Laevastu, T., 1959. Shoreward upslope of the layer of minimum oxygen off Bombay: Its influence on marine biology, especially fisheries. Nature 183, 1084-1087.
Carstensen, J., Andersen, J.H., Gustafsson, B.G., Conley, D.J., 2014a. Deoxygenation of the Baltic Sea during the last century. Proc. Natl. Acad. Sci. 111, 5628-5633. https:// doi.org/10.1073/pnas.1323156111.

Carstensen, J., Conley, D.J., Andersen, J.H., Ærtebjerg, G., 2006. Coastal eutrophication and trend reversal: a Danish case study. Limnol. Oceanogr. 51, 398-408. https://doi. org/10.4319/1o.2006.51.1_part_2.0398.

Carstensen, J., Conley, D.J., Bonsdorff, E., Gustafsson, B.G., Hietanen, S., Janas, U., Jilbert, T., Maximov, A., Norkko, A., Norkko, J., Reed, D.C., Slomp, C.P., Timmermann, K., Voss, M., 2014b. Hypoxia in the Baltic Sea: biogeochemical cycles, benthic fauna, and management. Ambio 43, 26-36. https://doi.org/10.1007/ s13280-013-0474-7.

Carstensen, J., Henriksen, P., Heiskanen, A.-S., 2007. Summer algal blooms in shallow estuaries: Definition, mechanisms, and link to eutrophication. Limnol. Oceanogr. 52 (1), 370-384. https://doi.org/10.4319/lo.2007.52.1.0370.

Carstensen, J., Krause-Jensen, D., Markager, S., Timmermann, K., Windolf, J., 2013. Water clarity and eelgrass responses to nitrogen reductions in the eutrophic Skive Fjord, Denmark. Hydrobiologia 704 (1), 293-309. https://doi.org/10.1007/s10750012-1266-y.

Casciotti, K.L., 2016. Nitrogen and oxygen isotopic studies of the marine nitrogen cycle. Ann. Rev. Mar. Sci. 8, 379-407.

Castillo, A., Valdés, J., Sifeddine, A., Reyss, J.-L., Bouloubassi, I., Ortlieb, L., 2017. Changes in biological productivity and ocean-climatic fluctuations during the last $1.5 \mathrm{kyr}$ in the Humboldt ecosystem off northern Chile $\left(27^{\circ} \mathrm{S}\right)$ : a multiproxy approach. Palaeogeogr. Palaeoclimatol. Palaeoecol. 485, 798-815.

Caverivière, A., Touré, D., 1990. Note sur les mortalités de mérou (Serranidae) observées en fin de saison chaude devant les côtes du Sénégal, particulièrement en 1987. Dakar Thiaroye: CRODT 116, 43-63.

Chan, F., Barth, T.A., Lubchenco, J., Kirincich, A., Weeks, H., Peterson, W.T., Menge, B. A., 2008. Emergence of anoxia in the California Current large marine ecosystem. Science 319, 920.

Chauca, Z., 2018. Caracterización de los eventos de aguas blancas frente a Pisco y Chincha (entre los $13^{\circ}-15^{\circ} \mathrm{S}$ ). Tesis para optar el grado de Maestro en Ciencias del Mar. Universidad Peruana Cayetano Heredia, 117 pp.

Chamorro, A., Echevin, V., Dutheilm, C., Tam, J., Gutiérrez, D., 2021. Projection of upwelling-favorable winds in the Peruvian upwelling system under the RCP8.5 scenario using a high-resolution regional model. Clim. Dyn. https://doi.org/ 10.1007/s00382-021-05689-w.

Chavez, F.P., Messié, M., Pennington, J.T., 2011. Marine primary production in relation to climate variability and change. Ann. Rev. Mar. Sci. 3, 227-260. https://doi.org/ 10.1146/annurev.marine.010908.163917.

Checkley, D.M., Barth, J.A., 2009. Patterns and processes in the California Current System. Prog. Oceanogr. 83, 49-64.

China River Sediment Bulletin, 2016. The Ministry of Water Resources of People's Republic of China, http://www.mwr.gov.cn/sj/tjgb/zghlnsgb/201709/t201709 08_999236.html.

Chust, G., Allen, J.I., Bopp, L., Schrum, C., Holt, J., Tsiaras, K., Zavatarelli, M., Chifflet, M., Cannaby, H., Dadou, I., Daewel, U., Wakelin, S.L., Machu, E., Pushpadas, D., Butenschon, M., Artioli, Y., Petihakis, G., Smith, C., Garçon, V., Goubanova, K., Le Vu, B., Fach, B.A., Salihoglu, B., Clementi, E., Irigoien, X., 2014. Biomass changes and trophic amplification of plankton in a warmer ocean. Glob. Change Biol. 20, 2124-2139.

Cockcroft, A.C., van Zyl, D., Hutchings, L., 2008. Large-scale changes in the spatial distribution of South African West Coast rock lobsters: an overview. Afr. J. Mar. Sci. 30, 149-159.

Codispoti, L.A., Barber, R.T., Friederich, G.E., 1989. Do nitrogen transformations in the poleward undercurrent off Peru and Chile have a globally significant influence? In: Neshyba, S.J., Mooers, C.N.K., Barber, R.T. (Eds.), Poleward flows along eastern ocean boundaries. Springer-Verlag, New York, pp. 281-310.

Codispoti, L.A., Brandes, J.A., Christensen, J.P., Devol, A.H., Naqvi, S.W.A., Paerl, H.W., Yoshinari, T., 2001. The oceanic fixed nitrogen and nitrous oxide budgets: moving targets as we enter the anthropocene? Scientia Marina 65, 85-105.

Conley, D.J., Björck, S., Bonsdorff, E., Carstensen, J., Destouni, G., Gustafsson, B.G., Hietanen, S., Kortekass, M., Kuosa, H., Meier, H.E.M., Müller-Karulis, B., Nordberg, K., Norkko, A., Nürnberg, G., Pitkänen, H., Rabalais, N.N., Rosenberg, R., Savchuk, O.P., Slomp, C.P., Voss, M., Wulff, F., Zillén, L., 2009a. Hypoxia-related processes in the Baltic Sea. Environ. Sci. Technol. 43, 3412-3420. https://doi.org/ 10.1021/es802762a.

Conley, D.J., Carstensen, J., Aigars, J., Axe, P., Bonsdorff, E., Eremina, T., Haahti, B.-M., Humborg, C., Jonsson, P., Kotta, J., Lännegren, C., Larsson, U., Maximov, A. Medina, M.R., Lysiak-Pastuszak, E., Remeikaitè-Nikienè, N., Walve, J., Wilhelms, S., Zillén, L., 2011. Hypoxia is increasing in the coastal zone of the Baltic Sea. Environ. Sci. Technol. 45, 6777-6783. https://doi.org/10.1021/es201212r.

Conley, D.J., Carstensen, J., Ærtebjerg, G., Christensen, P.B., Dalsgaard, T., Hansen, J.L. S., Josefson, A.B., 2007. Long-term changes and impacts of hypoxia in Danish coastal waters. Ecol. Appl. 17, S165-S184. https://doi.org/10.1890/05-0766.1.

Conley, D.J., Carstensen, J., Vaquer-Sunyer, R., Duarte, C.M., 2009b. Ecosystem thresholds with hypoxia. Hydrobiologia 629, 21-29. https://doi.org/10.1007 s10750-009-9764-2.

Connolly, T.P., Hickey, B.M., Geier, S.L., Cochlan, W.P., 2010. Processes influencing seasonal hypoxia in the northern California Current System. J. Geophys. Res. 115 C03021. https://doi.org/10.1029/2009JC005283.

Cooper, S.R., Brush, G.S., 1991. Long-term history of Chesapeake Bay anoxia. Science 254, 992-996.

Cooper, S.R., Brush, G.S., 1993. A 2,500-year history of anoxia and eutrophication in Chesapeake Bay. Estuaries 16 (3), 617-626. 
Crawford, W.R., Pena, M.A., 2013. Declining oxygen on the British Columbia continental shelf. Atmos, Ocean 51, 88-103.

Criales-Hernández, M.I., Schwamborn, R., Graco, M., Ayón, P., Hirche, H.-J., Wolff, M., 2008. Zooplankton vertical distribution and migration off Central Peru in relation to the oxygen minimum layer. Helgol. Mar. Res. 62 (Supplement 1), 85-100.

Cronin, T.M., Dwyer, G.S., Kamiya, T., Schwede, S., Willard, D.A., 2003. Medieval warm period, little ice age and 20th century temperature variability from Chesapeake Bay. Global Planet. Change 36, 17-29.

Cronin, T.M., Vann, C.D., 2003. The sedimentary record of climatic and anthropogenic influence on the Patuxent estuary and Chesapeake Bay ecosystems. Estuaries 26 (2), 196-209.

Czeschel, R., Stramma, L., Johnson, G.C., 2012. Oxygen decreases and variability in the eastern equatorial Pacific. J. Geophys. Res. 117, C01019. https://doi.org/10.1029/ 2012JC008043.

Czeschel, R., Stramma, L., Weller, R.A., Fischer, T., 2015. Circulation, eddies, oxygen and nutrient changes in the eastern tropical South Pacific Ocean. Ocean Sci. 11, 455-470. https://doi.org/10.5194/os-11-455-2015.

Dai, M., Guo, X., Zhai, W., Yuan, L., Wang, B., Wang, L., Cai, P., Tang, T., Cai, W.-J., 2006. Oxygen depletion in the upper reach of the Pearl River estuary during a winter drought. Mar. Chem. 102, 159-169.

Dale, A.W., Sommer, S., Lomnitz, U., Bourbonnais, A., Wallmann, K., 2016. Biological nitrate transport in sediments on the Peruvian margin mitigates benthic sulfide emissions and drives pelagic $\mathrm{N}$ loss during stagnation events. Deep-Sea Res. Part I: Oceanogr. Res. Papers 112, 123-136. https://doi.org/10.1016/j.dsr.2016.02.013.

Dale, A.W., Sommer, S., Ryabenko, E., Noffke, A., Bohlen, L., Wallmann, K. Stolpovsky, K., Greinert, J., Pfannkuche, O., 2014. Benthic nitrogen fluxes and fractionation of nitrate in the Mauritanian oxygen minimum zone (Eastern Tropical North Atlantic). Geochim. Cosmochim. Acta 134, 234-256.

Dalsgaard, T., Thamdrup, B., Farías, L., Revsbech, N.P., 2012. Anammox and denitrification in the oxygen minimum zone of the eastern South Pacific. Limnol. Oceanogr. 57 (5), 1331-1346.

Darelius, E., 2020. On the effect of climate trends in coastal density on deep water renewal frequency in sill fjords a statistical approach. Estuar. Coast. Shelf Sci. 243, 106904 https://doi.org/10.1016/j.ecss.2020.106904.

De Decker, A.H.B., 1970. Notes on an oxygen-depleted subsurface current off the west coast of South Africa. Investigational Report, Division of Sea Fisheries, Cape Town, South Africa 84, 1-24.

De Pol-Holz, R., Ulloa, O., Dezileau, L., Kaiser, J., Lamy, F., Hebbeln, D., 2014. Melting of the Patagonian Ice Sheet and deglacial perturbations of the nitrogen cycle in the eastern South Pacific. Geophys. Res. Lett. 33, L04704. https://doi.org/10.1029/ 2005GL024477.

Degens, E.T., Ross, D.A., 1972. Chronology of the Black Sea over the last 25,000 years Chem. Geol. 10 (1), 1-16.

Deutsch, C., Berelson, W., Thunell, R., Weber, T., Tems, C., McManus, J., Crusius, J., Ito, T., Baumgartner, T., Ferreira, V., Mey, J., van Geen, A., 2014. Centennial changes in North Pacific anoxia linked to tropical trade winds. Science 345, 665-668.

Deutsch, C., Brix, H., Ito, T., Frenzel, H., Thompson, L., 2011. Climate-forced variability of ocean hypoxia. Science 333, 336-339.

Dewitte, B., Vazquez-Cuervo, J., Goubanova, K., Illig, S., Takahashi, K., Cambon, G., Purca, S., Correa, D., Gutierrez, D., Sifeddine, A., Ortlieb, L., 2012. Change in El Niño flavours over 1958-2008: implications for the long-term trend of the upwelling off Peru. Deep-Sea Res. II 77-80, 143-156.

Di Lorenzo, E., Schneider, N., Cobb, K.M., Franks, P.J.S., Chhak, K., Miller, A.J., McWilliams, J.C., Bograd, S.J., Arango, H., Curchitser, E., Powell, T.M., Rivière, P. 2008. North Pacific Gyre Oscillation links ocean climate and ecosystem change. Geophys. Res. Lett. 35, L08607. https://doi.org/10.1029/2007GL032838.

Diakhaté, M., de Coetlogon, G., Lazar, A., Gaye, A.T., 2016. Intra-seasonal SST variability within tropical Atlantic upwellings. 2016. Q. J. R. Meteorolog. Soc. 142, 372-386. https://doi.org/10.1002/qj.2657.

Diaz, R.J., Rosenberg, R., 2008. Spreading dead zones and consequences for marine ecosystems. Science 321, 926-929.

Díaz-Ochoa, J., Pantoja, S., De Lange, G.J., Lange, C.B., Sánchez, G.E., Acuña, V.R. Muñoz, P., Vargas, G., 2011. Oxygenation variability in Mejillones Bay, off northern Chile, during the last two centuries. Biogeosciences 8, 137-146.

Dingle, R.V., Nelson, G., 1993. Sea-bottom temperature, salinity and dissolved oxygen on the continental margin off southwestern Africa. S. Afr. J. Mar. Sci. 13, 33-49.

Diop, C., Dewaelé, D., Diop, M., Touré, A., Cabral, M., Cazier, F., Fall, M., Diouf, A., Ouddane, B., 2014. Assessment of contamination, distribution and chemical speciation of trace metals in water column in the Dakar coast and the Saint Louis estuary from Senegal, West Africa. Mar. Pollut. Bull. 86 (1-2), 539-546.

Dortch, Q., Rabalais, N.N., Turner, R.E., Qureshi, N.A., 2001. Impacts of changing Si/N ratios and phytoplankton species composition. In: Rabalais, N.N., Turner, R.E. (Eds.), Coastal hypoxia: consequences for living resources and ecosystems. Coastal and Estuarine Studies 58. American Geophysical Union, Washington, D.C., pp. 37-48

Du, J., Shen, J., 2015. Decoupling the influence of biological and physical processes on the dissolved oxygen in the Chesapeake Bay. J. Geophys. Res. Oceans 120, 78-93.

Duarte, C.M., Conley, D.J., Carstensen, J., Sánchez-Camacho, M., 2009. Return to Neverland: Shifting baselines affect eutrophication restoration targets. Estuaries Coasts 32, 29-36. https://doi.org/10.1007/s12237-008-9111-2.

Duncan, C.P., Nel, J.H., 1969. Surface currents off the Cape Coast. Investigational Report, Division of Sea Fisheries, South Africa 76, 1-19.

Duncombe Rae, C.M., 2005. A demonstration of the hydrographic partition of the Benguela upwelling ecosystem at $26^{\circ} 40^{\prime}$ 'S. Afr. J. Mar. Sci. 27 (3), 617-628.
Dunn, D.E., 1996. Trends in nutrient inflows to the Gulf of Mexico from streams draining the conterminous United States, 1972-93. Water Resources Investigations Report 96-4113, U.S. Geological Survey, Austin, Texas, p. 60.

Durazo, R., 2009. Climate and upper ocean variability off Baja California, Mexico 1997-2008. Prog. Oceanogr. 83, 361-368.

Duteil, O., Böning, C.W., Oschlies, A., 2014a. Variability in subtropical-tropical cells drives oxygen levels in the tropical Pacific Ocean. Geophys. Res. Lett. 41, 8926-8934. https://doi.org/10.1002/2014GL061774.

Duteil, O., Oschlies, A., Böning, C.W., 2018. Pacific Decadal Oscillation and recent oxygen decline in the eastern tropical Pacific Ocean. Biogeosciences 15, 7111-7126.

Duteil, O., Schwarzkopf, F.U., Böning, C.W., Oschlies, A., 2014b. Major role of the equatorial current system in setting oxygen levels in the eastern tropical Atlantic Ocean: a high-resolution model study. Geophys. Res. Lett. 41, 2033-2040. https:// doi.org/10.1002/2013GL058888.

Duteil, O., Frenger, I., Getzlaff, J., 2020. Intermediate water masses, a major supplier of oxygen for the eastern tropical Pacific Ocean. Ocean Sci. Discuss. https://doi.org/ 10.5194/os-2020-17.

Eadie, B.J., McKee, B.A., Lansing, M.B., Robbins, J.A., Metz, S., Trefry, J.H., 1994. Records of nutrient-enhanced coastal ocean productivity in sediments from the Louisiana continental shelf. Estuaries 17, 754-765.

Echevin, V., Albert, A., Lévy, M., Graco, M., Aumont, O., Garric, G., 2014. Intraseasonal variability of nearshore productivity in the Northern Humboldt Current System: the role of coastal trapped waves. Cont. Shelf Res. 73, 14-30. https://doi.org/10.1016/j. csr.2013.11.015.

Echevin, V., Aumont, O., Ledesma, J., Flores, G., 2008. The seasonal cycle of surface chlorophyll in the Peruvian upwelling system: a modelling study. Prog. Oceanogr. 79, 167-176.

Echevin, V., Goubanova, K., Belmadani, A., Dewitte, B., 2011. Sensitivity of the Humboldt Current system to global warming: a downscaling experiment of the IPSLCM4 model. Clim. Dyn. 38, 761-774. https://doi.org/10.1007/s00382-011-1085-2.

Echevin, V., Gévaudan, M., Espinoza-Morriberón, D., Tam, J., Aumont, O., Gutiérrez, D., Colas, F., 2020. Physical and biogeochemical impacts of RCP8.5 scenario in the Peru upwelling system. Biogeosciences 17, 3317-3341. https://doi.org/10.5194/bg-173317-2020.

Eilola, K., Meier, H.E.M., Almroth, E., 2009. On the dynamics of oxygen, phosphorus and cyanobacteria in the Baltic Sea; a model study. J. Mar. Syst. 75, 163-184. https: doi.org/10.1016/j.jmarsys.2008.08.009.

Elderfield, H., Ferretti, P., Greaves, M., Crowhurst, S., McCave, I.N., Hodell, D., Piotrowski, A.M., 2012. Evolution of ocean temperature and ice volume through the mid-Pleistocene climate transition. Science 337, 704-709.

El Moussaoui, A., Arhan, M., Treguier, A.M., 2005. Model-inferred upper ocean circulation in the eastern tropics of the North Atlantic. Deep-Sea Research Part A 52, 1093-1120.

Emeis, K.-C., Bruchert, V., Currie, B., Endler, R., Ferdelman, T.G., Kiessling, A., Leipe, T., Noli-Peard, K., Struck, U., Vogt, T., 2004. Shallow gas in shelf sediments of the Namibian coastal upwelling ecosystem. Cont. Shelf. Res. 24, 627-642.

Engel, A., Wagner, H., Le Moigne, F.A.C., Wilson, S.T., 2017. Particle export fluxes to the oxygen minimum zone of the eastern tropical North Atlantic. Biogeosciences 14, 1825-1838. https://doi.org/10.5194/bg-14-1825-2017.

Erdem, Z., Schönfeld, J., 2017. Pleistocene to Holocene benthic foraminiferal assemblages from the Peruvian continental margin. Palaeontol. Electronica 20 (2), 35A. https://doi.org/10.26879/764.

Escribano, R., Hidalgo, P., Krautz, C., 2009. Zooplankton associated with the oxygen minimum zone system in the northern upwelling region of Chile during March 2000. Deep-Sea Res. II 56, 1083-1094.

Espinoza-Morriberón, D., 2018. Interannual and Decadal Variability of the Primary Productivity and Oxygen Minimum Zone in the Peruvian Upwelling System. PhD thesis. Sorbonne Université, Paris.

Espinoza-Morriberón, D., Echevin, V., Colas, F., Tam, J., Gutierrez, D., Graco, M., Ledesma, J., Quispe-Ccalluari, C., 2019. Oxygen variability during ENSO in the Tropical South Eastern Pacific. Front. Mar. Sci. 5, 526. https://doi.org/10.3389/ fmars. 2018.00526.

Espinoza-Morriberón, D., Echevin, V., Colas, F., Tam, J., Ledesma, J., Vásquez, L., Graco, M., 2017. Impacts of El Niño events on the Peruvian upwelling system productivity. J. Geophys. Res. Oceans 122, 5423-5444. https://doi.org/10.1002/ 2016JC012439.

Evans, N., Schroeder, I.D., Pozo Buil, M., Jacox, M.G., Bograd, S.J., 2020. Drivers of subsurface deoxygenation in the southern California Current System. e2020GL089274 Geophys. Res. Lett. 46. https://doi.org/10.1029/2020GL089274.

Farrenkopf, A.M., Luther, G.W., 2002. Iodine chemistry reflects productivity and denitrification in the Arabian Sea: evidence for flux of dissolved species from sediments of western India into the OMZ. Deep-Sea Res. II 49, 2303-2318.

Fawcett, A.L., Pitcher, G.C., Shillington, F.A., 2008. Nearshore currents on the southern Namaqua shelf of the Benguela upwelling system. Cont. Shelf Res. 28, 1026-1039.

Feely, R.A., Okazaki, R.R., Cai, W.-J., Bednaršek, N., Alin, S.R., Byrne, R.H., Fassbender, A., 2018. The combined effects of acidification and hypoxia on $\mathrm{pH}$ and aragonite saturation in the coastal waters of the California current ecosystem and the northern Gulf of Mexico. Cont. Shelf Res. 152, 50-60.

Feely, R.A., Sabine, C.L., Hernandez-Ayon, J.M., Ianson, D., Hales, B., 2008. Evidence for upwelling of corrosive "acidified" water onto the continental shelf. Science 320 1490-1492.

Fennel, K., Testa J.M., 2019. Biogeochemical Controls on Coastal Hypoxia, Annu. Rev. Mar. Sci. 11, 4.1-4.26. https://doi.org/10.1146/annurev-marine-010318-095138.

Fennel, W., Junker, T., Schmidt, M., Mohrholz, V., 2012. Response of the Benguela upwelling systems to spatial variations in the wind stress. Cont. Shelf Res. 45, 65-77. 
Fiedler, B., Grundle, D., Schütte, F., Karstensen, J., Löscher, C.R., Hauss, H., Wagner, H., Loginova, A., Kiko, R., Silva, P., Tanhua, T., Körtzinger, A., 2016. Oxygen utilization and downward carbon flux in an oxygen-depleted eddy in the eastern tropical North Atlantic. Biogeosciences 13, 5633-5647. https://doi.org/10.5194/bg-13-56332016.

Figueiras, F.G., Pitcher, G.C., Estrada, M., 2006. Harmful algal bloom dynamics in relation to physical processes. In: Granéli, E., Turner, J.T. (Eds.), Ecology of Harmful Algae, Ecological Studies 189. Springer-Verlag, Berlin, Heidelberg, pp. 127-138.

Florenchie, P., Lutjeharms, J.R.E., Reason, C.J.C., Masson, S., Rouault, M., 2003. The source of Benguela Niños in the South Atlantic Ocean. Geophys. Res. Lett. 30, 1505. https://doi.org/10.1029/2003GL017172.

Fiedler, P.C., Mantua, N.J., 2017. How are warm and cool years in the California Current related to ENSO? J. Geophys. Res. Oceans 122, 5936-5951. https://doi.org/ 10.1002/2017JC013094.

Franco, A.C., Hernández-Ayón, J.M., Beier, E., Garçon, V., Maske, H., Paulmier, A., Färber-Lorda, J., Castro, R., Sosa-Ávalos, R., 2014. Air-sea $\mathrm{CO}_{2}$ fluxes above the stratified oxygen minimum zone in the coastal region off Mexico. J. Geophys. Res. Oceans 119, 2923-2937. https://doi.org/10.1002/2013JC009337.

Frieder, C.A., Nam, S.H., Martz, T.R., Levin, L.A., 2012. High temporal and spatial variability of dissolved oxygen and $\mathrm{pH}$ in a nearshore California kelp forest. Biogeosciences 9, 3917-3930. https://doi.org/10.5194/bg-9-3917-2012.

Friedrich, J., Janssen, F., Aleynik, D., Bange, H.W., Boltacheva, N., Çagatay, M.N., Dale, A.W., Etiope, G., Erdem, Z., Geraga, M., Gilli, A., Gomoiu, M.T., Hall, P.O.J. Hansson, D., He, Y., Holtappels, M., Kirf, M.K., Kononets, M., Konovalov, S. Lichtschlag, A., Livingstone, D.M., Marinaro, G., Mazlumyan, S., Naeher, S., North, R.P., Papatheodorou, G., Pfannkuche, O., Prien, R., Rehder, G., Schubert, C.J. Soltwedel, T., Sommer, S., Stahl, H., Stanev, E.V., Teaca, A., Tengberg, A., Waldmann, C., Wehrli, B., Wenzhöfer, F., 2014. Investigating hypoxia in aquatic environments: diverse approaches to addressing a complex phenomenon. Biogeosciences 11, 1215-1259. https://doi.org/10.5194/bg-11-1215-2014.

Frischknecht, M., Münnich, M., Gruber, N., 2015. Remote versus local influence of ENSO on the California Current System. J. Geophys. Res. Oceans 120, 1353-1374. https:// doi.org/10.1002/2014JC010531.

Froelich, P.N., Arthur, M.A., Burnett, W.C., Deakin, M., Hensley, V., Jahnke, R., Kaul, L., Kim, K.-H., Roe, K., Soutar, A., Vathakanon, C., 1988. Early diagenesis of organic matter in Peru continental margin sediments: phosphorite precipitation. Mar. Geol. 80 (3-4), 309-343.

Froelich, P.N., Klinkhammer, G.P., Bender, M.L., Luedtke, N.A., Heath, G.R., Cullen, D. Dauphin, P., Hammond, D., Hartman, B., Maynard, V., 1979. Early oxidation of organic matter in pelagic sediments of the eastern equatorial Atlantic: suboxic diagenesis. Geochim. Cosmochim. Acta 43 (7), 1075-1090.

Fu, W., Primeau, R., Moore, J.K., Lindsay, K., Randerson, J.T., 2018. Reversal of increasing tropical ocean hypoxia trends with sustained climate warming. Global Biogeochem. Cycles 32. https://doi.org/10.1002/2017GB005788.

Fuenzalida, R., Schneider, W., Garcés-Vargas, J., Bravo, L., Lange, C., 2009. Vertical and horizontal extension of the oxygen minimum zone in the eastern South Pacific Ocean. Deep Sea Res. II 56, 992-1003. https://doi.org/10.1016/j.dsr2.2008.11.001.

Fujiwara, T., Yamada, Y., 2002. Inflow of oceanic water into Tokyo Bay and generation of a subsurface hypoxic water mass. J. Geophys. Res. 107 (C5), 3045. https://doi. org/10.1029/2000jc000749.

Funkey, C.P., Conley, D.J., Reuss, N.S., Humborg, C., Jilbert, T., Slomp, C.P., 2014. Hypoxia sustains cyanobacteria blooms in the Baltic Sea. Environ. Sci. Technol. 48 2598-2602. https://doi.org/10.1021/es404395a.

Furukawa, K., 2015. Eutrophication in Tokyo Bay. In: Yanagi, T. (Ed.), Eutrophication and Oligotrophication in Japanese Estuaries: The present status and future tasks. Springer, Dordrecht, pp. 5-37.

Furukawa, K., Okada, T., 2006. Tokyo Bay: its environmental status - past, present, and future. In: Wolanski, E. (Ed.), The Environment in Asia Pacific Harbours. Springer, Netherlands, pp. 15-34.

Gaarder, T., 1916. De vestlandske fjorders hydrografi (The hydrography of the west Norwegian fjords, in Norwegian). Bergen Museums Aarbok 1915-1916. Naturvidensk. Række. Nr. 2, 200 pp.

Gade, H.G., 1973. Deep Water Exchanges in a Sill Fjord: A Stochastic Process. J. Phys. Oceanogr. 3, 213-219.

Gade, H.G., Edwards, A., 1980. Deep water renewal in fjords. In: Freeland, H.J., Farmer, D.M., Levings, C.D. (Eds.), Fjord Oceanography. Plenum Publishing Corp, New York, pp. 453-489.

Galbraith, E.D., Kienast, M., and NICOPP working group members, 2013. The acceleration of oceanic denitrification during deglacial warming. Nat. Geosci. 6 579-584.

Gallagher, S.J., Kitamura, A., Iryu, Y., Itaki, T., Koizumi, I., Hoiles, P.W., 2015. The Pliocene to recent history of the Kuroshio and Tsushima Currents: a multi-proxy approach. Progr. Earth Planet. Sci. 2 (1), 17. https://doi.org/10.1186/s40645-0150045-6.

Gallagher, S.J., Sagawa, T., Henderson, A.C.G., Saavedra-Pellitero, M., De Vleeschouwer, D., Black, H., Itaki, T., Toucanne, S., Bassetti, M.-A., Clemens, S. Anderson, W., Alvarez-Zarikian, C., Tada, R., 2018. East Asian monsoon history and paleoceanography of the Japan Sea over the last 460,000 years. Paleoceanogr. Paleoclimatol. 33 (7), 683-702.

Galloway, J.N., Cowling, E.B., 2002. Reactive nitrogen and the world: two hundred years of change. Ambio 31, 64-71.

Galloway, J.N., Townsend, A.R., Erisman, J.W., Bekunda, M., Cai, Z., Freney, J.R., Martinelli, L.A., Seitzinger, S.P., Sutton, M.A., 2008. Transformation of the nitrogen cycle: recent trends, questions, and potential solutions. Science 320, 889-892.

Gamo, T., 2011. Dissolved oxygen in the bottom water of the Sea of Japan as a sensitive alarm for global climate change. TrAC, Trends Anal. Chem. 30 (8), 1308-1319.
García-Reyes, M., Sydeman, W.J., Schoeman, D.S., Rykaczewski, R.R., Black, B.A., Smit, A.J., Bograd, S.J., 2015. Under pressure: climate change, upwelling, and Eastern Boundary Upwelling Ecosystems. Front. Mar. Sci. 2, 109. https://doi.org/ 10.3389/fmars.2015.00109.

Garçon, V., Dewitte, B., Montes, I., Goubanova, K., 2019. Land-Sea-Atmosphere interactions exacerbating ocean deoxygenation in Eastern Boundary Upwelling Systems (EBUS). In: Laffoley, S.D., Baxter, J.M. (Eds.), Ocean Deoxygenation: Everyone's problem, causes, impacts, consequences and solutions. IUCN (International Union for Conservation of Nature and Natural Resources Report, Gland, Switzerland), pp. 171-186. \#

Gaye, B., Nagel, B., Dähnke, K., Rixen, T., Emeis, K,-C., 2013. Evidence of parallel denitrification and nitrite oxidation in the ODZ of the Arabian Sea from paired stable isotopes of nitrate and nitrite. Global Biogeochem. Cycles 27, 1059-1071.

Gelesh, L., Marshall, K., Boicourt, W., Lapham, L., 2016. Methane concentrations increase in bottom waters during summertime anoxia in the highly eutrophic estuary, Chesapeake Bay, USA. Limnol. Oceanogr. 61 (S1), S253-S266.

Gier, J., Löscher, C.R., Dale, A.W., Sommer, S., Lomnitz, U., Treude, T., 2017. Benthic dinitrogen fixation traversing the oxygen minimum zone off Mauritania (NW Africa). Front. Mar. Sci. 4, 390. https://doi.org/10.3389/fmars.2017.00390.

Gilbert, D., Rabalais, N.N., Díaz, R.J., Zhang, J., 2010. Evidence for greater oxygen decline rates in the coastal ocean than in the open ocean. Biogeosciences 7 , 2283-2296. https://doi.org/10.5194/bg-7-2283-2010.

Gillibrand, P.A., Turrell, W.R., Moore, D.C., Adams, R.D., 1996. Bottom water stagnation and oxygen depletion in a Scottish sea loch. Estuar. Coast. Shelf Sci. 43, 217-235.

Gilly, W.F., Beman, J.M., Litvin, S.Y., Robison, B.H., 2013. Oceanographic and biological effects of shoaling of the oxygen minimum zone. Ann. Rev. Mar. Sci. 5, 393-420.

Gilson, H.C., 1937. The nitrogen cycle. In: Gilson, H.C. (Ed.), The John Murray Expedition, 1933-34. British Museum Natural History, Scientific Reports, 2(8), 2181.

Glessmer, M.S., Eden, C., Oschlies, A., 2009. Contribution of oxygen minimum zone waters to the coastal upwelling off Mauritania. Prog. Oceanogr. 83, 143-150.

Gnanadesikan, A., Bianchi, D., Pradal, M.-A., 2013. Critical role of mesoscale eddy diffusion in supplying oxygen to hypoxic ocean waters. Geophys. Res. Lett. 40, 5194-5198.

Goes, J.I., Thoppil, P.G., Gomes, H.d.R., Fasullo, J.T., 2005. Warming of the Eurasian landmass is making the Arabian Sea more productive. Science 308, 545-547.

Gooday, A.J., Jorissen, F., Levin, L.A., Middelburg, J.J., Naqvi, W., Rabalais, N., Scranton, M., Zhang, J., 2009. Historical records of coastal eutrophication and hypoxia. Biogeosciences 6, 1-39.

Gomes, H.d.R., Goes, J.I., Matondkar, S.G.P., Buskey, E.J., Basu, S., Parab, S., Thoppil, P., 2014. Massive outbreaks of Noctiluca scintillans blooms in the Arabian Sea due to spread of hypoxia. Nat. Commun. 5, 4862, https://doi.org/10.1038/ncomms5862.

Gómez-Letona, M., Ramos, A.G., Coca, J., Arístegui, J., 2017. Trends in primary production in the Canary Current upwelling system - a regional perspective comparing remote sensing models. Front. Mar. Sci. 4, 370. https://doi.org/10.3389/ fmars.2017.00370.

Gordon, A.L., 2005. Oceanography of the Indonesian Seas and their throughflow. Oceanography 18, 14-27.

Goubanova, K., Echevin, V., Dewitte, B., Codron, F., Takahashi, K., Terray, P., Vrac, M., 2012. Statistical downscaling of sea-surface wind over the Peru-Chile upwelling region: diagnosing the impact of climate change from the IPSL-CM4 model. Clim. Dyn. 36, 1365-1378. https://doi.org/10.1007/s00382-010-0824-0.

Graco, M., Ledesma, J., Flores, G., Girón, M., 2007. Nutrientes, oxígeno y procesos biogeoquímicos en el sistema de surgencias de la corriente de Humboldt frente a Perú. Revista Peruana de Biologia 14 (1), 117-128.

Graco, M.I., Purca, S., Dewitte, B., Castro, C.G., Morón, O., Ledesma, J., Flores, G., Gutiérrez, D., 2017. The OMZ and nutrient features as a signature of interannual and low-frequency variability in the Peruvian upwelling system. Biogeosciences 14, 4601-4617. https://doi.org/10.5194/bg-14-4601-2017.

Grados, D., Bertrand, A., Colas, F., Echevin, V., Chaigneau, A., Gutiérrez, D., Vargas, G., Fablet, R., 2016. Spatial and seasonal patterns of fine-scale to mesoscale upper ocean dynamics in an eastern Boundary Current System. Prog. Oceanogr. 142, 105-116.

Grantham, B.A., Chan, F., Nielsen, K.J., Fox, D.S., Barth, J.A., Huyer, A., Lubchenco, J., Menge, B.A., 2004. Upwelling-driven nearshore hypoxia signals ecosystem and oceanographic changes in the northeast Pacific. Nature 429, 749-754.

Grégoire, M., Beckers, J.-M., Nihoul, J.C.J., Stanev, E., 1997. Coupled Hydrodynamic Ecosystem model of the Black Sea at basin scale. In: Ozsoy, E., Mikaelyan, A. (Eds.), Sensitivity to change: Black Sea, Baltic Sea and North Sea. Kluwer Academic Publishers, Dordrecht, Netherlands, pp. 487-499.

Grégoire, M., Lacroix, G., 2001. Study of the oxygen budget of the Black Sea waters using a 3D coupled hydrodynamical-biogeochemical model. J. Mar. Syst. 31, 175-202.

Grégoire, M., Raick, C., Soetaert, K., 2008. Numerical modeling of the central Black Sea ecosystem functioning during the late 80 's (eutrophication phase). Prog. Oceanogr. 76 (3), 286-333.

Grégoire, M., Soetaert, K., 2010. Carbon, nitrogen, oxygen and sulfide budgets in the Black Sea: a biogeochemical model of the whole water column coupling the oxic and anoxic parts. Ecol. Model. 221 (19), 2287-2301.

Gruber, N., Lachkar, Z., Frenzel, H., Marchesiello, P., Münnich, M., McWilliams, J.C., Nagai, T., Plattner, G.-K., 2011. Eddy-induced reduction of biological production in eastern boundary upwelling systems. Nat. Geosci. 4, 787-792. https://doi.org/ 10.1038/ngeo1273.

Gu, H.K., 1980. The maximum value of dissolved oxygen in its vertical distribution in Yellow Sea. Acta Oceanolog. Sin. 2 (2), 70-80 (in Chinese with English abstract).

Gupta, G.V.M., Sudheesh, V., Sudharma, K.V., Saravanane, N., Dhanya, V., Dhanya, K.R. Lakshmi, G., Sudhakar, M., Naqvi, S.W.A., 2016. Evolution to decay of upwelling 
and associated biogeochemistry over the southeastern Arabian Sea shelf. J. Geophys. Res. Biogeosci. 121, 159-175.

Gustafsson, B.G., Schenk, F., Blenckner, T., Eilola, K., Meier, H.E.M., Müller-Karulis, B. Neumann, T., Ruoho-Airola, T., Savchuk, O.P., Zorita, W., 2012. Reconstructing the development of Baltic Sea eutrophication 1850-2006. Ambio 41, 534-548, https:// doi.org/10.1007/s13280-012-0318-x.

Gutiérrez, D., Akester, M., Naranjo, L., 2016. Productivity and sustainable managemen of the Humboldt Current Large Marine Ecosystem under climate change. Environ. Dev. 17, 126-144.

Gutiérrez, D., Bouloubassi, I., Sifeddine, A., Purca, S., Goubanova, K., Graco, M. Field, D., Méjanelle, L., Velazco, F., Lorre, A., Salvatteci, R., Quispe, D., Vargas, G., Dewitte, B., Ortlieb, L., 2011. Coastal cooling and increased productivity in the main upwelling cell off Peru since the mid-twentieth century. Geophys. Res. Lett. 38. L07603-1-L07603-6 10.1029/2010GL046324.

Gutiérrez, D., Enríquez, E., Purca, S., Quipuzcóa, L., Marquina, R., Flores, G., Graco, M., 2008. Oxygenation episodes on the continental shelf of central Peru: remote forcing and benthic ecosystem response. Prog. Oceanogr. 79, 177-189.

Gutiérrez, D., Quipúzcoa, L., Enríquez, E., 2006. Oxygen deficiency and benthic communities in the Peruvian upper continental margin. Gayana (Concepcion) 70, 29-36.

Gutiérrez, D., Sifeddine, A., Field, D.B., Ortlieb, L., Vargas, G., Chavez, F.P., Velazco, F. Ferreira, V., Tapia, P., Salvatteci, R., Boucher, H., Morales, M.C., Valdes, J., Reyss, J. L., Campusano, A., Boussafir, M., Mandeng-Yogo, M., Garcia, M., Baumgartner, T. 2009. Rapid reorganization in ocean biogeochemistry off Peru towards the end of the Little Ice Age. Biogeosciences 6, 835-848.

Gutknecht, E., Dadou, I., Le Vu, B., Cambon, G., Sudre, J., Garcon, V., Machu, E. Rixen, T., Kock, A., Flohr, A., Paulmier, A., Lavik, G., 2013a. Coupled physical/ biogeochemical modeling including $\mathrm{O}_{2}$-dependent processes in the Eastern Boundary Upwelling Systems: application in the Benguela. Biogeosciences 10 (6), 3559-3591.

Gutknecht, E., Dadou, I., Marchesiello, P., Cambon, G., Le Vu, B., Sudre, J., Garçon, V., Machu, E., Rixen, T., Kock, A., Flohr, A., Paulmier, A., Lavik, G., 2013b. Nitrogen transfers off Walvis Bay: a 3-D coupled physical/biogeochemical modeling approach in the Namibian upwelling system. Biogeosciences 10, 4117-4135. https://doi.org/ 10.5194/bg-10-4117-2013.

Hagy, J.D., Boynton, W.R., Keefe, C.W., Wood, K.V., 2004. Hypoxia in Chesapeake Bay, 1950-2001: long-term change in relation to nutrient loading and river flow. Estuaries 27, 634-658.

Hahn, J., Brandt, P., Schmidtko, S., Krahmann, G., 2017. Decadal oxygen change in the eastern tropical North Atlantic. Ocean Sci. 13 (4), 551-576. https://doi.org/ 10.5194/os-13-551-2017.

Hamersley, M.R., Lavik, G., Woebken, D., Rattray, J.E., Lam, P., Hopmans, E.C., Sinninghe Damsté, J.S., Krüger, S., Graco, M., Gutiérrez, D., Kuypers, M.M.M., 2007. Anaerobic ammonium oxidation in the Peruvian oxygen minimum zone. Limnol. Oceanogr. 52, 923-933.

Hamukuaya, H., O'Toole, M.J., Woodhead, P.M.J., 1998. Observations of severe hypoxia and offshore displacement of Cape hake over the Namibian shelf in 1994. In: Pillar, S.C., Moloney, C.L., Payne, A.I.L., Shillington, F.A. (Eds,), Benguela Dynamics: Impacts of Variability on Shelf-Sea Environments and their Living Resources. South Afr. J. Mar. Sci. 19, 57-61.

Hansell, D.A., Peltzer, E.T., 1998. Spatial and temporal variations of total organic carbon in the Arabian Sea. Deep-Sea Res. II 45, 2171-2193.

Hansen, J.W., Carstensen, J., 2019. Oxygen conditions (In Danish). In: Hansen, J.W. (Ed.), Marine Områder 2017. NOVANA, Aarhus University, DCE, https://dce2.au. dk/pub/SR308.pdf.

Harrison, P.J., Yin, K.D., Lee, J.H.W., Gan, J.P., Liu, H.B., 2008. Physical-biological coupling in the Pearl River Estuary. Cont. Shelf Res. 28 (12), 1405-1415.

HELCOM, 2018. Our Baltic Sea. In State of the Baltic Sea, Helsinki Commission, Baltic Marine Environment Protection Commission, Helsinki, FI. http://stateofthebalticsea. helcom.fi/in-brief/our-baltic-sea/ \#.

Helly, J.J., Levin, L.A., 2004. Global distribution of naturally occurring marine hypoxia on continental margins. Deep-Sea Res. I Oceanographic Res. Papers 51, 1159-1168.

Helm, K.P., Bindoff, N.L., Church, J.A., 2011. Observed decreases in oxygen content of the global ocean. Geophys. Res. Lett. 38, L23602.

Higginson, M.J., Altabet, M.A., 2004. Initial test of the silicic acid leakage hypothesis using sedimentary biomarkers. Geophys. Res. Lett. 31, L18303. https://doi.org/ 10.1029/2004GL020511.

Hirose, K., Yasuhara, M., Tsujimoto, A., Yamazaki, H., Yoshikawa, S., 2008. The succession of diatom assemblages and anthropogenically-induced environmental changes over the last 120 years, Osaka Bay, Japan. The Quaternary Research (Daiyonki-Kenkyu) 47, 287-296 (in Japanese with English abstract).

Holden, C.J., 1985. Currents in St Helena Bay inferred from radio-tracked drifters. In: Shannon L.V. (Ed.), South African ocean colour and upwelling experiment. Sea Fisheries Research Institute, Cape Town, South Africa, pp. 97-109.

Holmer, M., Thorsen, S.W., Carlsson, M.S., Petersen, J.K., 2016. Pelagic and benthic nutrient regeneration processes in mussel cultures (Mytilus edulis) in a eutrophic coastal area (Skive Fjord, Denmark). Estuaries Coasts 38 (5), 1629-1641. https:// doi.org/10.1007/s12237-014-9864-8.

Hood, R.R., Shenk, G., Dixon, R., Ball, W., Bash, J., Cerco, C., Claggett, P., Harris, L., Ihde, T.F., Linker, L., Sherwood, C., Wainger, L., 2019. Chesapeake Bay Program Modeling in 2025 and Beyond: A Proactive Visioning Workshop. STAC Publication Number 19-002, Edgewater, MD, p. 62 pp..

Hoppe, H.G., Gocke, K., Koppe, R., Begler, C., 2002. Bacterial growth and primary production along a north-south transect of the Atlantic Ocean. Nature 416, 168-171.

Hormazábal, S., Shaffer, G., Silva, N., Navarro, E., 2006. La corriente sub-superficial del Perú-Chile y la variabilidad de la zona de mínimo oxígeno frente a Chile central.
Gayana (Concepción) 70 (supplement 1), 37-45. https://doi.org/10.4067/S071765382006000300009.

Howard, E.M., Penn, J.L., Frenzel, H., Seibel, B.A., Bianchi, D., Renault, L., Kessouri, F. Sutula, M.A., McWilliams, J.C., Deutsch, C., 2020. Climate-driven aerobic habitat loss in the California Current System. Sciences. Advances 6 (20) art.eaay3188.

Howard, M.D.A., Sutula, M., Caron, D.A., Chao, Y., Farrara, J.D., Frenzel, H., Jones, B. Robertson, G., McLaughlin, K., Sengupta, A., 2014. Anthropogenic nutrient sources rival natural sources on small scales in the coastal waters of the Southern California Bight. Limnol. Oceanogr. 59 (1), 285-297.

Howell, E.A., Doney, S.C., Fine, R.A., Olson, D.B., 1997. Geochemical estimates of denitrification in the Arabian Sea and the Bay of Bengal during WOCE. Geophys. Res. Lett. 24, 2549-2552.

Huang, H.-H.M., Yasuhara, M., Iwatani, H., Alvarez Zarikian, C.A., Bassetti, M.-A, Sagawa, T., 2018a. Benthic biotic response to climate changes over the last 700,000 years in a deep marginal sea: impacts of deoxygenation and the Mid-Brunhes Event. Paleoceanogr. Paleoclimatol. 33 (7), 766-777.

Huang, H.-H.M., Yasuhara, M., Iwatani, H., Yamaguchi, T., Yamada, K., Mamo, B., 2018b. Deep-sea ostracod faunal dynamics in a marginal sea: biotic response to oxygen variability and mid-Pleistocene global changes. Paleobiology 1-13.

Huang, J., Hu, J., Li, S., Wang, B., Xu, Y., Liang, B., Liu, D., 2019. Effects of physical forcing on summertime hypoxia and oxygen dynamics in the Pearl River estuary. Water 11, 2018.

Hutchings, L., Jarre, A., Lamont, T., van den Berg, M., Kirkman, S.P., 2012. St Helena Bay (southern Benguela) then and now: muted climate signals, large human impact. African Journal of Marine Science 34, 559-583.

Hutchings, L., van der Lingen, C.D., Shannon, L.J., Crawford, R.J.M., Verheye, H.M.S., Bartholomae, C.H., van der Plas, A.K., Louw, D., Kreiner, A., Ostrowski, M., Fidel, Q., Barlow, R.G., Lamont, T., Coetzee, J., Shillington, F., Veitch, J., Currie, J.C., Monteiro, P.M.S., 2009. The Benguela Current: an ecosystem of four components. Prog. Oceanogr. 83, 15-32.

Ibarra, A.A., 2015. Variabilidad temporal en la estructura y composición de la macrofauna bentónica en Playa Atenas, Pisco. Engineer Thesis. Universidad Nacional Agraria La Molina, Lima, 150 pp. \#.

Inall, M.E., Gillibrand, P.A., 2010. The physics of mid-latitude fjords: a review. In: Howe, J.A., Austin, W.E.N., Forwick, M., Paetzel, M. (Eds.), Fjord Systems and Archives, The Geological Society, London, Special Publications, pp. 17-33, https://doi.org/ 10.1144/SP344.3.

IPCC, 2013. Climate Change 2013: The Physical Science Basis. Working Group I contribution to the Fifth Assessment Report of the Intergovernmental Panel on Climate Change, Stocker, T.F., Qin, D., Plattner, G.-K., Tignor, M., Allen, S.K., Boschung, J., Nauels, A., Xia, Y., Bex, V., Midgley, P.M. (Eds.), Cambridge University Press, Cambridge, United Kingdom and New York, NY, USA, 1535 pp.

IPCC, 2019. IPCC Special Report on the Ocean and Cryosphere in a Changing Climate. In Press. Pörtner, H.-O., Roberts, D.C., Masson-Delmotte, V., Zhai, P., Tignor, M., Poloczanska, E., Mintenbeck, K., Alegría, A., Nicolai, M., Okem, A., Petzold, J., Rama, B., Weyer, N.M. (Eds.).

Irby, I.D., Friedrichs, M.A.M., Da, F., Hinson, K.E., 2018. The competing impacts of climate change and nutrient reductions on dissolved oxygen in Chesapeake Bay. Biogeosciences 15 (9), 2649-2668.

Irino, T., Tada, R., Ikehara, K., Sagawa, T., Karasuda, A., Kurokawa, S., Seki, A., Lu, S., 2018. Construction of perfectly continuous records of physical properties for darklight sediment sequences collected from the Japan Sea during Integrated Ocean Drilling Program Expedition 346 and their potential utilities as paleoceanographic studies. Prog. Earth Planet. Sci. 5, 23. https://doi.org/10.1186/s40645-018-0176-7.

Itaki, T., 2016. Transitional changes in microfossil assemblages in the Japan Sea from the Late Pliocene to Early Pleistocene related to global climatic and local tectonic events. Prog. Earth Planet. Sci. 3, 11. https://doi.org/10.1186/s40645-016-0087-4.

Itaki, T., Ikehara, K., Motoyama, I., Hasegawa, S., 2004. Abrupt ventilation changes in the Japan Sea over the last 30 ky: evidence from deep-dwelling radiolarians. Palaeogeogr. Palaeoclimatol. Palaeoecol. 208 (3-4), 263-278.

Ito, T., Deutsch, C., 2010. A conceptual model for the temporal spectrum of oceanic oxygen variability. Geophys. Res. Lett. 37, L03601. https://doi.org/10.1029/ 2009GL041595.

Ito, T., Nenes, A., Johnson, M.S., Meskhidze, N., Deutsch, C., 2016. Acceleration of oxygen decline in the tropical Pacific over the past decades by aerosol pollutants. Nat. Geosci. 9, 443-447.

Ito, T., Minobe, A., Long, M.C., Deutsch, C., 2017. Upper ocean $\mathrm{O}_{2}$ trends: 1958-2015. Geophys. Res. Lett. 44, 4214-4223.

Ittekkot, V., Haake, B., Bartsch, M., Nair, R.R., Ramaswamy, V., 1992. Organic carbon removal in the sea: the continental connection. In: Summerhayes, C.P. (Ed.), Upwelling systems: Evolution since the early Miocene, No 64. Special Publication Geological Society, pp. 167-176.

Jarre, A., Hutchings, L., Crichton, M., Wieland, K., Lamont, T., Blamey, L.K., Illert, C., Hill, E., Van den Berg, M., 2015. Oxygen-depleted bottom waters along the west coast of South Africa, 1950-2011. Fish. Oceanogr. 24 (Suppl. 1), 56-73.

Jensen, M.M., Lam, P., Revsbech, N.P., Nagel, B., Gaye, B., Jetten, M.S.M., Kuypers, M.M. M., 2011. Intensive nitrogen loss over the Omani Shelf due to anammox coupled with dissimilatory nitrite reduction to ammonium. ISME J. 5, 1660-1670.

Joh, H., 1986. Studies on the mechanism of eutrophication and the effect of it on fisheries production in Osaka Bay. Bull. Osaka Prefectural Fisheries Experimental Station 7, 1-174 (in Japanese).

Johansen, P.-O., Isaksen, T.E., Bye-Ingebrigtsen, E., Haaave, M., Dahlgren, T.G., Kvalø, S. E., Greenacre, M., Durand, D., Rapp, H.T., 2018. Temporal changes in benthic macrofauna on the west coast of Norway resulting from human activities. Mar. Pollut. Bull. 128, 483-495. 
Junker, T., Mohrholz, V., Siegfried, L., van der Plas, A., 2017. Seasonal to interannual variability of water mass characteristics and currents on the Namibian shelf. J. Mar. Syst. 165, 36-46.

Justić, D., Bierman, V.J., Scavia, D., Hetland, R.D., 2007. Forecasting Gulf's hypoxia: the next 50 years? Estuaries Coasts 30 (5), 791-801.

Kahru, M., Kudela, R.M., Manzano-Sarabia, M., Mitchell, B.G., 2012. Trends in the surface chlorophyll of the California Current: merging data from multiple ocean color satellites. Deep-Sea Res. II 77-80, 89-98.

Karstensen, J., Schütte, F., Pietri, A., Krahmann, G., Fiedler, B., Grundle, D., Hauss, H., Körtzinger, A., Löscher, C.R., Testor, P., Vieira, N., Visbeck, M., 2017. Upwelling and isolation in oxygen-depleted anticyclonic modewater eddies and implications for nitrate cycling. Biogeosciences 14, 2167-2181. https://doi.org/10.5194/bg-14 2167-2017.

Karstensen, J., Stramma, L., Visbeck, M., 2008. Oxygen minimum zones in the eastern tropical Atlantic and Pacific oceans. Prog. Oceanogr. 77, 331-350.

Keeling, R.F., Körtzinger, A., Gruber, N., 2010. Ocean deoxygenation in a warming world. Annu. Rev. Marin. Sci. 2, 199-229. https://doi.org/10.1146/annurev. marine.010908.16385.

Kemp, W.M., Boynton, W.R., Adolf, J.E., Boesch, D.F., Boicourt, W.C., Brush, G., Cornwell, J.C., Fisher, T.R., Glibert, P.M., Hagy, J.D., Harding, L.W., Houde, E.D., Kimmel, D.G., Miller, W.D., Newell, R.I.E., Roman, M.R., Smith, E.M., Stevenson, J. C., 2005. Eutrophication of Chesapeake Bay: historical trends and ecologica interactions. Mar. Ecol. Prog. Ser. 303, 1-29.

Kido, Y., Minami, I., Tada, R., Fujine, K., Irino, T., Ikehara, K., Chun, J.H., 2007. Orbital scale stratigraphy and high-resolution analysis of biogenic components and deepwater oxygenation conditions in the Japan Sea during the last 640 kyr. Palaeogeogr. Palaeoclimatol. Palaeoecol. 247 (1-2), 32-49.

Kim, H.-S., Flagg, C.N., Howden, S., 2001. Northern Arabian Sea variability from TOPEX/Poseidon altimetry data: an extension of the US JGOFS/ONR shipboard ADCP study. Deep-Sea Res. II 48, 1069-1096.

Klenz, T., Dengler, M., Brandt, P., 2018. Seasonal variability of the Mauritania Current and hydrography at 18 N. J. Geophys. Res. Oceans 123, 8122-8137.

Konovalov, K.S., Murray, J.W., 2001. Variations in the chemistry of the Black Sea on a time scale of decades (1960-1995). J. Mar. Syst. 31, 217-243.

Konovalov, S.K., Murray, J.W., Luther, G.W., Tebo, B.M., 2006. Processes controlling the redox budget for the oxic/anoxic water column of the black sea. Deep Sea Research II $53,1817-1841$

Kounta, L., Capet, X., Jouanno, J., Kolodziejczyk, N., Sow, B., Thierno Gaye, A., 2018. A model perspective on the dynamics of the shadow zone of the eastern tropical North Atlantic-Part 1: the poleward slope currents along West Africa. Ocean Sci. 14, 971-999. https://doi.org/10.5194/os-14-971-2018.

Krause-Jensen, D., Markager, S., Dalsgaard, T., 2012. Benthic and pelagic primary production in different nutrient regimes. Estuaries Coasts 35, 527-545. https://doi org/10.1007/s12237-011-9443-1.

Kubo, A., Hashihama, F., Kanda, J., Horimoto-Miyazaki, N., Ishimaru, T., 2019. Longterm variability of nutrient and dissolved organic matter concentrations in Tokyo Bay between 1989 and 2015. Limnol. Oceanogr. 64, S209-S222.

Kurczyn, J.A., Beier, E., Lavín, M.F., Chaigneau, A., 2012. Mesoscale eddies in the northeastern Pacific tropical-subtropical transition zone: statistical characterization from satellite altimetry. J. Geophys. Res. 117, C10021. https://doi.org/10.1029/ 2012JC007970.

Kuypers, M.M.M., Lavik, G., Woebken, D., Schmid, M., Fuchs, B.M., Amann, R., Bo, Barker J., Jetten, S.M., 2015. Massive nitrogen loss from the Benguela upwelling system through anaerobic ammonium oxidation. Proc. Natl. Acad. Sci. USA 102 (18), 6478-6483.

Lachkar, Z., Levy, M., Smith, S., 2018. Intensification and deepening of the Arabian Sea oxygen minimum zone in response to increase in Indian monsoon wind intensity. Biogeosciences 15, 159-186. https://doi.org/10.5194/bg-15-159-2018.

Lam, P., Lavik, G., Jensen, M.M., van de Vossenberg, J., Schmid, M., Woebken, D. Gutierrez, D., Amann, R., Jetten, M.S., Kuypers, M.M., 2009. Revising the nitrogen cycle in the Peruvian oxygen minimum zone. Proc. Natl. Acad. Sci. USA 106, $4752-4757$.

Largier, J.L., 2020. Upwelling bays: how coastal upwelling controls circulation, habitat, and productivity in bays. Ann. Rev. Mar. Sci. 12, 415-447.

Lam, P., Jensen, M.M., Kock, A., Lettmann, K.A., Plancherel, Y., Lavik, G., Bange, H.W., Kuypers, M.M.M., 2011. Origin and fate of the secondary nitrite maximum in the Arabian Sea. Biogeosciences 8, 1565-1577.

Lamont, T., García-Reyes, M., Bograd, S.J., van der Lingen, C.D., Sydeman, W.J., 2018 Upwelling indices for comparative ecosystem studies: variability in the Benguela Upwelling System. J. Mar. Syst. 188, 3-16.

Lass, H.U., Mohrholz, V., 2008. On the interaction between the subtropical gyre and the subtropical cell on the shelf of the SE Atlantic. J. Mar. Syst. 74 (1-2), 1-43.

Lavik, G., Stührmann, T., Brüchert, V., Van der Plas, A., Mohrholz, V., Lam, P., Mußmann, M., Fuchs, B.M., Amann, R., Lass, U., Kuypers, M.M.M., 2009. Detoxification of sulphidic African shelf waters by blooming chemolithotrophs. Nature 457, 581-584. https://doi.org/10.1038/nature07588.

Lefcheck, J.S., Orth, R.J., Dennison, W.C., Wilcox, D.J., Murphy, R.R., Keisman, J., Gurbisz, C., Hannam, M., Landry, J.B., Moore, K.A., Patrick, J.C., Testa, J., Weller, D. E., Batiuk, R.A., 2018. Long-term nutrient reductions lead to the unprecedented recovery of a temperate coastal region. Proc. Nat. Acad. Sci. U.S.A. 115(14), 3658-3662.

Lehmann, A., Hinrichsen, H.-H., Getzlaff, K., Myrberg, K., 2014. Quantifying the heterogeneity of hypoxic and anoxic areas in the Baltic Sea by a simplified coupled hydrodynamic-oxygen consumption model approach. J. Mar. Syst. 134, 20-28. https://doi.org/10.1016/j.jmarsys.2014.02.012.
León, V., Paulmier, A., Ledesma, J., Croot, P., Graco, M., Flores, G., Morón, O., Tenorio, J., 2010. pH como un trazador de la variabilidad biogeoquímica en el Sistema de Humboldt. Boletín Instituto del Mar del Perú 26 (-2), 19-24.

Levin, L.A., 2018. Manifestation, drivers, and emergence of open ocean deoxygenation. Ann. Rev. Mar. Sci. 10, 229-260.

Levin, L.A., Gallo, N.D., 2019. The significance of ocean deoxygenation for continental margin benthic and demersal biota. In: Laffoley, D., Baxter, J.M. (Eds.), Ocean deoxygenation: Everyone's problem. Causes, impacts, consequences and solutions. IUCN, Gland, Switzerland, pp. 341-361. https://doi.org/10.2305/IUCN. CH.2019.13.en.

Levin, L.A., Gutiérrez, D., Rathburn, A., Neira, C., Sellanes, J., Muñoz, P., Gallardo, V.A. Salamanca, M., 2002. Benthic processes on the Peru Margin: a transect across the oxygen minimum zone during the 1997-98 El Niño. Prog. Oceanogr. 53, 1-27.

Levin, L.A., Liu, K.K., Emeis, K.C., Breitburg, D.L., Cloern, J.E., Deutsch, C., Giani, M., Goffart, A., Hofmann, E.E., Lachkar, Z., Limburg, K., Liu, S.-M., Montes, E., Naqvi, W., Ragueneau, O., Rabouille, C., Kumar, Sarkar S., Swaney, D.P. Wassman, P., Wishner, K.F., 2015. Comparative biogeochemistry-ecosystem-human interactions on dynamic continental margins. J Mar. Sys. 141, 3-17.

Li, M., Lee, Y.J., Testa, J.M., Li, Y., Ni, W., Kemp, W.M., Di Toro, D.M., 2016. What drives interannual variability of hypoxia in Chesapeake Bay: climate forcing versus nutrient loading? Geophys. Res. Lett. 43, 2127-2134.

Li, D.J., Zhang, J., Huang, D.J., Wu, Y., Liang, J., 2002. Oxygen depletion off the Changjiang (Yangtze River) Estuary. Sci. China, Series D - Earth Sci. 45 (12), 1137-1146.

Lie, H.-J., Cho, C.-H., Lee, J.-H., Lee, S., 2003. Structure and eastward extension of the Changjiang River plume in the East China Sea. J. Geophys. Res. 108 (C3), 3077. https://doi.org/10.1029/2001JC001194.

Limeburner, R., Beardsley, R.C., Zhao, J., 1983. Water masses and circulation in the East China Sea. In: Proceedings of International Symposium on Sedimentation on the Continental Shelf, with Special Reference to the East China Sea. China Ocean Press, Hang Zhou.

Llanillo, P.J., Karstensen, J., Pelegrí, J.L., Stramma, L., 2013. Physical and biogeochemical forcing of oxygen and nitrate changes during El Niño/El Viejo and La Niña/La Vieja upper-ocean phases in the tropical eastern South Pacific along $86^{\circ}$ W. Biogeosciences 10, 6339-6355. https://doi.org/10.5194/bg-10-6339-2013.

Lohrenz, S.E., Fahnenstiel, G.L., Redalje, D.G., Lang, G.A., Chen, X., Dagg, M.J., 1997. Variations in primary production of northern Gulf of Mexico continental shelf waters linked to nutrient inputs from the Mississippi River. Mar. Ecol. Prog. Ser. 155, 45-54.

Lomovasky, B.J., Firstater, F.N., Gamarra, A., Mendo, J., Iribarne, O.O., 2011. Macro benthic community assemblage before and after the 2007 tsunami and earthquake at Paracas Bay, Peru. J. Sea Res. 65, 205-212.

Long, M.C., Deutsch, C., Ito, T., 2016. Finding forced trends in oceanic oxygen. Globa Biogeochem. Cycles 30 (2), 381-397. https://doi.org/10.1002/2015GB005310.

López, C.H., 2008. Variación estacional de especies productoras de floraciones algales nocivas y su relación co algunos factores físicos y químicos en Playa Atenas, Bahía de Paracas, Pisco. Universidad Nacional Agraria La Molina, p. 149 pp. durante setiembre 2004- agosto 2005.

Löscher, C.R., Fischer, M.A., Neulinger, S.C., Fiedler, B., Philippi, M., Schütte, F., Singh, A., Hauss, H., Karstensen, J., Körtzinger, A., Künzel, S., Schmitz, R.A., 2015. Hidden biosphere in an oxygen-deficient Atlantic open ocean eddy: future implications of ocean deoxygenation on primary production in the eastern tropical North Atlantic. Biogeosciences 12, 7467-7482. https://doi.org/10.5194/bg-127467-2015.

Louw, D.C., van der Plas, A., Mohrholz, V., Wasmund, N., Junker, T., Eggert, A., 2016. Seasonal and interannual phytoplankton dynamics and forcing mechanisms in the northern Benguela upwelling system. J. Mar. Syst. 157, 124-134. https://doi.org/ 10.1016/j.jmarsys.2016.01.009.

Lovecchio, E., Gruber, N., Münnich, M., 2018. Mesoscale contribution to the long-range offshore transport of organic carbon from the Canary Upwelling System to the open North Atlantic. Biogeosciences 15, 5061-5091.

Lu, J., Vecchi, G.A., Reichler, T., 2007. Expansion of the Hadley cell under global warming. Geophys. Res. Lett. 34, L06805. https://doi.org/10.1029/2006GL028443.

Ludwig, W., Dumont, E., Meybeck, M., Heussner, S., 2009. River discharges of water and nutrients to the Mediterranean and Black Sea: Major drivers for ecosystem changes during past and future decades? Prog. Oceanogr. 80 (3-4), 199-217.

Machu, E., Capet, X., Estrade, P.A., Ndoye, S., Brajard, J., Baurand, F., Auger, P.-A. Lazar, A., Brehmer, P., 2019. First evidence of anoxia and nitrogen loss in the Southern Canary upwelling system. Geophys. Res. Lett. 46, 2619-2627.

Machu, E., Goubanova, K., Le Vu, B., Gutknecht, E., Garçon, V., 2015. Downscaling biogeochemistry in the Benguela eastern boundary current. Ocean Model. 90, 57-71.

Maldonado, M., 1988. Condiciones físico-químicos y corrientes de la Bahía Paracas, durante dos días de noviembre de 1986. Boletin Instituto del Mar del Perú Extraordinario 35-45.

Malone, T.C., Conley, D.J., Fisher, T.R., Gilbert, P.M., Harding, L.W., Sellner, K., 1996. Scales of nutrient-limited phytoplankton productivity in Chesapeake Bay. Estuaries 19 (2B), 371-385.

Maltby, J., Sommer, S., Dale, A.W., Treude, T., 2016. Microbial methanogenesis in the sulfate-reducing zone of surface sediments traversing the Peruvian margin. Biogeosciences 13, 283-299.

Margolskee, A., Frenzel, H., Emerson, S., Deutsch, C., 2019. Ventilation pathways for the North Pacific oxygen deficient zone. Global Biogeochem. Cycles 33, 875-890.

Marsay, C.M., Sanders, R.J., Henson, S.A., Pabortsava, K., Achterberg, E.P., Lampitt, R.S., 2015. Attenuation of sinking particulate organic carbon flux through the mesopelagic ocean. Proc. Natl. Acad. Sci. U.S.A., 112(4), 1089-1094, https://doi. org/10.1073/ pnas.1415311112. 
Martin, T.S., Casciotti, K.L., 2017. Paired N and O isotopic analysis of nitrate and nitrite in the Arabian Sea oxygen deficient zone. Deep-Sea Res. I 121, 121-131.

Mashifane, T.B., Vichi, M., Waldron, H.N., Machu, E., Garçon, V., 2016. Modelling nitrite dynamics and associated feedback processes in the Benguela oxygen minimum zone. Cont. Shelf Res. 124, 200-212.

Maske, H., Medrano, R.C., Castro, A.T., Mercado, A.J., Jauregui, C.O.A., Castro, G.G., Ochoa, J., 2010. Inorganic carbon and biological oceanography above a shallow oxygen minimum in the entrance to the Gulf of California in the Mexican Pacific. Limnol. Oceanogr. 55, 481-491.

Matear, R.J., Hirst, A.C., 2003. Long-term changes in dissolved oxygen concentrations in the ocean caused by protracted global warming. Global Biogeochem. Cycles 17 (4), 1125. https://doi.org/10.1029/2002GB001997.

Matsumoto, E., 1981. Research on coastal marine pollution. Chishitsu News 319, 52-58 (in Japanese).

Matsumoto, E., 1983. Environmental changes recorded in sediments of coastal marine zone close to big city. Memoirs Geol. Soc. Japan 23, 91-95 (in Japanese with English abstract).

Matsumoto, E., Saito, Y., 1984. Environmental changes of Tokyo Bay by man in comparison with environmental changes by nature during geological history. Bull. Geol. Survey Japan 35, 243-260 (in Japanese with English abstract).

Matthews, S.G., Pitcher, G.C., 1996. Worst recorded marine mortality on the South African coast. In: Yasumoto, T., Oshima, Y., Fukuyo, Y. (Eds.), Harmful and Toxic Algal Blooms. Intergovernmental Oceanographic Commission of UNESCO, Sendai, Japan, pp. 89-92.

McClatchie, S., Goericke, R., Cosgrove, R., Auad, G., Vetter, R., 2010. Oxygen in the Southern California Bight: multidecadal trends and implications for demersal fisheries. Geophys. Res. Lett. 37, L19602. https://doi.org/10.1029/2010GL044497.

McCrackin, M.L., Muller-Karulis, B., Gustafsson, B., Howarth, R.W., Humborg, C., Svanbäck, A., Swaney, D.P., 2018. A century of legacy phosphorus dynamics in a large drainage basin. Global Biogeochem. Cycles 32, 1107-1122. https://doi.org/ 10.1029/2018GB005914.

McCreary, J.P., 1981. A linear stratified ocean model of the equatorial undercurrent Philos. Trans. R. Soc. Lond. Ser. A 298, 603-635.

McCreary, J.P., Yu, Z., Hood, R.R., Vinaychandran, P.N., Furue, R., Ishida, A., Richards, K.J., 2013. Dynamics of the Indian-Ocean oxygen minimum zones. Prog. Oceanogr. 112-113, 15-37.

MD-DNR (Maryland Department of Natural Resources), 2019. http://eyesonthebay.dnr maryland.gov/eyesonthebay/index.cfm.

Mee, L., 2006. Reviving dead zones. Sci. Am. 295, 78-85.

MEECE report, 2013. Deliverable D3.4 Synthesis report on climate simulations. Benguela Upwelling. http://www.meece.eu/documents/deliverables/WP3/D3\%204 Part9_Benguela.pdf.

Meier, H.E.M., 2007. Modeling the pathways and ages of inflowing salt- and freshwater in the Baltic Sea. Estuarine Coastal Shelf Sci. 74, 610-627. https://doi.org/10.1016/ j.ecss.2007.05.019.

Meier, H.E.M., Andersson, H.C., Eilola, K., Gustafsson, B.G., Kuznetsov, I., MüllerKarulis, B., Neumann, T., Savchuk, O.P., 2011. Hypoxia in future climates: a model ensemble study for the Baltic Sea. Geophys. Res. Lett. 38, L24608. https://doi.org/ 10.1029/2011GL049929.

Meier, H.E.M., Eilola, K., Almroth-Rosell, E., Schimanke, S., Kniebusch, M., Höglund, A., Pemberton, P., Liu, Y., Väli, G., Saraiva, S., 2018. Disentangling the impact of nutrient load and climate changes on Baltic Sea hypoxia and eutrophication since 1850. Clim. Dyn. 53, 1145-1166. https://doi.org/10.1007/s00382-018-4296-y.

Meinvielle, M., Johnson, G.C., 2013. Decadal water-property trends in the California Undercurrent, with implications for ocean acidification. J. Geophys. Res. Oceans 118, 6687-6703. https://doi.org/10.1002/2013JC009299.

Meisel, S., Emeis, K.-C., Struck, U., Kristen, I., 2011. Nutrient regime and upwelling in the northern Benguela since the middle Holocene in a global context - a multi-proxy approach. Fossil Rec. 14 (2), 171-193. https://doi.org/10.1002/mmng.201100006.

Merma, L., 2016. Foraminíferos bentónicos asociados a condiciones de hipoxia costera y bajo pH en la Bahía de Paracas. Tesis para optar el grado de Maestro en Ciencias del Mar. Universidad Peruana Cayetano Heredia, 134 pp.

Miller, S.H., Breitburg, D.L., Burrell, R.B., Keppel, A.G., 2016. Acidification increases sensitivity to hypoxia in important forage fishes. Mar. Ecol. Prog. Ser. 549, 1-8.

MINAM, 2016. Tercera Comunicación Nacional del Perú a la Convención Marco de las Naciones Unidas sobre el Cambio Climático. MINAM, 326 pp.

Minoura, K., Akaki, K., Nemoto, N., Tsukawaki, S., Nakamura, T., 2012. Origin of deep water in the Japan Sea over the last 145kyr. Palaeogeogr. Palaeoclimatol. Palaeoecol. 339-341, 25-38.

Mitra, S., Ghosh, S., Satpathy, K.K., Bhattacharya, B.D., Sarkar, S.K., Mishra, P., Raja, P. 2018. Water quality assessment of the ecologically stressed Hooghly River Estuary, India: a multivariate approach. Mar. Pollut. Bull. 126, 592-599.

Moffett, J.W., Vedamati, J., Goepfert, T.J., Pratihary, A., Gauns, M., Naqvi, S.W.A., 2015 Biogeochemistry of iron in the Arabian Sea. Limnol. Oceanogr. 60, 1671-1688.

Moffett, J.W., Goepfert, T.J., Naqvi, S.W.A., 2007. Reduced iron associated with secondary nitrite maxima in the Arabian Sea. Deep-Sea Res. I 54, 1341-1349.

Moffitt, S.E., Hill, T.M., Ohkushi, K., Kennett, J.P., Behl, R.J., 2014. Vertical oxygen minimum zone oscillations since $20 \mathrm{ka}$ in Santa Barbara Basin: a benthic foraminiferal community perspective. Paleoceanography 29, 44-57. https://doi.org/ 10.1002/2013PA002483.

Moffitt, S.E., Moffitt, R.A., Sauthoff, W., Davis, C.V., Hewett, K., Hill, T.M., 2015. Paleoceanographic insights on recent oxygen minimum zone expansion: lessons for modern oceanography. PLoS ONE 10 (1), e0115246. https://doi.org/10.1371/ journal.pone.0115246.
Mogollón, R., Calil, P.H.R., 2017. On the effects of ENSO on ocean biogeochemistry in the Northern Humboldt Current System (NHCS): a modeling study. J. Mar. Syst. 172, 137-159. https://doi.org/10.1016/j.jmarsys.2017.03.011.

Mohrholz, V., Bartholomae, C.H., van der Plas, A.K., Lass, H.U., 2008. The seasonal variability of the northern Benguela undercurrent and its relation to the oxygen budget on the shelf. Cont. Shelf Res. 28 (3), 424-441.

Monteiro, P.M.S., Dewitte, B., Scranton, M.I., Paulmier, A., van der Plas, A.K., 2011. The role of open ocean boundary forcing on seasonal to decadal-scale variability and long-term change of natural shelf hypoxia. Environ. Res. Lett. 6 https://doi.org/ 10.1088/1748-9326/6/2/025002.

Monteiro, P.M.S., Nelson, G., van der Plas, A., Mabille, E., Bailey, G.W., Klingelhoeffer, E., 2005. Internal tide-shelf topography interactions as a forcing factor governing the large-scale distribution and burial fluxes of particulate organic matter (POM) in the Benguela upwelling system. Cont. Shelf Res. 25, 1864-1876.

Monteiro, P.M.S., van der Plas, A.K., 2006. Low oxygen water (LOW) variability in the Benguela system: key processes and forcing scales relevant to forecasting. In: Hannon, V., Hempel, G., Moloney, C., Woods, J., Malanotte-Rizzoli, P. (Eds.), Benguela: predicting a Large Marine Ecosystem, Large Marine Ecosystems Ser, Vol. 14. Elsevier, Amsterdam, Netherlands, pp. 71-90.

Monteiro, P.M.S., van der Plas, A.K., Mélice, J.-L., Florenchie, P., 2008. Interannual hypoxia variability in a coastal upwelling system: ocean-shelf exchange, climate and ecosystem-state implications. Deep Sea Res. I 55, 435-450.

Monteiro, P.M.S., van der Plas, A.K., Mohrholz, V., Mabille, E., Pascall, A., Joubert, W., 2006. Variability of natural hypoxia and methane in a coastal upwelling system: oceanic physics or shelf biology? Geophys. Res. Lett. 33, L16614. https://doi.org/ 10.1029/2006GL026234.

Montes, I., Colas, F., Capet, X., Schneider, W., 2010. On the pathways of the equatorial subsurface currents in the eastern equatorial Pacific and their contributions to the Peru-Chile Undercurrent. J. Geophys. Res. Oceans 115, C09003. https://doi.org/ 10.1029/2009JC005710.

Montes, I., Dewitte, B., Gutknecht, E., Paulmier, A., Dadou, I., Oschlies, A., Garçon, V., 2014. High-resolution modeling of the Eastern Tropical Pacific oxygen minimum zone: sensitivity to the tropical oceanic circulation. J. Geophys. Res. Oceans 119, 5515-5532. https://doi.org/10.1002/2014JC009858.

Morales, M. del C., Field, D., Mayor Pastor, S., Gutierrez, D., Sifeddine, A., Ortlieb, Luc., Ferreira, V., Salvatteci, R., Velazco, F., 2006. Variaciones de foraminiferos de los ultimos 460 años en sedimentos laminados de la plataforma continental peruana. Boletin de la Sociedad Geologica del Peru 101, 5-18.

Morales, C.E., Hormazábal, S.E., Blanco, J.L., 1999. Inter-annual variability in the mesoscale distribution of the depth of the upper boundary of the oxygen minimum layer off northern Chile (18-24S): implications for the pelagic system and biogeochemical cycling. J. Mar. Res. 57, 909-932.

Mork, K.A., Skagseth, Ø., Søiland, H., 2019. Recent warming and freshening of the Norwegian Sea observed by Argo data. J. Clim. 32, 3695-3705. https://doi.org/ 10.1175/JCLI-D-18-0591.1.

Muñoz, P., Lange, C.B., Gutiérrez, D., Hebbeln, D., Salamanca, M.A., Dezileau, L., Reyss, J.L., Benninger, L.K., 2004. Recent sedimentation and mass accumulation rates based on ${ }^{210} \mathrm{~Pb}$ along the Peru-Chile continental margin. Deep Sea Res. II 51 (20-21), 2523-2541.

Murphy, R.R., Kemp, W.M., Ball, W.P., 2011. Long-term trends in Chesapeake Bay seasonal hypoxia, stratification, and nutrient loading. Estuaries Coasts 34 (6), 1293-1309.

Murray, J., Codispoti, L., Friederich, G., 1995. Redox environments: the suboxic zone in the black sea. In: Huang, C., Melia, C., Morgan, J. (Eds.), Aquatic Chemistry: Interfacial and Interspecies Processes. pp. 15-176.

Murray C.J., Müller-Karulis, B., Carstensen, J., Conley, D.J., Gustafsson, B.G., Andersen, J.H., 2019. Past, present and future eutrophication status of the Baltic Sea. Frontiers in Marine Science 6, 2, https://doi.org/10.3389/fmars.2019.00002.

Myhre, S.E., Kroeker, K.J., Hill, Tessa, M., Roopnarine, P., Kennett, J.P., 2017. Community benthic paleoecology from high-resolution climate records: mollusca and foraminifera in post-glacial environments of the California margin. Quaternary Sci. Rev. 155, 179-197.

Naik, R., Naqvi, S.W.A., Araujo, J., 2017. Anaerobic carbon mineralisation through sulphate reduction in the inner shelf sediments of eastern Arabian Sea. Estuaries Coasts 40, 134-144.

Najjar, R.G., Pyke, C.R., Adams, M.B., Breitburg, D., Hershner, C., Kemp, M., Howarth, R., Mulholland, M.R., Paolisso, M., Secor, D., Sellner, K., Wardrop, D., Wood, R., 2010. Potential climate-change impacts on the Chesapeake Bay. Estuar. Coast. Shelf Sci. 86 (1), 1-20.

Nakatsuji, K., Teraguchi, T., Yamane, T., 1998. Time change of water qualities in Osaka Bay during the past 70 years and numerical experiments. Proc. Coastal Eng. (JSCE) 45, 1011-1015 (In Japanese).

Nakayama, K., Maruya, Y., Nakaegawa, T., Komai, K., Kokubo, K., Ishida, T., Okada, T., 2013. Projection of "strong wind" events related to recovery from hypoxia in Tokyo Bay, Japan. Hydrol. Process. 27, 3280-3291.

Nakayama, K., Sivapalan, M., Sato, C., Furukawa, K., 2010. Stochastic characterization of the onset of and recovery from hypoxia in Tokyo Bay, Japan: derived distribution analysis based on "strong wind" events: Water Resources Res. 46, W12532, https:// doi.org/10.1029/2009WR008900.

Nam, S., Kim, H.-J., Send, U., 2011. Amplification of hypoxic and acidic events by La Niña conditions on the continental shelf off California. Geophys. Res. Lett. 38, L22602. https://doi.org/10.1029/2011GL049549.

Nam, S., Takeshita, Y., Frieder, C.A., Martz, T., Ballard, J., 2015. Seasonal advection of Pacific Equatorial Water alters oxygen and $\mathrm{pH}$ in the Southern California Bight. J. Geophys. Res. Oceans 120, 5387-5399. https://doi.org/10.1002/2015JC010859. 
Naqvi, S.W.A., 1987. Some aspects of the oxygen deficient conditions and denitrification in the Arabian Sea. J. Mar. Res. 49, 1049-1072.

Naqvi, W.A., 1991. Geographical extent of denitrification in the Arabian Sea in relation to some physical processes. Oceanol. Acta 14, 281-290.

Naqvi, S.W.A., 2021. Deoxygenation in Marginal Seas of the Indian Ocean. Front. Mar. Sci. 8, 624322 https://doi.org/10.3389/fmars.2021.624322.

Naqvi, S.W.A., George, M.D., Narvekar, P.V., Jayakumar, D.A., Shailaja, M.S., Sardesai, S., Sarma, V.V.S.S., Shenoy, D.M., Naik, H., Maheswaran, P.A., Krishnakumari, K., Rajesh, G., Sudhir, A.K., Binu, M.S., 1998a. Severe fish mortality associated with 'red tide' observed in the sea off Cochin. Curr. Sci. 75, 543-544.

Naqvi, S.W.A., Jayakumar, D.A., Narvekar, P.V., Naik, H., Sarma, V.V.S.S., D’Souza, W. Joseph, S., George, M.D., 2000. Increased marine production of $\mathrm{N}_{2} \mathrm{O}$ due to intensifying anoxia on the Indian continental shelf. Nature 408, 346-349.

Naqvi, S.W.A., Kumar, M.D., Narvekar, P.V., De Sousa, S.N., George, M.D., D’Silva, C., 1993. An intermediate nepheloid layer associated with high microbial metabolic rates and denitrification in the northwest Indian Ocean. J. Geophys. Res. 98 (C3), 16469-16479.

Naqvi, S.W.A., Naik, H., Pratihary, A., D' Souza, W., Narvekar, P.V., Jayakumar, D.A., Devol, A.H., Yoshinari, T., Saino, T., 2006b. Coastal versus open ocean denitrification in the Arabian Sea. Biogeosciences 3, 621-633.

Naqvi, S.W.A., Naik, H., Jayakumar, D.A., Shailaja, M.S., Narvekar, P.V., 2006c. Seasona oxygen deficiency over the western continental shelf of India In: Neretin, L. (Ed.), Past and Present Water Column Anoxia, NATO Science Series, IV Earth and Environmental Sciences, Springer, 64, 195-224.

Naqvi, S.W.A., Naik, H., Jayakumar, A., Pratihary, A.K., Narvenkar, G., Kurian, S., Agnihotri, R., Shailaja, M.S., Narvekar, P.V., 2009. Seasonal anoxia over the Western Indian continental shelf. Geophys. Monograph Series, Am. Geophys. Union 185 333-345. https://doi.org/10.1029/2008GM000745.

Naqvi, S.W.A., Naik, H., D’ Souza, W., Narvekar, P.V., Paropkari, A.L., Bange, H.W., 2010a. Carbon and nitrogen fluxes in the North Indian Ocean. In: Liu, K.K., Atkinson, L., Quinones, R., Talaue-McManus, L. (Eds.), Carbon and nutrient fluxes in continental margins: a global synthesis. Springer-Verlag, Berlin, pp. 180-192.

Naqvi, S.W.A., Narvekar, P.V., Desa, E., 2006a. Coastal biogeochemical processes in the North Indian Ocean. In: Robinson, A., Brink, K. (Eds.), The Sea, 14. Harvard University Press, pp. 723-780.

Naqvi, S.W.A., Moffett, J.W., Gauns, M., Narvekar, P.V., Pratihary, A.K., Naik, H., Shenoy, D.M., Jayakumar, D.A., Goepfert, T.J., Patra, P.K., Al-Azri, A., Ahmed, S.I, 2010b. The Arabian Sea as a high-nutrient, low-chlorophyll region during the late Southwest Monsoon. Biogeosciences 7, 2091-2100.

Naqvi, S.W.A., Shailaja, M.S., Kumar, M.D., Sen Gupta, R., 1996. Respiration rates in subsurface waters of the northern Indian Ocean: evidence for low decomposition rates of organic matter within the water column in the Bay of Bengal. Deep-Sea Res. II $43,73-81$.

Naqvi, S.W.A., Yoshinari, T., Jayakumar, D.A., Altabet, M.A., Narvekar, P.V., Devol, A H., Brandes, J.A., Codispoti, L.A., 1998b. Budgetary and biogeochemical implications of $\mathrm{N}_{2} \mathrm{O}$ isotope signatures in the Arabian Sea. Nature 394, 462-464.

National Research Council. Ocean Studies, B., 2011. Achieving nutrient and sediment reduction goals in the Chesapeake Bay: An evaluation of program strategies and implementation. National Academies Press, Washington, D.C.

Ndhlovu, A., Dhar, N., Garg, N., Xuma, T., Pitcher, G.C., Sym, S.D., Durand, P.M., 2017 A red tide forming dinoflagellate Prorocentrum triestinum: identification, phylogeny and impacts on St Helena Bay, South Africa. Phycologia 56, 649-665.

Ndoye, S., Capet, X., Estrade, P., Sow, B., Machu, E., Brochier, T., Döring, J., Brehmer, P. 2017. Dynamics of a "low-enrichment high-retention" upwelling center over the southern Senegal shelf. Geophys. Res. Lett. 44 (10), 5034-5043.

Neumann, T., Radtke, H., Seifert, T., 2017. On the importance of Major Baltic Inflows fo oxygenation of the central Baltic Sea. J. Geophys. Res. Oceans 122, 1090-1101. https://doi.org/10.1002/2016JC012525.

Newcombe, C.L., Horne, W.A., 1938. Oxygen-poor waters of the Chesapeake Bay. Science $88,80-81$.

Ni, X., Huang, D., Zeng, D., Zhang, T., Li, H., Chen, J., 2016. The impact of wind mixing on the variation of bottom dissolved oxygen off the Changjiang Estuary during summer. J. Mar. Syst. 154, 122-130.

Norkko, J., Reeds, D.C., Timmermann, K., Norkko, A., Gustafsson, B.G., Bonsdorff, E., Slomp, C.P., Carstensen, J., Conley, D.J., 2012. A welcome can of worms? Hypoxia mitigation by an invasive species. Glob. Change Biol. 18, 422-434. https://doi.org/ 10.1111/j.1365-2486.2011.02513.x.

Oerder, V., Colas, F., Echevin, V., Masson, S., Hourdin, C., Jullien, S., Madec, G., Lemarié, F., 2016. Mesoscale SST - wind stress coupling in the Peru-Chile current system: which mechanisms drive its spatial and seasonal variability? Clim. Dyn. 47, 2309-2330. https://doi.org/10.1007/s00382-015-2965-7.

Office of integrated oceanographic survey of China, Dataset of the national integrated oceanographic survey. Vol 1. Survey data of hydrometeorological and chemical elements in the Bohai, Huanghai and East China Seas. 1961: Beijing. pp. 811.

Oguz, T., 2002. Role of physical processes controlling oxycline and suboxic layer structures in the Black Sea. Global Biogeochem. Cycles 16 (2). https://doi.org/ 10.1029/2001GB001465.

Oguz, T., Ducklow, H.W., Malanotte-Rizzoli, P., 2000. Modeling distinct vertical biogeochemical structure of the Black Sea: dynamical coupling of the oxic, suboxic, and anoxic layers. Global Biogeochem. Cycles 14 (4), 1331-1352.

Oguz, T., Ducklow, H.W., Purcell, J.E., Malanotte-Rizzoli, P., 2001. Modeling the response of top-down control exerted by gelatinous carnivores on the Black Sea pelagic food web. J. Geophys. Res. Oceans 106 (C3), 4543-4564.

Ohde, T., 2018. Coastal sulfur plumes off Peru during El Niño, La Niña, and neutral phases. Geophys. Res. Lett. 45, 7075-7083. https://doi.org/10.1029/ 2018GL077618.
Ohde, T., Dadou, I., 2018. Seasonal and annual variability of coastal sulphur plumes in the northern Benguela upwelling system. PLoS ONE 13 (2), e0192140. https://doi. org/10.1371/journal.pone.0192140.

Ohde, T., Mohrholz, V., 2011. Interannual variability of sulphur plumes off the Namibian coast. Int. J. Remote Sens. 32 (24), 9327-9342.

Ohkushi, K., Kennett, J.P., Zeleski, C.M.M., Moffitt, S.E., Hill, T.M., Robert, C., Beaufort, L., Behl, R.J., 2013. Quantified intermediate water oxygenation history of the NE Pacific: A new benthic foraminiferal record from Santa Barbara basin. Paleoceanography 28, 453-467. https://doi.org/10.1002/palo.20043.

Olsson, T., Kämäräinen, M., Santos, D., Seitola, T., Tuomenvirta, K., Haavisto, R., Lavado-Casimiro, W., 2017. Downscaling climate projections for the Peruvian coastal Chancay-Huaral Basin to support river discharge modeling with WEAP. J. Hydrol.: Reg. Stud. 13, 26-42.

Oria, C., Avalos, G., 2013. Cambio climático en las Cuencas de los Ríos Ica y Pisco: Proyecciones para el año 2030. Proyecto "Adaptación al Cambio Climático y Reducción del Riesgo de desastres en cuencas priorizadas de Ica y Huancavelica ACCIH". SENAMHI, 40 pp.

Osaka City, 2002. Osakasi-toukeisyo (Data book of the Osaka City), Osaka City. (In Japanese).

Oschlies, A., Brandt, P., Stramma, L., Schmidtko, S., 2018. Drivers and mechanisms of ocean deoxygenation. Nat. Geosci. 11, 467-473.

Oschlies, A., Duteil, O., Getzlaff, J., Koeve, W., Landolfi, A., Schmidtko, S., 2017. Patterns of deoxygenation: sensitivity to natural and anthropogenic drivers. Philos. Trans. Royal Soc. A 375, 20160325. https://doi.org/10.1098/rsta.2016.0325.

Oschlies, A., Schulz, K.G., Riebesell, U., Schmittner, A., 2008. Simulated 21st century's increase in oceanic suboxia by $\mathrm{CO}_{2}$-enhanced biotic carbon export. Global Biogeochem. Cycles 22 (4), GB4008. https://doi.org/10.1029/2007GB003147.

Paerl, H.W., Scott, J.T., McCarthy, M.J., Newell, S.E., Gardner, W.S., Havens, K.E., Hoffman, D.K., Wilhelm, S.W., Wurtsbaugh, W.A., 2016. It takes two to tango: when and where dual nutrient $(\mathrm{N} \& \mathrm{P})$ reductions are needed to protect lakes and downstream ecosystems. Environ. Sci. Technol. 50, 10805-10813.

Pante, E., Simon-Bouhet, B., 2013. Marmap: a package for importing, plotting and analyzing bathymetric and topographic data in R. PLoS ONE 8 (9), e73051. https:// doi.org/10.1371/journal.pone.0073051.

Papadomanolaki, N.M., Dijkstra, N., Van Helmond, N.A.G.M., Hagens, M., Bauersachs, T., Kotthoff, U., Sangiorgi, F., Slomp, C.P., 2018. Controls on the onset and termination of past hypoxia in the Baltic Sea. Palaeogeogr. Palaeoclimatol. Palaeoecol. 490, 347-354. https://doi.org/10.1016/j.palaeo.2017.11.012.

Paulmier, A., Ruiz-Pino, D., 2009. Oxygen minimum zones (OMZs) in the modern ocean. Prog. Oceanogr. 80, 113-128.

Paulmier, A., Ruiz-Pino, D., Garçon, V., Farias, L., 2006. Maintaining of the Eastern South Pacific Oxygen Minimum Zone (OMZ) off Chile. Geophys. Res. Lett. 33, L20601. https://doi.org/10.1029/2006GL026801.

Peard, K.R., 2007. Seasonal and interannual variability of wind-driven upwelling at Lüderitz, Namibia. MSc. thesis. University of Cape Town, Cape Town, p. 108 pp..

Peña, M.A., Katsev, S., Oguz, T., Gilbert, D., 2010. Modeling dissolved oxygen dynamics and hypoxia. Biogeosciences 7, 933-957.

Peña-Izquierdo, J., Pelegrí, J.L., Pastor, M.V., Castellanos, P., Emelianov, M., Gasser, M., Salvador, J., Vázquez-Domínguez, E., 2012. The continental slope current system between Cape Verde and the Canary Islands. Scientia Marina 76 (S1), 65-78.

Pennington, J.T., Mahoney, K.L., Kuwahara, V.S., Kolber, D.D., Calienes, R., Chavez, F.P., 2006. Primary production in the eastern tropical Pacific: a review. Prog. Oceanogr. 69 (2-4), 285-317.

Penven, P., Roy, C., Colin de Verdiére, A., Largier, J., 2000. Simulation of a coastal jet retention process using a barotropic model. Oceanol. Acta 23, 615-634.

Pierce, S.D., Barth, J.A., Shearman, R.K., Erofeev, A., 2012. Declining oxygen in the Northeast Pacific. J. Phys. Oceanogr. 42, 495-501.

Pietri, A., Echevin, V., Testor, P., Chaigneau, A., Mortier, L., Grados, C., Albert, A., 2014. Impact of a coastal trapped wave on the near-coastal circulation of the Peru upwelling system from glider data. J. Geophys. Res. Oceans 119, 2109-2120. https://doi.org/10.1002/2013JC009270.

Piontkovski, S.A., Al-Oufi, H.S., 2015. The Omani shelf hypoxia and the warming Arabian Sea. Int. J. Environ. Stud. 72 (2) https://doi.org/10.1080/ 00207233.2015.1012361.

Piontkovski, S.A., Queste, B.Y., 2016. Decadal changes of the western Arabian Sea ecosystem. Int. Aquat. Res, 8, 49-64.

Pitcher, G.C., Figueiras, F.G., Hickey, B.M., Moita, M.T., 2010. The physical oceanography of upwelling systems and the development of harmful algal blooms. Prog. Oceanogr. 85, 5-32.

Pitcher, G.C., Jacinto, G.S., 2019. Ocean deoxygenation links to harmful algal blooms. In: Laffoley, D., Baxter, J.M. (Eds.), Ocean deoxygenation: Everyone's problem - Causes, impacts, consequences and solutions. Gland, Switzerland: IUCN. xxii+562pp.

Pitcher, G. C., Nelson, G., 2006. Characteristics of the surface boundary layer important to the development of red tide on the southern Namaqua shelf of the Benguela upwelling system. Limnol. Oceanogr. 51(6), 2660-2674.

Pitcher, G.C., Probyn, T.A., 2011. Anoxia in southern Benguela during the autumn of 2009 and its linkage to a bloom of the dinoflagellate Ceratium balechii. Harmful Algae 11, 23-32.

Pitcher, G.C., Probyn, T.A., 2012. Red tides and anoxia: an example from the southern Benguela current system. In: Pagou, PA., Hallegraeff, G.M. (Eds.), 14th International Conference on Harmful Algae. International Society for the Study of Harmful Algae and Intergovernmental Oceanography Commission, United Nations Educational, Scientific and Cultural Organization, Paris, pp. 175-177.

Pitcher, G.C., Probyn, T.A., 2016. Suffocating phytoplankton, suffocating waters - red tides and anoxia. Front. Mar. Sci. 3, 186. https://doi.org/10.3389/ fmars.2016.00186. 
Pitcher, G.C., Probyn, T.A., 2017. Seasonal and sub-seasonal oxygen and nutrient fluctuations in an embayment of an eastern boundary upwelling system: St Helena Bay. Afr. J. Mar. Sci. 39 (1), 95-110.

Pitcher, G.C., Probyn, T.A., du Randt, A., Lucas, A.J., Bernard, S., Evers-King, H., Lamont, T., Hutchings, L., 2014. Dynamics of oxygen depletion in the nearshore of a coastal embayment of the southern Benguela upwelling system. J. Geophys. Res. Oceans 119, 2182-2200. https://doi.org/10.1002/2013JC009443.

Pitcher, G.C., Weeks, S.J., 2006. The variability and potential for prediction of harmful algal blooms in the southern Benguela ecosystem. In: Shannon, V., Hempel, G., Malanotte-Rizzoli, P., Moloney, C., Woods, J. (Eds.) Benguela: predicting a large marine ecosystem. Large Marine Ecosystems 14, Elsevier B.V., pp.125-146.

Pritchard, D.W., 1956. The dynamic structure of a coastal plain estuary. J. Mar. Res. 15 (1), 33-42.

Pozo Buil, M., Di Lorenzo, E., 2017. Decadal dynamics and predictability of oxygen and subsurface tracers in the California Current System, Geophysical Research Letters 44 4204-4213, https://doi:10.1002/ 2017GL072931.

Pritchard, D.W., 1967. What is an estuary: physical viewpoint. In: Lauff, G.H. (Ed.), Estuaries. American Association for the Advancement of Science, Washington DC 1, $149-176$

Qian, W., Gan, J., Liu, J., He, B., Lu, Z., Guo, X., Wang, D., Guo, L., Huang, T., Dai, M., 2018. Current status of emerging hypoxia in a eutrophic estuary: The lower reach of the Pearl River Estuary, China. Estuar. Coast. Shelf Sci. 205, 58-67.

Qian, W., Dai, M., Xu, M., Kao, S.-J., Du, C., Liu, J., Wang, H., Guo, L., Wang, L., 2017. Non-local drivers of the summer hypoxia in the East China Sea off the Changjiang Estuary. Estuar. Coast. Shelf Sci. 198, 393-399.

Queste, B.Y., Vic, V., Heywood, K.J., Piontkovski, S.A., 2018. Physical controls on oxygen distribution and denitrification potential in the north west Arabian Sea. Geophys. Res. Lett. 45, 4143-4152.

Rabalais, N.N., 2004. Eutrophication. In: Robinson, A.R., McCarthy, J., Rothschild, B.J. (Eds.), The Global Coastal Ocean: Multiscale Interdisciplinary Processes. The Sea, 13 Harvard University Press, pp. 819-865.

Rabalais, N.N., Cai, W.-J., Carstensen, J., Conley, D.J., Fry, B., Hu, X., Quiñones Rivera, Z., Rosenberg, R., Slomp, C.P., Turner, R.E., Voss, M., Wissel, B., Zhang, J., 2014. Eutrophication-driven deoxygenation in the coastal ocean. Oceanography 27 (1), 172-183.

Rabalais, N.N., Díaz, R.J., Levin, L.A., Turner, R.E., Gilbert, D., Zhang, J., 2010. Dynamics and distribution of natural and human-caused coastal hypoxia. Biogeosciences 7, 585-619.

Rabalais, N.N., Smith, L.M., Turner, R.E., 2018. The Deepwater Horizon oil spill and Gulf of Mexico shelf hypoxia. Cont. Shelf Res. 152, 98-107.

Rabalais N.N., Turner, R.E., Justić, D., Dortch, Q., Wiseman, W.J., 1999. Characterization of hypoxia: Topic 1 Report for the integrated assessment of hypoxia in the Gulf of Mexico. NOAA Coastal Ocean Progress Decision Analysis Series 15, National Oceanic and Atmospheric Administration, Silver Spring, MD. $167 \mathrm{pp}$.

Rabalais, N.N., Turner, R.E., Justić, D., Dortch, Q., Wiseman, W.J., Sen Gupta, B.K., 1996. Nutrient changes in the Mississippi River and system responses on the adjacent continental shelf. Estuaries 19 (2B), 386-407.

Rabalais, N.N., Turner, R.E., Scavia, D., 2002. Beyond science into policy: Gulf of Mexico hypoxia and the Mississippi River. Bioscience 52, 129-142.

Rabalais, N.N., Turner, R.E., Sen Gupta, B.K., Boesch, D.F., Chapman, P., Murrell, M.C., 2007a. Hypoxia in the northern Gulf of Mexico: does the science support the plan to reduce, mitigate, and control hypoxia? Estuaries Coasts 30 (5), 753-772.

Rabalais, N.N., Turner, R.E., Sen Gupta, B.K., Platon, E., Parsons, M.L., 2007b. Sediments tell the history of eutrophication and hypoxia in the northern Gulf of Mexico. Ecol Appl. 17 (sp5). Supplement, S129-S143.

Rabalais, N.N., Turner, R.E., Wiseman, Jr., W.J., Boesch, D.F., 1991. A brief summary of hypoxia on the northern Gulf of Mexico continental shelf: 1985-1988, In: Tyson R.V. Pearson, T.H. (Eds.), Modern and Ancient Continental Shelf Anoxia, Geological Society Special Publication No. 58, The Geological Society, London, pp. 35-47.

Rabalais, N.N., Wiseman, W.J., Turner, R.E., 1994. Comparison of continuous records of near-bottom dissolved oxygen from the hypoxia zone along the Louisiana coast. Estuaries 17 (4), 850-861.

Rabouille, C., ley, D.J., Dai, M.H., Cai, W.J., Chen, C.T.A., Lansard, B., Green, R., Yin, K., Harrison, P.J., Dagg, M., McKee, B., 2008. Comparison of hypoxia among four riverdominated ocean margins: the Changjiang (Yangtze), Mississippi, Pearl, and Rhone rivers. Continental Shelf Research 28, 1527-1537.

Ramaiah, N., Furuya, K., 2002. Seasonal variations in phytoplankton composition and transparent exopolymer particles in a eutrophicated coastal environment. Aquat. Microb. Ecol. 30, 69-82.

Rao, C.K., Naqvi, S.W.A., Kumar, M.D., Varaprasad, S.J.D., Jayakumar, D.A., George, M. D., Singbal, S.Y.S., 1994. Hydrochemistry of the Bay of Bengal: possible reasons for different water-column cycling of carbon and nitrogen from the Arabian Sea. Mar. Chem. 47, 279-290.

Reed, D.C., Slomp, C.P., Gustafsson, B.G., 2011. Sedimentary phosphorus dynamics and the evolution of bottom-water hypoxia: a coupled benthic-pelagic model of a coastal system. Limnol. Oceanogr. 56, 1075-1092. https://doi.org/10.4319/ 10.2011.56.3.1075.

Ren, A.S., Chai, F., Xue, H., Anderson, D.M., Chavez, F.P., 2018. A Sixteen-year decline in dissolved oxygen in the Central California Current. Nature Scientific Reports 8 , 7290. https://doi.org/10.1038/s41598-018-25341-8.

Renaud, M.L., 1986. Hypoxia in Louisiana coastal waters during 1983: implications for fisheries. Fish. Bull. 84, 19-26.

Reusch, T.B.H., Dierking, J., Andersson, H.C., Bonsdorff, E., Carstensen, J., Casini, M., Czajkowski, M., Hasler, B., Hinsby, K., Hyytiäinen, K., Johannesson, K., Jomaa, S., Jormalainen, V., Kuosa, H., Kurland, S., Laikre, L., MacKenzie, B.R., Margonski, P., Melzner, F., Oesterwind, D., Ojaveer, H., Refsgaard, J.C., Sandström, A., Schwarz, G.,
Tonderski, K., Winder, M., Zandersen, M., 2018. The Baltic Sea as a time machine for the future coastal ocean. Science. Advances 4, eaar8195. https://doi.org/10.1126/ sciadv.aar8195.

Riemann, B., Carstensen, J., Dahl, K., Fossing, H., Hansen, J.W., Jakobsen, H.H., Josefson, A.B., Krause-Jensen, D., Markager, S., Stæhr, P.A., Timmermann, K. Windolf, J., Andersen, J.H., 2016. Recovery of Danish coastal ecosystems after reductions in nutrient loading: a holistic ecosystem approach. Estuaries Coasts 39, 82-97. https://doi.org/10.1007/s12237-015-9980-0.

Rixen, T., Baum, A., Gaye, B., Nagel, B., 2014. Seasonal and interannual variations in the nitrogen cycle in the Arabian Sea. Biogeosciences 11, 5733-5747.

Roman, M.R., Adolf, J.E., Bichy, J., Boicourt, W.C., Harding Jr, L.W., Houde, E.D., Jung, S., Kimmel, D.G., Miller, W.D., Zhang, X., 2005. Chesapeake Bay plankton and fish abundance enhanced by Hurricane Isabel. EOS Trans. Am. Geophys. Union 86 (28), 261-265.

Robinson, C., 2019. Microbial respiration, the engine of oceandeoxygenation. Front. Mar. Sci. 5, 533. https://doi.org/10.3389/fmars.2018.00533.

Rossi, V., López, C., Sudre, J., Hernandez-Garcia, E., Garçon, V., 2008. Comparative study of mixing and biological activity of the Benguela and Canary upwelling systems. Geophys. Res. Lett. 35, L11602. https://doi.org/10.1029/2008GL033610.

Rouault, M., Illig, S., Bartholomae, C., Reason, C.J.C., Bentamy, A., 2007. Propagation and origin of warm anomalies in the Angola Benguela upwelling system in 2001. J. Mar. Syst. 68, 473-488.

Rowe, G.T., 1971. Benthic biomass and surface productivity. In: Costlow, J.G. (Ed.), Fertility of the sea, Vol. 2. Gordon and Breach Science, New York, pp. 441-454.

Rykaczewski, R.R., Dunne, J.P., Sydeman, W.J., García-Reyes, M., Black, B.A., Bograd, S. J., 2015. Poleward displacement of coastal upwelling-favorable winds in the ocean's eastern boundary currents through the 21st century. Geophys. Res. Lett. 42, 6424-6431. https://doi.org/10.1002/2015GL064694.

Rykaczewski, R.R., Dunne, J.P., 2010. Enhanced nutrient supply to the California Current Ecosystem with global warming and increased stratification in an earth system model. Geophys. Res. Lett. 37 (21), L21606. https://doi.org/10.1029/ 2010 GL045019.

Saager, P.M., De Baar, H.J.W., Burkill, P.H., 1989. Manganese and iron in Indian Ocean waters. Geochim. Cosmochim. Acta 53 (9), 2259-2267.

Sagawa, T., Nagahashi, Y., Satoguchi, Y., Holbourn, A., Itaki, T., Gallagher, S.J., Saavedra-Pellitero, M., Ikehara, K., Irino, T., Tada, R., 2018. Integrated tephrostratigraphy and stable isotope stratigraphy in the Japan Sea and East China Sea using IODP Sites U1426, U1427, and U1429, Expedition 346 Asian Monsoon. Prog. Earth Planet. Sci. 5, 18. https://doi.org/10.1186/s40645-018-0168-7.

Sale, J.W., Skinner, W.W., 1917. The vertical distribution of dissolved oxygen and the precipitation by salt water in certain tidal areas. J. Franklin Inst. 184 (6), 837-848.

Salvanes, A.G.V., Aksnes, D.L., Fosså, J.H., Giske, J., 1995. Simulated carrying capacities of fish in Norwegian fjords. Fish. Oceanogr. 4, 17-32.

Salvatteci, R., Field, D., Gutiérrez, D., Baumgartner, T., Ferreira, V., Ortlieb, L., Sifeddine, A., Grados, D., Bertrand, A., 2018. Multifarious anchovy and sardine regimes in the Humboldt Current System during the last 150 years. Glob. Change Biol. 24, 1055-1068.

Salvatteci, R., Gutiérrez, D., Field, D., Sifeddine, A., Ortlieb, L., Bouloubassi, I., Boussafir, M., Boucher, H., Cetin, F., 2014. The response of the Peruvian Upwelling Ecosystem to centennial-scale global change during the last two millennia. Clim. Past $10,715-731$.

Salvatteci, R., Gutierrez, D., Sifeddine, A., Ortlieb, L., Druffel, E., Boussafir, M., Schneider, R., 2016. Centennial to millennial-scale changes in oxygenation and productivity in the Eastern Tropical South Pacific during the last 25,000 years. Quat. Sci. Rev. 131, 102-117.

Salvatteci, R., Gutierrez, D., Field, D., Sifeddine, A., Ortlieb, L., Caquineau, S. Baumgartner, T., Ferreira, V., Bertrand, A., 2019a. Fish debris in sediments from the last $25 \mathrm{kyr}$ in the Humboldt Current reveal the role of productivity and oxygen on small pelagic fishes. Prog. Oceanogr. 176, 102114.

Salvatteci, R., Schneider, R.R., Blanz, T., Mollier-Vogel, E., 2019b. Deglacial to Holocene ocean temperatures in the Humboldt Current System as indicated by alkenone paleothermometry. Geophys. Res. Lett. 46 https://doi.org/10.1029/2018GL080634.

Sánchez, G., Calienes, R., Zuta, S., 1999. The 1997-1998 El Niño and its effect on the marine coastal system off Perú. CALCOFI reports 41, 62-86.

Sanford, L.P., Sellner, K.G., Breitburg, D.L., 1990. Covariability of dissolved oxygen with physical processes in the summertime Chesapeake Bay. J. Mar. Res. 48 (3), 567-590.

Sarma, V.V.S.S., Krishna, M.S., Viswanadham, R., Rao, G.D., Rao, V.D., Sridevi, B., Kumar, B.S.K., Prasad, V.R., Subbaiah, Ch.V., Acharyya, T., Bandopadhyay, D., 2013. Intensified oxygen minimum zone on the western shelf of Bay of Bengal during summer monsoon: influence of river discharge. J. Oceanogr. 69 (1), 45-55.

Sato, C., Nakayama, K., Furukawa, K., 2012. Contributions of wind and river effects on DO concentration in Tokyo Bay. Estuar. Coast. Shelf Sci. 109, 91-97.

Satpathy, K.K., Panigrahi, S., Mohanty, A.K., Sahu, G., Achary, M.S., Bramha, S.N., Padhi, R.K., Samantara, M.K., Selvanayagam, M., Sarkar, S.K., 2013. Severe oxygen depletion in the shallow regions of the Bay of Bengal off Tamil Nadu coast. Curr. Sci. 104, 1467-1469.

Scavia, D., Yong, L., 2009. Exploring estuarine nutrient susceptibility. Environ. Sci. Technol. 43, 3474-3479. https://doi.org/10.1021/es803401y.

Schinke, H., Matthäus, W., 1998. On the causes of major Baltic inflows-an analysis of long time series. Cont. Shelf Res. 18, 67-97. https://doi.org/10.1016/S0278-4343 (97)00071-X.8.

Scholz, F., Hensen, C., Noffke, A., Rohde, A., Liebetrau, V., Wallmann, K., 2011. Early diagenesis of redox-sensitive trace metals in the Peru upwelling area - response to ENSO-related oxygen fluctuations in the water column. Geochim. Cosmochim. Acta 75, 7257-7276. 
Schmale, O., Krause, S., Holtermann, P., Power Guerra, N.C., Umlauf, L., 2016. Dense bottom gravity currents and their impact on pelagic methanotrophy at oxic/anoxic transition zones. Geophys. Res. Lett. 43, 5225-5232. https://doi.org/10.1002/ 2016GL069032.

Schmidtko, S., Stramma, L., Visbeck, M., 2017. Decline in global oceanic oxygen content during the past five decades. Nature 542, 335-339. https://doi.org/10.1038/ nature21399.

Schubel, J.R., Pritchard, D.W., 1986. Responses of upper Chesapeake Bay to variations in discharge of the Susquehanna River. Estuaries 9 (4), 236-249.

Schulz, H.N., Brinkhoff, T., Ferdelman, T.G., Marine, H.M., Teske, A., Jørgensen, B.B., 1999. Dense populations of a giant sulfur bacterium in Namibian sediments. Science 284, 493-495.

Schunck, H., Lavik, G., Desai, D.K., Großkopf, T., Kalvelage, T., Löscher, C.R., Paulmier, A., Contreras, S., Siegel, H., Holtappels, M., Rosenstiel, P., Schilhabel, M. B., Graco, M., Schmitz, R.A., Kuypers, M.M.M., LaRoche, J., 2013. Giant hydrogen sulfide plume in the Oxygen Minimum Zone off Peru supports chemolithoautotrophy. PLoS ONE 8 (8), e68661. https://doi.org/10.1371/journal. pone. 0068661 .

Schütte, F., Brandt, P., Karstensen, J., 2016a. Occurrence and characteristics of mesoscale eddies in the tropical northeastern Atlantic Ocean. Ocean Sci. 12 (3), 663-685.

Schütte, F., Karstensen, J., Krahmann, G., Hauss, H., Fiedler, B., Brandt, P., Visbeck, M., Körtzinger, A., 2016b. Characterization of "dead-zone" eddies in the eastern tropical North Atlantic. Biogeosciences 13, 5865-5881. https://doi.org/10.5194/bg-135865-2016.

Scully, M.E., 2010a. The importance of climate variability to wind-driven modulation of hypoxia in Chesapeake Bay. J. Phys. Oceanogr. 40 (6), 1435-1440.

Scully, M.E., 2010b. Wind modulation of dissolved oxygen in Chesapeake Bay. Estuaries Coasts 33 (5), 1164-1175.

Scully, M.E., 2016. Mixing of dissolved oxygen in Chesapeake Bay driven by the interaction between wind-driven circulation and estuarine bathymetry. J. Geophys. Res. Oceans 121, 5639-5654.

Sears, M., 1954. Notes on the Peruvian coastal current. 1. An introduction to the ecology of Pisco Bay. Deep Sea Research 1 (3), 141-169.

Seitzinger, S.P., Kroeze, C., Bouwman, A.F., Caraco, N., Dentener, F., Styles, R.V., 2002 Global patterns of dissolved inorganic and particulate nitrogen inputs to coastal systems: recent conditions and future projections. Estuaries 25, 640-655.

Sekula-Wood, E., Benitez-Nelson, C., Morton, S., Anderson, C., Burrell, C., Thunell, R., 2011. Pseudo-nitzschia and domoic acid fluxes in Santa Barbara Basin (CA) from 1993 to 2008. Harmful Algae 10, 567-575.

Seliger, H.H., Boggs, J.A., 1988. Long-term pattern of anoxia in the Chesapeake Bay. In: Lynch M., Krome, E.C. (Eds.), Understanding the estuary: advances in Chesapeake Bay research. Publication Number 129, Chesapeake Research Consortium, Edgewater, MD, pp. 570-583.

Sen Gupta, B.K., Turner, R.E., Rabalais, N.N., 1996. Seasonal oxygen depletion in continental shelf waters of Louisiana: historical record of benthic foraminifers. Geology 24, 227-230.

Send, U., Nam, S., 2012. Relaxation from upwelling: the effect on dissolved oxygen on the continental shelf. J. Geophys. Res. Oceans 117, C04024. https://doi.org/ 10.1029/2011JC007517.

Shannon, L.V., 1985. The Benguela Ecosystem, Part I. Evolution of the Benguela, physica features and processes. Oceanogr. Mar. Biol. Annu. Rev. 23, 105-182.

Shannon, L.V., Boyd, A.J., Brundrit, G.B., Taunton-Clark, J., 1986. On the existence of an El Niño-type phenomenon in the Benguela system. J. Mar. Sci. 44, 495-520.

Shchepetkin, A.F., McWilliams, J.C., 2005. The regional oceanic modeling system (ROMS): a split-explicit, free-surface, topography-following-coordinate oceanic model. Ocean Model. 9 (4), 347-404. https://doi.org/10.1016/j. ocemod.2004.08.002.

Shenk, G.W., Linker, L.C., 2013. Development and application of the 2010 Chesapeake Bay watershed total maximum daily load model. JAWRA J. Am. Water Resour. Assoc. 49 (5), 1042-1056. https://doi.org/10.1111/jawr.12109.

Shirodkar, G., Naqvi, S.W.A., Naik, H., Pratihary, A.K., Kurian, S., Shenoy, D.M., 2018. Methane dynamics in the shelf waters of the west coast of India during seasonal anoxia. Mar. Chem. 203, 55-63.

Siedlecki, S.A., Banas, N.S., Davis, K.A., Giddings, S., Hickey, B.M., MacCready, P. Connolly, T., Geier, S., 2015. Seasonal and interannual oxygen variability on the Washington and Oregon continental shelves. J. Geophys. Res. Oceans 120, 608-633.

Siegfried, W.R., Crawford, R.J.M., Pollock, D.E., Payne, A.I.L., Krohn, R.G., 1990. Scenarios for global-warming induced change in the open-ocean environment and selected fisheries of the west coast of southern Africa. S. Afr. J. Sci. 86, 281-285.

Sifeddine, A., Gutiérrez, D., Ortlieb, L., Boucher, H., Velazco, F., Field, D., Vargas, G., Boussafir, M., Salvatteci, R., Ferreira, V., García, M., Valdés, J., Caquineau, S., Mandeng Yogo, M., Cetin, F., Solis, J., Soler, P., Baumgartner, T., 2008. Laminated sediments from the central Peruvian continental slope: a 500 year record of upwelling system productivity, terrestrial runoff and redox conditions. Prog. Oceanogr. 79, 190-197.

Srain, B., Pantoja, S., Sepúlveda, J., Lange, C.B., Muñoz, P., Summons, R.E., McKay, J., Salamanca, M., 2015. Interdecadal changes in intensity of the oxygen minimum zone off Concepción, Chile $\left(\sim 36^{\circ}\right.$ S), over the last century. Biogeosciences 12 , 6045-6058.

Stanev, E., 1990. On the mechanisms of the Black Sea circulation. Earth Sci. Rev. 28, 285-319.

Stanev, E.V., He, Y., Staneva, J., Yakushev, E., 2014. Mixing in the Black Sea detected from the temporal and spatial variability of oxygen and sulfide - Argo float observations and numerical modelling. Biogeosciences 11 (5707-5732), 6.
Stigebrandt, A., 2012. Hydrodynamics and circulation of fjords. In: Bengtsson, L., Herschy, R.W., Fairbridge, R.W. (Eds.), Encyclopedia of Lakes and Reservoirs. Springer Science and Business Media B.V, pp. 327-344. https://doi.org/10.1007/ 978-1-4020-4410-6.

Stramma, L., Bange, H.W., Czeschel, R., Lorenzo, A., Frank, M., 2013. On the role of mesoscale eddies for the biological productivity and biogeochemistry in the eastern tropical Pacific Ocean off Peru. Biogeosciences 10, 7293-7306. https://doi.org/ 10.5194/bg-10-7293-2013.

Stramma, L., Johnson, G.C., Firing, E., Schmidtko, S., 2010a. Eastern Pacific oxygen minimum zones: Supply paths and multidecadal changes. J. Geophys. Res. Oceans 115, C09011. https://doi.org/10.1029/2009JC005976.

Stramma, L., Johnson, G.C., Sprintall, J., Mohrholz, V., 2008. Expanding oxygenminimum zones in the tropical oceans. Science 320, 655-658.

Stramma, L., Schmidtko, S., Levin, L.A., Johnson, G.C., 2010b. Ocean oxygen minima expansions and their biological impacts. Deep Sea Res. I Oceanogr. Res. Papers 57 (4), 587-595.

Strous, M., Fuerst, J.A., Kramer, E.H.M., Logemann, S., Muyzer, G., van de PasSchoonen, K.T., Webb, R., Kuenen, J.G., Jetten, M.S., 1999. Missing lithotroph identified as new planctomycete. Nature 400, 446-449.

Strub, P.T., Mesías, J.M., Montecino, V., Rutllant, J., Salinas, S., 1998. Coastal ocean circulation off western South America. In: Robinson, A., Brink, K. (Eds.), The Sea, Vol. 11, John Wiley Sons, New York, USA, pp. 273-313.

Su, J., Dai, M., He, B., Wang, L., Gan, J., Guo, X., Zhao, H., Yu, F., 2017. Tracing the origin of the oxygen-consuming organic matter in the hypoxic zone in a large eutrophic estuary: the lower reach of the Pearl River Estuary, China. Biogeosciences $14,4085-4099$.

Suits, N.S., Arthur, M.A., 2000. Bacterial production of anomalously high dissolved sulfate concentrations in Peru slope sediments: steady-state sulfur oxidation, or transient response to end of El Niño? Deep-Sea Res. I 47, 1829-1853.

Svåsand, T., Grefsrud, E.S., Karlsen, Ø., Kvamme, B.O., Glover, K., Husa, V., Kristiansen, T.S., 2017. Risikorapport for norsk fiskeoppdrett (Risk evaluation in Norwegian fish farming; in Norwegian). Fisken og Havet, særnummer 2. Institute of Marine Research, Bergen, p. 181.

Swallow, J.C., 1984. Some aspects of the physical oceanography of the Indian Ocean Deep-Sea Res. 31, 639-650.

Sydeman, W.J., Garcia-Reyes, M., Schoeman, D.S., Rykaczewski, R.R., Thompson, S.A., Black, B.A., Bograd, S.J., 2014. Climate change and wind intensification in coastal upwelling ecosystems. Science 345, 77-80.

Sylla, A., Mignot, J., Capet, X., Gaye, A.T., 2019. Weakening of the Senegalo-Mauritanian upwelling system under climate change. Clim. Dyn. 53, 4447-4473.

Syvitski, J.P.M., Burrell, D.C., Skei, J.M., 1987. Fjords: processes and products. Springer, New York, p. 377.

Sælen, O.H., 1950. The hydrography of some fjords in northern Norway. Troms $\varnothing$ Museums Årshefter 70 (1), 1-93.

Sælen, O.H., 1976. General Hydrography of Fjords. In: Skreslet, S., Leinebø, R., Matthews, J.B.L., Sakshaug, E. (Eds). Fresh water on the Sea. The association of Norwegian Oceanographers, pp. 43-49.

Sætre, R., 2007. The Norwegian Coastal Current - Oceanography and Climate. Tapir Academic Press, Trondheim, p. 159.

Sætre, R., Aure, J., Danielssen, D.S., 2003. Long-term hydrographic variability patterns off the Norwegian coast and in the Skagerrak. ICES Mar. Sci. Symposia 219, 150-159.

Sætre, R., Aure, J., Gade, H.G., 2010. Oseanografi og klima. In: Johannessen, P., Sætre, R., Kryvi, H., Hjelle, H. (Eds.), Bergensfjordene - Natur Og Bruk. Havforskningsinstituttet, Uni Research, Universitetet i Bergen, Bergen Kommune, John Grieg AS, Bergen, pp. 33-55.

Sætre, R., Aure, J., Ljøen, R., 1988. Wind effects on the lateral extension of the Norwegian Coastal Water. Cont. Shelf Res. 8, 229-253.

Tada, R., Irino, T., Ikehara, K., Karasuda, A., Sugisaki, S., Xuan, C., Sagawa, T., Itaki, T., Kubota, Y., Lu, S., Seki, A., Murray, R.W., Alvarez-Zarikian, C., Anderson, W.T., Bassetti, M.-A., Brace, B.J., Clemens, S.C., da Costa Gurgel, M.H., Dickens, G.R., Dunlea, A.G., Gallagher, S.J., Giosan, L., Henderson, A.C.G., Holbourn, A.E., Kinsley, C.W., Lee, G.S., Lee, K.E., Lofi, J., Lopes, C.I.C.D., Saavedra-Pellitero, M., Peterson, L.C., Singh, R.K., Toucanne, S., Wan, S., Zheng, H., Ziegler, M., 2018. Highresolution and high-precision correlation of dark and light layers in the Quaternary hemipelagic sediments of the Japan Sea recovered during IODP Expedition 346 Prog. Earth Planet. Sci. 5 (1), 19. https://doi.org/10.1186/s40645-018-0167-8.

Tada, R., Irino, T., Koizumi, I, 1999. Land-ocean linkages over orbital and millennial timescales recorded in late Quaternary sediments of the Japan Sea. Paleoceanography 14 (2), 236-247.

Tada, R., Murray, R.W., Alvarez Zarikian, C.A., and the Expedition 346 Scientists. 2015. Proceedings of the Integrated Ocean Drilling Program, Volume 346.

Taft, J.L., Taylor, W.R., Hartwig, E.O., Loftus, R., 1980. Seasonal oxygen depletion in Chesapeake Bay. Estuaries 3 (4), 242-247.

Tall, A.W., Machu, E., Echevin, V., Capet, X., Lazar, A., In Press. Variability of dissolved oxygen in the bottom layer of the southern Senegalese shelf. J. Geophys. Res.

Talley, L.D., Min, D.-H., Lobanov, V.B., Luchin, V.A., Ponomarev, I., Salyuk, A.N. Shcherbina, A.Y., Tishchenko, P.Y., Zhabin, I., 2006. Japan/East Sea water masses and their relation to the sea's circulation. Oceanography 19 (3), 32-49.

Tang, D., Di, B., Wei, G., Ni, I.-H., Oh, I.S., Wang, S., 2006. Spatial, seasonal and species variations of harmful algal blooms in the South Yellow Sea and East China Sea. Hydrobiologia 568 (1), 245-253. https://doi.org/10.1007/s10750-006-0108-1.

Tarazona, J., Salzwedel, H., Arntz, W., 1988. Positive effects of "El Niño" on macrozoobenthos inhabiting hypoxic areas of the Peruvian upwelling system. Oecologia 76, 184-190. 
Testa, J.M., Kemp, W.M., 2011. Oxygen - dynamics and biogeochemical consequences. In: Wolanski, E., McLusky, D.S. (Eds.), Treatise on Estuarine and Coastal Science, 5. Academic Press, Waltham, pp. 163-199.

Testa, J.M., Kemp, W.M., 2014. Spatial and temporal patterns of winter-spring oxygen depletion in Chesapeake Bay bottom water. Estuaries Coasts 37 (6), 1432-1448.

Testa, J.M., Clark, J.B., Dennison, W.C., Donovan, E.C., Fisher, A.W., Ni, W., Parker, M., Scavia, D., Spitzer, S.E., Waldrop, A.M., Vargas, V.M.D., Ziegler, G., 2017. Ecological forecasting and the science of hypoxia in Chesapeake Bay. BioScience 67, 614-626. https://doi.org/10.1093/biosci/bix048.

Testa, J.M., Kemp, W.M., Boynton, W.R., 2018a. Season-specific trends and linkages of nitrogen and oxygen cycles in Chesapeake Bay. Limnol. Oceanogr. 63 (5), 2045-2064.

Testa, J.M., Murphy, R.R., Brady, D.C., Kemp, W.M., 2018b. Nutrient- and climateinduced shifts in the phenology of linked biogeochemical cycles in a temperate estuary. Front. Mar. Sci. 5, 114. https://doi.org/10.3389/fmars.2018.00114.

Thamdrup, B., Dalsgaard, T., Jensen, M.M., Ulloa, O., Farias, L., Escribano, R., 2006. Anaerobic ammonium oxidation in the oxygen-deficient waters off northern Chile. Limnol. Oceanogr. 51, 2145-2156.

Thamdrup, B., Dalsgaard, T., Revsbech, N.P., 2012. Widespread functional anoxia in the oxygen minimum zone of the Eastern South Pacific. Deep-Sea Research I 65, 36-45.

The Changjiang water resources bulletin, 2015, Changjiang Water Resources Commission of the Ministry of Water Resources of China, http://www.cjw.gov. cn/UploadFiles/zwzc/2016/12/201612291107064317.pdf.

The Peal River water resources bulletin, 2016, Pearl River water resources commission of the Ministry of Water resources of China: http://www.pearlwater.gov.cn/xxcx/ szygg/16gb/201712/t20171204 81345.htm.

Thomsen, S., Kanzow, T., Colas, F., Echevin, V., Krahmann, G., Engel, A., 2016. Do submesoscale frontal processes ventilate the oxygen minimum zone off Peru? Geophys. Res. Lett. 43, 8133-8142. https://doi.org/10.1002/2016GL070548.

Thomsen, S., Karstensen, J., Kiko, R., Krahmann, G., Dengler, M., Engel, A., 2019. Remote and local drivers of oxygen and nitrate variability in the shallow oxygen minimum zone off Mauritania in June 2014. Biogeosciences 16, 979-998.

Thurber, A.R., Sweetman, A.K., Narayanaswamy, B.E., Jones, D.O.B., Ingels, J., Hansman, R.L., 2014. Ecosystem function and services provided by the deep sea. Biogeosciences 11, 3941-3963.

Tian, R.C., Hu, F.X., Martin, J.M., 1993. Summer Nutrient Fronts in the Changjiang (Yantze River) Estuary. Estuar. Coast. Shelf Sci. 37 (1), 27-41.

Timmermann, M., Maar, M., Bolding, K., Larsen, J., Windolf, J., Nielsen, P., Petersen, J. K., 2019. Mussel production as a nutrient mitigation tool for improving marine water quality. Aquaculture Environment Interactions 11, 191-204. https://doi.org/ 10.3354/aei00306.

Top, Z., Östlund, G., Pope, L., Grall, C., 1991. Helium isotopes, neon and tritium in the Black Sea: a comparison with the 1975 observations. Deep Sea Research Part A 38 (Supplement 2), S747-S760.

Trucco-Pignata, P.N., Hernández-Ayón, J.M., Santamaria-del-Angel, E., Beier, E., Sánchez-Velasco, L., Godínez, V.M., Norzagaray, O., 2019. Ventilation of the upper oxygen minimum zone in the coastal region off Mexico: implications of El Niño 2015-2016. Front. Mar. Sci. 6, 459. https://doi.org/10.3389/fmars.2019.00459.

Tsuchiya, M., 1975. Subsurface countercurrents in the eastern equatorial Pacific Ocean. J. Mar. Res. 33 (Supplement), 145-175.

Tsujimoto, A., Nomura, R., Yasuhara, M., Yoshikawa, S., 2006a. Benthic foraminiferal assemblages in Osaka Bay, southwestern Japan: faunal changes over the last 50 years. Paleontolog. Res. 10, 141-161.

Tsujimoto, A., Nomura, R., Yasuhara, M., Yamazaki, H., Yoshikawa, S., 2006b. Impact of eutrophication on shallow marine benthic foraminifers over the last 150 years in Osaka Bay, Japan. Mar. Micropaleontol. 60, 258-268.

Tsujimoto, A., Yasuhara, M., Nomura, R., Yamazaki, H., Sampei, Y., Hirose, K., Yoshikawa, S., 2008a. Development of modern benthic ecosystems in eutrophic coastal oceans: the foraminiferal record over the last 200 years, Osaka Bay, Japan. Mar. Micropaleontol. 69, 225-239.

Tsujimoto, A., Yasuhara, M., Yamazaki, H., Hirose, K., Yoshikawa, S., 2008b. Environmental changes during the last 150 years in Osaka Bay, Japan: historical record of eutrophication based on microfossil assemblages: The. Quat. Res. 47 (4), 273-285 (in Japanese with English abstract).

Tuğrul, S., Murray, J.W., Friederich, G.E., Salihoğlu, I., 2014. Spatial and temporal variability in the chemical properties of the oxic and suboxic layers of the Black Sea. J. Mar. Syst. 135, 29-43.

Turner, A.G., Annamalai, H., 2012. Climate change and the South Asian summer monsoon. Nat. Clim. Change 2, 587-595.

Turner, R.E., Qureshi, N., Rabalais, N.N., Dortch, Q., Justić, D., Shaw, R.F., Cope, J., 1998. Fluctuating silicate:nitrate ratios and coastal plankton food webs. Proc. Natl. Acad. Sci., USA 95, 13048-13051.

Turner, R.E., Rabalais, N.N., 1994. Coastal eutrophication near the Mississippi river delta. Nature 368, 619-621.

Turner, R.E., Rabalais, N.N., 2013. Nitrogen and phosphorus phytoplankton growth limitation in the northern Gulf of Mexico. Aquat. Microb. Ecol. 68, 159-169.

Turner, R.E., Rabalais, N.N., Justić, D., 2008. Gulf of Mexico hypoxia: alternate states and a legacy. Environ. Sci. Technol. 42, 2323-2327.

Tveranger, B., Eilertsen, M., Furset, T.T., 2019. MOM C - evaluation of localities Bergsvik and Barlingebotn I Masfjorden Kommune (in Norwegian). Rådgivende Biologer AS, Report 27 pp. ISBN 978-82-8308-141-1.

Vallivattathillam, P., Iyyappan, S., Lengaigne, M., Ethé, C., Vialard, J., Levy, M., Suresh, N., Aumont, O., Resplandy, L., Naik, H., Naqvi, W., 2017. Positive Indian Ocean Dipole events prevent anoxia off the west coast of India. Biogeosciences 14, 1541-1559.
Van der Plas, A.K., Monteiro, P.M.S., Pascall, A., 2007. Cross shelf biogeochemical characteristics of sediments in the central Benguela and their relationship to overlying water column hypoxia. Afr. J. Mar. Sci. 29 (1), 37-47.

Van Helmond, N.A.G.M., Jilbert, T., Slomp, C.P., 2018. Hypoxia in the Holocene Baltic Sea: Comparing modern versus past intervals using sedimentary trace metals. Chem. Geol. 493, 478-490. https://doi.org/10.1016/j.chemgeo.2018.06.028.

Vecchi, G.A., Soden, B.J., 2007. Global warming and the weakening of the tropical circulation. J. Clim. 20, 4316-4340. https://doi.org/10.1175/JCLI4258.1.

Velazco, F., Solís, J., 2000. Estudio sedimentológico de la bahía de Paracas. Informe Progresivo Instituto del Mar del Perú $\mathrm{N}^{\circ}$ 133, 3-22.

Vélez-Belchí, P., González-Carballo, M., Pérez-Hernández, M.D., Hernández-Guerra, A. 2015. Open ocean temperature and salinity trends in the Canary Current Large Marine Ecosystem. In: Valdés, L., Déniz-González, I. (Eds.), Oceanographic and biological features in the Canary Current Large Marine Ecosystem. IOC-UNESCO, Paris. IOC Technical Series, No. 115, pp. 299-308.

Vergara, O., Dewitte, B., Montes, I., Garçon, V., Ramos, M., Paulmier, A., Pizarro, O., 2016. Seasonal variability of the oxygen minimum zone off Peru in a high-resolution regional coupled model. Biogeosciences 13, 4389-4410. https://doi.org/10.5194/ bg-13-4389-2016.

VIMS, 2018. https://www.vims.edu/research/topics/dead_zones/_docs/2018_cb_hypo xic_report.pdf. \#.

Voituriez, B., Chuchla, R., 1978. Influence of the Southern Atlantic Central Water on the distribution of salinity and oxygen in the northeast tropical Atlantic Ocean. Deep-Sea Res. 25, 107-117.

Waldron, H.N., Probyn, T.A., 1991. Short-term variability during an anchor station study in the southern Benguela upwelling system: nitrogen supply to the euphotic zone during a quiescent phase in the upwelling cycle. Prog. Oceanogr. 28, 153-166.

Walker, N.D., Rabalais, N.N., 2006. Relationships among satellite chlorophyll a, river inputs, and hypoxia on the Louisiana continental shelf, Gulf of Mexico. Estuaries and Coasts 29 (6B), 1081-1093.

Wang, B., 2006. Cultural eutrophication in the Changjiang (Yangtze River) plume: history and perspective. Estuar. Coast. Shelf Sci. 69, 471-477.

Wang, B., 2009. Hydromorphological mechanisms leading to hypoxia off the Changjiang estuary. Marine Environ. Res. 67, 53-58.

Wang, B., Chen, J., Jin, H., Li, H., Huang, D., Cai, W.-J., 2017. Diatom bloom-derived bottom water hypoxia off the Changjiang estuary, with and without typhoon influence. Limnol. Oceanogr. 62 (4), 1552-1569.

Wang, H., Dai, M., Liu, J., Kao, S.-J., Zhang, C., Cai, W.-J., Wang, G., Qian, W., Zhao, M., Sun, Z., 2016. Eutrophication-driven hypoxia in the East China Sea off the Changjiang Estuary. Environ. Sci. Technol. 50, 225-2263.

Wang, D., Gouhier, T.C., Menge, B.A., Ganguly, A.R., 2015. Intensification and spatial homogenization of coastal upwelling under climate change. Nature 518, 390-394.

Wang, B., Wang, X., 2007. Chemical hydrography of coastal upwelling in the East China Sea. Chin. J. Oceanol. Limnol. 25 (1), 16-26.

Ward, B.B., Devol, A.H., Rich, J.J., Chang, B.X., Bulow, S.E., Naik, H., Pratihary, A., Jayakumar, A., 2009. Denitrification as the dominant nitrogen loss process in the Arabian Sea. Nature 461, 78-81.

Warren, B.A., 1994. Context of the suboxic layer of the Arabian Sea. Proc. Indian Acad. Sci. - Earth Planet. Sci. 103(2), 301-314.

Wassmann, P., 1983. Sedimentation of organic and inorganic particulate material in Lindåspollene, a stratified, land-locked fjord in Western Norway. Mar. Ecol. Prog. Ser. 13, 237-248.

Wassmann, P., 1985. Sedimentation of particulate material in Nordåsvannet, a hypertrophic, land-locked fjord in western Norway. Mar. Ecol. Prog. Ser. 22, 259-271.

Watanabe, S., Tada, R., Ikehara, K., Fujine, K., Kido, Y., 2007. Sediment fabrics, oxygenation history, and circulation modes of Japan Sea during the Late Quaternary. Palaeogeogr. Palaeoclimatol. Palaeoecol. 247 (1-2), 50-64.

Weeks, S.J., Barlow, R., Roy, C., Shillington, F.A., 2006. Remotely sensed variability of temperature and chlorophyll in the southern Benguela: upwelling frequency and phytoplankton response. Afr. J. Mar. Sci. 28, 493-509.

West, S., Jansen, J.H.F., Stuut, J.-B., 2004. Surface water conditions in the Northern Benguela Region (SE Atlantic) during the last 450 ky reconstructed from assemblages of planktonic foraminifera. Mar. Micropaleontol. 51, 321-344.

Whitney, F.A., Freeland, H.J., Robert, M., 2007. Persistently declining oxygen levels in the interior waters of the eastern subarctic Pacific. Prog. Oceanogr. 75, 179-199. https://doi.org/10.1016/j.pocean.2007.08.007.

Willard, D.A., Cronin, T.M., Verardo, S., 2003. Late-Holocene climate and ecosystem history from Chesapeake Bay sediment cores, USA. The Holocene 13 (2), 201-214.

Williams, P.J. le B., del Giorgio, P.A., 2005. Respiration in aquatic ecosystems: history and background. In: del Giorgio, P.A., Williams P.J. (Eds.), Respiration in Aquatic Ecosystems. Oxford University Press, Oxford, pp. 1-17.

Wollast, R., 1998. Evaluation and comparison of the global carbon cycle in the coastal zone and in the open ocean. In: Brink, K.H., Robinson, A.R. (Eds.), The global coastal ocean, processes and methods. The Sea, Vol 10, John Wiley and Sons, New York, pp. 213-252.

Wyrtki, K., 1971. Oceanographic Atlas of the International Indian Ocean Expedition. National Science Foundation, Washington, DC, p. 531.

Wyrtki, K., 1973. Physical oceanography of the Indian Ocean. In: Zeitzschel, B. Gerlach, S.A. (Eds.), The Biology of the Indian Ocean. Ecological Studies: Analysis and Synthesis, Vol. 3. Springer, Berlin, Heidelberg, pp. 18-36. https://doi.org/ 10.1007/978-3-642-65468-8 3.

Xiu, P., Chai, F., Curchitser, E.N., Castruccio, F.S., 2018. Future changes in coastal upwelling ecosystems with global warming: the case of the California Current System. Sci. Rep. 8, 2866. https://doi.org/10.1038/s41598-018-21247-7. 
Xu, X., Segschneider, J., Schneider, B., Park, W., Latif, M., 2015. Oxygen minimum zone variations in the tropical Pacific during the Holocene. Geophys. Res. Lett. 42, 8530-8537. https://doi.org/10.1002/2015GL064680.

Yakushev, E.V., Neretin, L.V., 1997. One-dimensional modeling of nitrogen and sulfur cycles in the aphotic zones of the Black and Arabian Seas. Global Biogeochem. Cycles 11 (3), 401-414.

Yakushev, E.V., Pollehne, F., Jost, G., Kuznetso, I., Schneider, B., Umlauf, L., 2007. Analysis of the water column oxic/anoxic interface in the Black and Baltic seas with a numerical model. Mar. Chem. 107, 388-410.

Yamaguchi, T., Kuroki, K., Yamada, K., Itaki, T., Niino, K., Motoyama, I., 2017. Pleistocene deep-sea ostracods from the Oki Ridge, Sea of Japan (IODP Site U1426) and condition of the intermediate water. Quaternary Research (United States) 88 (3), 430-445.

Yan, W., Zhang, S., 2003. How do nitrogen inputs to the Changjiang basin impact the Changjiang River nitrate: a temporal analysis for 1968-1997. Global Biogeochem. Cycles 17 (4), 1091. https://doi.org/10.1029/2002GB002029.

Yanagi, T., 2015a. Eutrophication and oligotrophication in Japanese estuaries: A synthesis. In: Yanagi, T. (Ed.), Eutrophication and Oligotrophication in Japanese Estuaries: The present status and future tasks. Springer, Dordrecht, pp. 1-4.

Yanagi, T., 2015b. Eutrophication and oligotrophication in Japanese estuaries: The present status and future tasks. Springer, Dordrecht.

Yanagi, T., 2015c. Oligotrophication in the Seto Inland Sea. In: Yanagi, T. (Ed.), Eutrophication and Oligotrophication in Japanese Estuaries: The present status and future tasks. Springer, Dordrecht, pp. 39-67.

Yasuhara, M., Hunt, G., Breitburg, D., Tsujimoto, A., Katsuki, K., 2012, Human-induced marine ecological degradation: micropaleontological perspectives: Ecology and Evolution 2, 3242-3268.

Yasuhara, M., Yamazaki, H., 2005. The impact of 150 years of anthropogenic pollution on the shallow marine ostracode fauna, Osaka Bay, Japan. Mar. Micropaleontol. 55, 63-74.

Yasuhara, M., Yamazaki, H., Tsujimoto, A., Hirose, K., 2007. The effect of long-term spatiotemporal variations in urbanization-induced eutrophication on a benthic ecosystem, Osaka Bay, Japan. Limnol. Oceanogr. 52, 1633-1644.

Yim, B.Y., Yeh, S.-W., Song, H.-J., Dommenget, D., Sohn, B.J., 2017. Land-sea thermal contrast determines the trend of Walker circulation simulated in atmospheric general circulation models. Geophys. Res. Lett. 44, 5854-5862. https://doi.org/10.1002 2017GL073778.

Yin, K.D., Lin, Z.F., Ke, Z.Y., 2004. Temporal and spatial distribution of dissolved oxygen in the Pearl River Estuary and adjacent coastal waters. Cont. Shelf Res. 24, 1935-1948.

Yin, K., Qian, P.-Y., Wu, M.C.S., Chen, J.C., Huang, L., Song, X., Jian, W., 2001. Shift from P to N limitation of phytoplankton growth across the Pearl River estuarine plume during summer. Mar. Ecol. Prog. Ser. 221, 17-28.

Yzocupe, V., 2002. Modelo numérico de flujo bidimensional en la Bahía de Paracas. Revista de Investigación en Física 5, 1-9.
Zhai, W-d., Zhao, H-d., Su, J-l., Liu, P-f., Li, Y-w., Zheng, N., 2019. Emergence of summertime hypoxia and concurrent carbonate mineral suppression in the Central Bohai Sea, China. J. Geophys. Res. Biogeosci. 124(9), 2768-2785, 2019.

Zhang, J., Zhang, Z.F., Liu, S.M., Wu, Y., Xiong, H., Chen, H.T., 1999. Human impacts on the large world rivers: would the Changjiang (Yangtze River) be an illustration? Global Biogeochem. Cycles 13, 1099-1105.

Zhang, J., Liu, S.M., Ren, J.L., Wu, Y., Zhang, G.L., 2007. Nutrient gradients from the eutrophic Changjiang (Yangtze River) estuary to the oligotrophic Kuroshio waters and re-evaluation of budgets for the East China Sea Shelf. Prog. Oceanogr. 74 (4), 449-478.

Zhou, J., Zhu, Z.-Y., Hu, H.-T., Zhang, G.-L., Wang, Q.-Q., 2021. Clarifying water column respiration and sedimentary oxygen respiration under oxygen depletion off the Changjiang Estuary and adjacent East China Sea. Front. Mar. Sci. 7, 623581 https:// doi.org/10.3389/fmars.2020.623581.

Zhu, Z.-Y., Ng, W.-M., Liu, S.-M., Zhang, J., Chen, J.-C., Wu, Y., 2009. Estuarine phytoplankton dynamics and shift of limiting factors: a study in the Changiiang (Yangtze River) Estuary and adjacent area. Estuar. Coast. Shelf Sci. 84 (3), 393-401.

Zhu, Z.-Y., Wu, H., Liu, S.-M., Wu, Y., Huang, D.-J., Zhang, J., Zhang, G.-S., 2017. Hypoxia off the Changiiang (Yangtze River) Estuary and in the adjacent East China Sea: quantitative approaches to estimating the tidal impact and nutrient regeneration. Mar. Pollut. Bull. 125, 103-114.

Zhu, Z.-Y., Wu, Y., Zhang, J., Du, J.-Z., Zhang, G.-S., 2014. Reconstruction of anthropogenic eutrophication in the region off the Changjiang Estuary and central Yellow Sea: from decades to centuries. Cont. Shelf Res. 72, 152-162.

Zhu, Z.-Y., Zhang, J., Wu, Y., Zhang, Y.-Y., Lin, J., Liu, S.-M., 2011. Hypoxia off the Changjiang (Yangtze River) Estuary: oxygen depletion and organic matter decomposition. Mar. Chem. 125, 108-116.

Zhu, J., Zhu, Z., Lin, J., Wu, H., Zhang, J., 2016. Distribution of hypoxia and pycnocline off the Changjiang Estuary, China. J. Mar. Syst. 154, 28-40.

Zillén, L., Conley, D.J., Andréen, T., Andréen, E., Björck, S., 2008. Past occurrences of hypoxia in the Baltic Sea and the role of climate variability, environmental change and human impact. Earth-Sci. Rev. 91, 77-92. https://doi.org/10.1016/j. earscirev.2008.10.001.

Zimmerman, A.R., Canuel, E.A., 2000. A geochemical record of eutrophication and anoxia in Chesapeake Bay sediments: anthropogenic influence on organic matter composition. Mar. Chem. 69, 117-137.

\section{Further reading}

Montes, I., Schneider, W., Colas, F., Blanke, B., Echevin, V., 2011. Subsurface connections in the eastern tropical Pacific during La Niña 1999-2001 and El Niño 2002-2003. J. Geophys. Res. 116, C12022. https://doi.org/10.1029/ 2011JC007624. 